\author{
Universidade de São Paulo \\ Instituto de Astronomia, Geofísica e Ciências Atmosféricas \\ Departamento de Geofísica
}

Dissertação de Mestrado

\title{
Mapeamento Geoelétrico TDEM por meio da técnica Tx- Fixo e Rx-Móvel Aplicado em Estudos Hidrogeológicos na região central da Bacia de Taubaté-SP
}

\author{
Aluno: Luiz Rodrigo Hamada \\ Orientador: Prof. Dr. Jorge Luís Porsani
}

São Paulo - Brasil

Maio de 2018 

Luiz Rodrigo Hamada

\title{
Mapeamento Geoelétrico TDEM por meio da técnica Tx-Fixo e Rx-Móvel Aplicado em Estudos Hidrogeológicos na região central da Bacia de Taubaté-SP
}

\begin{abstract}
Versão Corrigida
(A versão original encontra-se disponível na unidade)

Dissertação apresentada ao Instituto de Astronomia, Geofísica e Ciências Atmosféricas da Universidade de São Paulo para a obtenção do título de Mestre em Ciências.
\end{abstract}

Área de concentração: Geofísica

Orientador: Prof. Dr. Jorge Luís Porsani

São Paulo - Brasil

Maio de 2018 

"O Verdadeiro é Simples"

(Johann Wolfgang von Goethe) 



\section{Agradecimentos}

Agradeço primeiramente a Deus, pela minha vida.

À minha família, por todo o suporte que me deu durante esses dois anos, por ser a minha base.

À minha noiva, Gabrielly, que durante esses anos de mestrado esteve comigo cada segundo dando toda a atenção e suporte possível, me ajudando, sem dúvida, a concluir esta etapa.

Aos amigos que conquistei durante esse período (Rodrigo, Bruno, Vitor, Cassiano (Pira), Marco (Marcão), Gabi, Marcelo, Ernande (Er Costa), Oscar, Emerson), os quais somaram ricamente na minha vida durante o mestrado.

Ao professor Jorge Porsani, pela oportunidade única que me concedeu permitindo que eu fizesse parte do grupo de pesquisa, pela paciência, pelos ensinamentos e pela oportunidade incrível que tive nos trabalhos de campo.

Aos amigos de república (Laís, Ludy e Caio) que participaram, sem dúvida, dessa importante etapa na minha vida.

À todos os professores do IAG pelos ensinamentos que adquiri durante as disciplinas.

A CAPES pelo auxílio financeiro concedido para realização desta pesquisa.

Às secretárias do IAG/USP pelo excelente trabalho e que sempre estão dispostas a nos ajudar (inclusive quando esquecemos a chave da sala). 



\section{Sumário}

LISTA DE FIGURAS

LISTA DE TABELAS....................................................................................................vii

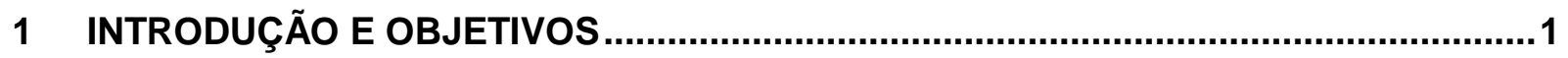

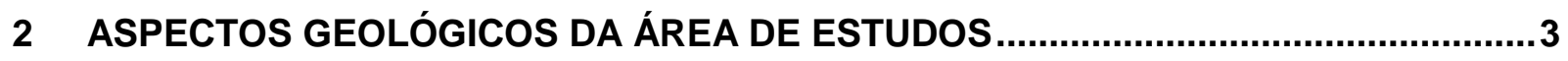

2.1 Caracterização Geral do Aquífero Taubaté...................................................11

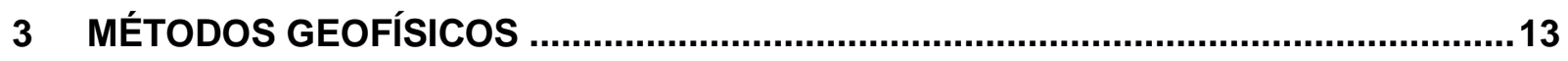

3.1 Eletromagnético no Domínio do Tempo (TDEM) …..........................................13

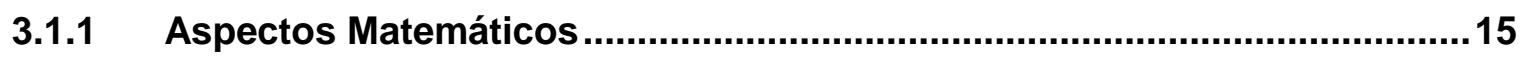

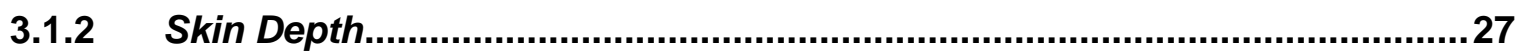

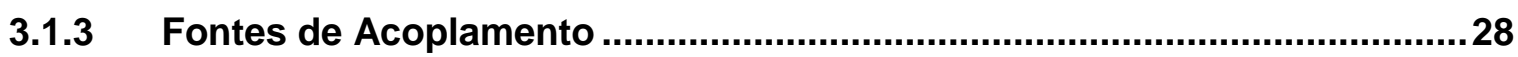

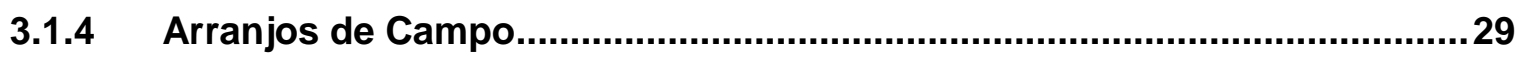

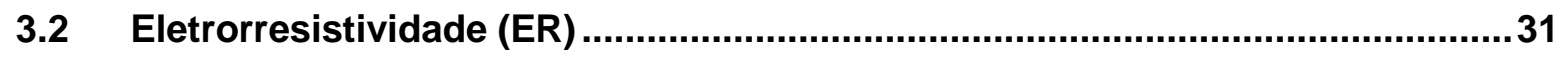

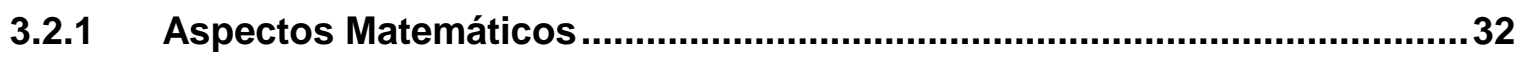

3.2.2 Sondagem Elétrica Vertical (SEV) ...............................................................

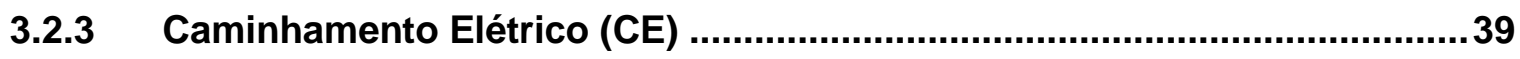

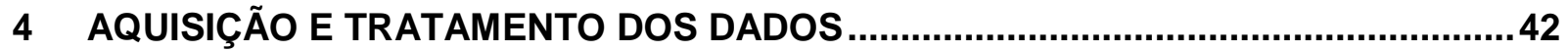

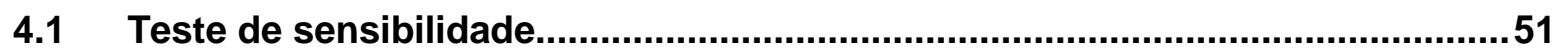

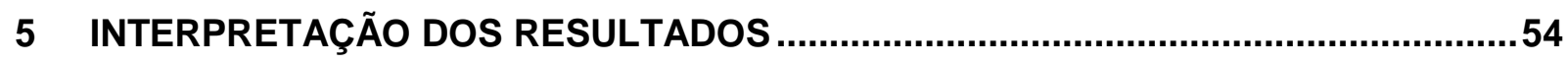

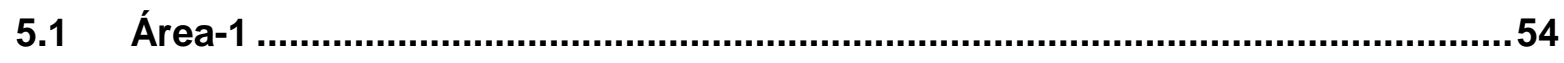

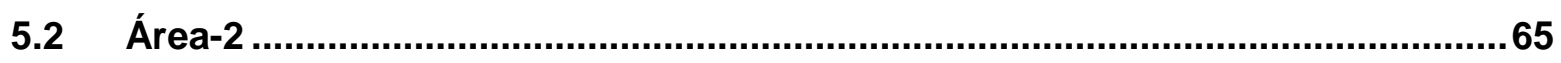

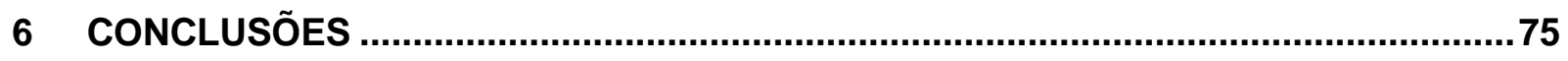

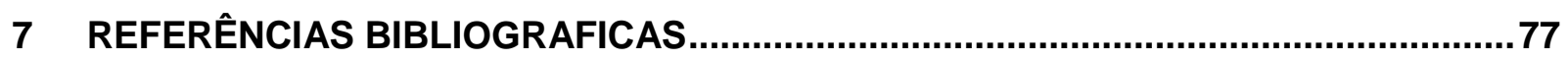

Apêndice A: Inversões individuais dos dados TDEM dentro do Loop vermelho (Área-1)

Apêndice B: Inversões individuais dos dados TDEM dentro do Loop preto (Área-2) ...96 Apêndice C: Tabela com informações dos poços da cidade de Taubaté (SP). 108 


\section{LISTA DE FIGURAS}

Figura 1: Bacia sedimentar de Taubaté (Modificado de Souza Filho, M. N., et al., 2012)

Figura 2: Compartimentação estrutural da Bacia de Taubaté de acordo com DAEE (1977). Os números representam as sub-bacias: 1) Parateí, 2) Jacareí, 3) Eugênio de Melo, 4) Tremembé, 5) Lorena, 6) Cruzeiro. As letras representam os altos estruturais: A) Rio Putins, B) Caçapava, C) Aparecida, D) Cachoeira Paulista (Modificado de Carvalho, et al., 2010).

Figura 3: Mapa estrutural da Bacia de Taubaté (Modificado de Fernandes e Chang, 2003)

Figura 4: Quadro estratigráfico da Bacia de Taubaté (Modificado de Riccomini, 1989).

Figura 5: Localização das 11 seções sísmicas na Bacia de Taubaté. Em vermelho, a localização da área de estudos em questão (Adaptado de Carvalho, et al., 2010).

Figura 6: Mapa de localização dos poços na cidade de Taubaté, associado aos perfis construtivos 3500051191 e 3500051190 que atingem o topo do embasamento (Adaptado de SIAGAS - CPRM).

Figura 7: Perfil litológico da área de estudos com base nos poços dos SIAGASCPRM (2018).

Figura 8: Domínios hidrogeológicos do estado de São Paulo (DAEE/LEBAC, 2013).

Figura 9: Mapa de caracterização geral do potencial hídrico da Bacia de Taubaté. 12

Figura 10: Curva de decaimento da tensão (Adaptado de McNeill, 1994). 13

Figura 11: Esquema do funcionamento do método TDEM (Modificado de McNeill, 1994) 14

Figura 12: Correntes secundárias difundindo-se em subsuperfície (Modificado de McNeill, 1994). 15

Figura 13: Fontes de acoplamento do método TDEM (Adaptado de Sørensen, et al., 2000) 29

Figura 14: Arranjos de Campo utilizados na aquisição de dados. 31

Figura 15: Cilindro condutor infinitesimal representando os parâmetros utilizados na definição de resistividade (Adaptado de Kearey, et. al., 2009). 32

Figura 16: Fluxo de corrente e as linhas equipotenciais (Adaptado de Kearey, et. al., 2009) 34

Figura 17: Esquema geral da configuração de eletrodos para medição de resistividade (Adaptado de Kearey, et. al., 2009). 
Figura 18: Arranjo de campo Schlumberger - SEV ........................................... 38

Figura 19: Arranjo de campo Wenner - SEV. ….............................................. 38

Figura 20: Esquema do funcionamento da técnica SEV, arranjo Schlumberger

(Adaptado de Telford, 1990).

Figura 21: Esquema do funcionamento da técnica CE com arranjo dipolo-dipolo

(Adaptado de Telford, 1990).

Figura 22: Esquema do funcionamento da técnica CE com arranjo polo-dipolo

(Adaptado de Telford, 1990).

Figura 23: Croqui utilizado para aquisição de dados TDEM, CTDEM, SEV e CE..... 42

Figura 24: Aquisição dos dados CE, SEV, TDEM e perfis CTDEM nas Áreas-1 e -2 na região de Taubaté-SP

Figura 25: Aquisição de dados TDEM: A) O fio amarelo é usado para montar o loop transmissor de corrente ao qual está conectado ao transmissor de corrente TEM57-MK2 sendo alimentado pelo gerador; B) Ao fundo está a bobina receptora 3D e o receptor PROTEM-D sendo manuseado pelo operador 44

Figura 26: Aquisição de dados de SEV e de CE. 44

Figura 27: Aquisição TDEM sendo realizada a grandes distâncias do acoplamento Galvânico.

Figura 28: Tratamento de um dado TDEM. Os quadrados em vermelho refere-se à frequência de $30 \mathrm{~Hz}$, em verde a frequência de $7,5 \mathrm{~Hz}$ e em azul a frequência de $3 \mathrm{~Hz}$. a) Curva de resistividade TDEM sem o tratamento dos dados; b) Remoção da influência do campo magnético primário e dos níveis de ruído na curva voltagem vs tempo. 46

Figura 29: Curva de resistividade TDEM da Figura 28 após o tratamento dos dados.

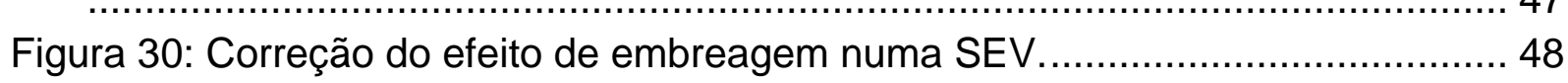

Figura 31: Correção do static shift da SEV, usando uma sondagem TDEM. ............ 49

Figura 32: Sondagem TDEM (TEM04) da Área-2 sem a curva de $3 \mathrm{~Hz}$................ 50 Figura 33: Comparação entre os modelos geoelétricos gerados pelo software IX1D:

a) Sondagem loop-central TDEM da Área- 1 com as frequências de $30 \mathrm{~Hz}, 7,5 \mathrm{~Hz}$ e $3 \mathrm{~Hz}$; b) Sondagem loop-central TDEM da Área-2 com as frequências de $30 \mathrm{~Hz}$ e $7,5 \mathrm{~Hz}$. 51

Figura 34: Modelo geoelétrico de uma sondagem individual TDEM representando quatro camadas geoelétricas. 52

Figura 35: Teste de sensibilidade entre modelos. a) Modelo geoelétrico de quatro camadas; b) Modelo geoelétrico de três camadas. 53

Figura 36: Inversão individual TDEM (TEM04-1) e o modelo geoelétrico associado da Área-1. 55

Figura 37: Perfil CTDEM 1 gerado mediante a interpolação das inversões individuais das sondagens da Área-1. 56 
Figura 38: Perfil CTDEM 2 gerado mediante a interpolação das inversões individuais das sondagens da Área-1.

Figura 39: Perfil CTDEM 3 gerado mediante a interpolação das inversões individuais das sondagens da Área-1.

Figura 40: Perfil CTDEM 4 gerado mediante a interpolação das inversões individuais das sondagens da Área-1 57

Figura 41: Inversão individual SEV (SEV1) e o modelo geoelétrico associado da Área-1. 58

Figura 42: Inversão conjunta SEV1/TEM04-1 e modelo geoelétrico associado da Área-1. 59

Figura 43: Perfil CTDEM 1 referente à Área-1 com os resultados interpretados 63 Figura 44: Modelo litoestratigráfico interpretado com base nas informações geofísicas e de poços para a Área-1. 64

Figura 45: Inversão individual TDEM (TEM04-2) e o modelo geoelétrico associado da Área-2 sem a frequência de $3 \mathrm{~Hz}$. 65

Figura 46: Perfil CTDEM 1 gerado mediante a interpolação das inversões individuais das sondagens da Área-2.

Figura 47: Perfil CTDEM 2 gerado mediante a interpolação das inversões individuais das sondagens da Área-2. 67

Figura 48: Perfil CTDEM 3 gerado mediante a interpolação das inversões individuais das sondagens da Área-2. 67

Figura 49: Perfil CTDEM 4 gerado mediante a interpolação das inversões individuais das sondagens da Área-2. 68

Figura 50: Inversão individual TDEM (TEM04-3) e o modelo geoelétrico associado da Área-2 com as frequências de $30 \mathrm{~Hz}, 7,5 \mathrm{~Hz}$ e $3 \mathrm{~Hz}$. 69

Figura 51: Inversão individual SEV (SEV2) e o modelo geoelétrico associado da Área-2.

Figura 52: Inversão conjunta SEV2/TEM04-3 e o modelo geoelétrico associado da Área-2. 71

Figura 53: Perfil 1 CTDEM referente à Área-2 com os resultados interpretados....... 72 Figura 54: Modelo litoestratigráfico interpretado com base nas informações geofísicas e de poços para a Área-2. 74

Figura A 1: Inversão individual TDEM da sondagem TEM22 e modelo geoelétrico associado.

Figura A 2: Inversão individual TDEM da sondagem TEM11 e o modelo geoelétrico associado. 
Figura A 3: Inversão individual TDEM da sondagem TEM23 o modelo geoelétrico associado.

Figura A 4: Inversão individual TDEM da sondagem TEM24 e o modelo geoelétrico associado

Figura A 5: Inversão individual TDEM da sondagem TEM18 e o modelo geoelétrico associado

Figura A 6: Inversão individual TDEM da sondagem TEM25 e o modelo geoelétrico associado

Figura A 7: Inversão individual TDEM da sondagem TEM01 e o modelo geoelétrico associado.

Figura A 8: Inversão individual TDEM da sondagem TEM02 e o modelo geoelétrico associado.

Figura A 9: Inversão individual TDEM da sondagem TEM03 e o modelo geoelétrico associado.

Figura A 10: Inversão individual TDEM da sondagem TEM05 e o modelo geoelétrico associado. 88

Figura A 11: Inversão individual TDEM da sondagem TEM06 e o modelo geoelétrico associado

Figura A 12: Inversão individual TDEM da sondagem TEM07 e o modelo geoelétrico associado.

Figura A 13: Inversão individual TDEM da sondagem TEM08 e o modelo geoelétrico associado.

Figura A 14: Inversão individual TDEM da sondagem TEM09 e modelo geoelétrico associado.

Figura A 15: Inversão individual TDEM da sondagem TEM10 e o modelo geoelétrico associado

Figura A 16: Inversão individual TDEM da sondagem TEM12 e o modelo geoelétrico associado

Figura A 17: Inversão individual TDEM da sondagem TEM13 e o modelo geoelétrico associado

Figura A 18: Inversão individual TDEM da sondagem TEM14 e o modelo geoelétrico associado

Figura A 19: Inversão individual TDEM da sondagem TEM15 e o modelo geoelétrico associado

Figura A 20: Inversão individual TDEM da sondagem TEM16 e o modelo geoelétrico associado.

Figura A 21: Inversão individual TDEM da sondagem TEM17 e o modelo geoelétrico associado.

Figura A 22: Inversão individual TDEM da sondagem TEM19 e o modelo geoelétrico associado 
Figura A 23: Inversão individual TDEM da sondagem TEM20 e o modelo geoelétrico associado.

Figura A 24: Inversão individual TDEM da sondagem TEM21 e o modelo geoelétrico associado.

Figura B 1: Inversão individual TDEM da sondagem TEM01 e modelo geoelétrico

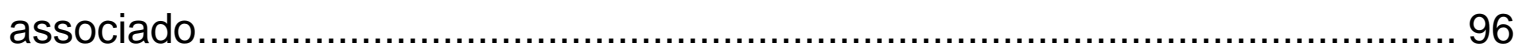

Figura B 2: Inversão individual TDEM da sondagem TEM02 e modelo geoelétrico

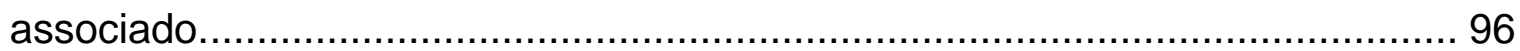

Figura B 3: Inversão individual TDEM da sondagem TEM03 e modelo geoelétrico

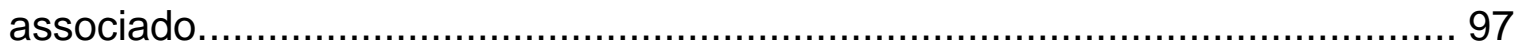

Figura B 4: Inversão individual TDEM da sondagem TEM05 e modelo geoelétrico associado

Figura B 5: Inversão individual TDEM da sondagem TEM06 e modelo geoelétrico associado

Figura B 6: Inversão individual TDEM da sondagem TEM07 e modelo geoelétrico associado.

Figura B 7: Inversão individual TDEM da sondagem TEM08 e modelo geoelétrico associado

Figura B 8: Inversão individual TDEM da sondagem TEM09 e modelo geoelétrico associado

Figura B 9: Inversão individual TDEM da sondagem TEM10 e modelo geoelétrico associado.

Figura B 10: Inversão individual TDEM da sondagem TEM11 e modelo geoelétrico associado

Figura B 11: Inversão individual TDEM da sondagem TEM12 e modelo geoelétrico associado

Figura B 12: Inversão individual TDEM da sondagem TEM13 e modelo geoelétrico associado

Figura B 13: Inversão individual TDEM da sondagem TEM14 e modelo geoelétrico associado.

Figura B 14: Inversão individual TDEM da sondagem TEM15 e modelo geoelétrico associado.

Figura B 15: Inversão individual TDEM da sondagem TEM16 e modelo geoelétrico associado.

Figura B 16: Inversão individual TDEM da sondagem TEM17 e modelo geoelétrico associado.

Figura B 17: Inversão individual TDEM da sondagem TEM18 e modelo geoelétrico associado. 
Figura B 18: Inversão individual TDEM da sondagem TEM19 e modelo geoelétrico associado

Figura B 19: Inversão individual TDEM da sondagem TEM20 e modelo geoelétrico associado 105

Figura B 20: Inversão individual TDEM da sondagem TEM21 e modelo geoelétrico associado 105

Figura B 21: Inversão individual TDEM da sondagem TEM22 e modelo geoelétrico

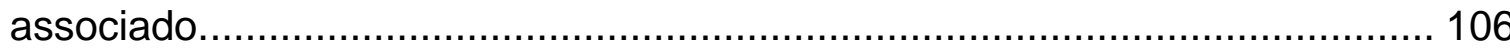

Figura B 22: Inversão individual TDEM da sondagem TEM23 e modelo geoelétrico

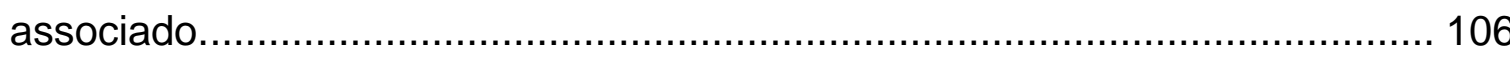

Figura B 23: Inversão individual TDEM da sondagem TEM24 e modelo geoelétrico associado

Figura B 24: Inversão individual TDEM da sondagem TEM25 e modelo geoelétrico associado. 


\section{LISTA DE TABELAS}

Tabela 1: Análise da profundidade teórica com valores de resistividade distintos. ... 28

Tabela 2: Modelo geoelétrico gerado pela inversão individual TEM04-1 da Área-1.. 55

Tabela 3: Modelo geoelétrico gerado pela inversão individual SEV1 da Área-1...... 59

Tabela 4: Modelo geoelétrico gerado pela inversão conjunta SEV1/TEM04-1 da Área-

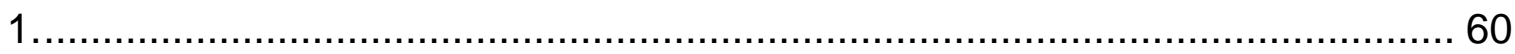

Tabela 5: Modelo geoelétrico gerado pela inversão individual TEM04-2 da Área-2

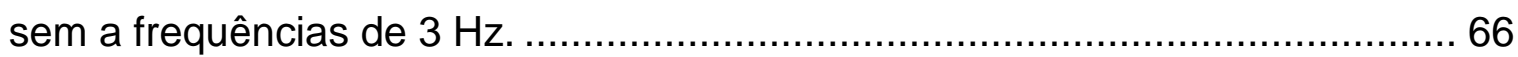

Tabela 6: Modelo geoelétrico gerado pela inversão individual TEM04-3 da Área-2

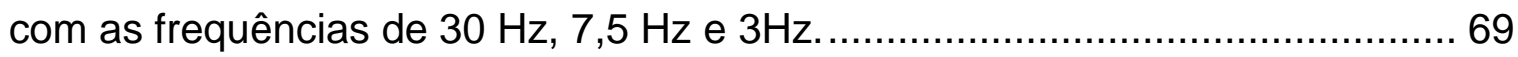

Tabela 7: Modelo geoelétrico gerado pela inversão individual SEV2 da Área-2 ...... 70 Tabela 8: Modelo geoelétrico gerado pela inversão conjunta SEV2/TEM04-3 da Área-

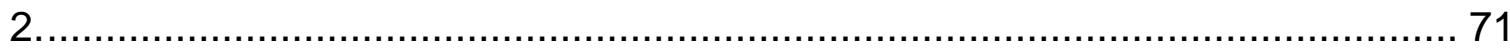




\section{Resumo}

Nesta pesquisa foram analisados dados utilizando os métodos geofísicos Eletromagnético no Domínio do Tempo (TDEM) e Eletrorresistividade (ER) adquiridos na região central da Bacia sedimentar de Taubaté-SP com a finalidade de contribuir com estudos hidrogeológicos e realizar uma caracterização geoelétrica da área. Os dados TDEM foram obtidos por meio da técnica de caminhamento TDEM (CTDEM) usando um loop transmissor (Tx) fixo e uma bobina receptora (Rx) - 3D móvel, também conhecida como técnica fixed-loop. Os dados de ER foram coletados utilizando a técnica de Sondagem Elétrica Vertical (SEV) e perfis de Caminhamento Elétrico (CE). A interpretação das camadas geoelétricas da subsuperfície foram realizadas por meio de inversões individuais TDEM, inversões conjunta 1D de SEV/TDEM coincidentes e de pseudoseções CTDEM geradas através da interpolação dos resultados das inversões individuais TDEM, permitindo, desta forma, gerar um modelo geoelétrico para a região específica dentro do loop transmissor. A área de estudos localiza-se numa área rural da cidade de Taubaté, $\mathrm{SP}$, de maneira que os resultados dos perfis de CTDEM integrados com as inversões conjuntas SEV/TDEM e informações litológicas de poços permitiram mapear 0 contato entre os sedimentos Quaternários e Terciários (Grupo Taubaté e Formação Pindamonhangaba). O topo do embasamento da bacia na área de estudos foi inferido com base nas informações litológicas de poços catalogados e disponibilizados pelo Sistema de Informações de Águas Subterrâneas e pelo Serviço Geológico Brasileiro (SIAGAS-CPRM). Os resultados apresentam-se de acordo com as informações geológicas e contribuem com as pesquisas hidrogeofísicas no Estado de São Paulo.

Palavras-chave: CTDEM, SEV, inversão individual, inversão conjunta 1D SEV/TDEM, técnica fixed loop, bacia sedimentar de Taubaté. 


\section{Abstract}

In this research the geophysics data were analyzed through the Time Domain Electromagnetic Method (TDEM) and Electrical Method (DC), which one were acquired in central region of sedimentary Taubaté basin, SP, for the purpose to contribute to hydrogeological studies and perform a geoelectrical characterization of this area. TDEM data were obtained by 3D mobile receiver coil $(\mathrm{Rx})$ and transmitter fixed-loop techniques. The DC data were collected using Vertical Electric Sounding (VES) and Electrical Resistivity Tomography (ERT) techniques. The geoelectrical layers interpretation of subsurface were performed by TDEM individual invertions and 1D joint inversions VES/TDEM and the TDEM profiles were generated through interpolation of TDEM individual inversions, allowing to generate a geoelectrical model to the specific region inside the loop transmitter. The study area is located around Taubate city, SP, in a rural area, so that TDEM profile results associated with joint inversions VES/TDEM and wells lithological informations allows mapping the contact between Quaternary and Tertiary (Taubaté Group and Pindamonhangaba Formation) sediments. The top of the basement in the studies area was inferred through of wells informations available in Groundwater Information System and Brazilian Geological Service (SIAGAS-CPRM). The results are consistent with geological informations, contributing with hydrogeophysical studies at São Paulo state.

Keywords: TDEM profile, VES, individual inversion, 1D joint inversion VES/TDEM, fixed-loop technique, sedimentary basin of Taubaté. 


\section{INTRODUÇÃO E OBJETIVOS}

Os métodos geofísicos eletrorresistivo e eletromagnéticos têm sido amplamente utilizados em todo o mundo em diferentes aplicações, como em estudos hidrogeológicos e na exploração mineral, devido à grande sensibilidade para mapear o contraste na resistividade elétrica das rochas em subsuperfície.

O método eletromagnético no domínio do tempo (TDEM) consiste em determinar a variação da resistividade elétrica das rochas em subsuperfície através do decaimento do campo magnético secundário gerado pela variação de uma corrente secundária (corrente eddy) em função do tempo. O método TDEM é bastante versátil e tem grande sensibilidade para mapear camadas condutoras na subsuperfície, além de ser robusto para realizar mapeamentos geoelétricos em bacias sedimentares (Morais e Menezes, 2005; Carrasquila e Ulugergerli, 2006), exploração de águas subterrâneas (Fitterman e Stewart, 1986; McNeill, 1994; Danielsen, et al., 2003; Land, et al., 2003), exploração mineral (McNeill, 1994), contaminação ambiental (N.G.A., 2002; Moreira, 2005), dentre outros.

No Brasil, o método TDEM foi útil no mapeamento de aquíferos sedimentares e na determinação de fraturas dentro dos basaltos da Formação Serra Geral, Bacia do Paraná (Bortolozo, 2011; Almeida, 2011; Porsani, et al., 2012a, 2012b; Leite, 2013; Bortolozo et al., 2014, 2015; Couto 2015; Campaña, 2015; Bortolozo, 2016; Campaña, et al., 2017; Leite, et al., 2018; Rangel, et al., 2018).

O método da eletrorresistividade (ER) é um dos mais populares métodos geofísicos para exploração de água subterrânea devido a simplicidade logística e boa capacidade de mapear contrastes de rochas condutoras/resistoras em subsuperfície (Singhal, B. B. S., Gupta, R. P., 2010). O método consiste em obter a resistividade elétrica das rochas por meio da injeção de correntes elétricas na subsuperfície (eletrodos de corrente) e na medida da diferença de potencial entre outros dois eletrodos (eletrodos de potencial), sendo bastante utilizado em bacias sedimentares, apresentando-se como uma ferramenta útil para mapear formações arenosas, argilosas (Feitosa, F. A. C., Filho, J. M., 2000), bem como zonas saturadas (Zohdy, A. R., 1969; 
Abdullahi, M. G., et al., 2015; Braga, A. C. O., 2006; Feitosa, F. A. C., Filho, J. M., 2000; Bortolozo, 2011; Bortolozo, 2016).

Nesta pesquisa os dados TDEM foram adquiridos por meio da técnica de caminhamento TDEM (CTDEM) usando um loop transmissor (Tx) fixo e uma bobina receptora $(\mathrm{Rx})$ - 3D móvel, conhecida como técnica fixed-loop. Os dados de ER foram adquiridos por meio da técnica de Sondagem Elétrica Vertical (SEV) e perfis de Caminhamento Elétrico (CE). A SEV foi adquirida no centro de um loop transmissor de corrente, coincidente com a sondagem TDEM (loop-central), visando um estudo integrado, onde o perfil de CE foi adquirido sobreposto ao perfil de CTDEM.

Embora tanto o método da ER quanto o TDEM sejam recomendados para estudos hidrogeológicos e na exploração mineral, cada método geofísico apresenta a sua ambiguidade no processo de interpretação. Uma forma de reduzir as ambiguidades é por meio de um estudo integrado usando diferentes métodos geofísicos, bem como informações litológicas de poços. Outra forma de minimizar essas ambiguidades é através da inversão conjunta de dados, uma vez que a resistividade elétrica é a propriedade física obtida por ambos os métodos. Desta forma, é possível realizar uma interpretação integrada utilizando ambos os métodos, permitindo que as informações adquiridas sejam mais confiáveis.

Os resultados desta pesquisa baseiam-se, principalmente, nas informações obtidas através do método TDEM, o qual investiga as informações geoelétricas da subsuperfície a grandes profundidades. Através destas informações, associadas com as respostas da SEV para as camadas mais rasas e com informações de poços, a pesquisa contribuiu com os estudos hidrogeofísicos, apresentando o comportamento das camadas geoelétricas através de perfis de CTDEM, das inversões individuais TDEM e inversões conjuntas SEV/TDEM (Bortolozo e Porsani, 2012). Portanto, a estratigrafia geoelétrica da subsuperfície foi obtida, com ênfase no mapeamento do pacote sedimentar saturado (Grupo Taubaté), estimativa do contato entre os sedimentos Quaternários/Terciários e na estimativa da profundidade do topo do embasamento cristalino da bacia na área de estudos. 


\section{ASPECTOS GEOLÓGICOS DA ÁREA DE ESTUDOS}

A área de estudos está localizada nas proximidades da cidade de Taubaté, estado de São Paulo. Geologicamente, a área está assentada sobre a Bacia sedimentar de Taubaté (Figura 1), localizada na porção leste do Estado de São Paulo entre a Serra da Mantiqueira e a Serra do Mar. De acordo com Riccomini (1989), a Bacia de Taubaté faz parte de um conjunto de bacias pertencentes ao Rifte Continental do Sudeste do Brasil (RCSB) e sua origem está relacionada com a evolução da margem continental brasileira. A arquitetura rifte da bacia é caracterizada por uma série de semi-grabens separados por zonas de transferências ou de acomodação, com depocentros invertidos, em típica geometria de bacia do tipo rifte.

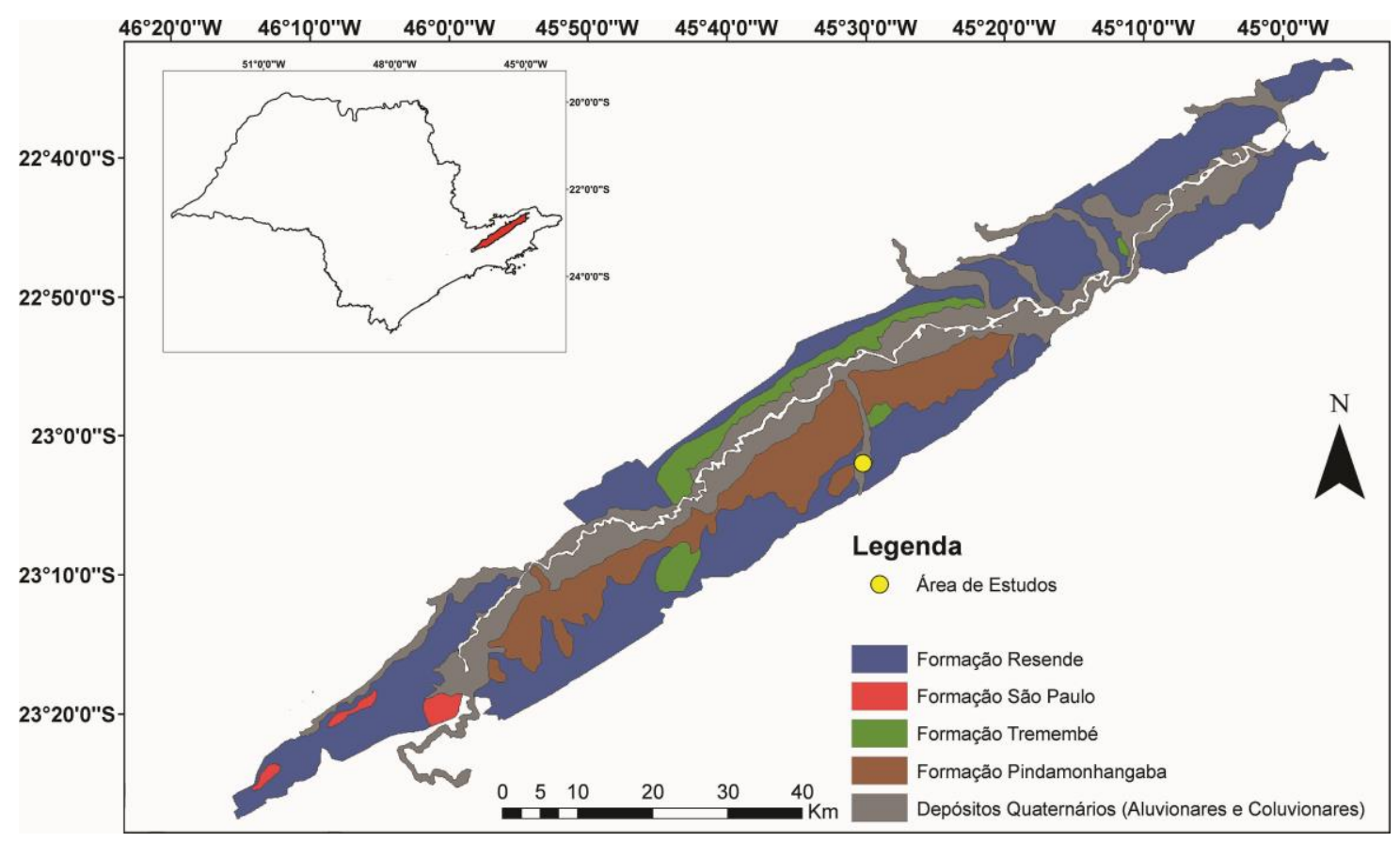

Figura 1: Bacia sedimentar de Taubaté (Modificado de Souza Filho, M. N., et al., 2012).

Diversos trabalhos foram realizados para analisar a topografia do embasamento com a delimitação dos altos estruturais e as principais falhas. Os primeiros estudos foram relizados pelo Departamento de Águas e Energia Elétrica (DAEE) em 1977 (Apud Carvalho, et al., 2010), onde foram utilizadas informações de campo e dados de poço 
sugerindo a compartimentação da Bacia de Taubaté em seis sub-bacias: Parateí, Jacaréi, Eugênio de Melo, Tremembé, Lorena e Cruzeiro. A sub-bacia de Parateí é separada das demais pela Falha de São José, sendo que as demais são divididas pelos altos estruturais do embasamento denominados de Alto do Rio Putins, Alto de Caçapava, Alto de Aparecida e Alto de Cachoeira Paulista (Figura 2).

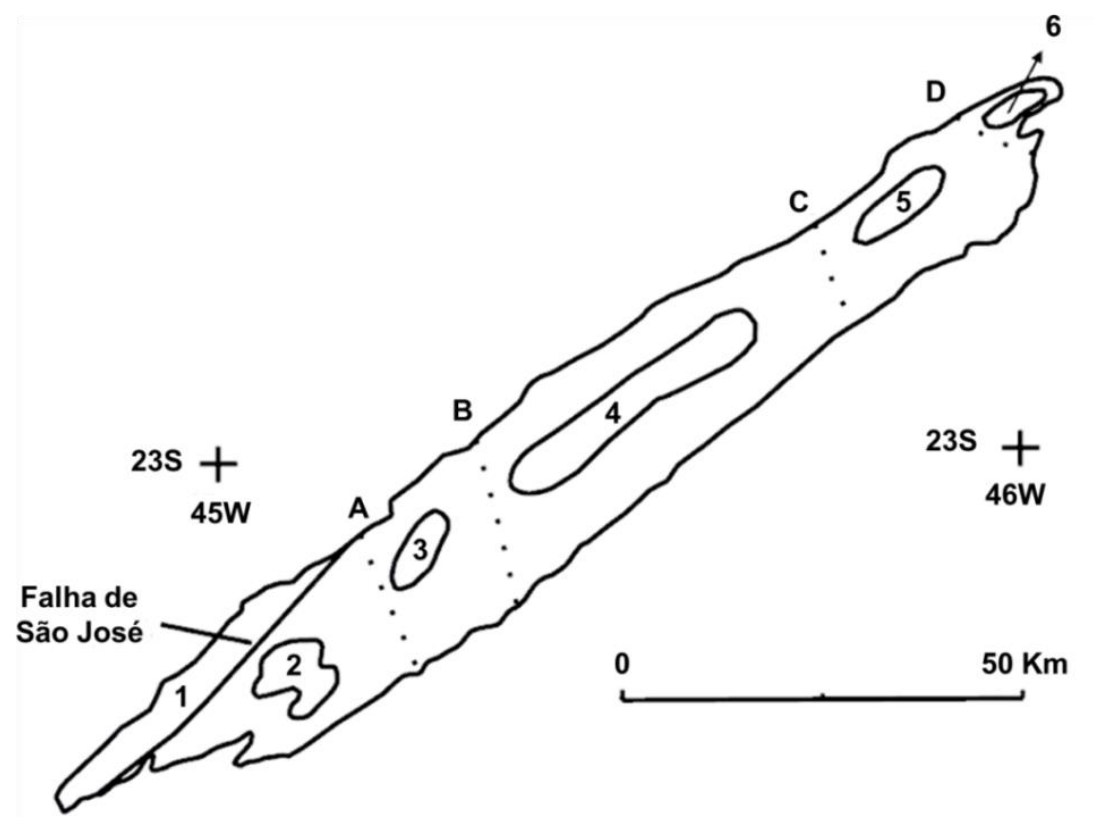

Figura 2: Compartimentação estrutural da Bacia de Taubaté de acordo com DAEE (1977). Os números representam as sub-bacias: 1) Parateí, 2) Jacareí, 3) Eugênio de Melo, 4) Tremembé, 5) Lorena, 6) Cruzeiro. As letras representam os altos estruturais: A) Rio Putins, B) Caçapava, C) Aparecida, D) Cachoeira Paulista (Modificado de Carvalho, et al., 2010).

Com base em informações de seções sísmicas, Marques (1990) reconheceu quatro depocentros na região nordeste e central da bacia (Eugenio de Melo, Quiririm, Roseira e Lorena), visto ainda que as seções sísmicas não detectaram depocentros significativos na região sudeste da bacia (Parateí e Jacareí), reconhecendo também os altos estruturais B, C e D da Figura 2.

Fernandes (1993) ao interpretar as seções sísmicas de Marques (1990) juntamente com dados gravimétricos, identifica quatro sub-bacias denominadas de Parateí, Jacareí-São José dos Campos, Quiririm-Taubaté e Aparecida-Lorena, bem 
como os altos estruturais que dividem as sub-bacias, que são a Falha de São Carlos, Alto de Caçapava e Alto de Pindamonhangaba (Carvalho, et al., 2010).

A proposta de repartição da Bacia de Taubaté vem com os trabalhos de Fernandes e Chang (2001), os quais através de dados gravimétricos dividem a Bacia de Taubaté em três compartimentos: São José dos Campos, Taubaté e Aparecida, separados pelos altos de Caçapava e Pindamonhangaba (Figura 3). O compartimento de São José Dos Campos apresenta $300 \mathrm{~m}$ de profundidade. Já o compartimento Taubaté apresenta profundidade máxima de $600 \mathrm{~m}$. E o compartimento Aparecida atinge profundidades de $800 \mathrm{~m}$ (Vidal, et al., 2004).

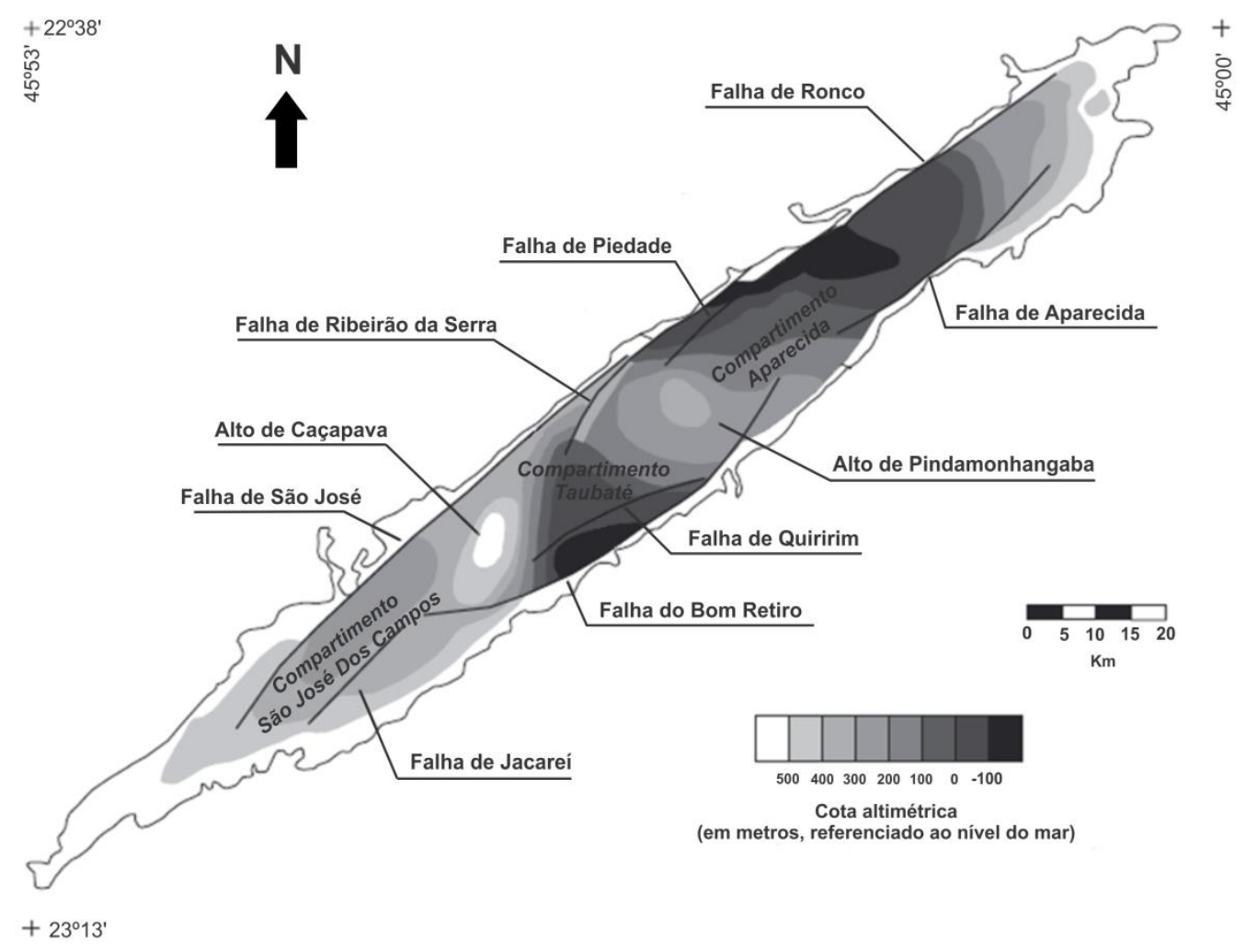

Figura 3: Mapa estrutural da Bacia de Taubaté (Modificado de Fernandes e Chang, 2003).

Através de dados magnetotelúricos, a Bacia de Taubaté pôde ser caracterizada em duas camadas geoelétricas. A camada superior, condutiva, composta por sedimentos Terciários e Quaternários, e a camada inferior, composta pelo embasamento cristalino pré-cambriano (Carvalho, et al., 2010). 
De acordo com Riccomini (1989), o preenchimento desta bacia pode ser dividido em duas etapas. A primeira etapa, sin-tectônica ao rifte com a deposição dos sedimentos do Grupo Taubaté, os quais compõem as Formações Resende, Tremembé e São Paulo. E a segunda etapa seguinte à tectônica diastrófica, com a deposição da Formação Pindamonhangaba e dos depósitos aluviais e coluviais (sedimentos Quaternários).

A Formação Resende é composta basicamente por arenitos, conglomerados, diamictitos e lamitos. Já a Formação Tremembé é preenchida por argilitos, folhelhos, margas e calcários dolomíticos. A formação São Paulo, presente na porção sudoeste da bacia, mais restrita, constitui em sua sedimentação arenitos, argilitos, siltitos e arenitos conglomeráticos (DAEE, IG, IPT, CPRM, 2005).

Sobrepostos ao Grupo Taubaté, encontram-se os sedimentos da Formação Pindamonhangaba (Mioceno), a qual é constituída por arenitos, conglomerados, argilitos e siltitos. Os depósitos aluviais e coluviais, embora apresentem uma grande distribuição superficial pela bacia, possuem uma espessura pouco expressiva. $\mathrm{Na}$ Figura 4 pode-se observar o quadro estratigráfico da Bacia de Taubaté.

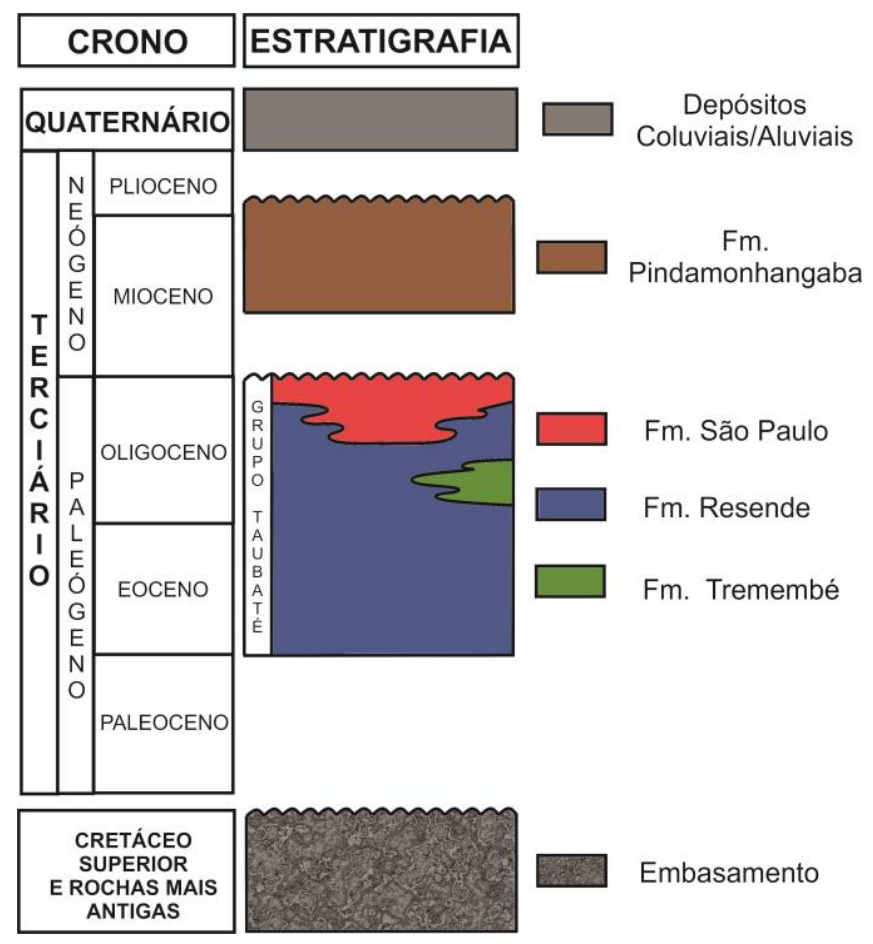

Figura 4: Quadro estratigráfico da Bacia de Taubaté (Modificado de Riccomini, 1989). 
Em um trabalho que visou delimitar embasamento da Bacia de Taubaté, Carvalho et al., (2010) utilizaram informações de 79 poços que atingiram o embasamento e 11 seções sísmicas adquiridas pela PETROBRAS em 1988 e disponibilizadas pela ANP (Agência Nacional de Petróleo) para realização do estudo da delimitação do embasamento (Figura 5).

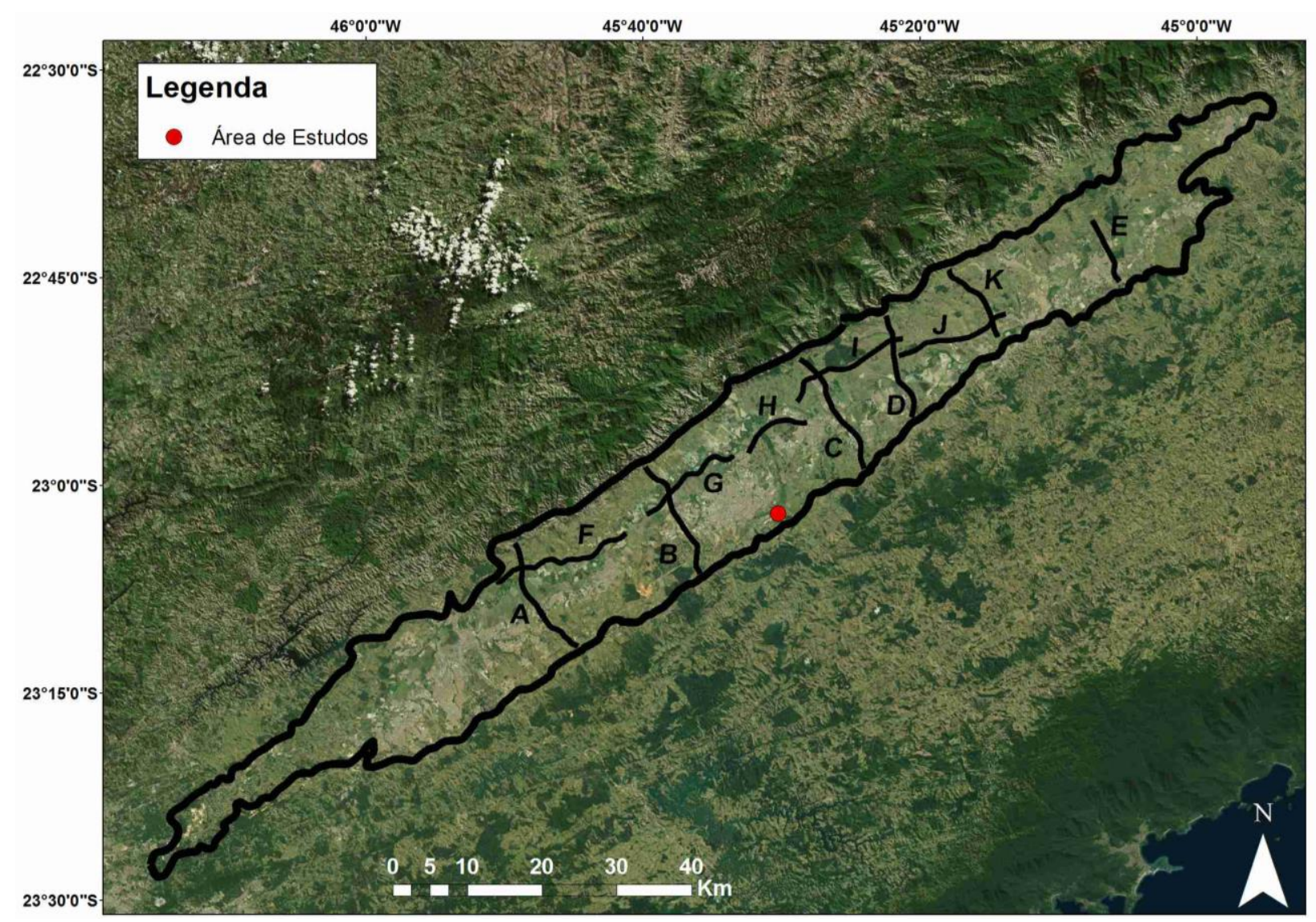

Figura 5: Localização das 11 seções sísmicas na Bacia de Taubaté. Em vermelho, a localização da área de estudos em questão (Adaptado de Carvalho, et al., 2010).

A área de estudos localiza-se entre as seções sísmicas B, C, G e H. De acordo com as informações sísmicas, a seção sísmica $B$ apresenta-se como um semigráben com profundidades que variam entre 300 e 800 metros. A seção sísmica $C$ destaca um semigráben basculado para NW variando entre 300 e 750 metros de profundidade. Em relação ao perfil sísmico G, as profundidades variam entre 300 e 700 metros. Não foram 
disponibilizadas as informações de algumas seções sísmicas, dentre elas a seção sísmica H (Carvalho, et al., 2010).

De acordo com o Sistema de Informações de Águas Subterrâneas (SIAGAS CPRM, 2018), existem 75 poços perfurados na cidade de Taubaté e em suas proximidades (Apêndice $C$ ), os quais descrevem a litologia da área em cada um dos respectivos pontos de perfuração. As informações litológicas descritas pelos poços são coerentes entre si e com a literatura, contendo um solo areno-argiloso, seguido por uma composição de arenitos, argilitos e em sua maioria por folhelhos. Dos 75 poços analisados, apenas dois atingiram o embasamento nas profundidades de 442 e 510 metros, ambos distantes aproximadamente $9 \mathrm{Km}$ da área de estudos. Na Figura 6 temse o mapa de localização dos poços, bem como os perfis construtivos dos poços que atingiram o topo do embasamento. 


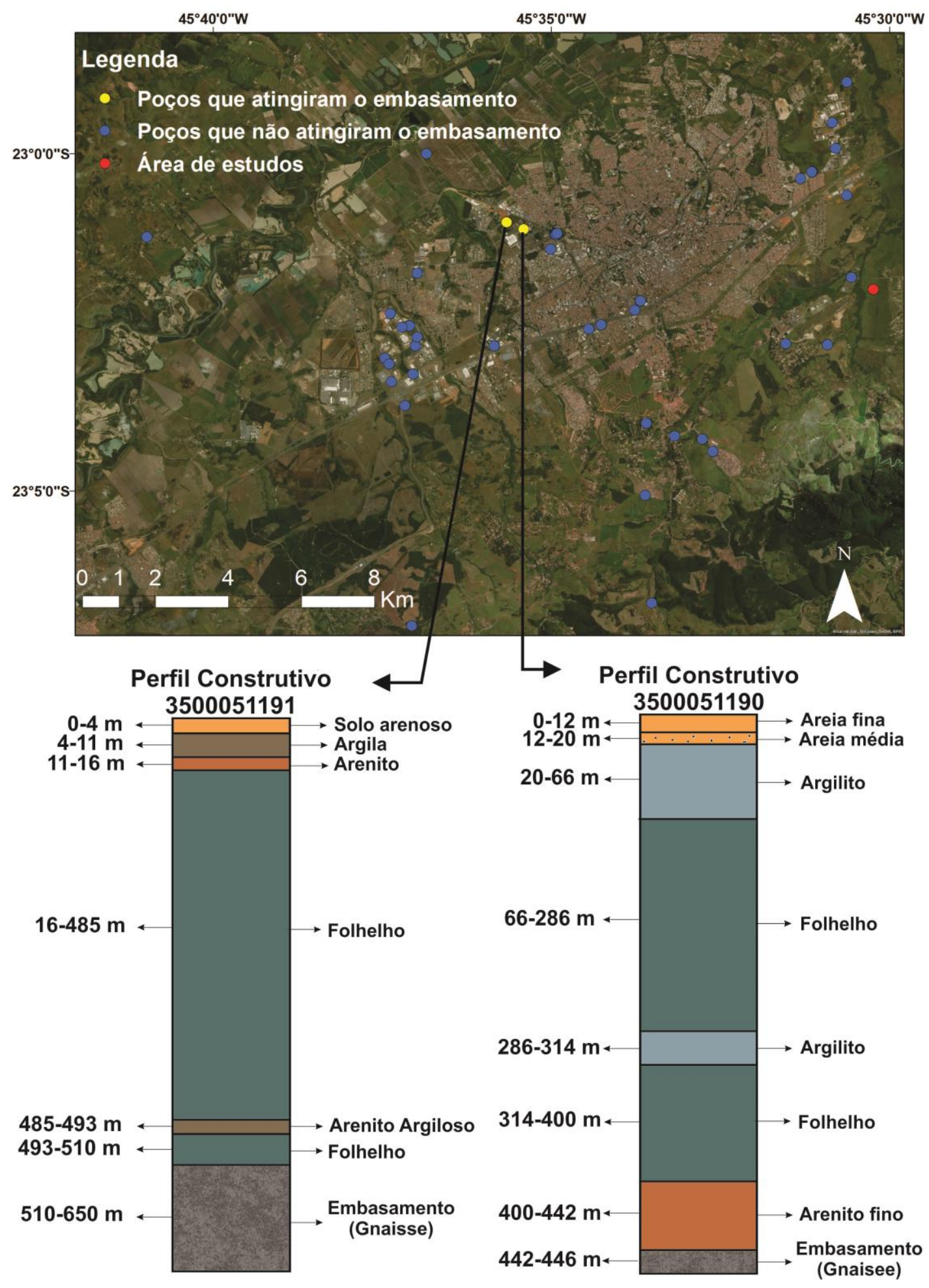

Figura 6: Mapa de localização dos poços na cidade de Taubaté, associado aos perfis construtivos 3500051191 e 3500051190 que atingem o topo do embasamento (Adaptado de SIAGAS - CPRM). 
Na Figura 6, são apresentados os perfis construtivos dos dois poços que atingiram o embasamento. O perfil construtivo 3500051191 é constituído nos primeiros $16 \mathrm{~m}$ de profundidade de um solo arenoso, argila e arenito, respectivamente, e dos $16 \mathrm{~m}$ até 485 $\mathrm{m}$ é constituído predominantemente por folhelhos, onde uma pequena camada de argila intercala-se com os folhelhos que atinge o embasamento em $510 \mathrm{~m}$ de profundidade.

Em relação ao perfil construtivo 3500051190 , os primeiros $20 \mathrm{~m}$ de profundidade são intercalados por areia fina e média, respectivamente. Na sequência, há uma alternância na composição do perfil que variando em argilitos, folhelhos e arenito fino, sendo constituído em sua maioria por folhelhos. Aos $442 \mathrm{~m}$ de profundidade atinge-se o topo da rocha cristalina (SIAGAS - CPRM).

De maneira geral, nota-se que os perfis litológicos dos poços possuem uma composição bastante intercalada. Contudo, a presença de folhelhos e argilitos é mais expressiva. Desta forma, baseando-se na litologia dos poços disponibilizados pela SIAGAS-CPRM (2018), nas informações dos aspectos geológicos da área de estudos e na profundidade do topo do embasamento visto na Figura 6, a Figura 7 mostra um perfil litológico representativo da área de estudos.

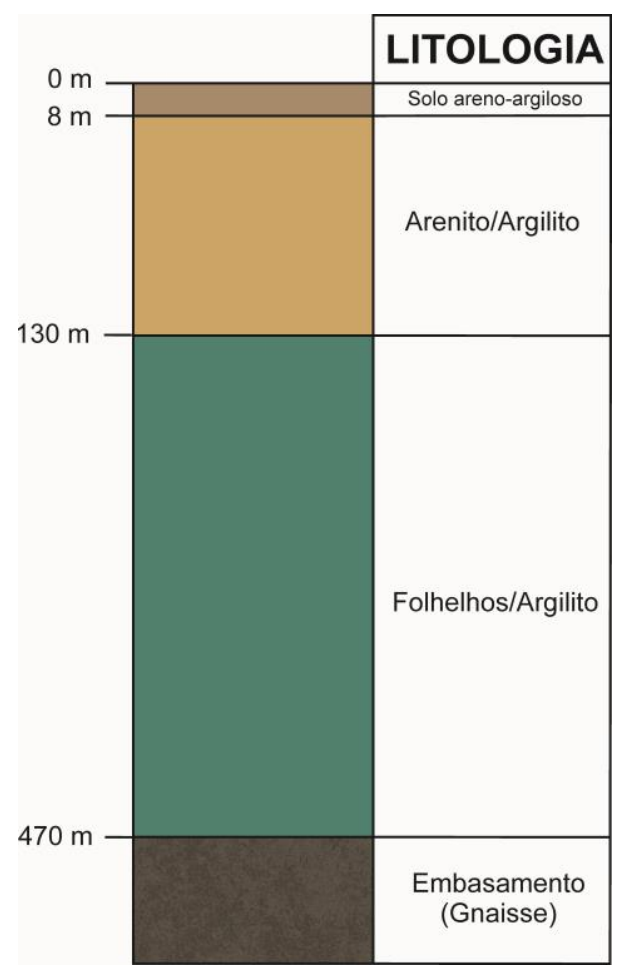

Figura 7: Perfil litológico da área de estudos com base nos poços dos SIAGAS-CPRM (2018). 


\subsection{Caracterização Geral do Aquífero Taubaté}

O aquífero sedimentar de Taubaté está localizado no vale do rio Paraíba do Sul, entre a Serra do Mar e a Serra da Mantiqueira na porção leste do estado de São Paulo, o qual se apresenta de forma alongada na direção ENE ocupando uma área de aproximadamente $2371 \mathrm{Km}^{2}$, como visto na Figura 8 (DAEE/LEBAC, 2013).

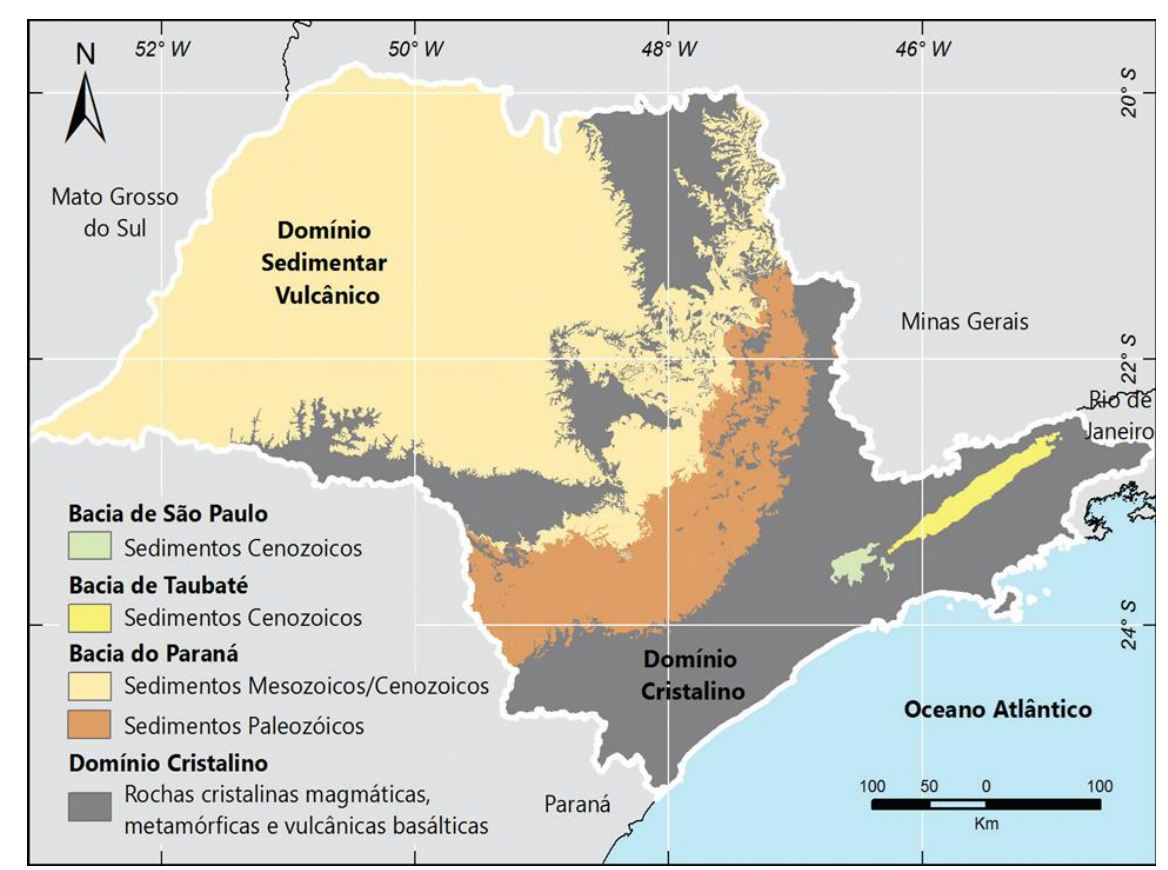

Figura 8: Domínios hidrogeológicos do estado de São Paulo (DAEE/LEBAC, 2013).

No compartimento central da bacia ocorrerem as maiores espessuras de sedimentos saturados, podendo variar de 200 a 300 m. A região central da bacia, onde se localizam as cidades de Taubaté, Tremembé e Pindamonhangaba, é preenchida, em sua maioria, por argilitos e folhelhos, caracterizando-se em um aquiclude devido à baixa permeabilidade destes sedimentos. (DAEE, IG, IPT, CPRM, 2005).

Nas porções nordeste e sudoeste, as quais predominam uma sedimentação mais arenosa, ocorrem as maiores produtividades do aquífero, podendo atingir vazões de $120 \mathrm{~m}^{3} / \mathrm{h}$, diferentemente da região central da bacia, a qual apresenta um potencial exploratório menos favorável com vazões inferiores a $10 \mathrm{~m}^{3} / \mathrm{h}$, onde em seu ambiente deposicional predominam argilitos e folhelhos (SIAGAS-CPRM, 2018), caracterizando a 
região saturada em um aquiclude (DAEE, IG, IPT, CPRM, 2005; DAEE/LEBAC, 2013). $\mathrm{Na}$ Figura 9 observa-se o mapa gerado através de informações do potencial hidrogeológico do aquífero de Taubaté disponibilizadas pela CPRM.

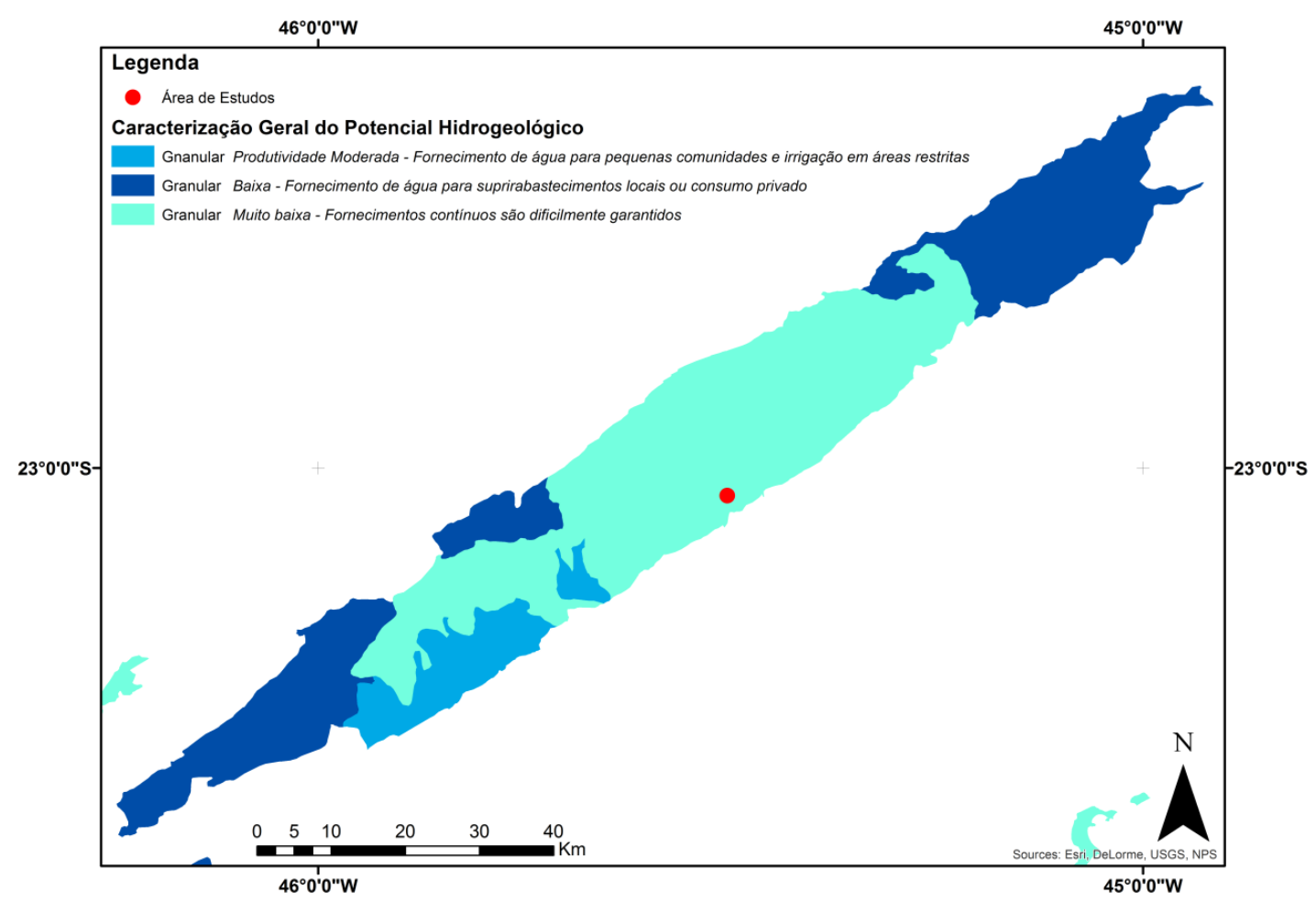

Figura 9: Mapa de caracterização geral do potencial hídrico da Bacia de Taubaté. 


\section{MÉTODOS GEOFÍ́SICOS}

\subsection{Eletromagnético no Domínio do Tempo (TDEM)}

O Método Eletromagnético no Domínio do Tempo tem como objetivo, determinar a resistividade elétrica dos materiais em subsuperfície através do decaimento do campo magnético secundário devido à variação do fluxo temporal do campo magnético primário. No Método Eletromagnético no Domínio da Frequência (FDEM), as medidas são realizadas na presença dos campos primário e secundário. O campo magnético primário é muito intenso se comparado com o campo magnético secundário, o que faz com que as medidas sejam distorcidas, diminuindo a confiabilidade dos dados obtidos. O regime de tempo em que é observada a presença do campo primário é denominado early times. Com intuito de minimizar a presença do campo magnético primário, o TDEM efetua suas medidas em tempos tardios (late times), como visto na Figura 10.

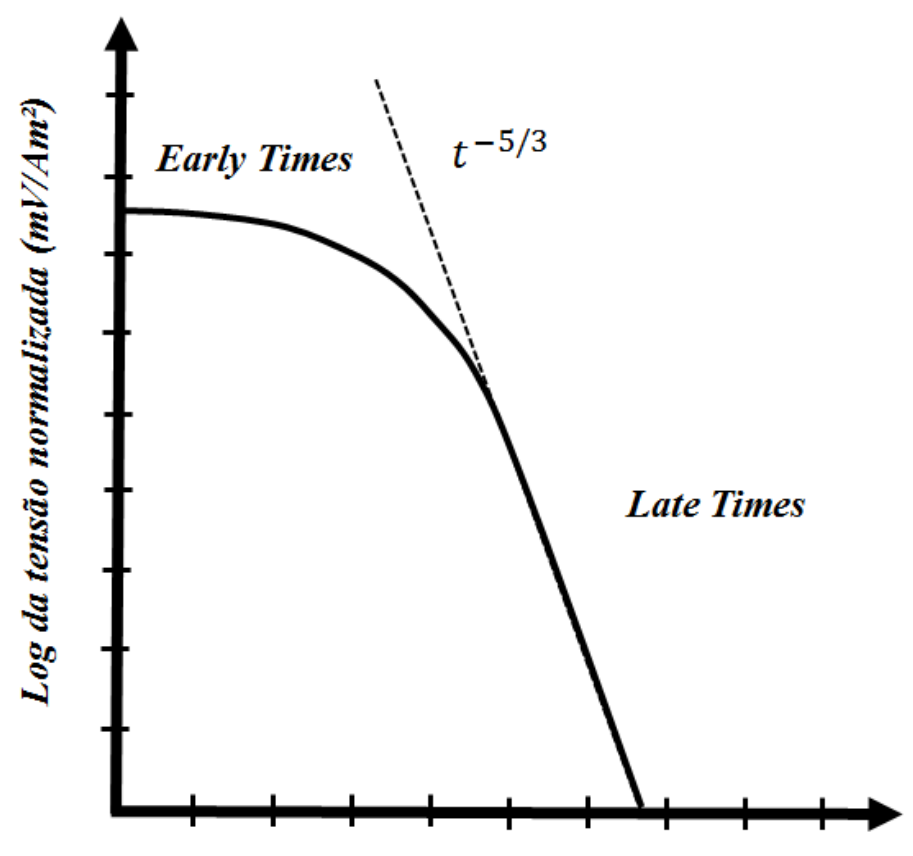

Log do tempo (s)

Figura 10: Curva de decaimento da tensão (Adaptado de McNeill, 1994). 
O Método TDEM funciona da seguinte maneira: No loop transmissor de corrente (geralmente um loop quadrado de $100 \mathrm{~m} \times 100 \mathrm{~m}$ ou $200 \mathrm{~m} \times 200 \mathrm{~m}$ ) circula uma corrente elétrica a qual é alimentada por um gerador. Pela Lei de Ampere, o fluxo desta corrente gera um campo magnético primário que não varia com o tempo. Para que o campo primário varie com o tempo, desliga-se a corrente que circula pelo loop transmissor. Contudo, este desligamento da corrente não é instantâneo e demora um curto intervalo de tempo (turn off time) da ordem de microssegundos, e é nesse momento em que ocorre a variação temporal do fluxo do campo magnético primário. Pela Lei de Faraday, a variação do fluxo do campo primário induz uma força eletromotriz (F.E.M.) nos materiais que se encontram em subsuperfície e, devido a resistividade que cada material apresenta, pela Lei de Ohm geram-se as correntes secundárias (eddy currents) associadas a essa F.E.M. que, por sua vez, estão associadas à um campo magnético secundário. Esta sequência de eventos pode ser vista na Figura 11.

O TDEM é altamente sensível a camadas de baixa resistividade (camadas condutivas) devido a alta densidade de corrente que flui nessas camadas. O tempo de difusão das correntes depende da resistividade das camadas, isto é, quanto mais condutivo for o meio, maior será a perda de energia do sinal e maior será o tempo para que ocorra a difusão das correntes secundárias. Este processo gera um fenômeno conhecido como Smoke Rings (Figura 12).

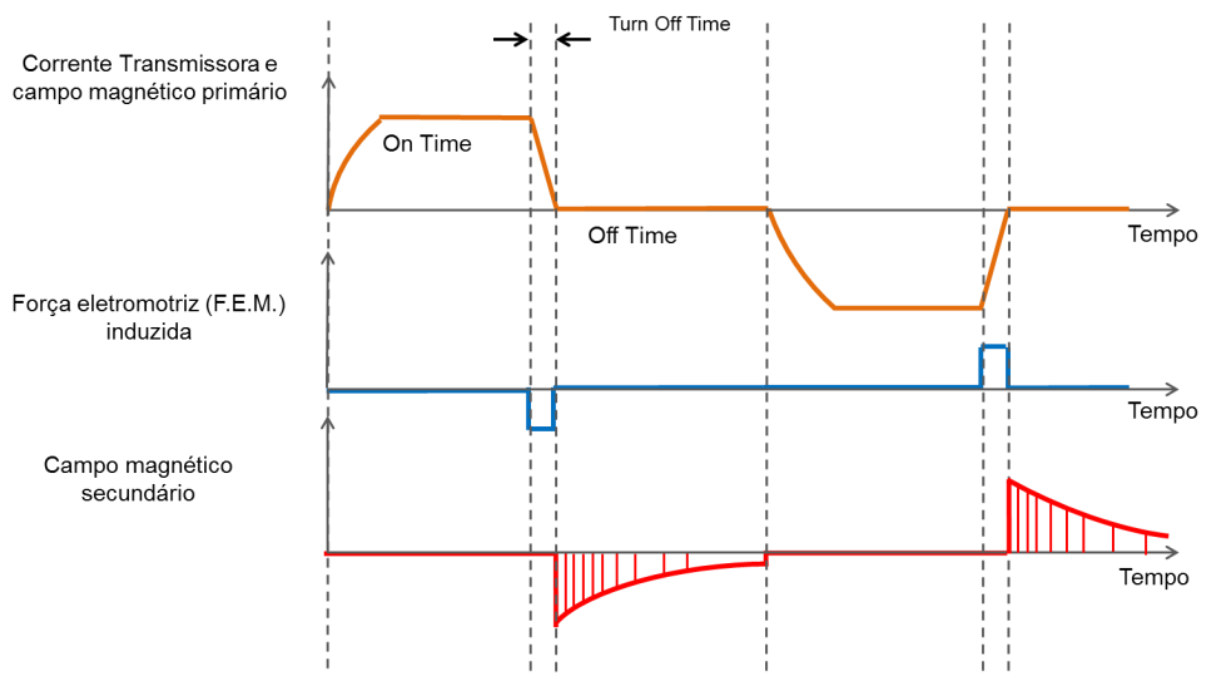

Figura 11: Esquema do funcionamento do método TDEM (Modificado de McNeill, 1994). 


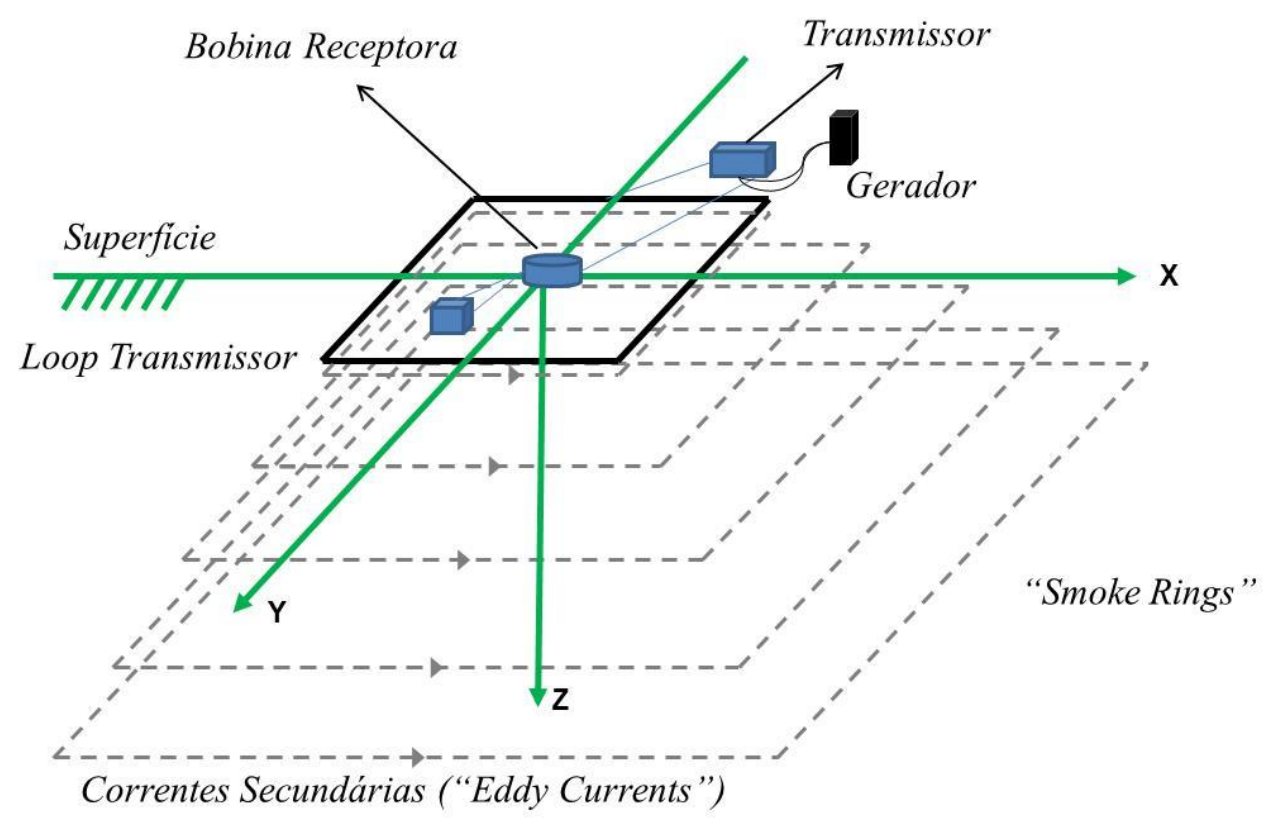

Figura 12: Correntes secundárias difundindo-se em subsuperfície (Modificado de McNeill, 1994).

\subsubsection{Aspectos Matemáticos}

No TDEM, todo o processo físico e matemático parte das Equações de Maxwell. Serão mostrados os aspectos matemáticos da dedução da Equação da resistividade do método TDEM a partir das deduções vistas em (Kirsch, 2006), Nabighian (1988) e Kaufman e Keller (1983). Considere as equações de Maxwell:

$$
\begin{aligned}
& \nabla x E=-\frac{\partial B}{\partial t}, \\
& \nabla x H=j+\frac{\partial D}{\partial t}, \\
& \nabla \cdot B=0, \\
& \nabla \cdot D=\rho,
\end{aligned}
$$


em que $E$ é a intensidade do campo elétrico $\left(\mathrm{V} / \mathrm{m}^{2}\right), H$ é o campo magnético $(\mathrm{A} / \mathrm{m}), j$ é a densidade de corrente elétrica $\left(\mathrm{A} / \mathrm{m}^{2}\right), D$ é a densidade do fluxo magnético $\left(\mathrm{C} / \mathrm{m}^{2}\right), B$ é o vetor indução magnética $\left(\mathrm{Wb} / \mathrm{m}^{2}\right.$ ou $\left.\mathrm{T}\right)$ e $\rho$ é a densidade volumétrica de carga elétrica $\left(\mathrm{C} / \mathrm{m}^{3}\right)$.

Os campos vetoriais $E, D, B$ e $H$ e a densidade de corrente elétrica $j$ relacionamse da seguinte maneira:

$$
\begin{aligned}
& D=\varepsilon E, \\
& \mathrm{~B}=\mu H, \\
& j=\sigma E,
\end{aligned}
$$

sendo $\varepsilon$ na Equação (3.1.5) a permissividade dielétrica do meio e $\mu$ na Equação (3.1.6) a permeabilidade magnética do meio.

Aplicando a transformada de Fourier nas Equações (3.1.1) e (3.1.2) e realizando as devidas substituições das Equações (3.1.5), (3.1.6) e (3.1.7), tem-se que, para Equação (3.1.1):

$$
F[\nabla x E](w)=-\mu \int_{-\infty}^{\infty} \frac{\partial H}{\partial t} e^{-i \omega t} d t=-\mu\left(\left.H e^{-i \omega t}\right|_{-\infty} ^{\infty}+i w \int_{-\infty}^{\infty} H e^{-i \omega t} d t\right)
$$

Lembrando que: $\nabla x E=-\frac{\partial B}{\partial t}=-\frac{\partial[\mu H]}{\partial t}=-\mu \frac{\partial H}{\partial t}$.

Supondo que para tempos infinitos o campo elétrico e magnético é nulo, tem-se que:

$$
\begin{gathered}
F[\nabla x E](w)=-\mu \int_{-\infty}^{\infty} \frac{\partial H}{\partial t} e^{-i \omega t} d t=-\mu i w \int_{-\infty}^{\infty} H e^{-i \omega t} d t \\
F[\nabla x E](w)=-i w \mu F[H](w)
\end{gathered}
$$

Aplicando a Transformada de Fourier para a Equação (3.1.2) e fazendo as devidas substituições, tem-se: 


$$
F[\nabla x H-\sigma E](w)=-\varepsilon \int_{-\infty}^{\infty} \frac{\partial E}{\partial t} e^{-i \omega t} d t=-\varepsilon\left(\left.E e^{-i \omega t}\right|_{-\infty} ^{\infty}+i w \int_{-\infty}^{\infty} E e^{-i \omega t} d t\right),
$$

Para tempos infinitos, $E=H=0$. Logo:

$$
F[\nabla x H-\sigma E](w)=-i w \varepsilon F[E](w)
$$

Note que as Equações (3.1.9) e (3.1.11) relacionam o campo elétrico e o campo magnético no domínio da frequência. Para problemas geoelétrico, considera-se $\mu=\mu_{0}=4 \pi \times 10^{-7} \mathrm{H} / \mathrm{m}$, que é o valor da permeabilidade magnética no vácuo. Sendo assim, no domínio da frequência as Equações (3.1.1) e (3.1.2) podem ser escritas da seguinte forma:

$$
\begin{gathered}
\nabla x E+i w \mu_{0} H=0, \\
\nabla x H-(\sigma+i w \varepsilon) E=0,
\end{gathered}
$$

em que $\left(i w \mu_{0}\right)$ é a impeditividade $(\hat{z})$ e $(\sigma+i w \varepsilon)$ é a admissividade $(\hat{y})$.

As Equações (3.1.12) e (3.1.13) são aplicadas em fontes onde há a ausência de correntes elétricas. Para regiões onde há correntes elétricas, apresentam-se as seguintes equações não homogêneas:

$$
\begin{aligned}
& \nabla x E+\hat{z} H=-J_{m}^{s}, \\
& \nabla x H-\hat{y} E=J_{e}^{s},
\end{aligned}
$$

sendo $J_{m}^{s}$ a corrente de fonte magnética e $J_{E}^{s}$ a corrente de fonte elétrica.

Se $J_{m}^{S}$ e $J_{E}^{S}$ forem definidas, as equações não-homogêneas (3.1.14) e (3.1.15) podem ser resolvidas para regiões homogêneas. Para isso, os campos $E$ e $H$ são escritos em função dos potenciais de Schelkunoff $A$ e $F$, respectivamente. Estes 
potenciais tornam as equações diferenciais mais simples de serem resolvidas, pois são paralelos as fontes de correntes, ao contrário dos campos elétrico e magnético.

O campo elétrico e magnético em cada região homogênea são dados pela superposição de cada tipo de fonte: elétrica e magnética.

$$
\begin{gathered}
E=E_{m}+E_{e}, \\
H=H_{m}+H_{e} .
\end{gathered}
$$

O campo eletromagnético é descrito pelo par de campos $\left(E_{m}\right.$ e $\left.H_{m}\right)$ e $\left(E_{e}\right.$ e $\left.H_{e}\right)$. Para o primeiro par $J_{m}^{s}$, assume-se que seja igual a zero, e para o último par $J_{e}^{s}$ assumese, também, que seja igual a zero. Isto significa que a fonte de corrente elétrica é nula para campos elétricos e magnéticos gerados numa fonte magnética e vice-versa. Sendo assim, substituindo (3.1.16) e (3.1.17) em (3.1.14) e (3.1.15), segue que:

$$
\begin{gathered}
J_{e}^{s}=0\left\{\begin{array}{c}
\nabla x E_{m}=-\hat{z} H_{m}-J_{m}^{s}, \\
\nabla x H_{m}=\hat{y} E_{m},
\end{array}\right. \\
J_{m}^{s}=0\left\{\begin{array}{c}
\nabla x E_{e}=-\hat{z} H_{e}, \\
\nabla x H_{e}=\hat{y} E_{e}+J_{e}^{s} .
\end{array}\right.
\end{gathered}
$$

O método TDEM utiliza somente fonte magnética $\left(J_{m}^{s}\right)$, transmitindo um campo elétrico transversal. $O$ que simplifica a equação, pois somente o potencial $F$ é necessário para o cálculo. O potencial de Schelkunoff em $\mathrm{F}$ é definido como:

$$
E_{m}=-\nabla x \mathrm{~F}
$$

sendo $E_{m}$ o campo elétrico gerado pela fonte magnética.

Uma interpretação adequada dos dados geofísicos relacionados ao campo eletromagnético requer a solução das equações de Helmholtz ou das equações de 
Laplace. Usando o potencial de Schelkunoff em $F$ na Equação (3.1.18), é possível derivar a equação não-homogênea de Helmholtz dada por:

$$
\nabla^{2} \mathrm{~F}+k^{2} \mathrm{~F}=-J_{m}^{s}
$$

em que $k$ é o número de onda dado por:

$$
k^{2}=\mu_{0} \varepsilon w^{2}-i \mu_{0} \sigma w .
$$

Lembrando da relação de impeditividade e admissividade, tem-se a seguinte relação para o número de onda:

$$
k^{2}=\mu_{0} \varepsilon w^{2}-i \mu_{0} \sigma w=i w \mu_{0}(\sigma+i \varepsilon w)=\hat{z} \hat{y} .
$$

Para materiais geológicos e frequências menores que $10^{5} \mathrm{~Hz}$, a corrente de deslocamento torna-se desprezível $\left(k^{2} \cong-i \mu_{0} \sigma w\right)$. Esta é chamada aproximação quase-estática.

Observa-se que a Equação (3.1.23) é a equação de Helmholtz não-homogênea para o Potencial de Schelkunoff em F. Portanto, analogamente a Equação (3.1.23), a equação de Helmholtz não-homogênea para o Potencial de Schelkunoff em A é dada por:

$$
\nabla^{2} A+k^{2} A=-J_{e}^{S}
$$

Analisando novamente as Equações (3.1.18), (3.1.19), (3.1.20) e (3.1.21), e aplicando o divergente em cada uma dessas equações, são dadas as seguintes relações:

$$
\begin{aligned}
& J_{e}^{s}=0\left\{\begin{array}{l}
\nabla \cdot\left(\nabla x E_{m}\right)=\nabla \cdot\left(-\hat{z} H_{m}\right)-\nabla \cdot J_{m}^{S} \rightarrow \nabla \cdot\left(\nabla x E_{m}\right)=0 \\
-\hat{z} \nabla \cdot H_{m}=\nabla \cdot J_{m}^{S} \rightarrow \nabla \cdot H_{m}=\frac{\nabla \cdot J_{m}^{S}}{\hat{z}},
\end{array}\right. \\
& J_{e}^{s}=0\left\{\begin{array}{l}
\nabla \cdot\left(\nabla x H_{m}\right)=\nabla \cdot\left(-\hat{z} H_{m}\right) \rightarrow \nabla \cdot\left(\nabla x H_{m}\right)=0 \\
\hat{y} \nabla \cdot E_{m}=0 \rightarrow \nabla \cdot E_{m}=0
\end{array}\right.
\end{aligned}
$$




$$
\begin{aligned}
& J_{m}^{s}=0\left\{\begin{array}{c}
\nabla \cdot\left(\nabla x E_{e}\right)=\nabla \cdot\left(-\hat{z} H_{e}\right) \rightarrow \nabla \cdot\left(\nabla x E_{e}\right)=0, \\
-\hat{z} \nabla \cdot H_{E}=0 \rightarrow \nabla \cdot H_{e}=0,
\end{array}\right. \\
& J_{m}^{s}=0\left\{\begin{array}{c}
\nabla \cdot\left(\nabla x H_{e}\right)=\nabla \cdot\left(\hat{y} E_{e}\right)+\nabla \cdot\left(J_{e}^{S}\right) \rightarrow \nabla \cdot\left(\nabla x H_{e}\right)=0, \\
-\hat{y} \nabla \cdot E_{e}=\nabla \cdot J_{e}^{S} \rightarrow \nabla \cdot E_{e}=\frac{\nabla \cdot J_{e}^{S}}{\hat{y}} .
\end{array}\right.
\end{aligned}
$$

Segue das Equações (3.1.30) e (3.1.32) que o campo $E_{m}$ é dado pela Equação (3.1.22) e que o campo $H_{e}$ é dado por:

$$
H_{e}=\nabla x A,
$$

em que A e F são os potenciais de Schelkunoff. Substituindo as Equações (3.1.22) e (3.1.35) em (3.1.19) e (3.1.20), obtêm-se:

$$
\begin{gathered}
\nabla x H_{m}=\hat{y} E_{m} \rightarrow \nabla x H_{m}=\hat{y}(-\nabla x \mathrm{~F}) \rightarrow H_{m}=-\hat{y} \mathrm{~F}-\nabla U, \\
\nabla x E_{e}=-\hat{z} H_{e} \rightarrow \nabla x E_{e}=-\hat{z}(\nabla x A) \rightarrow E_{e}=-\hat{z} A-\nabla V .
\end{gathered}
$$

Na situação descrita em (3.1.36) e (3.1.37), $U$ e $V$ são potenciais escalares que foram introduzidos nas relações devido a igualdade dos rotacionais dos campos. De maneira que, substituindo as Equações (3.1.22) e (3.1.36) na Equação (3.1.18) e as Equações (3.1.35) e (3.1.37) na Equação (3.1.21), respectivamente, tem-se:

$$
\begin{gathered}
\nabla x E_{m}=-\hat{z} H_{m}-J_{m}^{S} \\
\nabla x(-\nabla \times \mathrm{F})=-\hat{z}(-\hat{y} \mathrm{~F}-\nabla U)-J_{m}^{S} \rightarrow \nabla x(-\nabla \times \mathrm{F})=\hat{z}(-\hat{y} \mathrm{~F}-\nabla U)+J_{m}^{S}, \\
\nabla(\nabla . \mathrm{F})-\nabla^{2} \mathrm{~F}=\hat{z}(-\hat{y} \mathrm{~F}-\nabla U)+J_{m}^{S} \\
\nabla x H_{e}=\hat{y} E_{e}+J_{e}^{S}
\end{gathered}
$$




$$
\begin{gathered}
\nabla x(\nabla \times A)=\hat{y}(-\hat{z} A-\nabla V)-J_{e}^{S}, \\
\nabla(\nabla \cdot A)-\nabla^{2} A=\hat{y}(-\hat{z} A-\nabla V)+J_{e}^{S} .
\end{gathered}
$$

Como dito anteriormente, os potenciais escalares $U$ e $V$ são arbitrários, o que permite impor condições de restrição arbitrárias. Convenientemente, impor-se-á as condições de Lorentz, a qual é utilizada para simplificar as equações de Maxwell.

$$
\begin{aligned}
& \nabla \cdot \mathrm{F}=-\hat{z} U, \\
& \nabla \cdot A=-\hat{y} V .
\end{aligned}
$$

Lembrando-se da relação do número de onda na Equação (3.1.25), é possível substituir as Equações (3.1.44) e (3.1.45) em (3.1.40) e (3.1.43), respectivamente.

$$
\begin{gathered}
\nabla(\nabla \cdot \mathrm{F})-\nabla^{2} \mathrm{~F}=\hat{z}(-\hat{y} \mathrm{~F}-\nabla U)+J_{m}^{S}, \\
\nabla(-\hat{z} U)-\nabla^{2} \mathrm{~F}=-\hat{z} \hat{y} \mathrm{~F}-\hat{z} \nabla U+J_{m}^{S}, \\
\therefore \nabla^{2} \mathrm{~F}+k^{2} \mathrm{~F}=-J_{m}^{S} .
\end{gathered}
$$

Segue ainda que:

$$
\begin{gathered}
\nabla(\nabla . A)-\nabla^{2} A=\hat{y}(-\hat{z} A-\nabla V)+J_{e}^{S}, \\
\nabla(-\hat{y} V)-\nabla^{2} A=-\hat{y} \hat{z} A-\hat{y} \nabla V+J_{e}^{S}, \\
\therefore \nabla^{2} A+k^{2} A=-J_{e}^{S} .
\end{gathered}
$$

No método TDEM, é necessário apenas a utilização do Potencial $\mathrm{F}$ de Schelkunoff, visto que este método utiliza um dipolo magnético vertical o qual induz campos elétricos horizontais.

As Equações (3.1.48) e (3.1.51) são equações de Helmholtz não-homogêneas para os Potenciais de Schelkunoff. Os campos totais são dados pelas somas das Equações (3.1.22) com a (3.1.37) e (3.1.35) com a (3.1.36). 


$$
\begin{gathered}
\left\{\begin{array}{c}
H_{m}=-\hat{y} \mathrm{~F}-\nabla U, \\
H_{e}=\nabla x A,
\end{array}\right. \\
\left\{\begin{array}{c}
E_{e}=-\hat{z} A-\nabla V, \\
E_{m}=-\nabla x \mathrm{~F},
\end{array}\right.
\end{gathered}
$$

sendo os campos totais dados pelas Equações (3.1.16) e (3.1.17), e relacionando estes campos com as Equações (3.1.22), (3.1.35), (3.1.36) e (3.1.37), obtém-se:

$$
\begin{gathered}
E=-\hat{z} A-\nabla V-\nabla x \mathrm{~F}, \\
H=\nabla x A-\hat{y} \mathrm{~F}-\nabla U .
\end{gathered}
$$

Rearranjando as equações às condições de Lorentz vistas em (3.1.44) e (3.1.45), pode-se aplicar nas Equações (3.1.56) e (3.1.57). Logo:

$$
\begin{aligned}
& \nabla \cdot \mathrm{F}=-\hat{z} U \rightarrow U=\frac{-\nabla \cdot \mathrm{F}}{\hat{z}}, \\
& \nabla \cdot A=-\hat{y} V \rightarrow V=\frac{-\nabla \cdot A}{\hat{y}} .
\end{aligned}
$$

Portanto:

$$
\begin{aligned}
& E=-\hat{z} A+\frac{\nabla(\nabla \cdot A)}{\hat{y}}-\nabla x \mathrm{~F}, \\
& H=\nabla x A-\hat{y} \mathrm{~F}+\frac{\nabla(\nabla \cdot \mathrm{F})}{\hat{z}} .
\end{aligned}
$$

Como foi ressaltado anteriormente, no método TDEM é necessário apenas o potencial $F$ de Schelkunoff dados pelas Equações (3.1.22) e (3.1.52).

Assumindo uma Terra estratificada e unidimensional, o Potencial de Shelkunoff $F$ consiste apenas da componente z. Sendo assim: 


$$
\mathrm{F}=\mathrm{F}_{z} \hat{k}_{z}
$$

em que $\mathrm{F}_{z}=\mathrm{F}_{z}(x, y, z)$ é uma função escalar de $\mathrm{x}, \mathrm{y}, \mathrm{z}$ e $\hat{k}_{z}$ é um vetor unitário na direção $z$.

O campo elétrico é transverso, propagando-se na direção $x y$. Substituindo a Equação (3.1.62) em (3.1.22) e (3.1.36), respectivamente, é possível calcular o rotacional do Potencial de Shelkunoff F. Da Equação (3.1.22), segue que:

$$
\begin{gathered}
E_{m}=-\nabla x \mathrm{~F}(x, y, z) \\
E_{m}=-\nabla x \mathrm{~F}=-\left(\frac{\partial \mathrm{F}_{z}}{\partial y} \hat{\imath}+\frac{\partial \mathrm{F}_{x}}{\partial z} \hat{\jmath}+\frac{\partial \mathrm{F}_{y}}{\partial x} \hat{k}-\frac{\partial \mathrm{F}_{x}}{\partial y} \hat{k}-\frac{\partial \mathrm{F}_{y}}{\partial z} \hat{\imath}-\frac{\partial \mathrm{F}_{z}}{\partial x} \hat{\jmath}\right) \\
\therefore E_{m}=\frac{\partial \mathrm{F}_{z}}{\partial x} \hat{\jmath}-\frac{\partial \mathrm{F}_{z}}{\partial y} \hat{\imath} .
\end{gathered}
$$

Da Equação (3.1.52), tem-se:

$$
\begin{aligned}
& H_{m}=-\hat{y} \mathrm{~F}_{z} \hat{k}_{z}+\frac{\nabla\left(\nabla \cdot \mathrm{F}_{z} \hat{k}_{z}\right)}{\hat{z}}, \\
& \therefore H_{m}=-\hat{y}\left(\mathrm{~F}_{z} \hat{k}_{z}\right)+\nabla \frac{\partial \mathrm{F}_{z}}{\partial z} .
\end{aligned}
$$

Os versores cartesianos $\hat{\jmath}$ e $\hat{k}$ representam as coordenadas y e $\mathrm{x}$, respectivamente. Portanto, conclui-se que as componentes do campo $E_{m}$ são:

$$
E_{x}=-\frac{\partial \mathrm{F}_{z}}{\partial y} ; E_{y}=\frac{\partial \mathrm{F}_{z}}{\partial x} ; E_{z}=0
$$

As componentes de $H_{m}$ são dadas por:

$$
\begin{gathered}
H_{m}=-\hat{y}\left(\mathrm{~F}_{z} \hat{k}_{z}\right)+\nabla \frac{\partial \mathrm{F}_{z}}{\partial z}, \\
\nabla \frac{\partial \mathrm{F}_{z}}{\partial z}=\left(\frac{\partial^{2} \mathrm{~F}_{z}}{\partial x \partial z}, \frac{\partial^{2} \mathrm{~F}_{z}}{\partial y \partial z}, \frac{\partial^{2} \mathrm{~F}_{z}}{\partial z \partial z}\right),
\end{gathered}
$$




$$
H_{m x}=\frac{1}{\hat{z}} \frac{\partial^{2} \mathrm{~F}_{z}}{\partial x \partial z} ; H_{m y}=\frac{1}{\hat{z}} \frac{\partial^{2} \mathrm{~F}_{z}}{\partial y \partial z} ; H_{m z}=-\hat{y} \mathrm{~F}_{z}+\frac{1}{\hat{z}} \frac{\partial^{2} \mathrm{~F}_{z}}{\partial z \partial z}
$$

Como dito anteriormente, o campo elétrico produzido no método TDEM é um campo transversal. É necessário, portanto, calcular o valor do campo magnético vertical no centro do loop transmissor de corrente. O campo magnético no centro do loop nada mais é que a soma de todos os dipolos magnéticos verticais, sendo o loop transmissor circular ou quadrado. Neste caso, entende-se que o Potencial de Shelkunoff é um dipolo magnético vertical e a integração desses dipolos no centro do loop é dada por:

$$
\mathrm{F}(r, z)=\frac{\hat{z}_{0} m}{4 \pi} \int_{0}^{\infty}\left[e^{-\mu_{0}|z-h|}+r_{T E} e^{\mu_{0}(z+h)}\right] \frac{\lambda}{\mu_{0}} J_{0}\left(\lambda_{r}\right) d r,
$$

em que:

- $\quad m$ : momento de dipolo magnético;

- $\quad J_{0}$ : função de Bessel de ordem zero;

- $\quad \lambda=\left(k_{x}{ }^{2}+k_{y}{ }^{2}\right)^{2}$; onde $k_{x}$ e $k_{y}$ são as frequências espaciais nas direções $\mathrm{x}$ e $\mathrm{y}$, respectivamente;

- $\quad r=\left(x^{2}+y^{2}\right)^{1 / 2}$; onde $r$ é a distância radial da fonte ao receptor;

- $\quad r_{T E}$ : é o coeficiente de reflexão e mostra como o substrato modifica o campo primário;

- $\quad h$ : é a altura do loop transmissor em relação ao solo.

Considera-se agora um loop transmissor circular de raio a por onde transita um corrente I Integrando a Equação (3.1.72) com os referidos parâmetros, conclui-se que:

$$
\mathrm{F}(r, z)=\frac{\hat{z}_{0} I a}{2} \int_{0}^{\infty} \frac{1}{\mu_{0}}\left[e^{-\mu_{0}(z+h)}+r_{T E} e^{\mu_{0}(z-h)}\right] \frac{\lambda^{2}}{\mu_{0}} J_{1}\left(\lambda_{a}\right) J_{0}\left(\lambda_{r}\right) d \lambda,
$$

sendo $J_{1}$ a função de Bessel de $1^{\text {a }}$ ordem. Substituindo a Equação (3.1.73) na Equação (3.1.67) e realizando as devidas simplificações para um arranjo no qual o receptor encontra-se no centro do loop transmissor, o campo magnético vertical é dado por: 


$$
H_{z}=\frac{I a}{2} \int_{0}^{\infty}\left[e^{-\mu_{0}(z+h)}+r_{T E} e^{\mu_{0}(z-h)}\right] \frac{\lambda^{2}}{\mu_{0}} J_{1}\left(\lambda_{a}\right) d \lambda .
$$

A Equação (3.1.74) é a integral de Hankel sendo expressa no domínio da frequência, visto que $r_{T E}$ está em função da frequência. A resposta no domínio do tempo é obtida pela transformada inversa de Laplace ou pela transformada inversa de Fourier. A integral de Hankel não pode ser calculada de forma analítica, entretanto, para um arranjo loop central, na superfície e tratando-se de um substrato homogêneo, tem-se:

em que:

$$
r_{T E}=\frac{\lambda-u}{\lambda+u}
$$

- $\quad u_{n}=\left(\lambda^{2}-k_{n}{ }^{2}\right)^{1 / 2}$; sendo $k_{n}$ é o número de onda da e-nésima camada a qual satisfaz a condição da aproximação quase-estática $k_{n}{ }^{2}=\left(x^{2}+y^{2}\right)^{1 / 2}$.

Tendo conhecimento dessas informações, a Equação (3.1.74) pode ser reescrita da seguinte maneira:

$$
H_{z}=I a \int_{0}^{\infty} \frac{\lambda^{2}}{\lambda-u} J_{1}\left(\lambda_{a}\right) d \lambda .
$$

Da Equação (3.1.6), em que $B=\mu_{0} H$, resolvendo a integral (3.1.76) e aplicando a transformada inversa de Laplace, $B_{z}$ fica da seguinte forma:

$$
B_{z}=\frac{\mu_{0} I}{2 a}\left[\frac{3}{\pi^{\frac{1}{2}} \theta a} e^{-\theta^{2} a^{2}}+\left(1-\frac{3}{2 \theta^{2} a^{2}}\right) \operatorname{erf}(\theta a)\right]
$$

em que:

$$
\begin{aligned}
& \text { - } \quad \theta=\left(\mu_{0} \sigma / 4 t\right)^{\frac{1}{2}} ; \\
& \text { - } \quad \operatorname{erf}(\theta a) \text { : função erro. }
\end{aligned}
$$

Quando $t \rightarrow 0, B_{z} \rightarrow \frac{\mu_{0} I}{2 a}$. Esta é a intensidade do campo magnético que corresponde a intensidade magnética antes da corrente ser desligada. Da Equação 
(3.1.77), é possível obter a variação temporal da componente vertical do campo magnético.

$$
\frac{\partial B_{z}}{\partial t}=-\frac{I}{\sigma a^{3}}\left[3 \operatorname{erf}(\theta a)-\frac{2 \theta a}{\pi^{\frac{1}{2}}}\left(3+2 \theta^{2} a^{2}\right) e^{-\theta^{2} a^{2}}\right] .
$$

A resposta física que é medida em campo pelo método TDEM é a Equação (3.1.78). Devido a limitações do próprio equipamento, não é possível medir o campo magnético secundário logo após o desligamento da corrente no loop transmissor ( $100 \mu s)$. Desta forma, a medida para tempos tardios, ou seja, tempos posteriores ao desligamento da corrente $(t \rightarrow \infty, \theta \rightarrow 0)$. Sendo assim, tendo em vista essas condições, a Equação (3.1.78) é aproximada da seguinte maneira:

$$
\frac{\partial B_{z}}{\partial t} \cong-\frac{I\left(\sigma^{\frac{3}{2}}\right)\left(\mu_{0}^{\frac{5}{2}}\right)\left(a^{2}\right) t^{-\frac{5}{2}}}{20 \pi^{\frac{1}{2}}}
$$

Nota-se um decaimento proporcional em $t^{-\frac{5}{2}}$. Contudo, a equação de decaimento do campo magnético não se apresenta muito elucidativa. Desta forma, para tempos tardios, segundo (Christiansen, et al., 2006), a resistividade aparente $\left(\rho_{a}\right)$ é calculada por meio da Equação (3.1.80), dada por:

$$
\rho_{a}=\left(\frac{I a^{2}}{\frac{\partial B_{z}}{\partial t} 20}\right)^{\frac{2}{3}} \frac{\mu_{0}^{\frac{5}{3}} t^{-\frac{5}{3}}}{\pi^{\frac{1}{3}}}
$$

em que:

- $\quad \rho_{a}$ : Resistividade elétrica aparente ( $\Omega . m$ );

- $\quad t$ : Tempo (s);

- $\frac{\partial B_{Z}}{\partial t}$ : Variação do campo magnético secundário em função do tempo;

- $\quad$ I: Corrente que circula pelo loop transmissor (A);

- $\quad a$ : Raio do loop transmissor de corrente $(\mathrm{m})$. 


\subsubsection{Skin Depth}

A profundidade de investigação no método TDEM depende de alguns fatores, como o momento magnético do loop transmissor de corrente, da resistividade da área de estudo, dos níveis de ruído que o TDEM é susceptível e o intervalo de tempo medido.

O skin depth representa uma profundidade de investigação que corresponde a uma fração de 1/e do campo eletromagnético (Telford, et al., 1976). Spies (1989), analogamente ao domínio da frequência, representa matematicamente o Skin Depth da seguinte forma:

$$
\delta_{T D}=\sqrt{\frac{2 t}{\mu \sigma}} \cong 1,26 \sqrt{\rho t},
$$

em que $\mu$ é a permeabilidade magnética dos materiais em subsuperfície, $\sigma$ é a condutividade do meio, $\rho$ é a resistividade do meio e $t$ é o tempo transiente do campo eletromagnético. Ainda segundo Spies (1989), a profundidade de investigação para tempos tardios (late times) é dada por:

$$
d \cong 0,55\left[\frac{I A}{\sigma N_{v}}\right]^{\frac{1}{5}}
$$

em que I é a corrente que circula pelo loop transmissor, $A$ é a área do loop transmissor e $N_{v}$ é o nível de ruído na bobina receptora, onde o autor atribui um nível de ruído típico de aproximadamente $0,5 \mathrm{nV} / \mathrm{m}^{2}$.

Assumindo as condições realizadas em Taubaté, onde a corrente que circula pelo loop transmissor foi de $18 \mathrm{~A}$ e o loop de $200 \mathrm{~m}$ de lado (Área $=40000 \mathrm{~m}^{2}$ ), bem como o nível de ruído típico, é possível atribuir certos valores de resistividade e analisar a variação da profundidade teórica em situações com valores de resistividade distintos, como pode ser visto na Tabela 1. 


\begin{tabular}{ccc}
\hline Resistividade $(\boldsymbol{\Omega} . \mathbf{m})$ & Condutividade $(\mathbf{S} / \mathbf{m})$ & Profundidade Teórica $(\mathbf{m})$ \\
\hline 5 & 0,2 & $\mathbf{8 1 6 , 3}$ \\
10 & 0,1 & $\mathbf{9 3 7 , 6}$ \\
15 & 0,0666 & $\mathbf{1 0 1 6 , 8}$ \\
20 & 0,05 & $\mathbf{1 0 7 7 , \mathbf { 1 }}$ \\
25 & 0,04 & $\mathbf{1 1 2 6 , 2}$ \\
30 & 0,0333 & $\mathbf{1 6 6 8 , 0}$ \\
35 & 0,0285 & $\mathbf{1 2 0 4 , 6}$ \\
40 & 0,025 & $\mathbf{1 2 3 7 , 2}$ \\
45 & 0,0222 & $\mathbf{1 2 6 6 , 7}$ \\
50 & 0,02 & $\mathbf{1 2 9 3 , 7}$ \\
100 & 0,01 & $\mathbf{1 4 8 6 , \mathbf { 1 }}$ \\
200 & 0,005 & $\mathbf{1 7 0 7 , 0}$ \\
\hline
\end{tabular}

Tabela 1: Análise da profundidade teórica com valores de resistividade distintos.

\subsubsection{Fontes de Acoplamento}

As principais fontes de ruído do método TDEM são antropogênicas, como linhas de transmissão de energia, cabos e tubulações enterradas. Essas fontes de acoplamento são divididas em dois grupos, o acoplamento Galvânico e o acoplamento Capacitivo (Figura 13).

O acoplamento Galvânico ocorre quando linhas de transmissão de energia encontram-se próximas a área de aquisição, onde as torres que estão aterradas comportam-se como um circuito indutor-resistor (circuito LR). O TDEM interage com essas linhas de transmissão induzindo correntes elétricas que, por sua vez, interagem com o TDEM interferindo nas correntes de indução geradas pelo loop transmissor. De maneira que esta interferência apresenta um decaimento exponencial do campo magnético em fase com o decaimento do campo magnético do loop transmissor, interferindo assim no sinal recebido. 
O acoplamento Capacitivo ocorre quando há um cabo ou tubulação enterrada, o qual funciona neste caso como um indutor acoplado a capacitores, gerando um circuito resistor-indutor-capacitor (RLC), onde o loop transmissor carrega o capacitor do circuito e este, quando descarregado, apresentada um comportamento oscilante das correntes induzidas. Este acoplamento pode ser facilmente identificado nos dados devido o seu comportamento oscilante, diferentemente do acoplamento Galvânico. Portanto, é imprescindível ter um conhecimento prévio da existência desses tipos de acoplamento que possam circundar a área de estudo desejada.
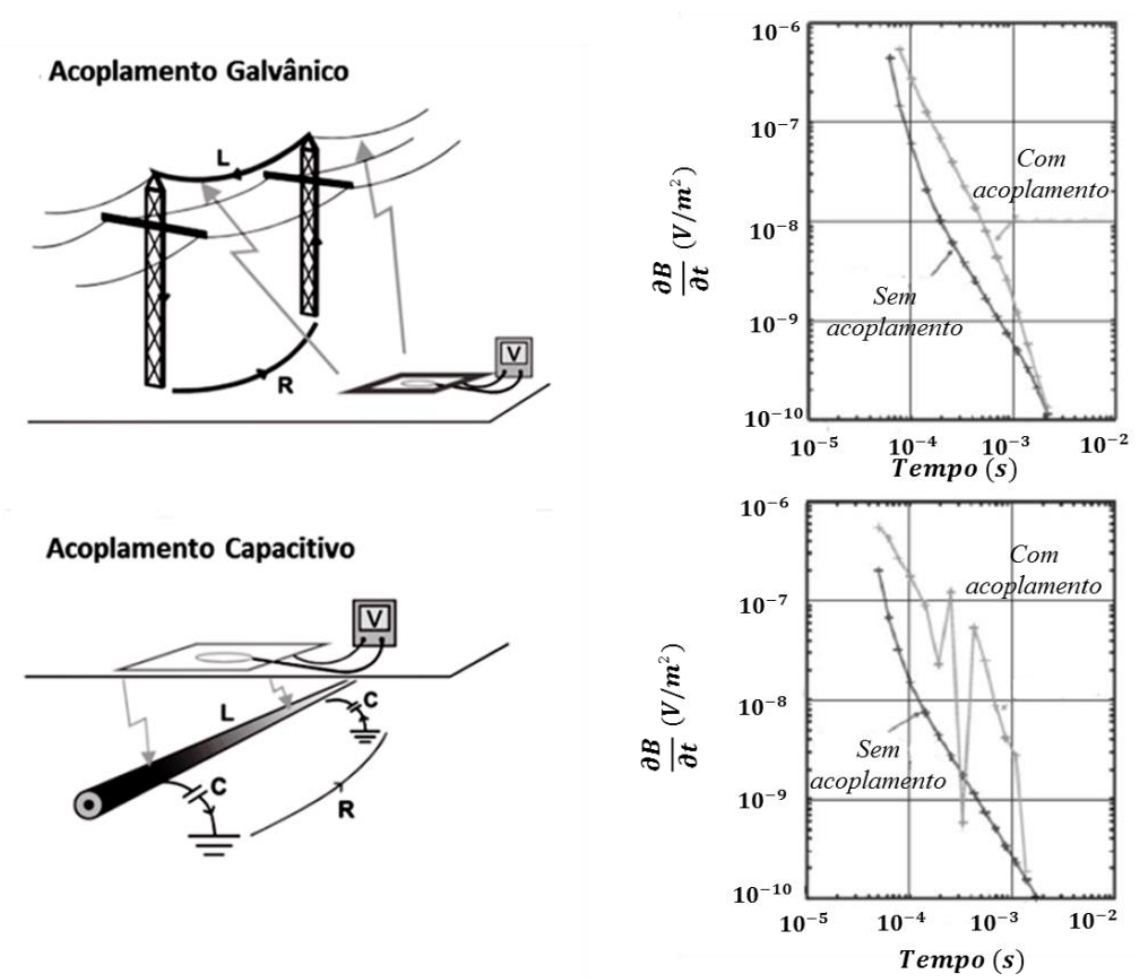

Figura 13: Fontes de acoplamento do método TDEM (Adaptado de Sørensen, et al., 2000).

\subsubsection{Arranjos de Campo}

No método TDEM, existem diferentes maneiras realizar a aquisição dos dados, onde cada arranjo tem suas vantagens de acordo com o interesse a ser investigado. 
Dependendo da configuração transmissor-receptor, os arranjos TDEM podem ser do tipo (Telford, 1990):

- Single Loop: Utiliza um único loop como transmissor e receptor. Enquanto a corrente estiver fluindo no loop, ele atua como um transmissor;

- Loop Transmissor-Receptor Coincidente: Este arranjo tem a mesma geometria e resposta que a configuração de single loop, exceto que o transmissor e o receptor são loops separados dispostos simetricamente um em relação ao outro;

- Loop Central: Este arranjo é uma variante do arranjo loop transmissor-receptor coincidente, onde se tem uma bobina receptora posicionada no centro do loop transmissor quadrado. Este arranjo é o mais utilizado para estudos hidrogeológicos (Danielsen, et al., 2003);

- Loops Separados: Ambos os loops são simétricos, de maneira que o loop receptor é posicionado fora da geometria do loop transmissor, onde são separados por uma distância fixa;

- Loop-Loop: É uma variante do arranjo loops separados. Ocorre que o loop receptor posicionado fora do loop transmissor, possui dimensões menores e um maior número de espiras, compensando assim o seu diâmetro.

- Dual Loop: Este arranjo utiliza dois loops conectados em paralelos para um melhor acoplamento com condutores verticais;

- Loop Transmissor Fixo e Bobina Receptora Móvel ou Caminhamento TDEM (CTDEM): As sondagens TDEM realizadas por esse arranjo permitem a construção de uma pseudoseção da área de interesse, ou seja, é possível interpolar os dados de cada sondagem realizada dentro ou fora do loop.

As aquisições realizadas neste trabalho foram através dos arranjos CTDEM e Loop Central, considerando um loop quadrado com 200 m de lado (Figura 14). 


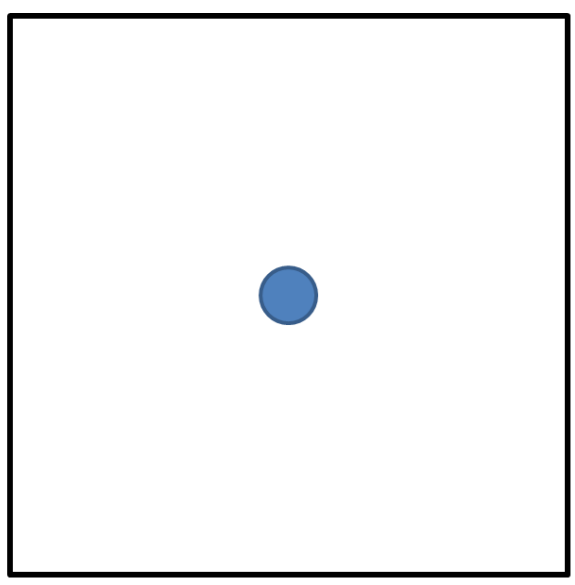

Loop Central

Loop Transmissor de corrente

Bobina receptora

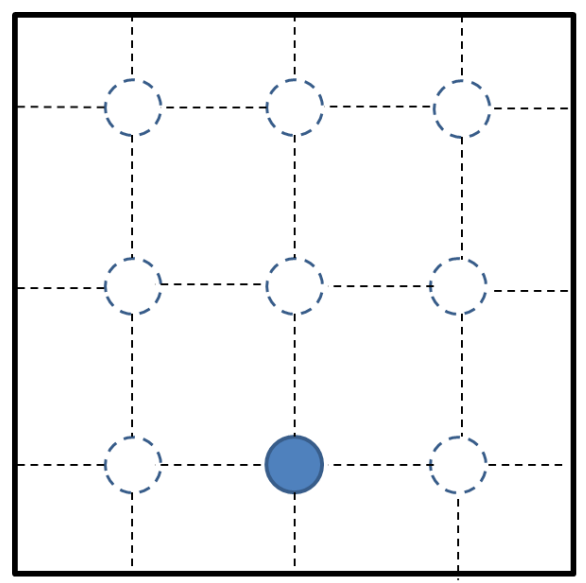

Caminhamento TDEM - CTDEM

:

Linha do CTDEM

Figura 14: Arranjos de Campo utilizados na aquisição de dados.

\subsection{Eletrorresistividade (ER)}

A eletrorresistividade é um método que se baseia na determinação da variação lateral e vertical da resistividade elétrica dos materiais em subsuperfície. Este método é bastante utilizado, por exemplo, em estudos geotécnicos, de contaminação e hidrogeológicos para investigar a geologia de superfície rasa (Kearey, et al., 2009).

Neste processo, a determinação da resistividade ocorre através da injeção de correntes elétricas em subsuperfície, onde é medido na superfície o valor da diferença de potencial, sendo que este valor medido esta relacionado com a característica elétrica (resistividade) dos materiais presentes no subsolo.

Para realizar uma aquisição através do método eletrorresistivo, existem algumas técnicas de aquisição de dados: Caminhamento Elétrico (CE), Sondagem Elétrica Vertical (SEV) e Perfilagem Elétrica de Poço. Neste trabalho, foram utilizadas as 
técnicas SEV e CE, onde cada uma delas visa determinar o mesmo parâmetro físico, que é determinar a variação da resistividade elétrica no subsolo.

\subsubsection{Aspectos Matemáticos}

A resistividade elétrica é uma propriedade física dos materiais. Ela é definida como a resistência elétrica entre as faces opostas de um cubo unitário do material (Kearey, et al., 2009), em outras palavras, é a resistência que um material oferece à passagem de corrente elétrica.

Seja um condutor cilíndrico infinitesimal de resistência $R$, comprimento $L$ e área de seção $A$, como mostra a Figura 15 , sendo a resistividade $\rho$ expressa da seguinte forma:

$$
\rho=\frac{R A}{d L}
$$

No SI a resistividade elétrica é dada por Ohm.m e o inverso da resistividade é representado pela condutividade $\left(\Omega^{-1} \cdot \mathrm{m}^{-1}\right.$ ou $\left.\mathrm{S} / \mathrm{m}\right)$ :

$$
\sigma=\frac{1}{\rho}
$$

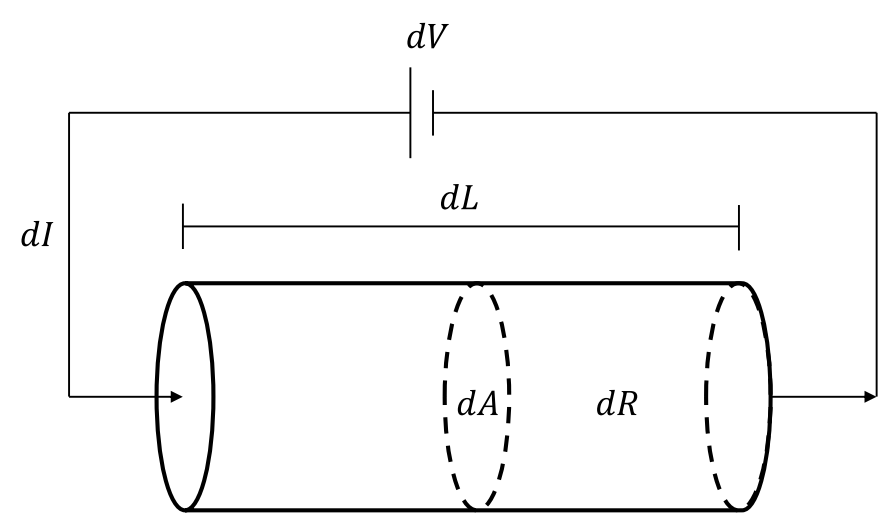

Figura 15: Cilindro condutor infinitesimal representando os parâmetros utilizados na definição de resistividade (Adaptado de Kearey, et. al., 2009). 
A porosidade das rochas é um dos principais fatores que interferem na resistividade dos materiais geológicos, quanto maior for a porosidade, menor será a resistividade. Certos minerais como metais nativos e o grafite conduzem eletricidade através da passagem de elétrons. Contudo, a maioria dos minerais formadores de rochas são isolantes, de maneira que a condução de eletricidade ocorre pela passagem de íons na água presente nos poros. De maneira que a principal forma de passagem de corrente elétrica nos materiais em subsuperfície se dá por condução eletrolítica, seguida pela condução eletrônica.

Considera-se a Figura 15 como sendo um cilindro homogêneo, tomando ainda uma parte infinitesimal deste cilindro pela qual transita a corrente $I$, a qual causa uma queda do potencial - $d V$ entre as extremidades do elemento infinitesimal. A Lei de Ohm diz que:

$$
I=-\frac{d V}{R}
$$

em que $d V$ é a diferença de potencial entre os extremos do cilindro e $R$ é a resistência elétrica do material à passagem de corrente. $O$ sinal negativo indica que a corrente flui do maior potencial para o menor potencial. Substituindo a Equação (3.2.3) na Equação (3.2.1), tem-se a seguinte relação:

$$
I=-\frac{d V}{R} ; \rho=\frac{R A}{d r} \rightarrow R=\frac{\rho d r}{A}
$$

segue que:

$$
\frac{I}{A}=\frac{1}{\rho}\left(-\frac{d v}{d r}\right)
$$

em que $\frac{I}{A}$ é a densidade de corrente elétrica $j$ que passa pelo cilindro de seção $A$. Já $\frac{1}{\rho}\left(-\frac{d v}{d r}\right)$ é a relação do produto da condutividade elétrica do material $\sigma(S / m)$ pela 
intensidade do campo elétrico $E(\mathrm{~V} / \mathrm{m})$ devido a diferença de potencial. Desta forma, a Equação (3.2.5) pode ser reescrita como:

$$
j=\sigma E,
$$

sendo o cilindro infinitesimal ( $d L \rightarrow 0$ ), homogêneo e isotópico, a relação (3.2.6) é conhecida como a Lei de Ohm.

Considera-se agora um único eletrodo fixo em um meio de resistividade homogênea, o qual injeta corrente em subsuperfície (Figura 16). O sorvedouro de corrente encontra-se muito distante, de maneira que a corrente injetada em subsuperfície flui radialmente a partir deste eletrodo pontual, de forma que a distribuição de corrente é uniforme em relação a distribuição das cascas hemisféricas (linhas equipotenciais).

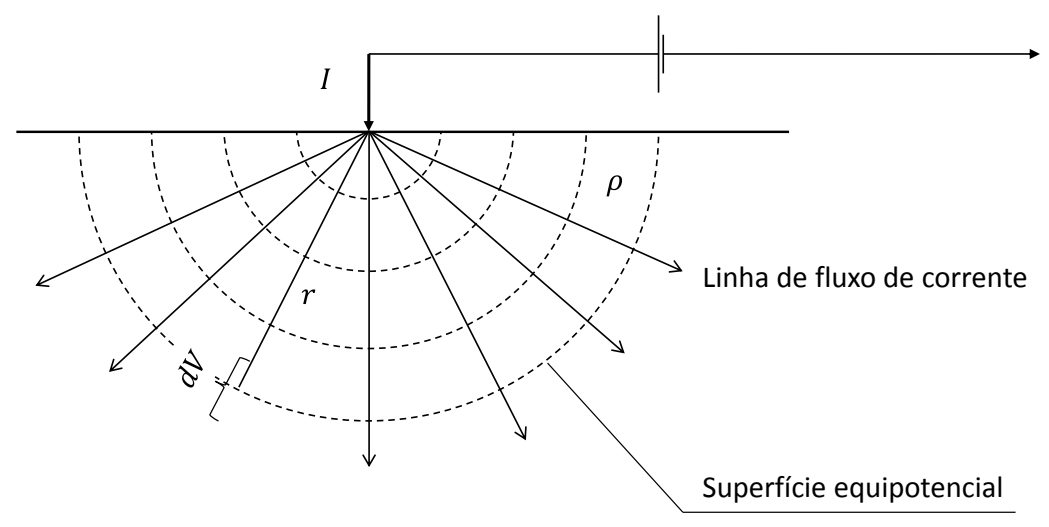

Figura 16: Fluxo de corrente e as linhas equipotenciais (Adaptado de Kearey, et. al., 2009).

A uma distância $r$ do eletrodo e a área da casca sendo $2 \pi r^{2}$, a densidade de corrente é expressa da seguinte maneira:

$$
j=\frac{I}{2 \pi r^{2}}
$$

Das Equações (3.2.6) e (3.2.7), segue que: 


$$
\begin{gathered}
\frac{I}{2 \pi r^{2}}=\frac{1}{\rho}\left(-\frac{d v}{d r}\right) \\
\frac{d V}{d r}=\frac{I \rho}{2 \pi r^{2}}, \\
\int d V=\int \frac{I \rho}{2 \pi r^{2}} d r \rightarrow V(r)=\frac{I \rho}{2 \pi r}+C .
\end{gathered}
$$

Estabelecendo condições de contorno, onde se considera que a uma distância infinita $(r \rightarrow \infty)$ o potencial elétrico seja nulo $(V(\infty) \rightarrow 0)$, a Equação (3.2.10) fica:

$$
V(r)=\frac{I \rho}{2 \pi r} .
$$

A Equação (3.2.11) permite o cálculo do potencial elétrico em qualquer ponto abaixo do eletrodo.

Segue uma situação em que o sumidouro de corrente encontra-se a uma distância finita da fonte (Figura 17).

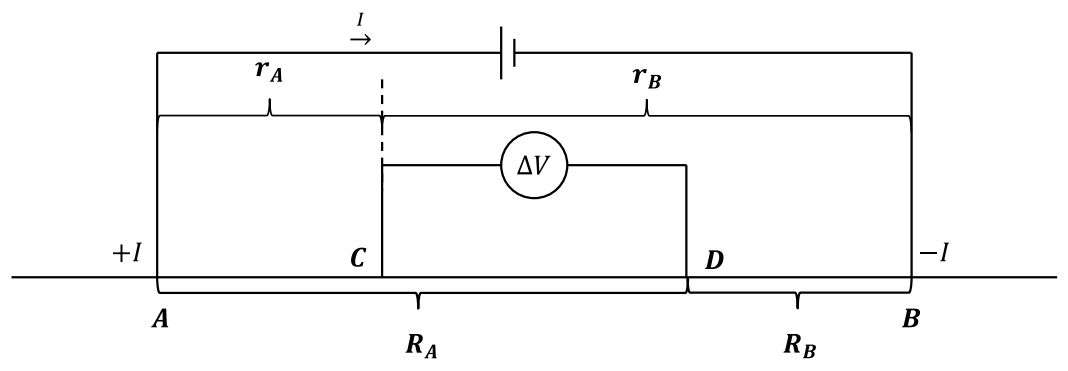

Figura 17: Esquema geral da configuração de eletrodos para medição de resistividade (Adaptado de Kearey, et. al., 2009).

Os eletrodos $A$ e $B$ agora tem uma distância finita e a corrente flui de $A$ para $B$. Para medir a diferença de potencial provocada pelos eletrodos de corrente $A$ e $B$, devem-se instalar dois eletrodos de potencial $C$ e $D$. Desta forma, obtêm-se: 


$$
\begin{aligned}
& r_{C}=r_{A}-r_{B}=\overline{A C}-\overline{B C}, \\
& r_{D}=R_{A}-R_{B}=\overline{A D}-\overline{B D} .
\end{aligned}
$$

Assim, o potencial $C$ e $D$ é dado por:

$$
\begin{aligned}
& V_{C}=\frac{\rho I}{2 \pi}\left(\frac{1}{\overline{A C}}-\frac{1}{\overline{B C}}\right), \\
& V_{D}=\frac{\rho I}{2 \pi}\left(\frac{1}{\overline{A D}}-\frac{1}{\overline{B D}}\right) .
\end{aligned}
$$

De maneira que a diferença de potencial entre $C$ e $D$ é:

$$
\begin{gathered}
\Delta V_{C D}=V_{C}-V_{D}=\frac{\rho I}{2 \pi}\left(\frac{1}{\overline{A C}}-\frac{1}{\overline{B C}}\right)-\frac{\rho I}{2 \pi}\left(\frac{1}{\overline{A D}}-\frac{1}{\overline{B D}}\right), \\
\Delta V_{C D}=\frac{\rho I}{2 \pi}\left(\frac{1}{\overline{A C}}-\frac{1}{\overline{B C}}-\frac{1}{\overline{A D}}+\frac{1}{\overline{B D}}\right) .
\end{gathered}
$$

Da Equação (3.2.17), é possível obter a resistividade elétrica dos materiais em subsuperfície. Portanto:

$$
\rho=\frac{\Delta V_{C D} 2 \pi}{I}\left(\frac{1}{\overline{A C}}-\frac{1}{\overline{B C}}-\frac{1}{\overline{A D}}+\frac{1}{\overline{B D}}\right)^{-1},
$$

em que $k=1 /\left(\frac{1}{\overline{A C}}-\frac{1}{\overline{B C}}-\frac{1}{\overline{A D}}+\frac{1}{\overline{B D}}\right)$ é o fator geométrico e depende da disposição dos eletrodos. Logo:

$$
\rho=\frac{k \Delta V_{C D}}{I}
$$


As Equações aqui demonstradas consideram um meio idealizado, homogêneo e isotópico. Ao utilizar o mesmo arranjo de eletrodos para efetuar medições em um meio heterogêneo, a diferença de potencial será diferente da que foi medida em um meio homogêneo devido às modificações do campo elétrico em função da heterogeneidade dos materiais em subsuperfície.

Como na prática o subsolo não pode ser considerado homogêneo, o valor da resistividade medida é uma "média ponderada" de todas as resistividades verdadeiras que representam um certo volume dos materiais em subsuperfície. Portanto, a Equação (3.2.20) representa uma resistividade aparente dos materiais em subsuperfície, sendo:

$$
\therefore \rho_{a}=\frac{k \Delta V_{C D}}{I}
$$

em que $\mathrm{k}$ é o fator geométrico, que depende do arranjo dos eletrodos.

\subsubsection{Sondagem Elétrica Vertical (SEV)}

A técnica de SEV tem por finalidade analisar e interpretar a resistividade elétrica obtida a partir de medidas efetuadas na superfície do terreno, investigando de maneira pontual (1D) a variação vertical desta propriedade física de acordo com a profundidade. Existem dois principais arranjos na execução da técnica SEV, que são Schlumberger e Wenner (Telford, et al., 1990).

O levantamento de campo da uma SEV com o arranjo Schlumberger é feito da seguinte maneira: Na superfície são dispostos quatro eletrodos, sendo dois eletrodos que medem a diferença de potencial $(\overline{M N})$ e outros dois eletrodos que injetam corrente elétrica no subsolo $(\overline{A B})$. Neste arranjo, não é necessário o deslocamento dos quatro eletrodos em cada uma das sondagens, somente quando o sinal se torna fraco ou ruidoso. Quando isso ocorre, mantem-se fixo os eletrodos de corrente movimentandose apenas os eletrodos de potencial. Este processo é chamado de embreagem. $\mathrm{Na}$ Figura 18 a seguir, tem-se um arranjo de campo Schlumberger. 


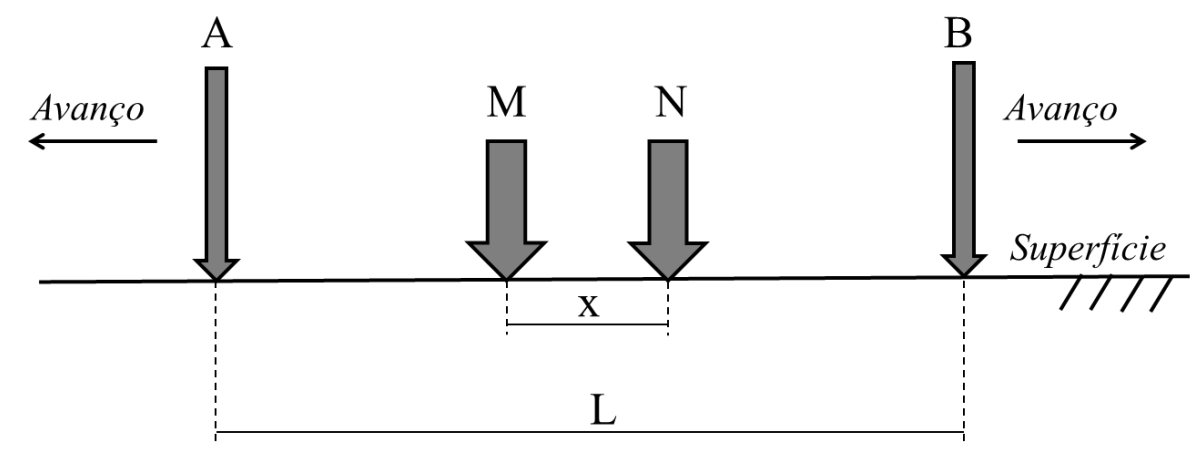

Figura 18: Arranjo de campo Schlumberger - SEV.

O arranjo Wenner possui o mesmo procedimento que o Schlumberger, a diferença é que ao movimentar os eletrodos, tanto os de potencial $(\overline{M N})$ quanto os de corrente $(\overline{A B})$, a distância entre eles deve permanecer crescente e constante durante todo 0 processo de aquisição. Na Figura 19 é apresentado o esquema do arranjo Wenner.

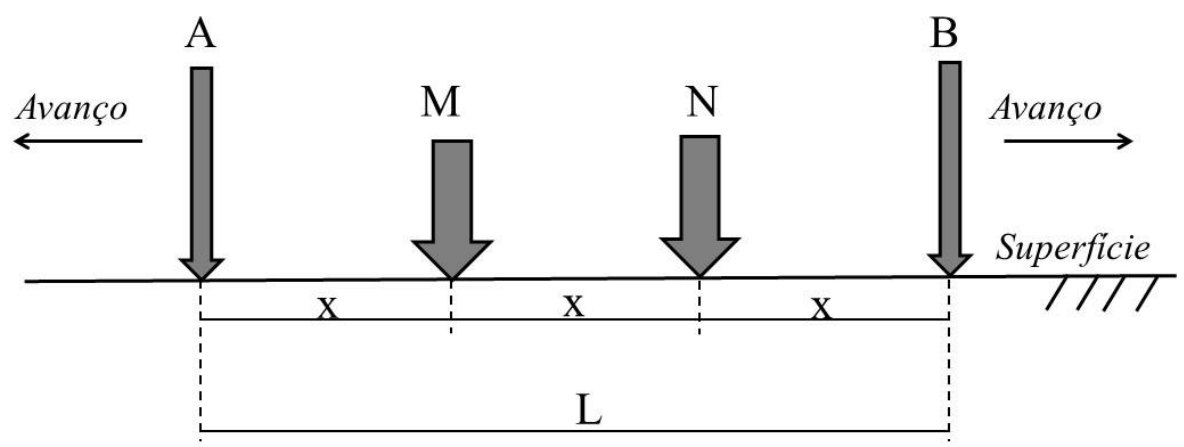

Figura 19: Arranjo de campo Wenner - SEV.

Existem certas desvantagens do arranjo Wenner em relação ao Schlumberger. No arranjo Schlumberger, quando comparado com o Wenner, os ruídos referentes aos potenciais artificiais produzidos por cabos e estações de alta tensão são inferiores, além da facilidade de manejo em campo, onde no arranjo Wenner movimenta-se todos os eletrodos durante a aquisição, não sendo possível realizar a correção do efeito da embreagem, tornando-se mais suscetível aos erros interpretativos devido as heterogeneidades laterais.

A profundidade de investigação em uma aquisição SEV depende de alguns fatores como a resistividade do meio, a corrente que é injetada através dos eletrodos e do 
distanciamento dos eletrodos $\overline{A B}$, de maneira que à medida que se aumenta a distância entre os eletrodos de corrente, maior será a profundidade de investigação (Figura 20). A profundidade teórica de investigação com a distância $\overline{A B}$, normalmente considerado por $h \cong A B / 5=0,2 A B$ (Braga, 2006), sendo que o valor da resistividade elétrica pode ser calculado pela Equação (3.2.20).

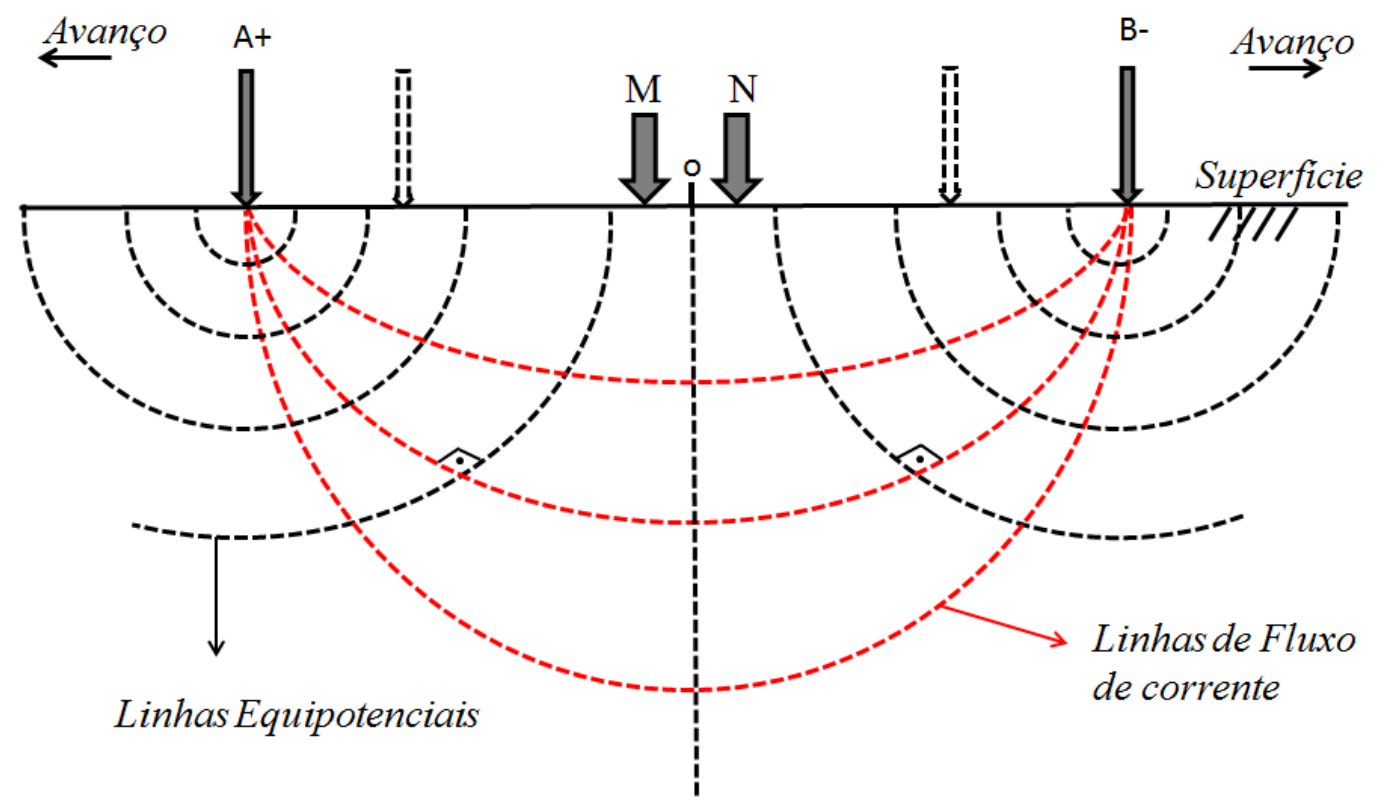

Figura 20: Esquema do funcionamento da técnica SEV, arranjo Schlumberger (Adaptado de Telford, 1990).

\subsubsection{Caminhamento Elétrico (CE)}

A técnica de CE, analogamente a SEV, tem a finalidade de analisar e interpretar um parâmetro físico (resistividade) a partir de medidas efetuadas na superfície do terreno. O CE, além de realizar investigações em profundidade, investiga também como este parâmetro físico varia lateralmente (2D). Existem diferentes arranjos para a técnica de $C E$, onde os mais utilizados são o dipolo-dipolo e polo-dipolo, sendo estes os arranjos que foram utilizados nas atividades de campo realizadas na Bacia de Taubaté.

No levantamento de campo referente ao arranjo dipolo-dipolo, realizam-se várias medidas, onde o espaçamento entre o par de eletrodos de corrente $\overline{A B}$ e de potencial $\overline{M N}$ permanece constante, somente a separação entre eles aumenta em um fator " $n x "$. A medida que ocorre o afastamento, o nível de investigação teórica de profundidade 
( $\mathrm{N}=1, \mathrm{~N}=2, \mathrm{~N}=3$, etc.) aumenta. Quanto maior for a distância entre os pontos médios dos eletrodos $\overline{A B}$ e $\overline{M N}$, maior será a profundidade teórica de investigação (Figura 21).

Já no arranjo polo-dipolo, a disposição dos eletrodos é semelhante ao arranjo dipolo-dipolo. Contudo, movimentam-se três eletrodos por aquisição, sendo um de potencial e dois de corrente. Isso ocorre, pois no arranjo polo-dipolo um dos eletrodos de potencial é fixo a uma distância relativamente grande, cerca de dez vezes a distância dos eletrodos extremos do arranjo (Keller e Frischknecht, 1966) para garantir que ele não influencie no restante do arranjo. Analogamente o arranjo dipolo-dipolo, a medida que se avança na linha de aquisição, os níveis de investigação entre o eletrodo de corrente e os de potencial aumentam (Figura 22).

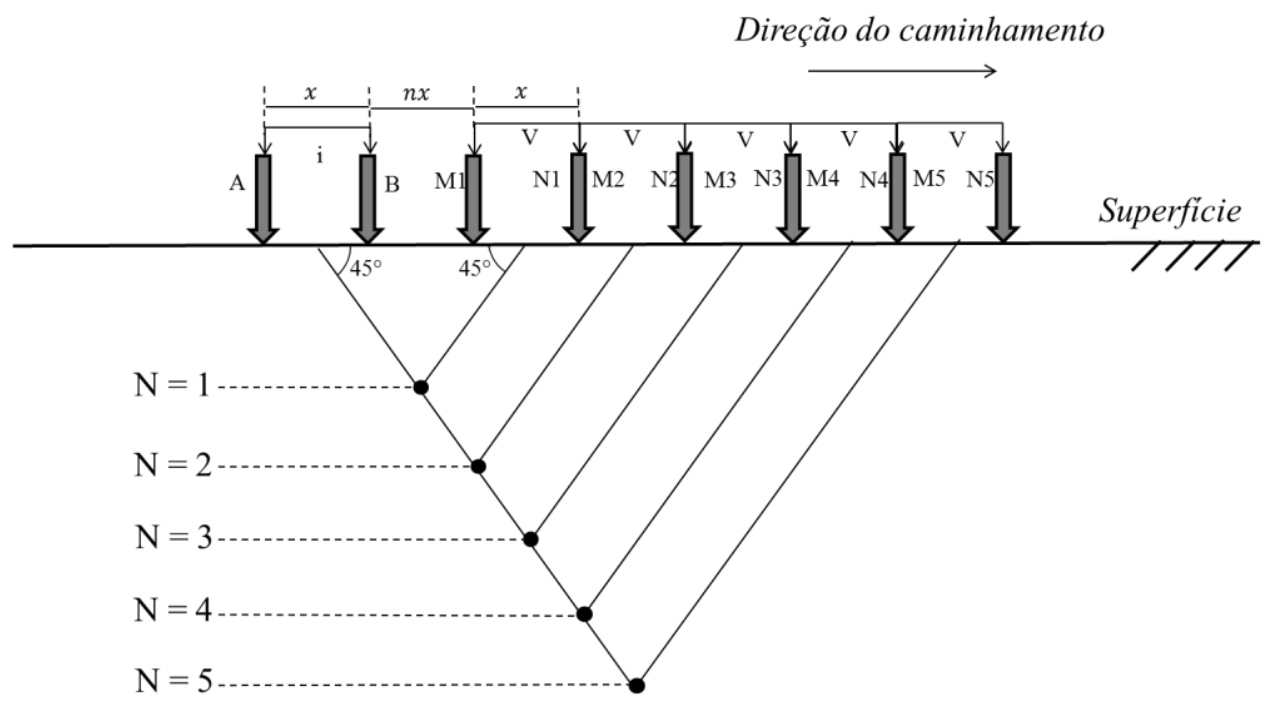

Figura 21: Esquema do funcionamento da técnica CE com arranjo dipolo-dipolo (Adaptado de Telford, 1990). 


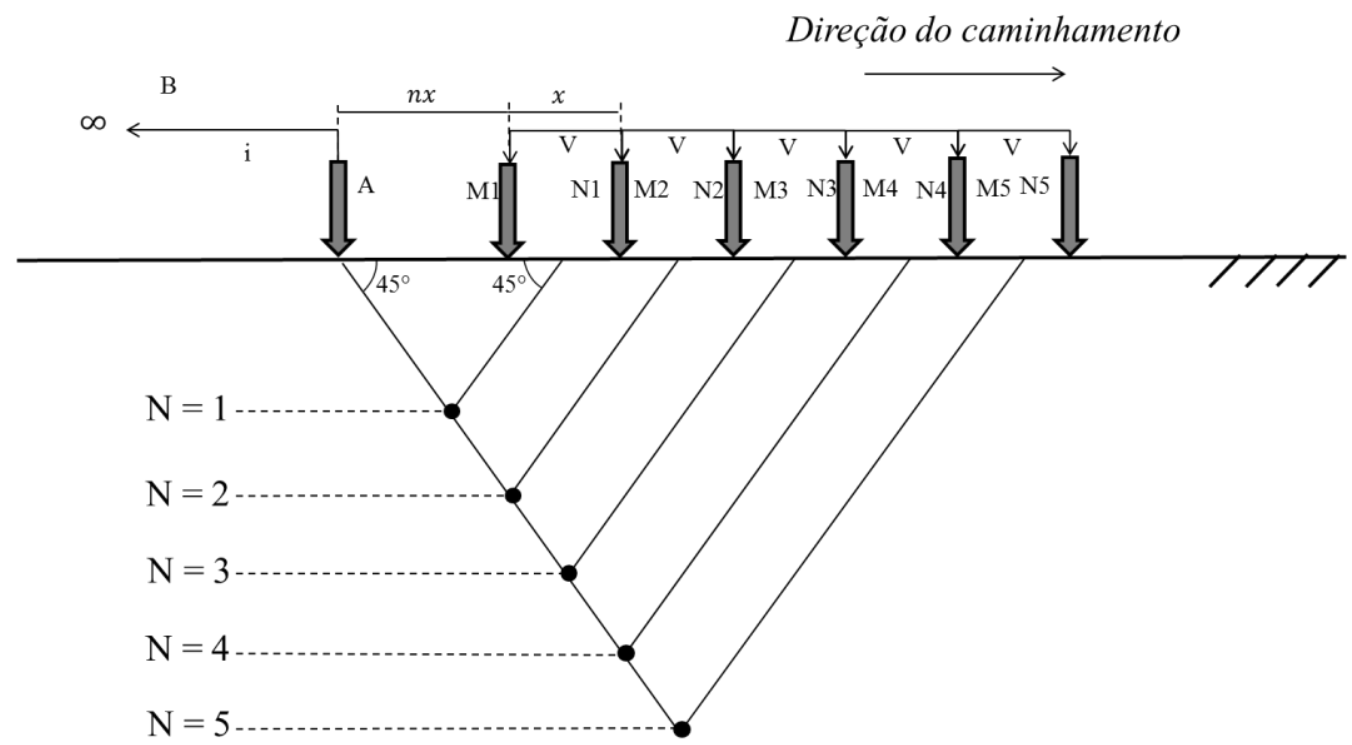

Figura 22: Esquema do funcionamento da técnica CE com arranjo polo-dipolo (Adaptado de Telford, 1990).

O cálculo da resistividade elétrica é dado pela Equação (3.2.20). Contudo, a relação que exprime o fator geométrico $K$ difere de acordo com a disposição dos eletrodos. O fator geométrico pode também ser expresso como $K=2 \pi G x$, em que $G$ é uma constante que depende do tipo de arranjo utilizado. Portanto, para os arranjos dipolo-dipolo e polo-dipolo, o fator geométrico $K$ é dado, respectivamente por:

$$
\begin{gathered}
K=\pi n(n+1)(n+2) x, \\
K=2 \pi n(n+1) x .
\end{gathered}
$$




\section{AQUISIÇÃO E TRATAMENTO DOS DADOS}

A aquisição dos dados foi realizada na região central da Bacia de Taubaté, em uma área rural próxima à cidade de Taubaté, SP, onde foram realizadas três campanhas de aquisição de dados. Na Figura 23 abaixo, segue o croqui utilizado na aquisição dos dados.

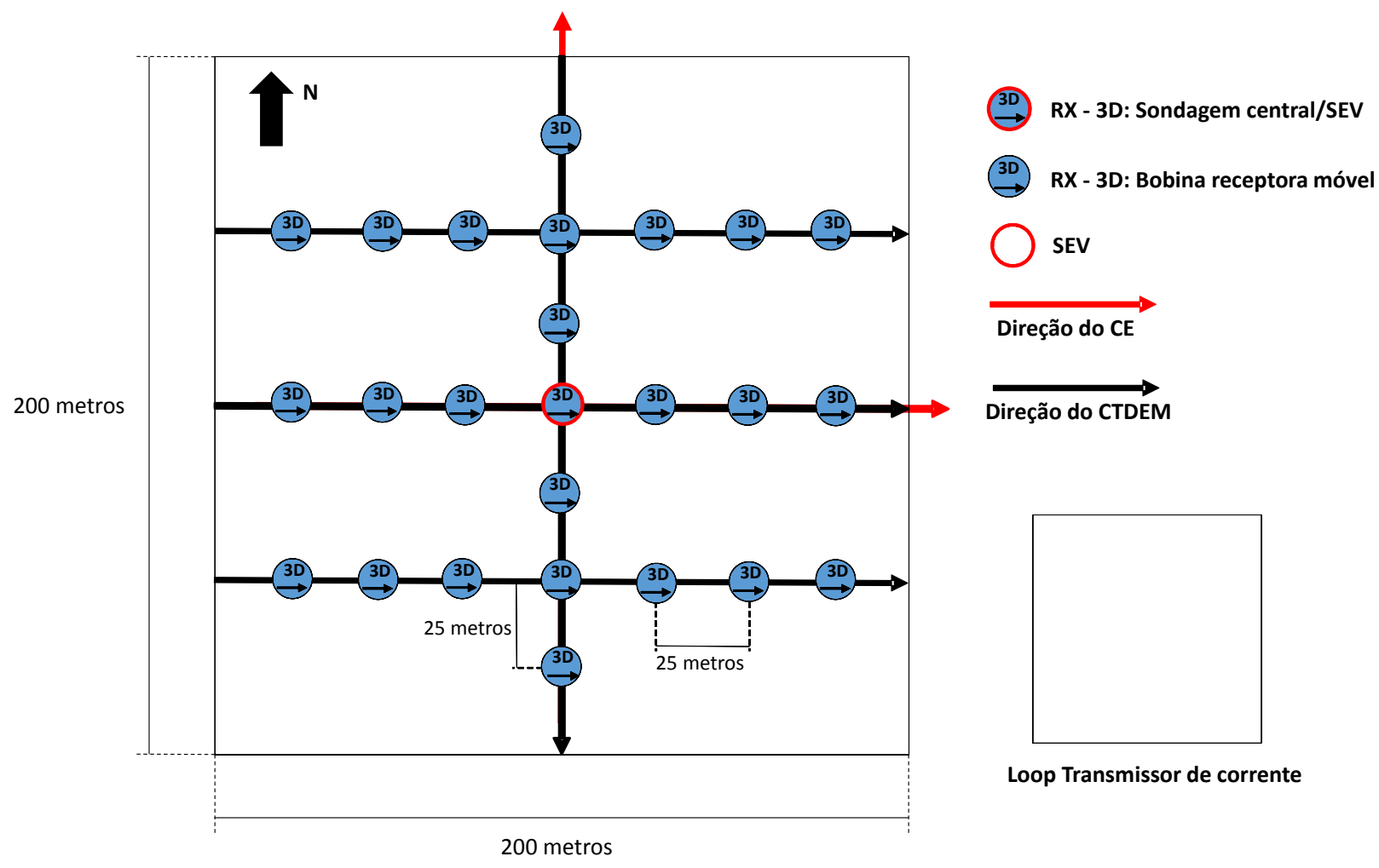

Figura 23: Croqui utilizado para aquisição de dados TDEM, CTDEM, SEV e CE.

Na Figura 24 observa-se a logística de campo realizada durante a aquisição dos dados. Na Área-1, referente ao loop vermelho, a aquisição dos dados foi realizada entre os dias 25 e 29 de abril de 2016, onde foram adquiridas 25 sondagens TDEM, correspondendo a quatro perfis de CTDEM e uma sondagem SEV1 no centro do loop transmissor. Entre os dias 01 e 04 de junho de 2016, foi realizado o levantamento dos dados de CE com os arranjos dipolo-dipolo e polo-dipolo. Na Área-2, referente ao loop preto, a aquisição dos dados foi realizada entre os dias 03 e 07 de setembro de 2016, onde foram adquiridas 25 sondagens TDEM, correspondendo a quatro perfis de 
CTDEM e duas SEVs, sendo a SEV2 no centro do arranjo TDEM e a outra SEV3 na interface entre os dois arranjos. As coordenadas da área de estudos em UTM são: $448358.00 \mathrm{~m} \mathrm{E}, 7452685.00 \mathrm{~m} \mathrm{~S}$, Zona 23K. Essa localização refere-se ao centro da logística das aquisições, ou seja, na interface dos dois loops, coincidente com a SEV3.

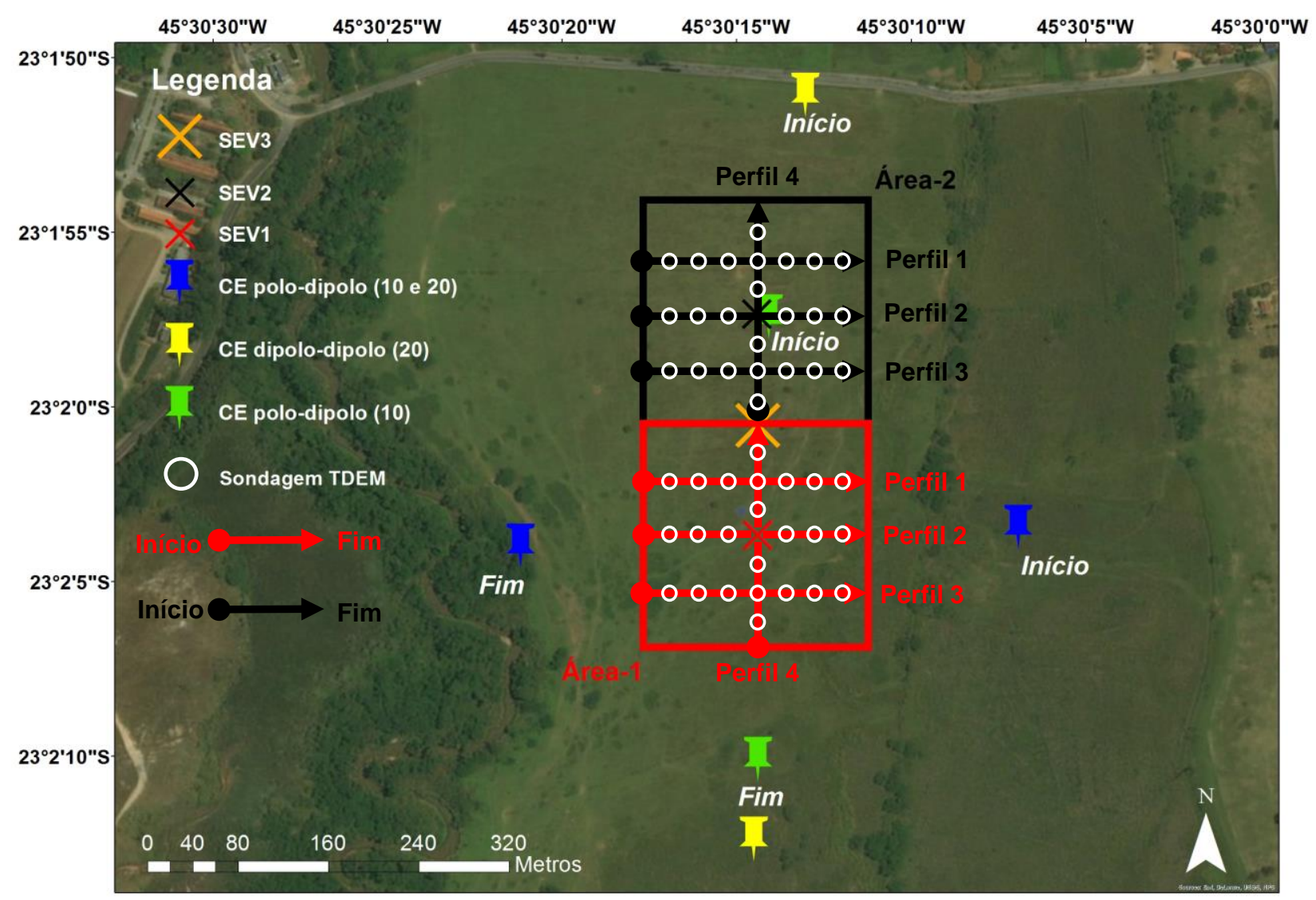

Figura 24: Aquisição dos dados CE, SEV, TDEM e perfis CTDEM nas Áreas-1 e -2 na região de TaubatéSP.

Para a aquisição das sondagens TDEM utilizou-se um receptor PROTEM-D e uma fonte transmissora TEM57-MK2, e uma bobina receptora 3D, a qual mede as três componentes do campo magnético (Geonics - Operating Manual, 1998). A Figura 25 mostra os equipamentos usados na aquisição dos dados TDEM. Para a aquisição de dados SEV e CE foi utilizado um equipamento Syscal R2 da Iris Instrument e um conversor DCDC de 250 W (Figura 26). 


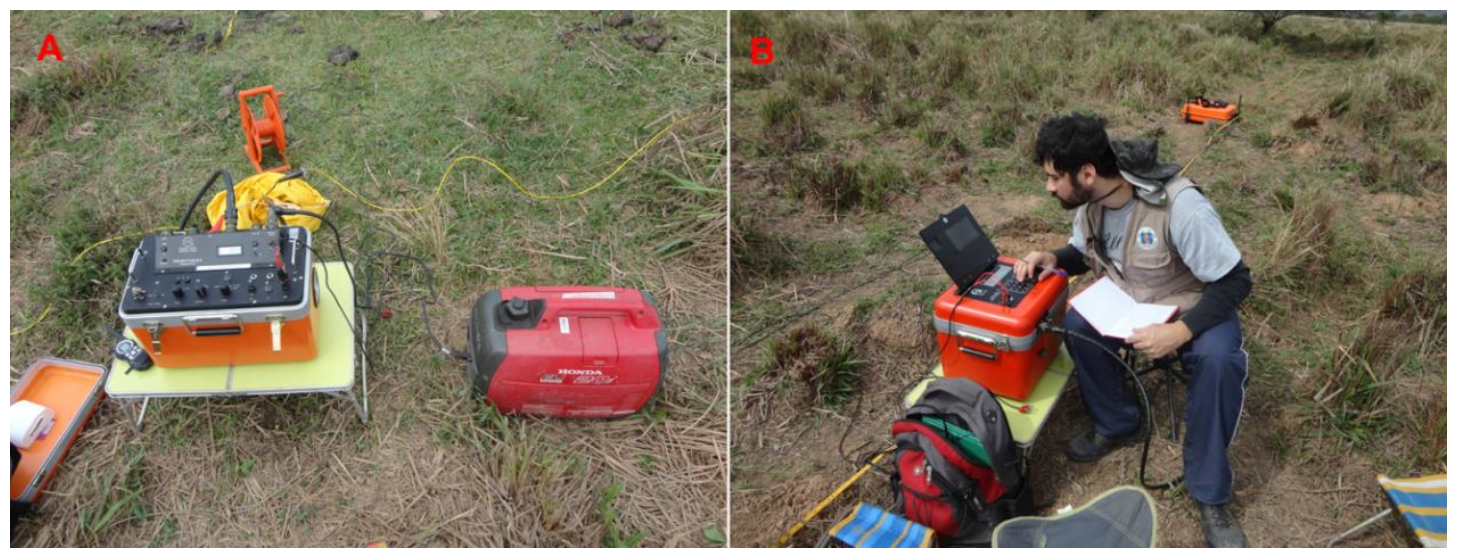

Figura 25: Aquisição de dados TDEM: A) O fio amarelo é usado para montar o loop transmissor de corrente ao qual está conectado ao transmissor de corrente TEM57-MK2 sendo alimentado pelo gerador; B) Ao fundo está a bobina receptora 3D e o receptor PROTEM-D sendo manuseado pelo operador.

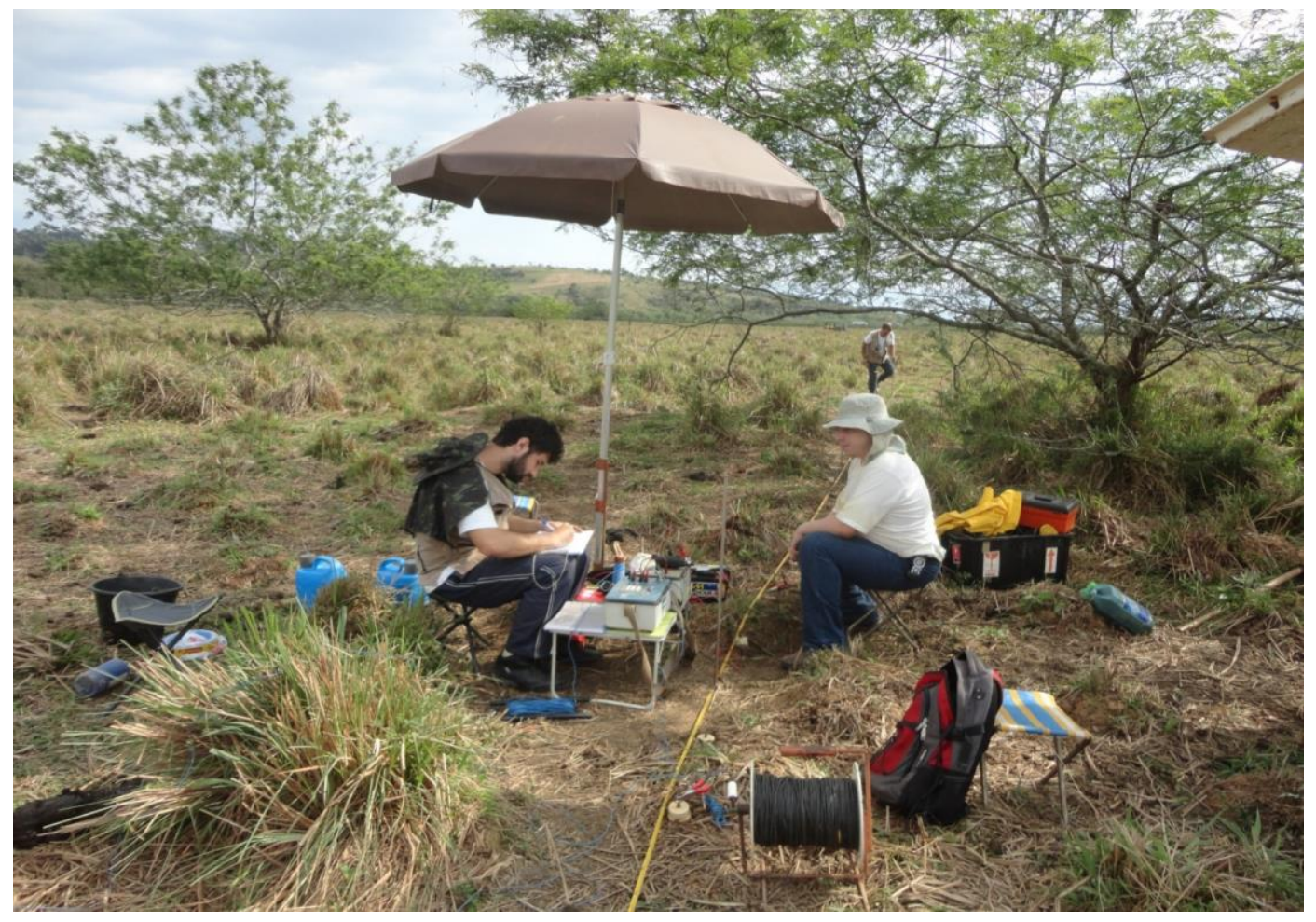

Figura 26: Aquisição de dados de SEV e de CE.

A área de estudos situa-se em uma área rural da cidade de Taubaté, de maneira que os acoplamentos que podem interferir nos dados TDEM são praticamente nulos. Neste caso, o único tipo de acoplamento que poderia interferir nas medidas era 0 acoplamento Galvânico (Figura 27). Contudo, tomaram-se todas as medidas cabíveis 
para que o loop transmissor de corrente fosse disposto a uma distância consideravelmente grande (mais que $100 \mathrm{~m}$ ) de forma que este acoplamento não interferisse nas aquisições TDEM.

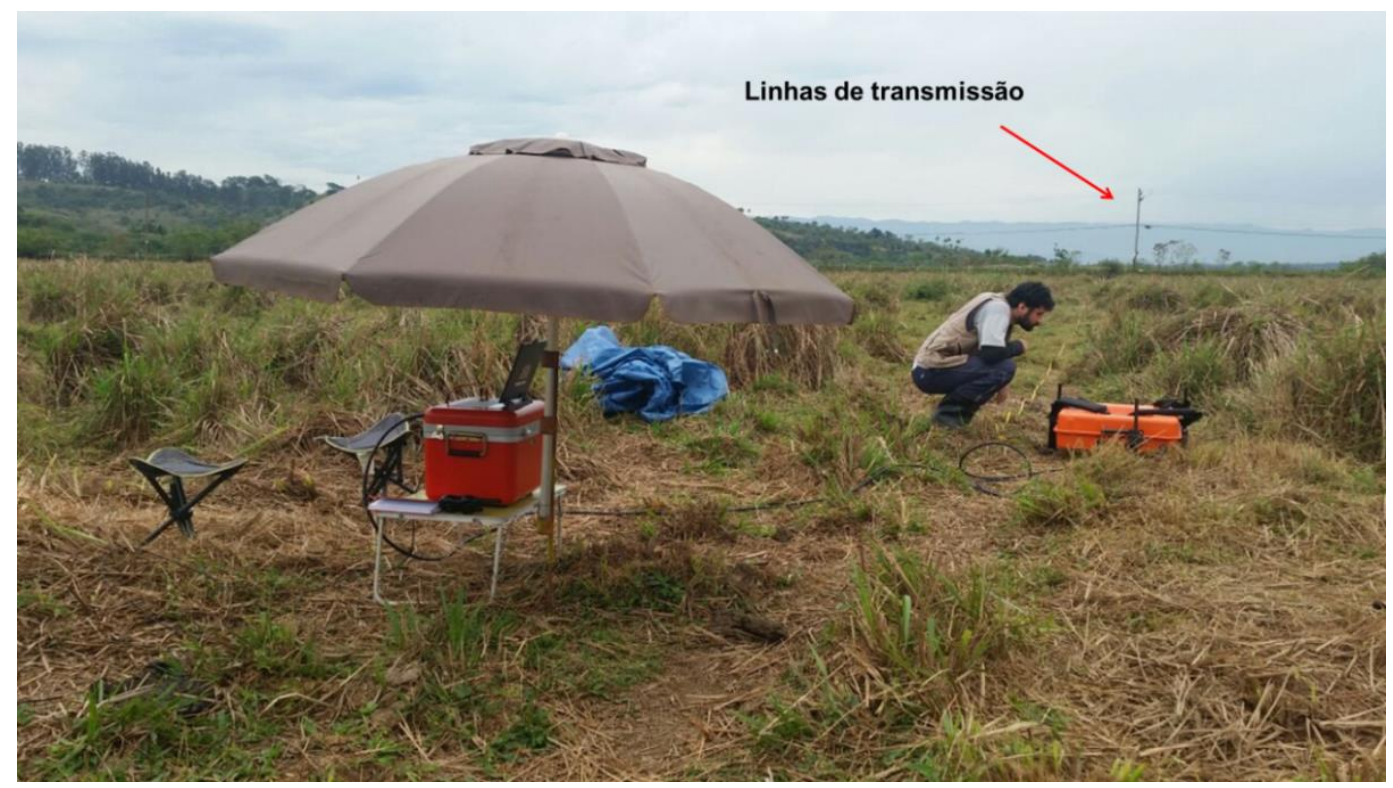

Figura 27: Aquisição TDEM sendo realizada a grandes distâncias do acoplamento Galvânico.

Após a aquisição, deu-se início o tratamento dos dados. Para realizar esta etapa, utilizou-se o software comercial de inversão de dados geoelétricos IX1D (Interpex LTDA), o qual é necessário para a remoção da influência do campo magnético primário, pontos espúrios, bem como os níveis de ruído padrão $\left(N_{v}=0,5 \mathrm{nV} / \mathrm{m}^{2}\right.$; Spies, 1989), como visto na Figura 28. Na Figura 29 tem-se a curva de resistividade aparente com os dados já tratados. 

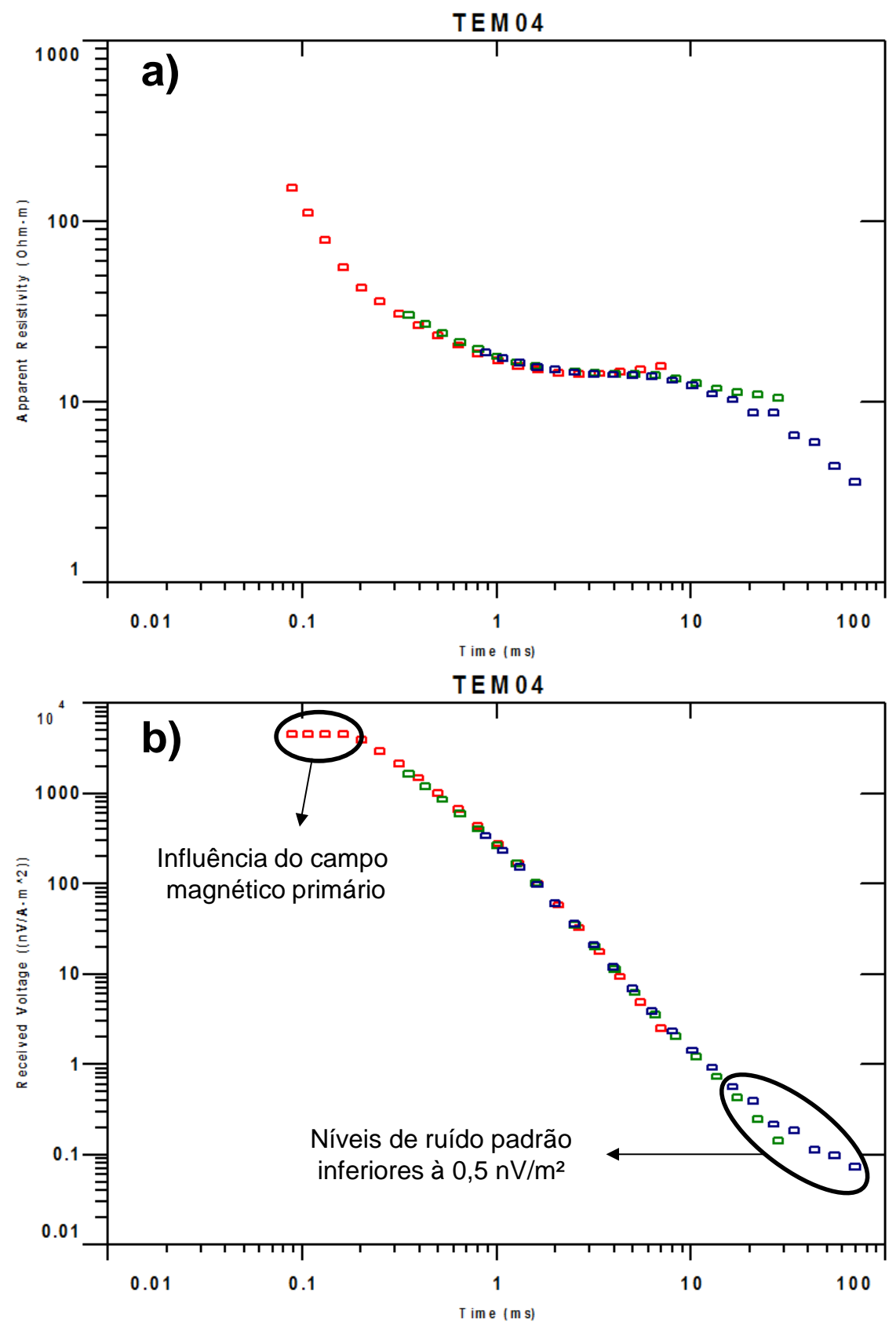

Figura 28: Tratamento de um dado TDEM. Os quadrados em vermelho refere-se à frequência de $30 \mathrm{~Hz}$, em verde a frequência de $7,5 \mathrm{~Hz}$ e em azul a frequência de $3 \mathrm{~Hz}$. a) Curva de resistividade TDEM sem o tratamento dos dados; b) Remoção da influência do campo magnético primário e dos níveis de ruído na curva voltagem vs tempo. 


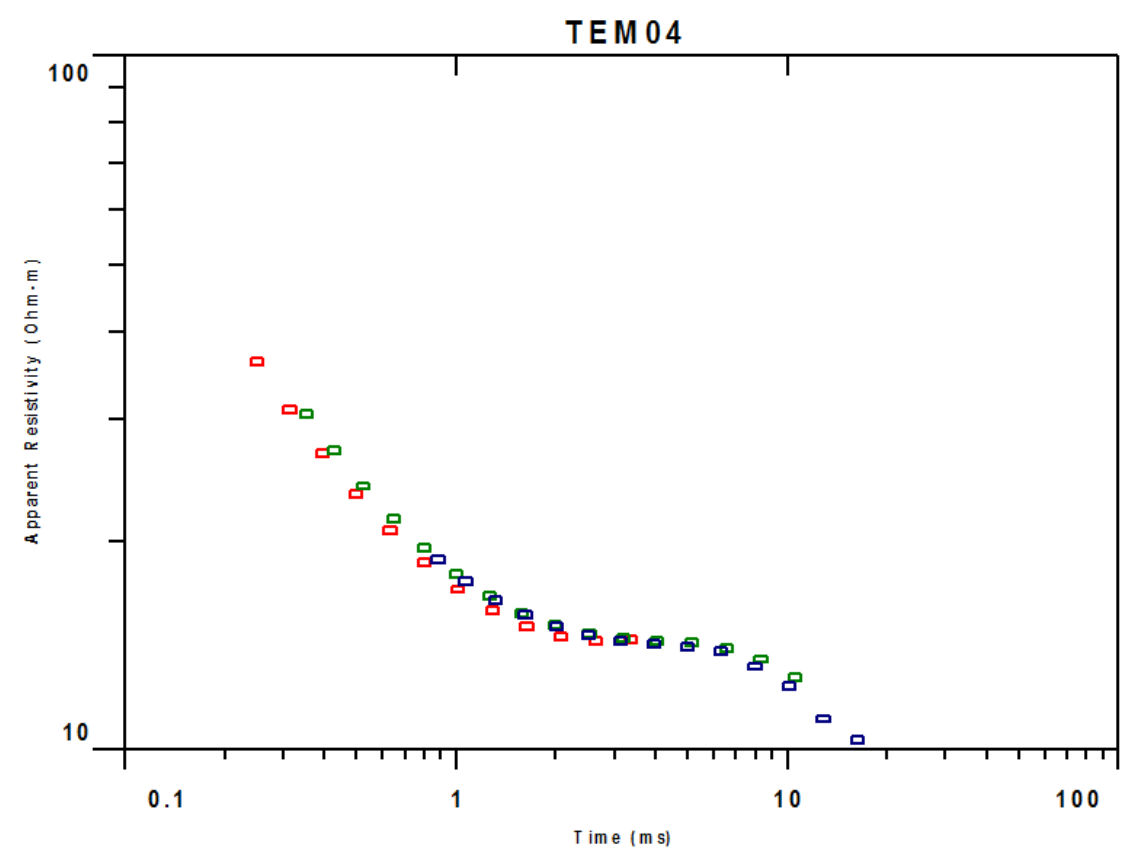

Figura 29: Curva de resistividade TDEM da Figura 28 após o tratamento dos dados.

Os dados de SEV também exigem que seja corrigido o efeito da embreagem. Para isso, utiliza-se o software comercial IPI2win. O paralelismo visto na correção do efeito de embreagem no tratamento de dados SEV (Figura 30) é o indicativo de que os dados foram adquiridos corretamente. 


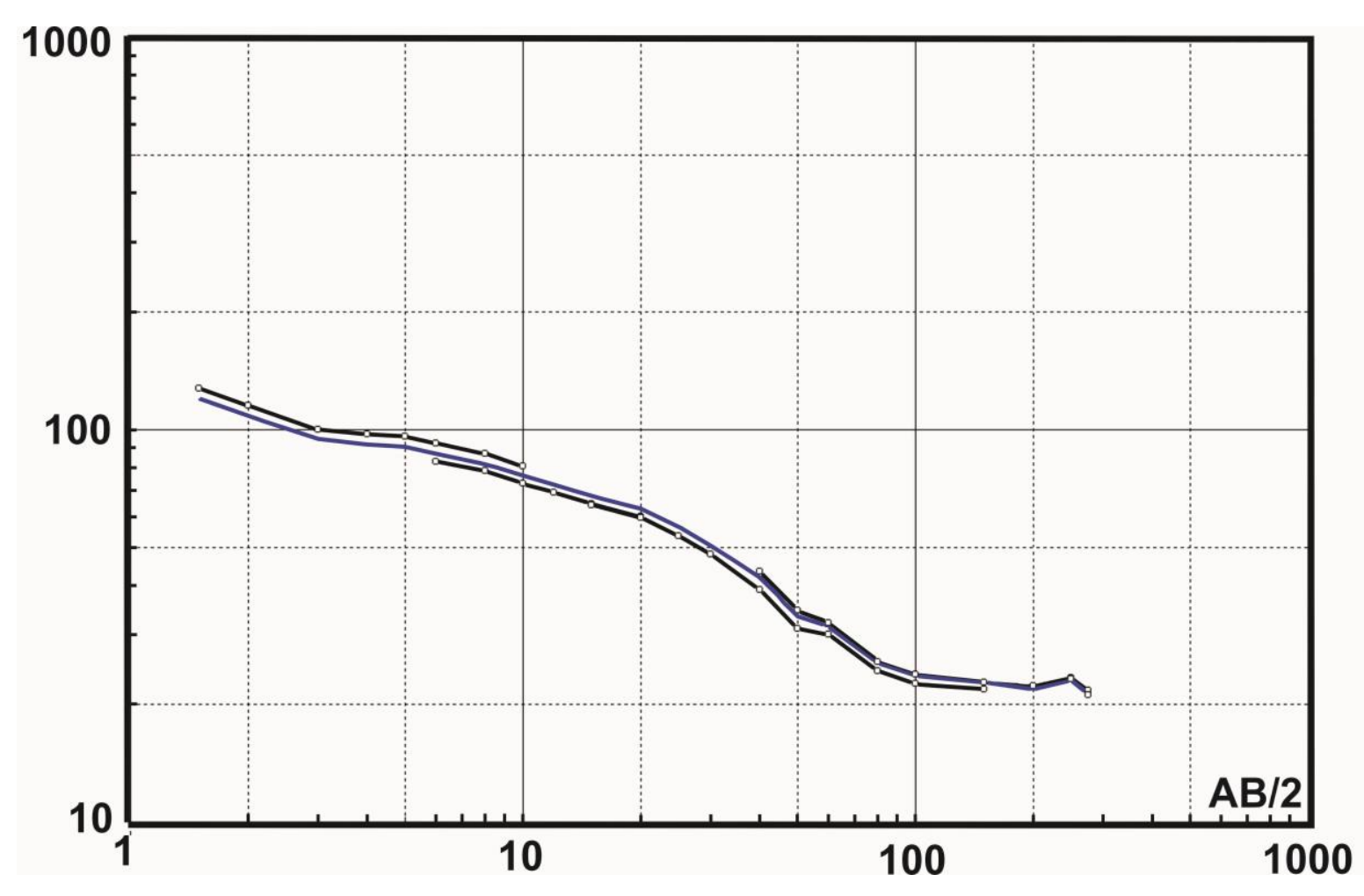

Figura 30: Correção do efeito de embreagem numa SEV.

Após o tratamento dos dados, realizaram-se as inversões individuais utilizando o software Curupira, bem como as inversões conjuntas SEV/TDEM (Bortolozo e Porsani, 2012). Para realização das inversões conjuntas 1D foi necessário realizar a correção do static shift. O static shift é um efeito causado pelas heterogeneidades do solo em técnicas que utilizam eletrodos, como é o caso da SEV, causando um deslocamento na curva de resistividade. Esse efeito é corrigido através de curva de resistividade TDEM que, por ser um método indutivo e não utilizar eletrodos, não sofre do efeito de static shift.

Para a correção do static shift, a escala da curva da SEV de AB/2 (metros) foi recalculada para a escala de tempo (s), assim como a curva do TDEM. Para tanto, foi utilizado o artigo de Meju (2005) que faz uso da seguinte equação empírica para a realização desta conversão:

$$
T=2 \pi \mu_{0} \sigma L^{2},
$$


em que $T$ é o tempo (s), $L(\mathrm{~m})$ é a distância AB/2 dos eletrodos e $\sigma$ é a condutividade do meio $(\mathrm{S} / \mathrm{m})$. A Figura 31 mostra a correção do static shift de uma SEV.

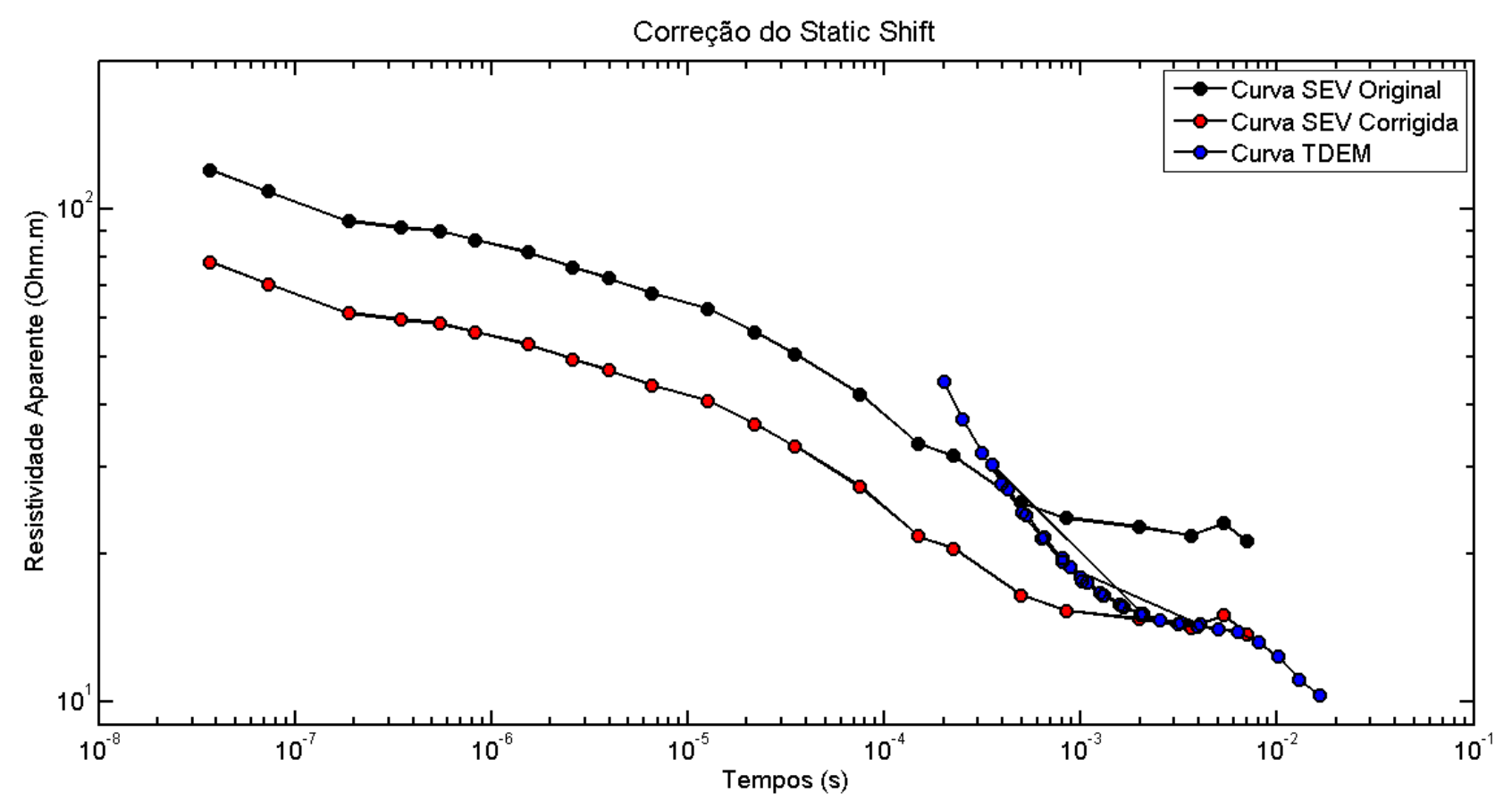

Figura 31: Correção do static shift da SEV, usando uma sondagem TDEM.

Durante a aquisição TDEM na campanha realizada na Área-2, notou-se uma dispersão acentuada na curva de $3 \mathrm{~Hz}$ em todas as sondagens. Ao iniciar o tratamento dos dados, foi constatado que a frequência de $3 \mathrm{~Hz}$ encontrava-se ruidosa devido a um problema eletrônico com o equipamento, consequentemente, os dados da frequência de $3 \mathrm{~Hz}$ tornaram-se inutilizáveis. Portanto, realizou-se o tratamento de dados utilizando somente as frequências de $30 \mathrm{~Hz}$ e $7,5 \mathrm{~Hz}$ (Figura 32). 

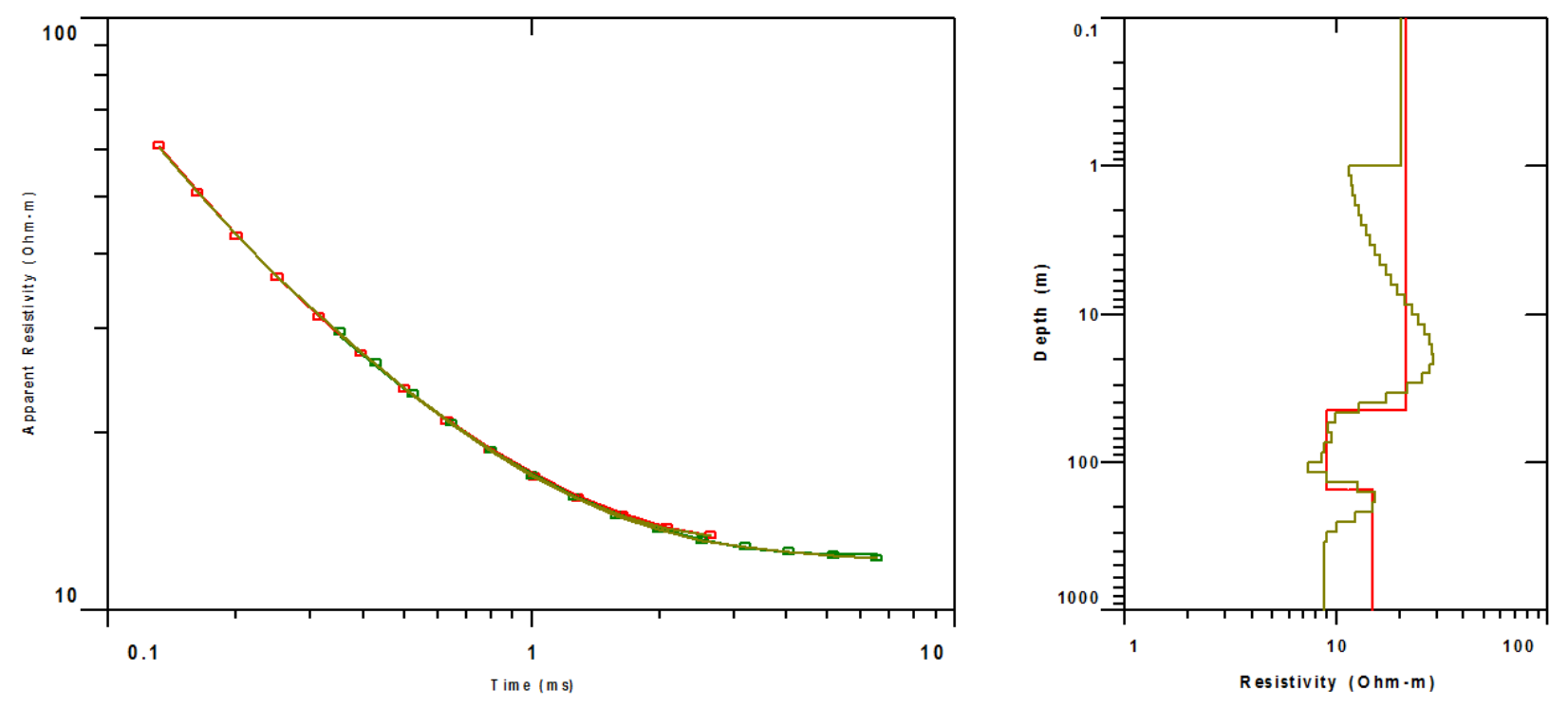

Figura 32: Sondagem TDEM (TEM04) da Área-2 sem a curva de $3 \mathrm{~Hz}$.

Após o tratamento dos dados, observou-se que o modelo geoelétrico gerado era semelhante àqueles gerados pelas sondagens da Área-1, com exceção da última camada (Figura 33). Observa-se a perda de sinal em aproximadamente $200 \mathrm{~m}$ de profundidade nos modelos gerados pelas sondagens adquiridas na Área-2 com as frequências de 30 e 7,5 Hz. Desta forma, não sendo possível utilizar a frequência de 3 $\mathrm{Hz}$, todos os resultados referentes à Área-2 fornecem informações até 200 m de profundidade. 

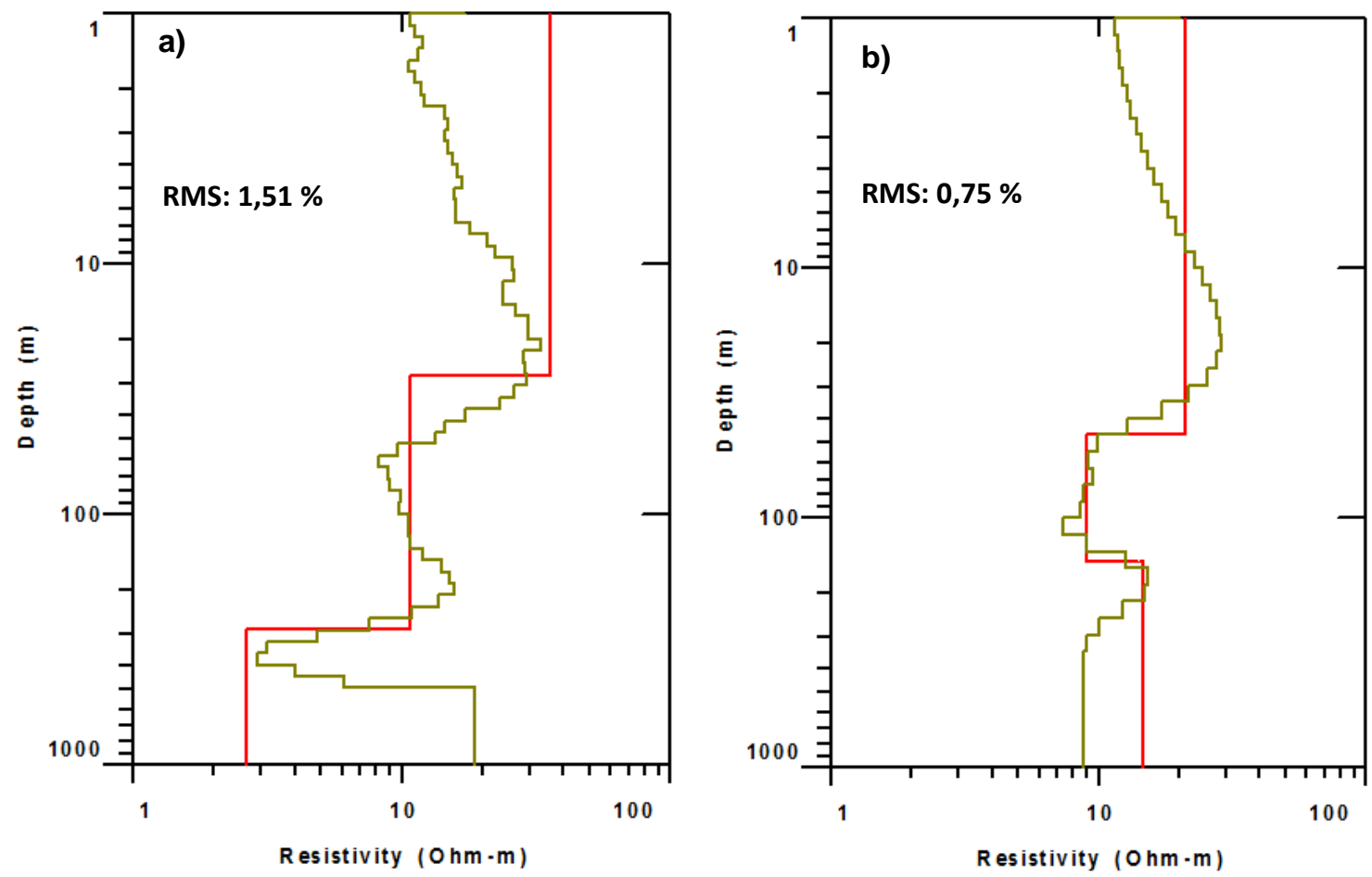

Figura 33: Comparação entre os modelos geoelétricos gerados pelo software IX1D: a) Sondagem loopcentral TDEM da Área-1 com as frequências de $30 \mathrm{~Hz}, 7,5 \mathrm{~Hz}$ e $3 \mathrm{~Hz}$; b) Sondagem loop-central TDEM da Área-2 com as frequências de $30 \mathrm{~Hz}$ e $7,5 \mathrm{~Hz}$.

Visto isso, na data de 09 de novembro de 2017, foi realizado um campo extraordinário na cidade de Taubaté com o intuito de realizar somente uma sondagem TDEM no centro do arranjo da Área-2, coincidente com a SEV2, com o propósito de realizar um estudo integrado com as três frequências por meio da inversão conjunta SEV/TDEM. A análise desse resultado está apresentada no Capítulo 5.

\subsection{Teste de sensibilidade}

Antes de analisar os resultados, é preciso compreender a área de estudos e o método que está sendo utilizado. A Bacia de Taubaté é composta por sedimentos pertencentes ao período Terciário e Quaternário. De acordo com as informações da literatura, trata-se de uma área com um pacote sedimentar bastante condutivo. 
De acordo com a Figura 34, o TDEM identifica quatro camadas geoelétricas referente ao modelo geoelétrico. Contudo, é importante estar ciente das particularidades da área de estudos e do método TDEM em si. A Figura 35 mostra a inversão individual considerando um modelo de quatro e três camadas geoelétricas (linha vermelha), bem como os respectivos modelos de camadas equivalentes (linha tracejada azul).
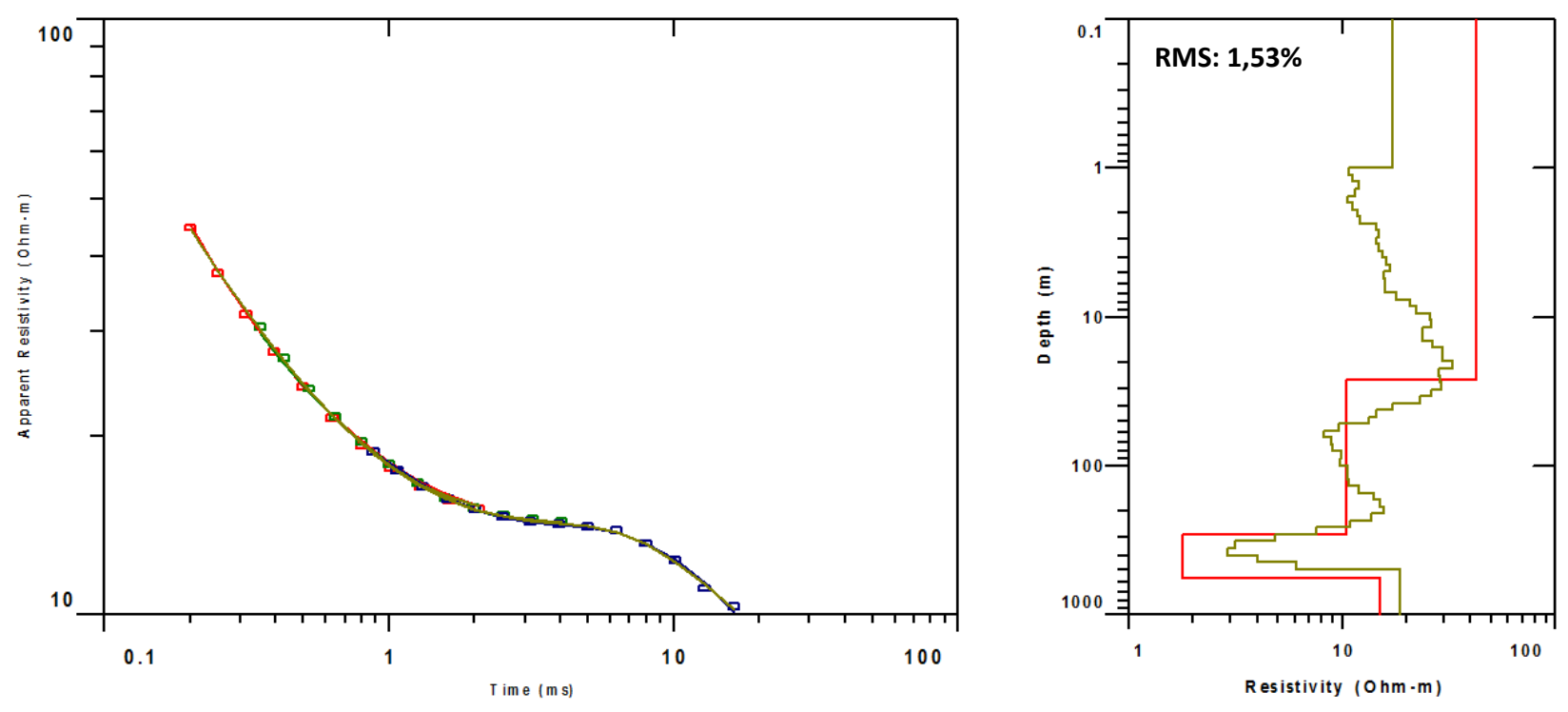

Figura 34: Modelo geoelétrico de uma sondagem individual TDEM representando quatro camadas geoelétricas. 

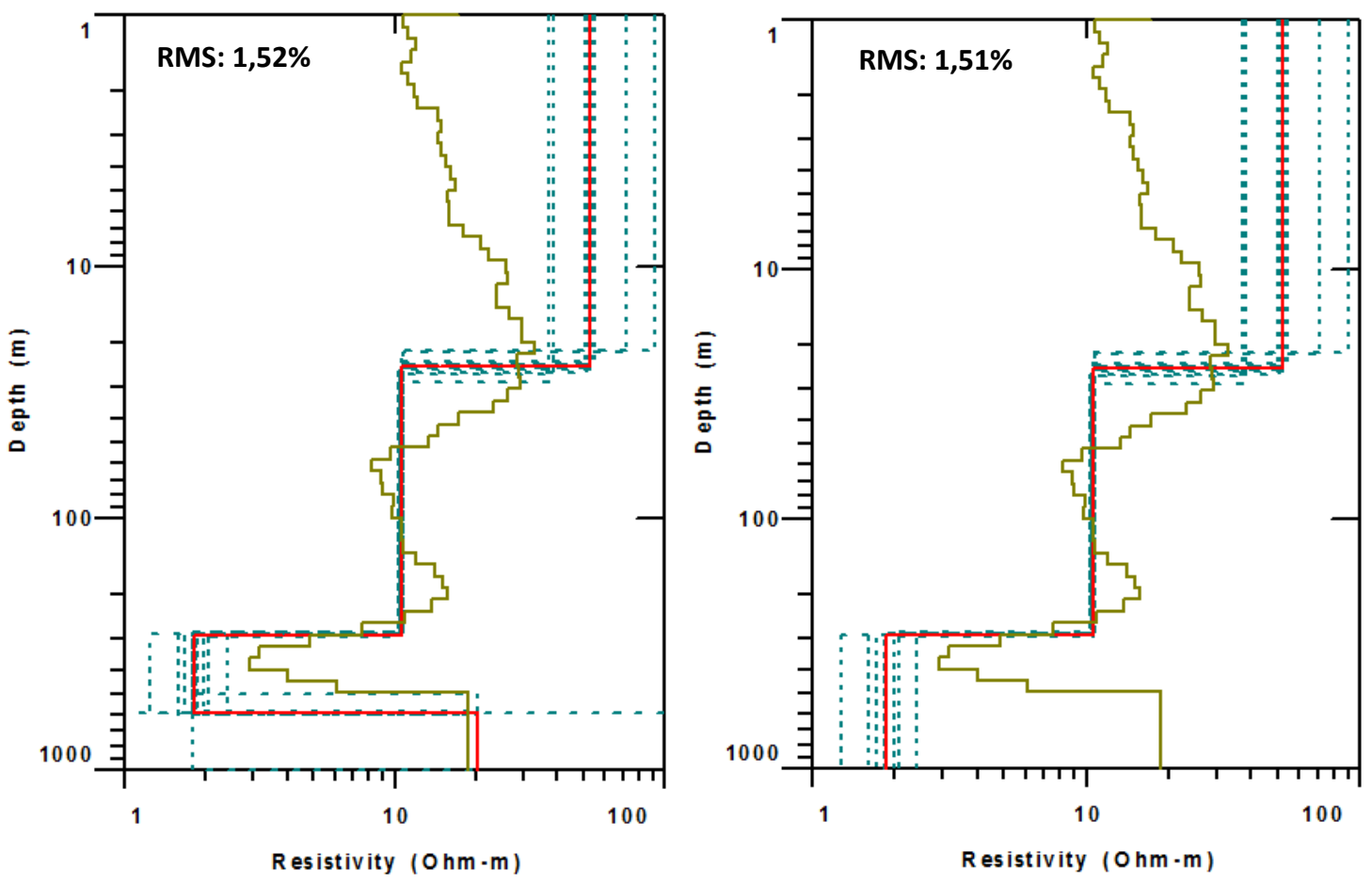

Figura 35: Teste de sensibilidade entre modelos. a) Modelo geoelétrico de quatro camadas; b) Modelo geoelétrico de três camadas.

Nota-se que o modelo de três camadas apresenta-se discretamente melhor ajustado e com menos flutuações que o de quatro camadas, ou seja, os modelos de camadas equivalentes apresentam um comportamento mais coerente, em especial na última camada. Sabendo das singularidades do método TDEM e tendo conhecimento das características geológicas da área de estudos, interpreta-se, portanto, que em aproximadamente $300 \mathrm{~m}$ de profundidade o sinal TDEM é dissipado devido a condutividade ( 10 Ohm.m) que os materiais em subsuperfície apresentam, bem como a espessura ( $280 \mathrm{~m})$ do pacote sedimentar da segunda camada geoelétrica. Sendo assim, optou-se por um modelo de três camadas geoelétricas para que fossem realizadas as inversões individuais TDEM. 


\section{INTERPRETAÇÃO DOS RESULTADOS}

Neste capítulo são apresentados os resultados referentes às aquisições TDEM e SEV da Área-1 (loop vermelho) e Área-2 (loop preto). Uma análise 1D foi realizada através das inversões conjuntas SEV/TDEM e dos perfis de CTDEM. Adicionalmente, informações de poços disponíveis (SIAGAS-CPRM, 2018) também foram utilizadas visando um estudo integrado, permitindo mapear o contato entre os sedimentos Quaternários e Terciários, bem como inferir o topo do embasamento na área de estudos. Esta análise conjunta de dados geofísicos e informações litológicas de poços serão apresentadas a seguir.

\section{1 Área-1}

$\mathrm{Na}$ Área-1, representada pelo loop vermelho na Figura 24, foram realizadas inversões individuais das 25 sondagens TDEM adquiridas dentro do loop transmissor, as quais geraram quatro perfis de CTDEM. Os resultados individuais das sondagens TDEM estão apresentados no apêndice $A$.

A área de estudos em questão encontra-se em uma bacia sedimentar tipicamente 1D, onde o vale deposicional apresenta-se com camadas geoelétricas plano-paralelas. Desta forma, todas as inversões individuais TDEM apresentaram as mesmas características geoelétricas. Assim sendo, as inversões individuais podem ser representadas com base em uma sondagem TDEM, conforme mostra a Figura 36, a qual corresponde à sondagem TDEM posicionada no centro do loop vermelho (TEM041). Na Tabela 2 seguem as informações do modelo geoelétrico gerado. 

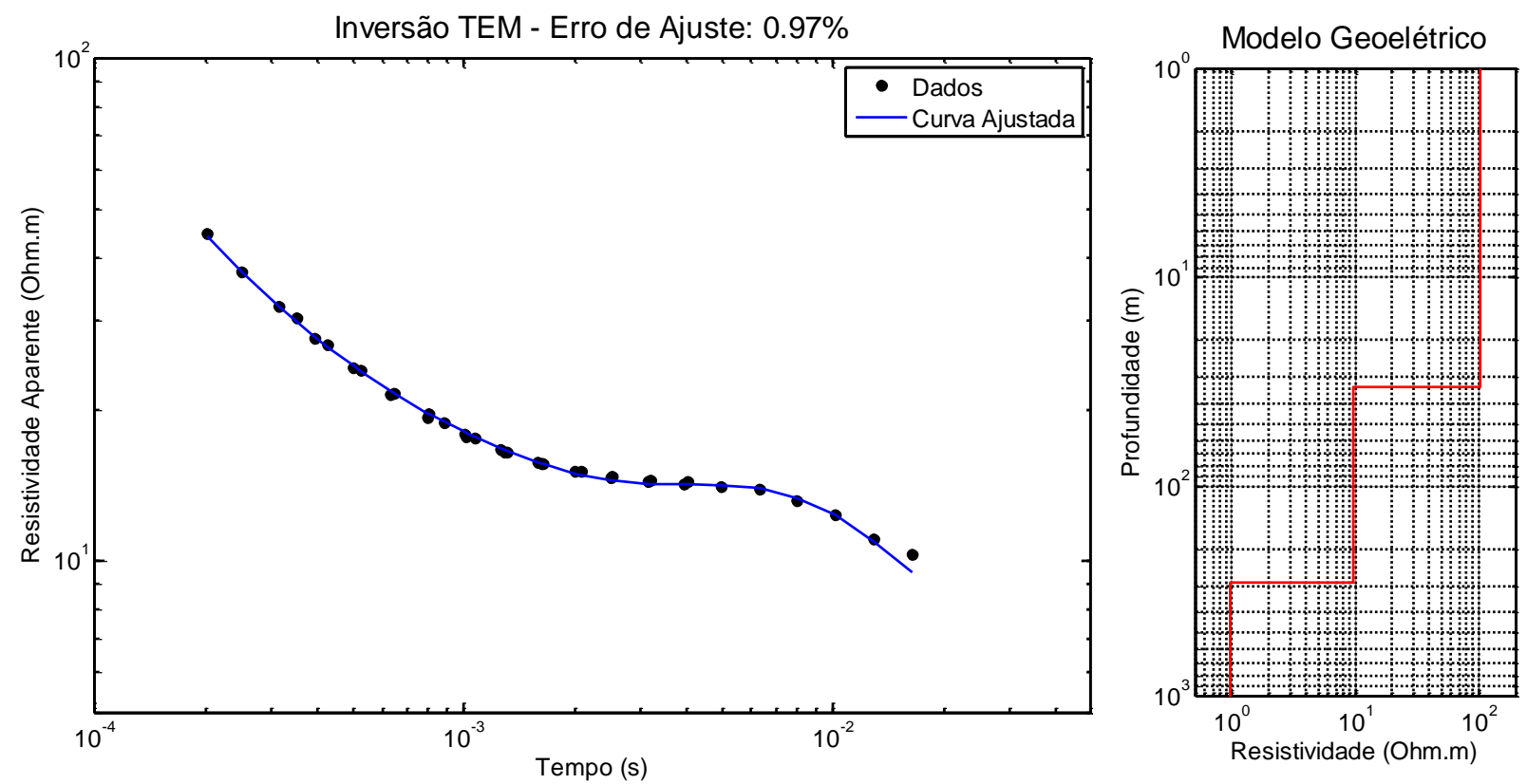

Figura 36: Inversão individual TDEM (TEM04-1) e o modelo geoelétrico associado da Área-1.

A inversão individual TEM04-1 apresenta as seguintes características: primeira camada geoelétrica apresenta-se como a mais resistiva com 103 Ohm.m e 33 m de espessura; a segunda camada apresenta-se condutiva com espessura média de $254 \mathrm{~m}$ e resistividade de 10 Ohm.m; a terceira camada indica uma resistividade de 1 Ohm.m.

\begin{tabular}{ccc}
\hline & Resistividade (Ohm.m) & Espessura (m) \\
\hline Camada 1 & 103 & 33 \\
Camada 2 & 10 & 254 \\
Camada 3 & 1 & - \\
\hline
\end{tabular}

Tabela 2: Modelo geoelétrico gerado pela inversão individual TEM04-1 da Área-1.

De acordo com o croqui da Figura 23, foram obtidos quatro perfis CTDEM, os quais foram gerados através da interpolação das inversões individuais de cada sondagem disposta ao longo do perfil. Para visualizar a variação da resistividade da subsuperfície da área de estudos, foram desenvolvidas rotinas de programação no software MATLAB, o qual é um software interativo de alto desempenho bastante útil para o processamento de sinais e construção de gráficos. Utilizando as informações de profundidade e resistividade de cada uma das sondagens, realizaram-se interpolações 
lineares para cada um dos quatro perfis CTDEM, conforme mostram as Figuras 37, 38, 39 e 40.

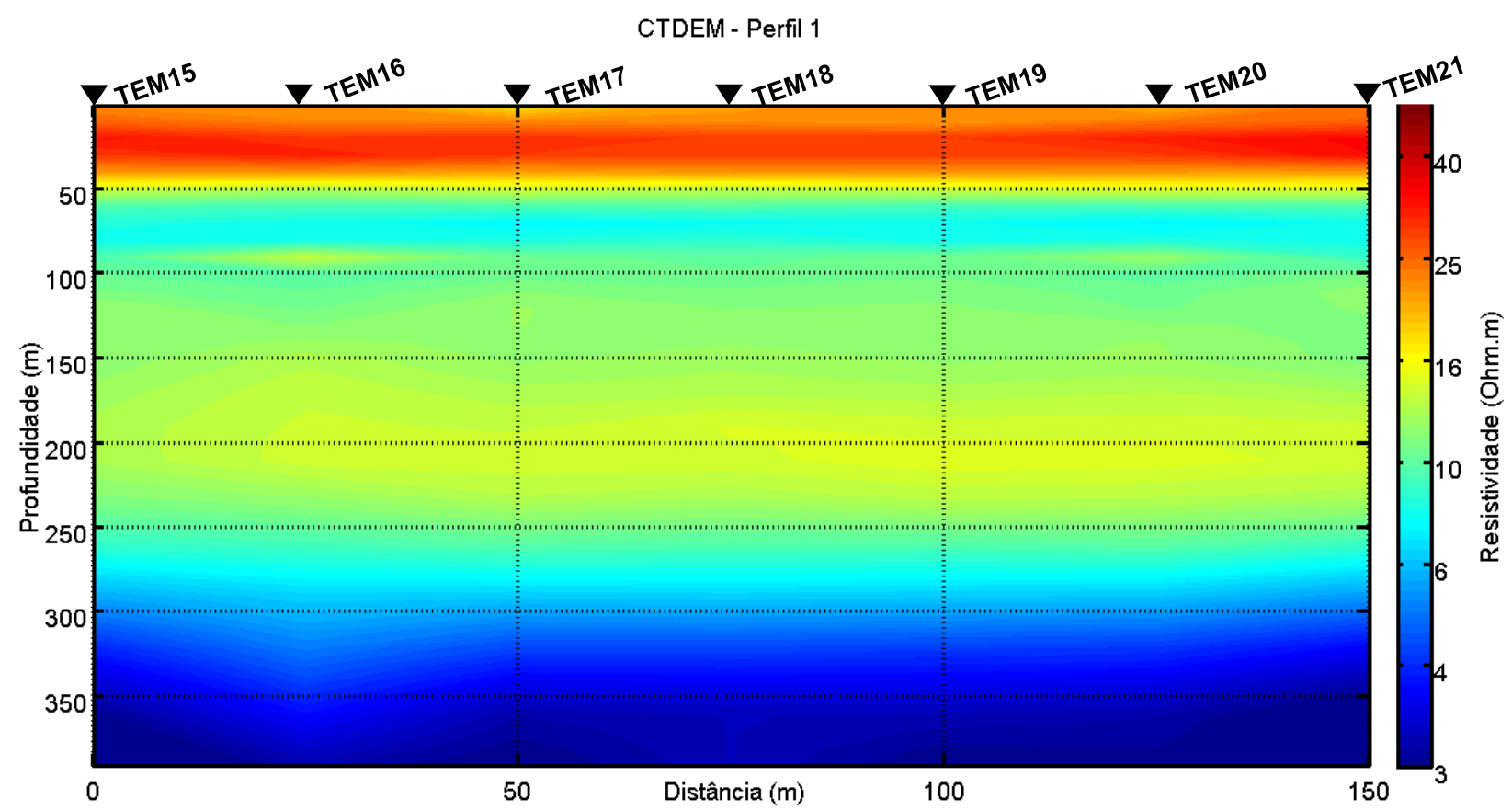

Figura 37: Perfil CTDEM 1 gerado mediante a interpolação das inversões individuais das sondagens da Área-1.

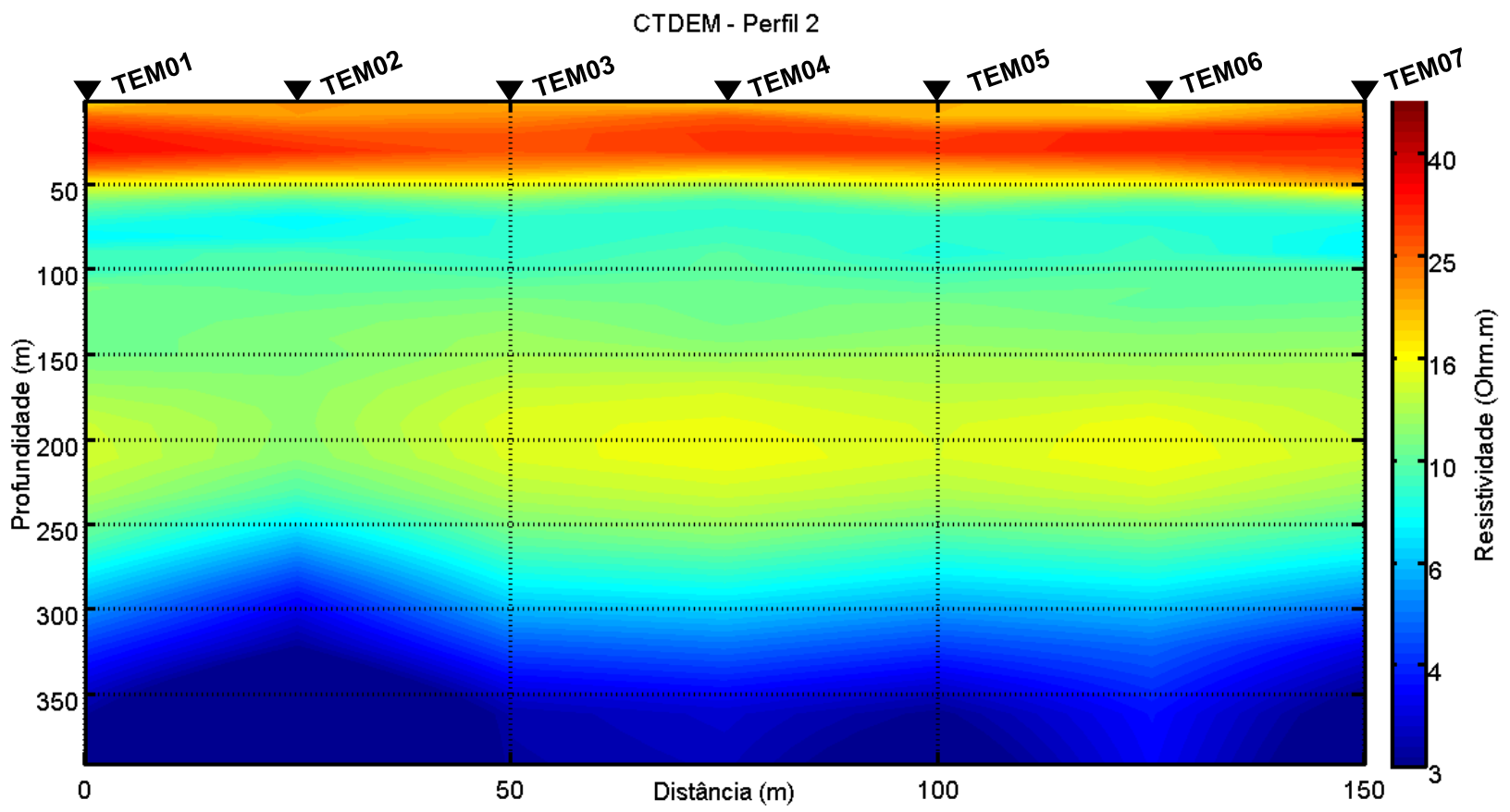

Figura 38: Perfil CTDEM 2 gerado mediante a interpolação das inversões individuais das sondagens da Área-1. 


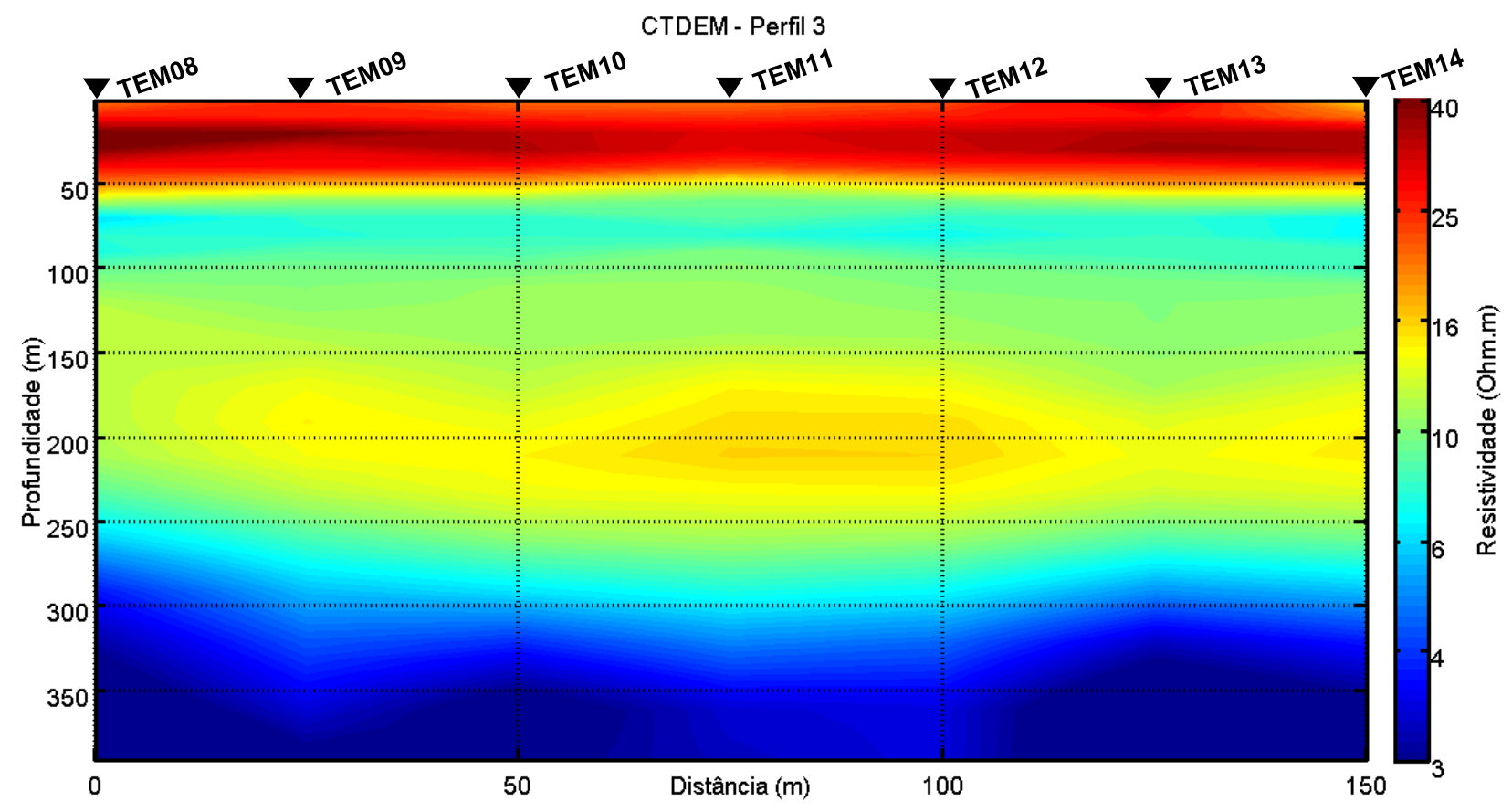

Figura 39: Perfil CTDEM 3 gerado mediante a interpolação das inversões individuais das sondagens da Área-1.

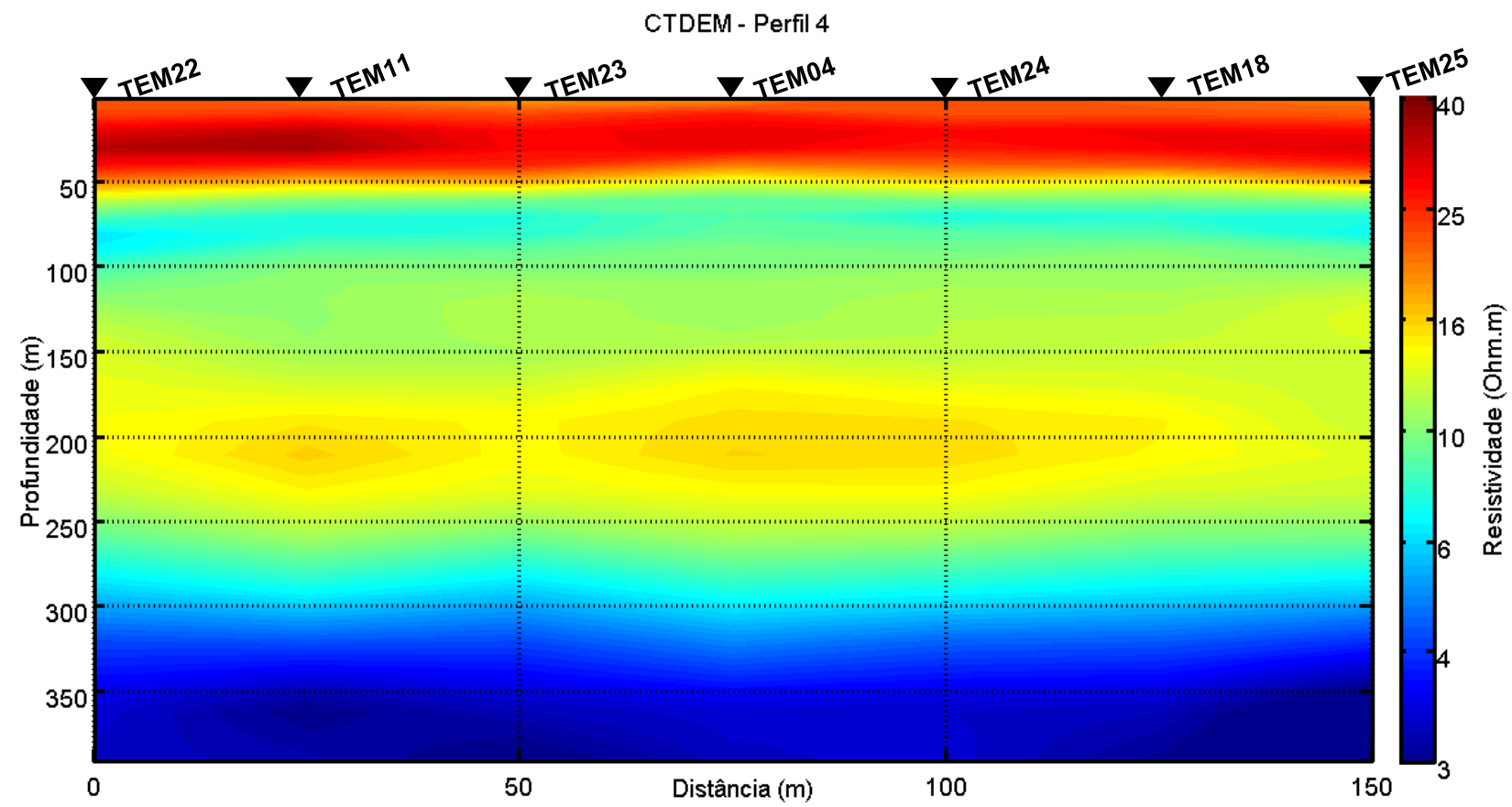

Figura 40: Perfil CTDEM 4 gerado mediante a interpolação das inversões individuais das sondagens da Área-1. 
De acordo com as interpolações realizadas, nota-se que o pacote sedimentar da área de estudos é bastante condutivo. O TDEM é um método robusto em muitos aspectos, contudo, nos primeiros metros de investigação ele não detecta com confiabilidade as características geoelétricas. Este fato esta relacionado com as limitações do próprio equipamento, da influência do campo magnético primário e das características geológicas da área de estudo. Assim sendo, uma interpretação baseada apenas em perfis CTDEM torna-se infactível.

Os quatro perfis gerados na Área-1 podem ser analisados conjuntamente sendo divididos em três camadas geoelétricas: a primeira mais resistiva variando de $0 \mathrm{~m}$ até $50 \mathrm{~m}$ de profundidade; a segunda, variando entre $50 \mathrm{~m}$ e $270 \mathrm{~m}$ de profundidade, observando uma região condutiva; a terceira camada inicia-se aproximadamente em $270 \mathrm{~m}$ de profundidade, a qual é identificada pelo TDEM como a camada mais condutiva dos perfis CTDEM.

A técnica SEV possui maior resolução para investigação nas camadas mais rasas, sendo bastante eficiente na investigação da interface entre materiais condutores/resistores. Na Área-1 e Área-2, realizou-se uma aquisição SEV coincidente com o centro do loop transmissor, conforme mostra a Figura 24. Na Figura 41, observase a inversão individual SEV1 (Área-1), bem como o modelo geoelétrico associado.
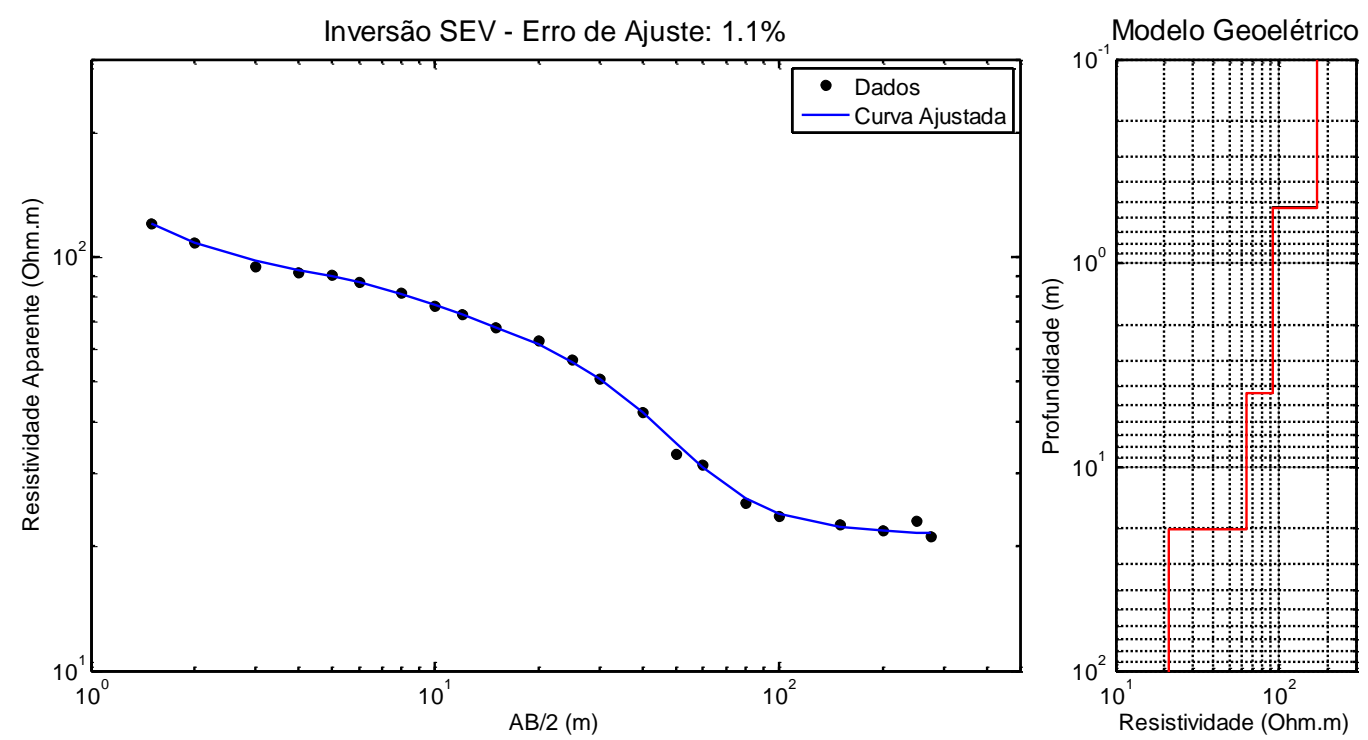

Figura 41: Inversão individual SEV (SEV1) e o modelo geoelétrico associado da Área-1. 
A inversão individual SEV1, com um espaçamento de $A B / 2$ de $275 \mathrm{~m}$, mostra um pacote sedimentar que aumenta a condutividade conforme aumenta a profundidade de investigação. Diferentemente do TDEM, a SEV realiza a investigação em camadas mais rasas, onde foram consideradas quatro camadas para o modelo geoelétrico. Na Tabela 3, segue o modelo gerado a partir do resultado da inversão individual SEV1.

\begin{tabular}{ccc}
\hline & Resistividade (Ohm.m) & Espessura (m) \\
\hline Camada 1 & 173 & 0,5 \\
Camada 2 & 92 & 4 \\
Camada 3 & 63 & 16 \\
Camada 4 & 21 & - \\
\hline
\end{tabular}

Tabela 3: Modelo geoelétrico gerado pela inversão individual SEV1 da Área-1.

Para que as inerentes ambiguidades dos métodos fossem reduzidas, realizou-se uma inversão conjunta SEV/TDEM no centro do arranjo (loop vermelho), onde a sondagem SEV1 coincide com a sondagem TEM04-1. A Figura 42 mostra o resultado da inversão conjunta SEV1/TEM04-1 no centro do arranjo e as informações do modelo geoelétrico associado podem ser vistas na Tabela 4.
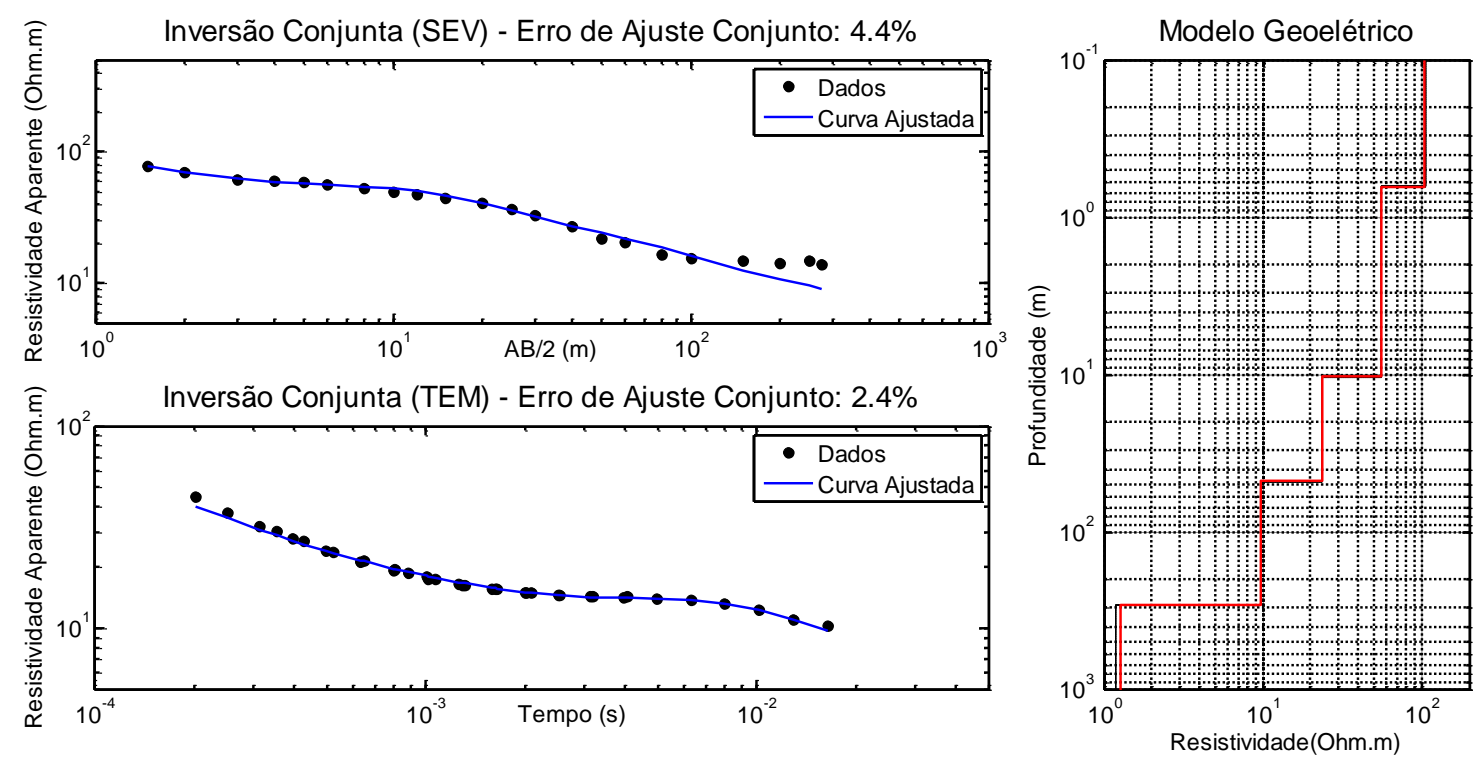

Figura 42: Inversão conjunta SEV1/TEM04-1 e modelo geoelétrico associado da Área-1. 


\begin{tabular}{lccc}
\hline & Resistividade (Ohm.m) & Profundidade (m) & Espessura (m) \\
\hline Camada 1 & 105 & 0 & 0,6 \\
Camada 2 & 56 & 1 & 10 \\
Camada 3 & 24 & 11 & 37 \\
Camada 4 & 10 & 48 & 245 \\
Camada 5 & 1 & 293 & - \\
\hline
\end{tabular}

Tabela 4: Modelo geoelétrico gerado pela inversão conjunta SEV1/TEM04-1 da Área-1.

De acordo com informações de 75 poços distribuídos no município de Taubaté, a profundidade máxima que esses poços atingem varia de $7,5 \mathrm{~m}$ até $647 \mathrm{~m}$ de profundidade. Os perfis construtivos dos poços indicam um solo areno-argiloso, seguido de sedimentos argilosos, arenitos, argilitos e folhelhos (em sua maioria) intercalados, como mostrado na Figura 7.

A última formação depositada no período Terciário é a Fm. Pindamonhangaba, sendo os sedimentos desta formação compostos por arenitos, argilitos e siltitos, os quais estão sobrepostos discordantemente ao Grupo Taubaté (Mancini, 1995).

Analisando os perfis litológicos dos poços disponíveis, nota-se que a presença de arenito se dá em todos os perfis construtivos, estando intercalados especialmente com argilitos nas camadas mais rasas. O Grupo Taubaté é composto em sua maioria por folhelhos, intercalando-se com argilitos e arenitos. O modelo geoelétrico gerado mediante a inversão conjunta SEV1/TEM04-1 (Figura 42) fornece informações que contribuem para estimar o contato da sedimentação entre os períodos Quaternário/Terciário.

Nos perfis CTDEM, é possível observar o contraste geoelétrico na profundidade de aproximadamente $50 \mathrm{~m}$. Interpreta-se que este contraste esteja relacionado às etapas de deposição sedimentar da bacia proposto por Riccomini (1989), onde a primeira etapa ocorre à deposição dos sedimentos do Grupo Taubaté, e na segunda a deposição dos sedimentos da Fm. Pindamonhangaba e dos sedimentos Quaternários.

No que se refere aos perfis litológicos dos poços, as camadas mais rasas predominam pela composição de arenito, argila e argilito que, de acordo com os poços 
catalogados e disponibilizados pelo SIAGAS-CPRM (2018), inicia-se em uma profundidade média de aproximadamente $30 \mathrm{~m}$. A presença de folhelhos vista nos perfis construtivos, é um indicativo do inicio dos sedimentos que compõem o Grupo Taubaté. Posto que nos perfis CTDEM o contraste geoelétrico se dá em $\sim 50 \mathrm{~m}$ de profundidade e considerando que a profundidade da quarta camada geoelétrica da inversão conjunta SEV1/TEM04-1 atinge $48 \mathrm{~m}$, estima-se, portanto, que o contato entre os sedimentos Quaternários e Terciários ocorra entre $~ 30-50 \mathrm{~m}$ de profundidade.

A profundidade de contato entre os sedimentos Quaternários e Terciários é uma estimativa de acordo com as informações da litologia dos poços, dos perfis CTDEM e da inversão conjunta SEV1/TEM04-1. Há de se ressaltar ainda que, estando a Fm. Pindamonhangaba depositada sobre o Grupo Taubaté, ambos depositados no período Terciário, a Fm. Pindamonhangaba pode ainda indicar uma zona de transição, indicando uma variação faciológica dentro do Grupo Taubaté.

No modelo geoelétrico associado à inversão conjunta SEV1/TEM04-1, observa-se o pacote sedimentar mais espesso e condutivo na quarta camada geoelétrica, com 242 m e 9 Ohm.m, respectivamente. Integrando essa informação com os perfis CTDEM, observa-se que esta camada geoelétrica pode ser associada com a camada condutora vista nos perfis de CTDEM, a qual varia de $\sim 50-300$ m de profundidade sendo todo este pacote condutivo interpretado como sendo o Grupo Taubaté.

De acordo com o Mapa de Águas Subterrâneas do Estado de São Paulo, é na porção central da bacia onde ocorre a maior espessura de sedimentos, diminuindo na região das margens e a noroeste. Na região central ocorre a maior espessura saturada, variando entre 200 e $300 \mathrm{~m}$ de espessura (DAEE, IG, IPT, CPRM, 2005).

$\mathrm{O}$ aquífero Taubaté ocorre em duas principais áreas na bacia, as quais estão localizadas na porção sudoeste e nordeste. Entre essas duas regiões encontra-se um compartimento preenchido predominantemente por argilitos e folhelhos, pouco permeável e com características de um aquiclude localizado sob as cidades de Taubaté, Tremembé e Pindamonhangaba (DAEE, IG, IPT, CPRM, 2005).

Portanto, em conformidade com as informações de poços do município de Taubaté (SIAGAS-CPRM (2018); Figura 6), nota-se a presença significativa de folhelhos e argilitos intercalados nos perfis construtivos, caracterizando, desta forma, o 
pacote de sedimentos saturado que formam o Grupo Taubaté em um aquiclude. Como visto na Figura 6, de acordo com as informações de poços, nota-se a presença de arenitos nos perfis construtivos. Portanto, na área de estudos em questão, o Grupo Taubaté caracteriza-se não só em um aquiclude, mas também em um aquífero. Entretanto, o método TDEM não possui sensibilidade para diferenciar arenitos de argilitos nessas condições, desta forma, identifica-se toda essa região saturada como sendo um único pacote condutivo.

Nos perfis CTDEM foi possível observar um condutor raso limitado entre 50-100 $m$ de profundidade, o qual não é identificado pela inversão conjunta SEV/TDEM nem através das inversões individuais TDEM. Como discutido anteriormente, o TDEM identifica o pacote sedimentar condutivo como um todo, não tendo sensibilidade para mapear o condutor raso nessas condições, visto as características geoelétricas dos sedimentos do Grupo Taubaté. Embora em $\sim 150 \mathrm{~m}$ de profundidade os perfis CTDEM apresentem um aumento de resistividade, este ínfimo aumento da resistividade não é significativo.

A Bacia sedimentar de Taubaté pode ser caracterizada em duas camadas: uma altamente condutiva composta pelos sedimentos Terciários e Quaternários, e a outra camada resistiva, composta pelo embasamento cristalino. Carvalho, et al. (2010), apresenta 11 seções sísmicas (Figura 5) com intuito de delimitar o embasamento da Bacia de Taubaté, onde são fornecidos resultados de uma variação da espessura sedimentar de 300 e $800 \mathrm{~m}$.

O TDEM é um método robusto para identificar a interface entre camadas resistoras/condutoras. O campo magnético secundário, o qual é medido na superfície, esta associado às correntes secundárias (ou correntes eddy). A atenuação das correntes eddy esta associada à resistividade do material geológico, de maneira que, quanto mais condutivo for o meio, maior será a perda de energia do sinal e maior será o tempo para que ocorra a difusão das correntes secundárias.

De acordo com o modelo geoelétrico gerado pela inversão conjunta SEV1/TEM041, a quinta camada geoelétrica apresenta-se muito condutiva. Entretanto, dada às particularidades da geologia do local, bem como informações de poços da cidade, nesta profundidade não há informações que possa representar este valor de resistividade (3 
Ohm.m), sendo este valor um indicativo da perda de energia das correntes secundárias na camada condutora mais espessa (Grupo Taubaté).

Desta forma, através de informações de poços bem como trabalhos que relacionam o embasamento da Bacia de Taubaté (Carvalho, et al., 2010; Souza Filho, et al., 2012; Vidal, et al., 2004), infere-se, desta forma, que o topo do embasamento possa estar ocorrendo em $\sim 300 \mathrm{~m}$ de profundidade. Contudo, os resultados mostraram que somente utilizando o método TDEM não é possível afirmar a presença do embasamento naquela profundidade, sendo necessários outros métodos geofísicos de investigação na área de estudos para que esta informação seja analisada com maior grau de confiabilidade.

Uma vez que os perfis CTDEM apresentam a mesma característica de camadas plano-paralelas, qualquer um dos quatro perfis CTDEM pode representar este contato sedimentar interpretado. Na Figura 43 tem-se o perfil CTDEM 1 representando o contato entre os sedimentos Terciários e Quaternários.

CTDEM - Perfil 1

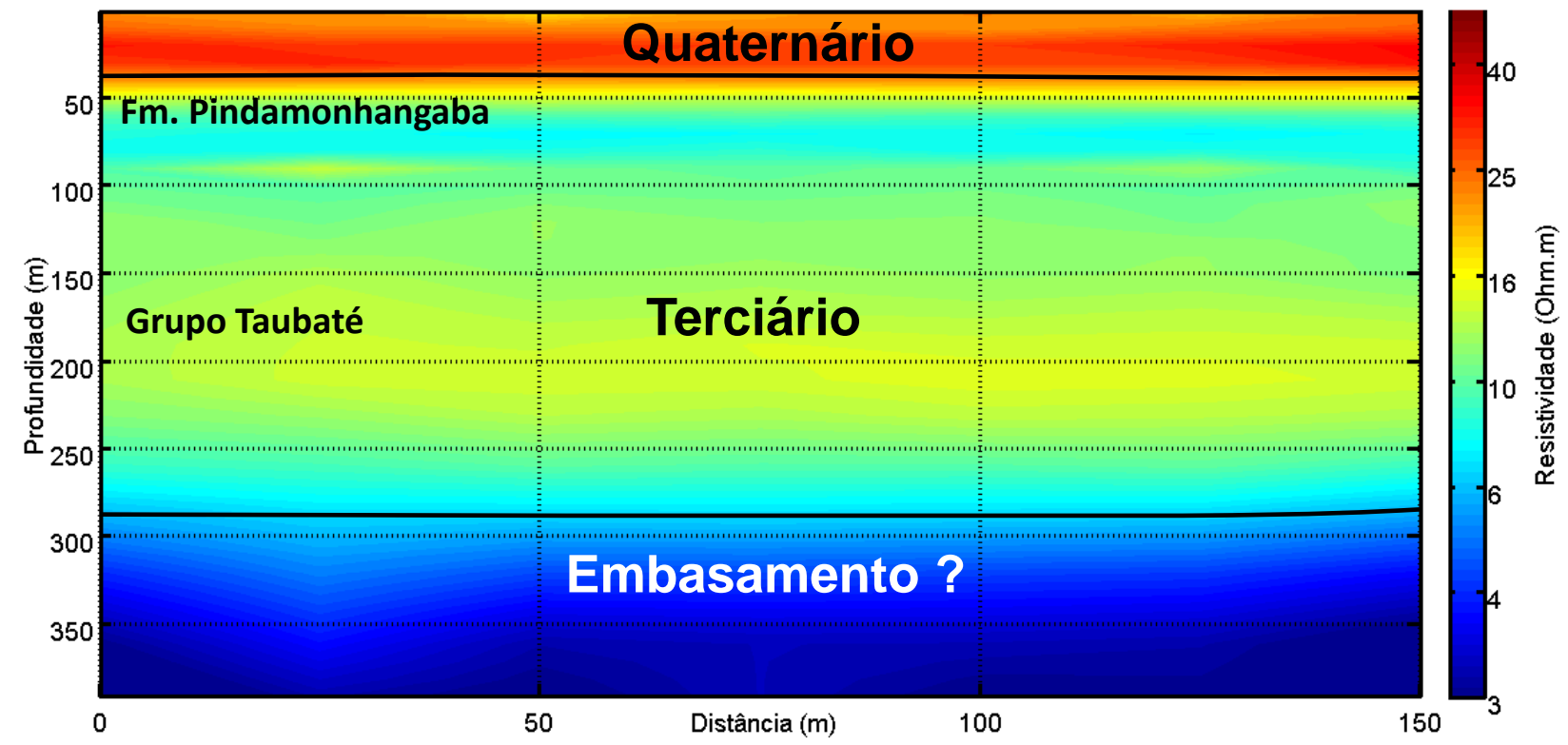

Figura 43: Perfil CTDEM 1 referente à Área-1 com os resultados interpretados.

Contudo, é necessário ponderar tais interpretações. De acordo com a Figura 43, o "embasamento" apresenta-se como sendo uma camada condutiva, o que não condiz 
com a realidade, sendo o embasamento altamente resistivo. Desta forma, o TDEM nestas condições, pode também estar detectando uma variação faciológica dentro do Grupo Taubaté, manifestando novamente a necessidade de utilizar outros métodos geofísicos para que o topo do embasamento possa ser detectado com mais credibilidade.

Portanto, tendo em vista as características da geologia da área de estudos disponíveis pelas informações de poços e trabalhos relacionados à Bacia de Taubaté, é possível obter um modelo geológico interpretado com base nessas informações e nas informações obtidas por meio das análises geofísicas, conforme mostra a Figura 44.

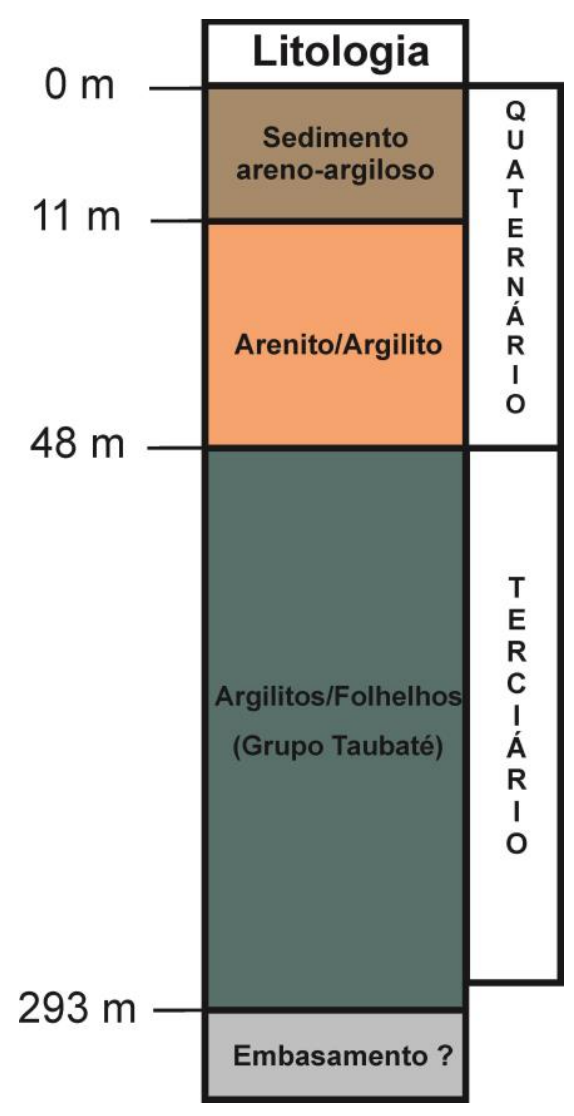

Figura 44: Modelo litoestratigráfico interpretado com base nas informações geofísicas e de poços para a Área-1. 


\section{$5.2 \quad$ Área-2}

$\mathrm{Na}$ Área-2, representada pelo loop preto na Figura 24, foram realizadas inversões individuais das 25 sondagens TDEM adquiridas dentro do loop transmissor, as quais geraram quatro perfis de CTDEM. Os resultados individuais das sondagens TDEM estão apresentados no Apêndice B.

A mesma análise realizada para Área-1 equivale para a Área-2, onde as inversões individuais TDEM podem ser representadas por uma sondagem, visto o comportamento tipicamente 1D da Bacia de Taubaté. Na Figura 45 segue a inversão individual da sondagem TDEM correspondente ao centro do loop preto (TEM04-2), sem a frequência de $3 \mathrm{~Hz}$. Na Tabela 5 seguem as informações do modelo geoelétrico gerado.
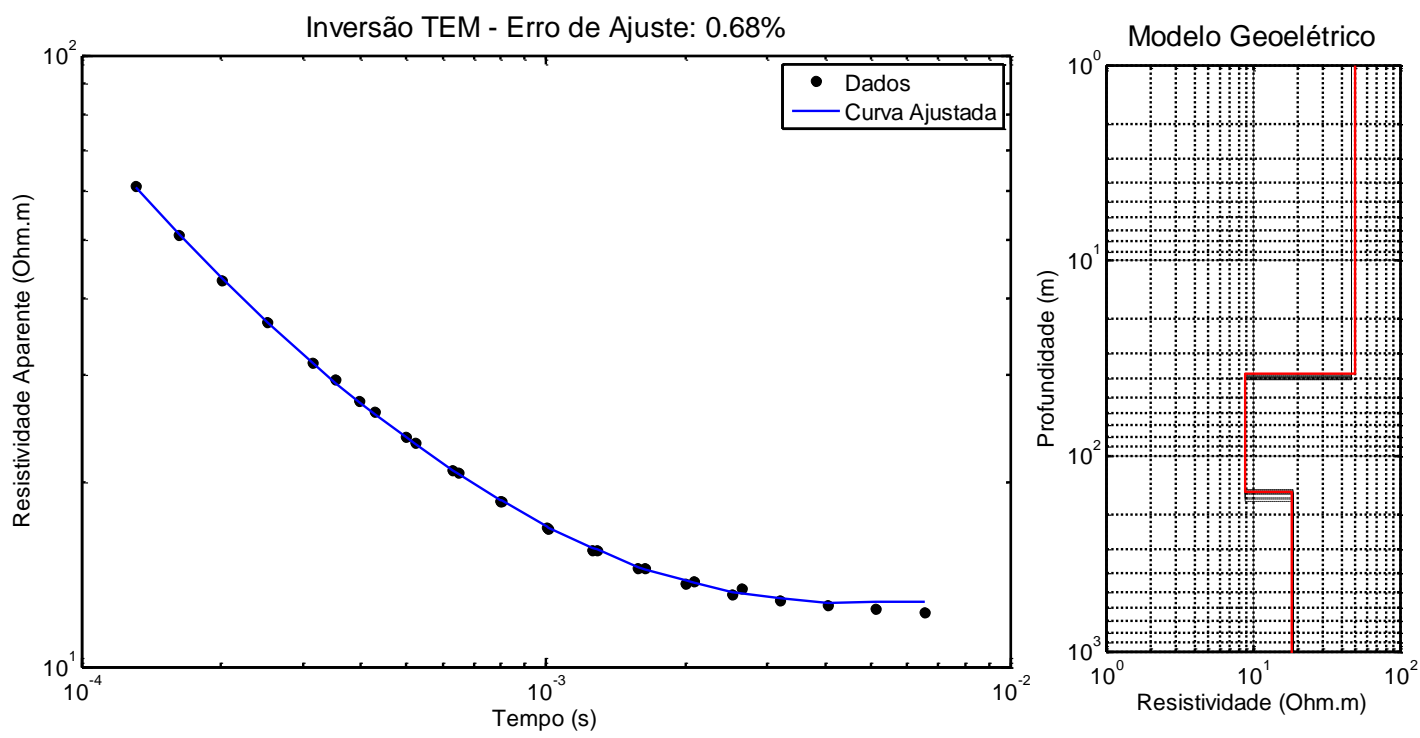

Figura 45: Inversão individual TDEM (TEM04-2) e o modelo geoelétrico associado da Área-2 sem a frequência de $3 \mathrm{~Hz}$.

A inversão individual TEM04-2 apresenta as seguintes características: primeira camada geoelétrica apresenta resistividade $\sim 49$ Ohm.m e 38 m de espessura; a segunda camada com resistividade de 9 Ohm.m e espessura de $115 \mathrm{~m}$; a terceira camada é caracterizada por uma resistividade $\sim 18$ Ohm.m. 


\begin{tabular}{ccc}
\hline & Resistividade (Ohm.m) & Espessura (m) \\
\hline Camada 1 & 49 & 38 \\
Camada 2 & 9 & 115 \\
Camada 3 & 18 & - \\
\hline
\end{tabular}

Tabela 5: Modelo geoelétrico gerado pela inversão individual TEM04-2 da Área-2 sem a frequências de 3 $\mathrm{Hz}$.

Analogamente ao que foi realizado na Área-1, realizou-se a interpolação das inversões individuais de cada sondagem, gerando quatros perfis CTDEM como mostrado no croqui da Figura 23. As Figuras 46, 47, 48 e 49 mostram o resultado da interpolação.

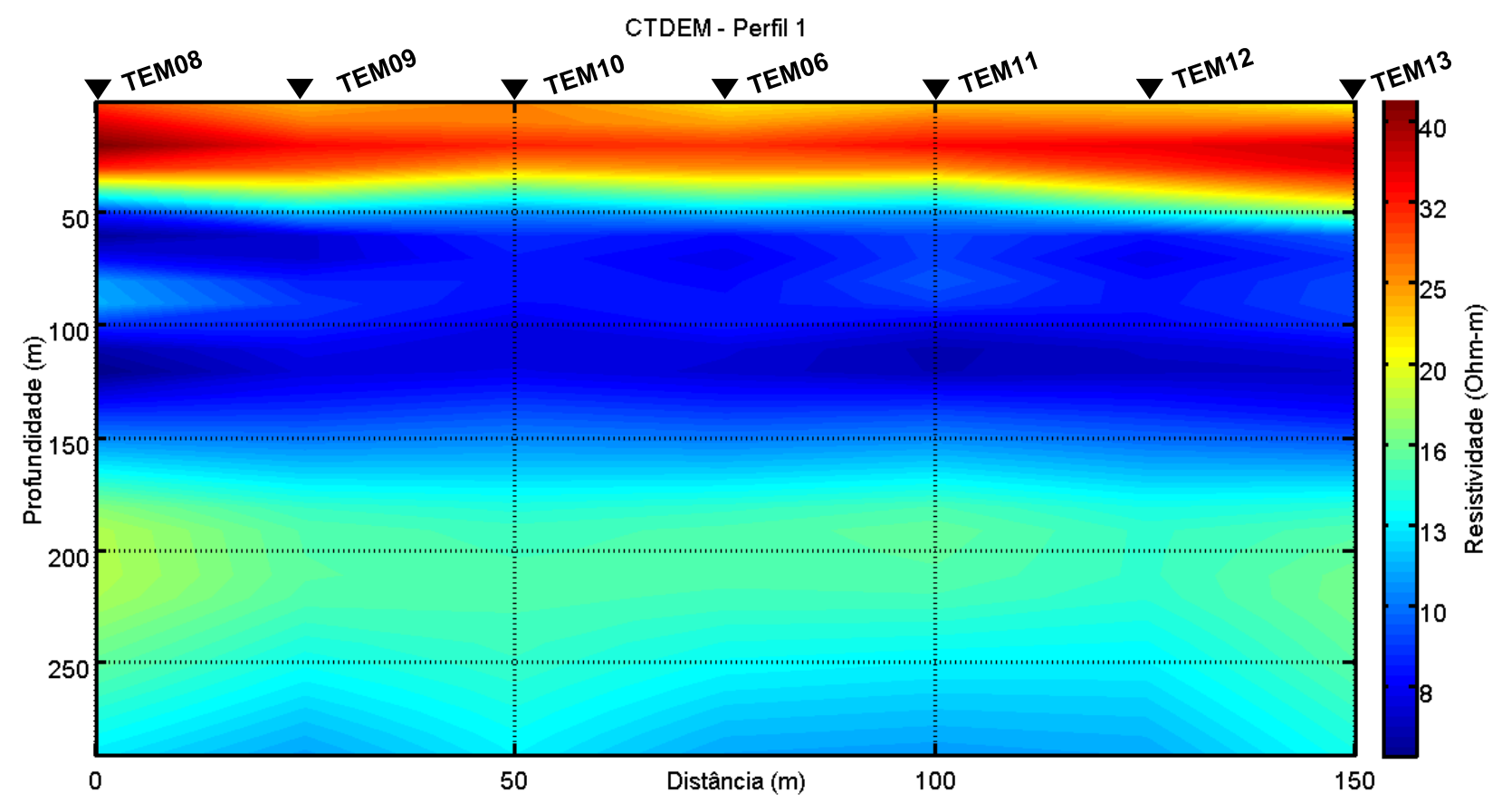

Figura 46: Perfil CTDEM 1 gerado mediante a interpolação das inversões individuais das sondagens da Área-2. 


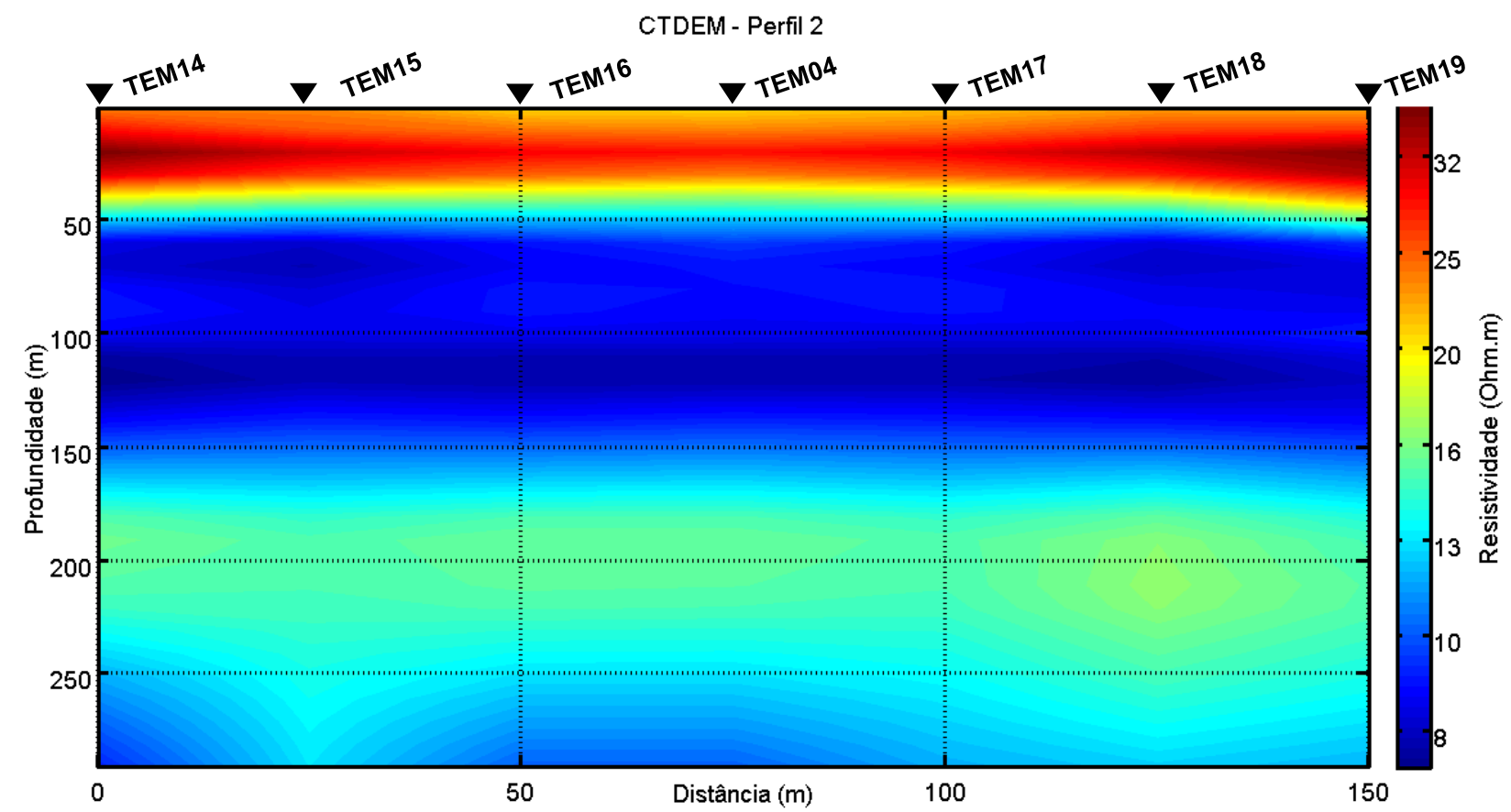

Figura 47: Perfil CTDEM 2 gerado mediante a interpolação das inversões individuais das sondagens da Área-2.

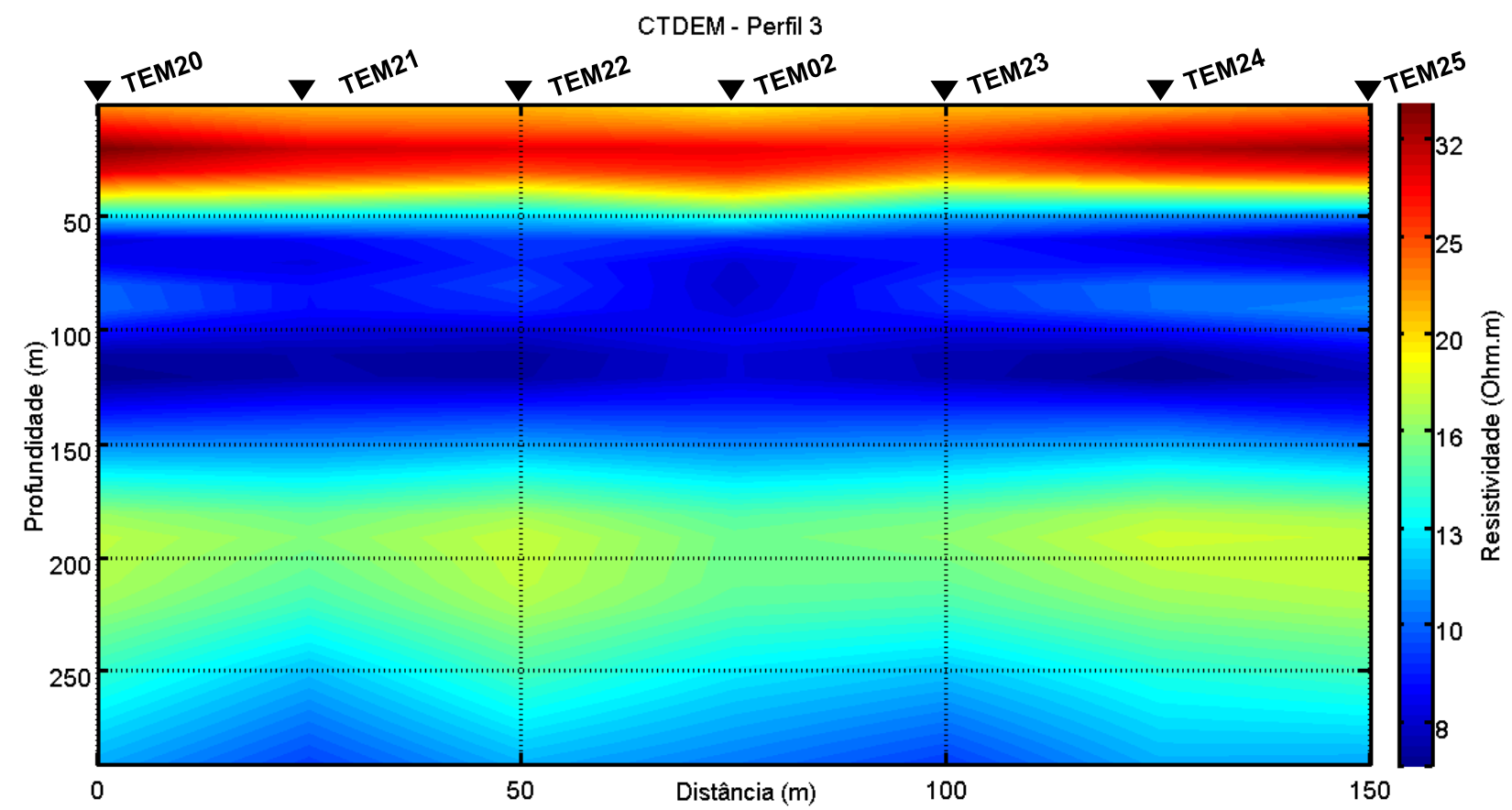

Figura 48: Perfil CTDEM 3 gerado mediante a interpolação das inversões individuais das sondagens da Área-2. 


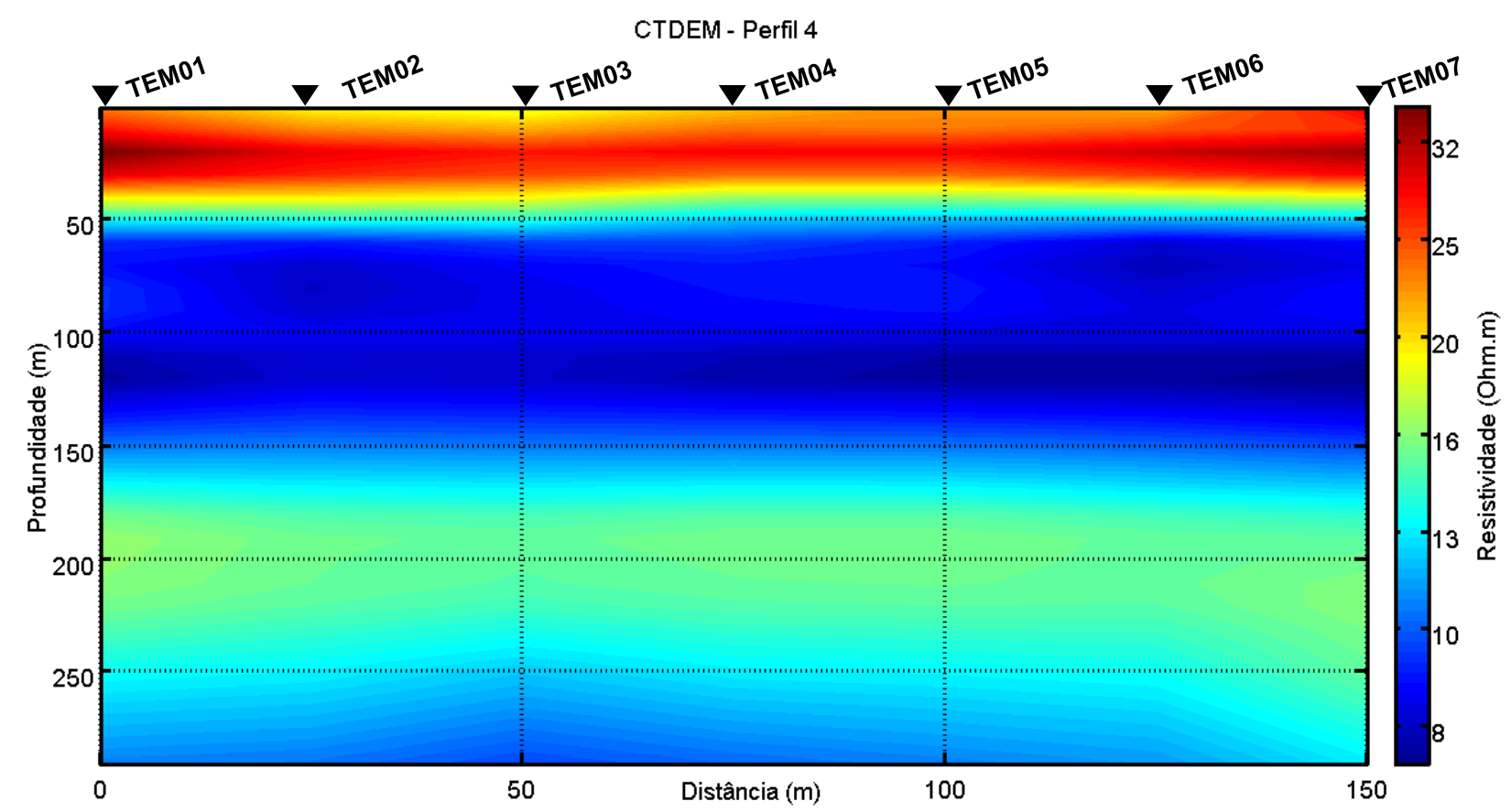

Figura 49: Perfil CTDEM 4 gerado mediante a interpolação das inversões individuais das sondagens da Área-2.

Os quatro perfis CTDEM apresentados possuem características semelhantes entre si para a Área-1. A primeira camada vai de $0 \mathrm{~m}$ até $50 \mathrm{~m}$ de profundidade composto por um pacote sedimentar mais resistivo; na segunda camada, dos $50 \mathrm{~m}$ até os $250 \mathrm{~m}$ de profundidade nota-se um pacote sedimentar condutivo, diferentemente dos perfis CTDEM da Área-1, onde se destaca o condutor entre $\sim 50-150 \mathrm{~m}$; a partir de 250 $\mathrm{m}$ de profundidade há uma dispersão do sinal quando comparado com os perfis da Área-1 devido a ausência da frequência de $3 \mathrm{~Hz}$.

Com intuito de realizar a inversão conjunta SEV/TDEM utilizando as três frequências, foram utilizados os dados da campanha extraordinária realizada na data de 09 de novembro de 2017. A Figura 50 mostra a inversão individual TDEM (TEM04-3) com as frequências de $30 \mathrm{~Hz}, 7,5 \mathrm{~Hz}$ e $3 \mathrm{~Hz}$, a qual foi adquirida no centro do arranjo da Área-2, coincidente com a SEV2 e TEM04-2. Na Tabela 6 têm-se as informações do modelo geoelétrico gerado. 

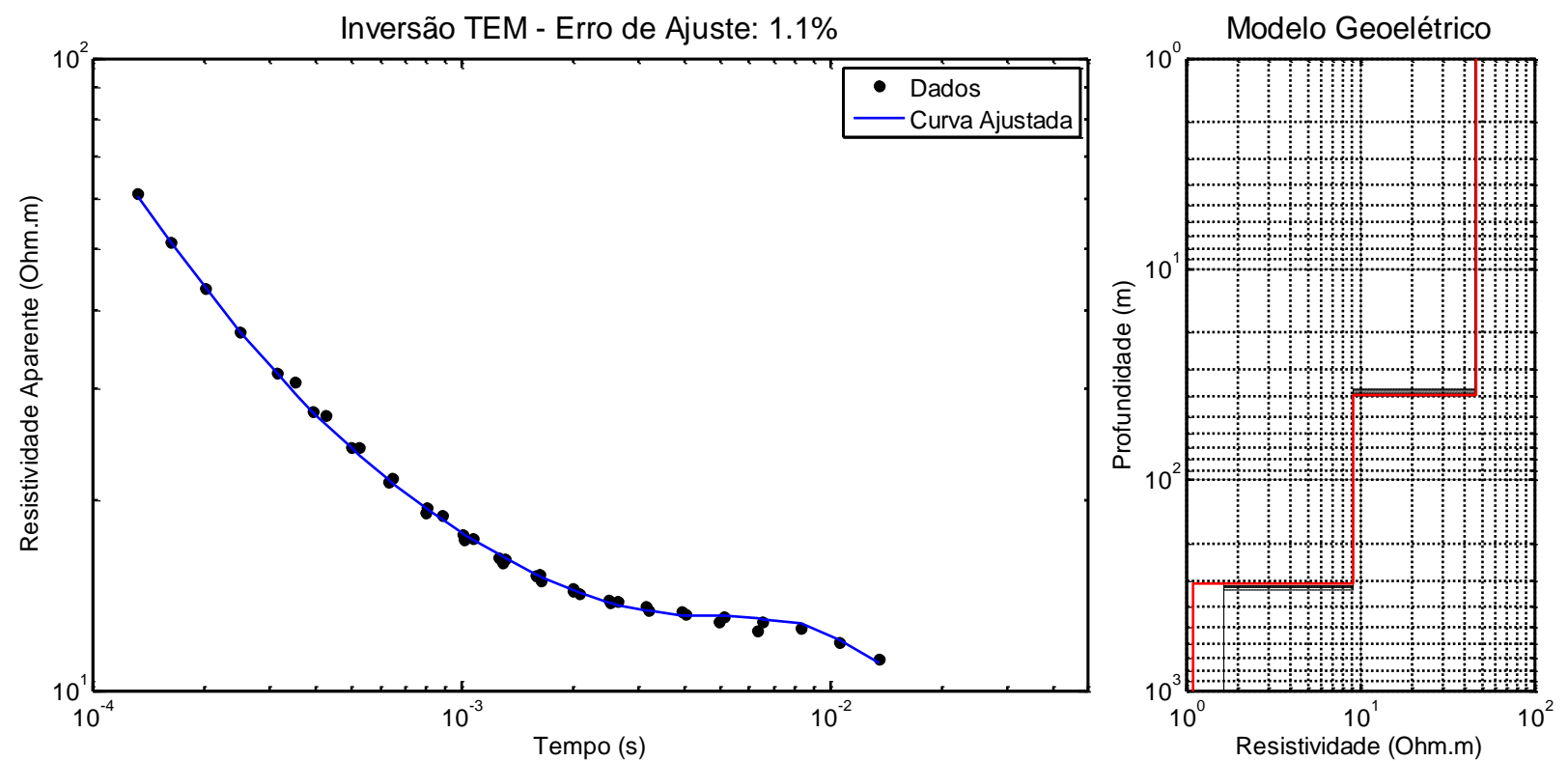

Figura 50: Inversão individual TDEM (TEM04-3) e o modelo geoelétrico associado da Área-2 com as frequências de $30 \mathrm{~Hz}, 7,5 \mathrm{~Hz}$ e $3 \mathrm{~Hz}$.

\begin{tabular}{ccc}
\hline & Resistividade (Ohm.m) & Espessura (m) \\
\hline Camada 1 & 46 & 39 \\
Camada 2 & 9 & 272 \\
Camada 3 & 1 & -
\end{tabular}

Tabela 6: Modelo geoelétrico gerado pela inversão individual TEM04-3 da Área-2 com as frequências de $30 \mathrm{~Hz}, 7,5 \mathrm{~Hz}$ e $3 \mathrm{~Hz}$.

A inversão individual TEM04-3 apresenta-se com as seguintes características: primeira camada sendo a mais resistiva apresentando um valor de $46 \mathrm{Ohm} . \mathrm{m}$ e espessura de $39 \mathrm{~m}$; a segunda camada condutiva com valores de resistividade de 9 Ohm.m espessura de $272 \mathrm{~m}$ e; a terceira camada apresentando-se bastante condutiva, analogamente à inversão individual TEM04-1, atingindo um valor de 1 Ohm.m.

$\mathrm{Na}$ inversão individual SEV2, com um espaçamento $\mathrm{AB} / 2$ de $200 \mathrm{~m}$, nota-se a tendência do pacote sedimentar condutivo que a área de estudos apresenta, além de apresentar as camadas geoelétricas em profundidades mais rasas. Contudo, na SEV2 observa-se uma camada geoelétrica resistiva nos primeiros metros de investigação. A Figura 51 mostra a inversão individual SEV2 e o modelo geoelétrico associado. $\mathrm{Na}$ 
Tabela 7, têm-se os dados do modelo geoelétrico gerado a partir do resultado da inversão individual SEV2.
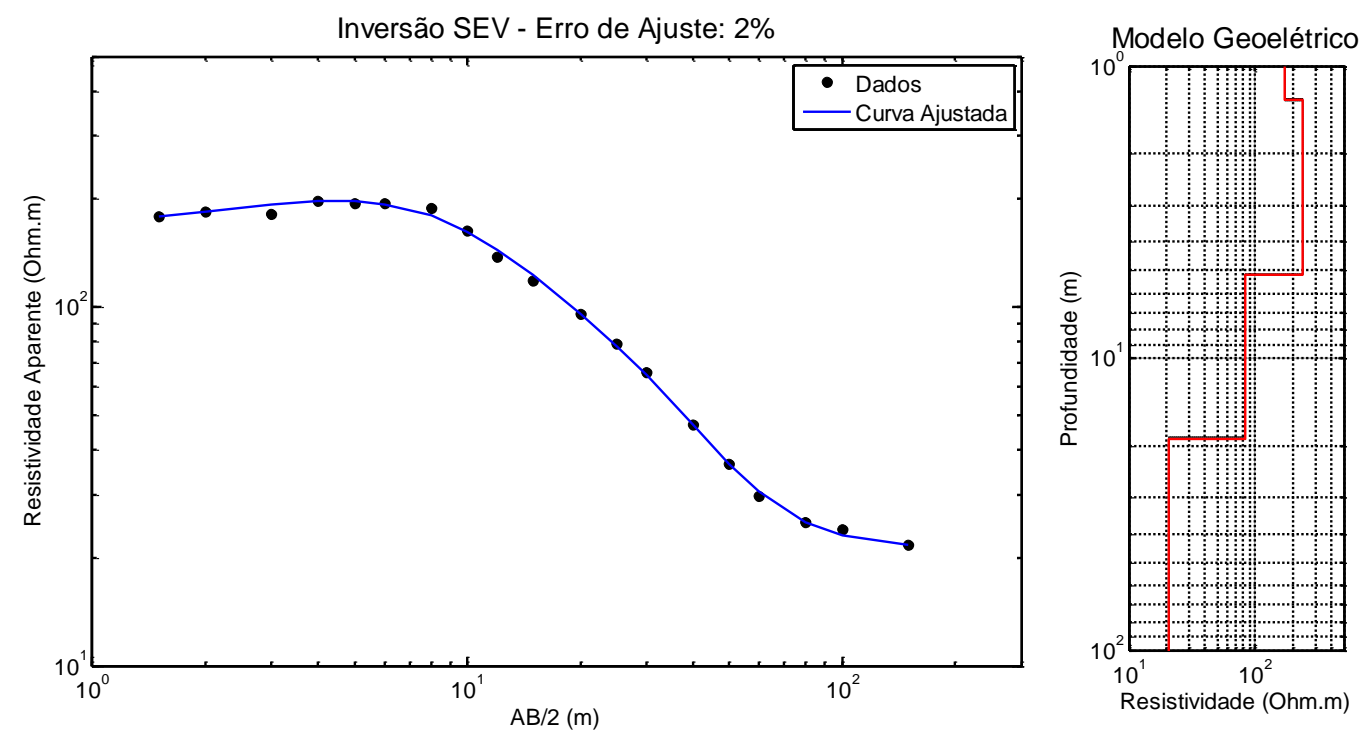

Figura 51: Inversão individual SEV (SEV2) e o modelo geoelétrico associado da Área-2.

\begin{tabular}{ccc}
\hline & Resistividade (Ohm.m) & Espessura (m) \\
\hline Camada 1 & 172 & 1,3 \\
Camada 2 & 236 & 4 \\
Camada 3 & 83 & 14 \\
Camada 4 & 21 & - \\
\hline
\end{tabular}

Tabela 7: Modelo geoelétrico gerado pela inversão individual SEV2 da Área-2.

Analogamente ao processo realizado com os dados da Área-1, para que as inerentes ambiguidades dos métodos fossem reduzidas, realizou-se uma inversão conjunta SEV/TDEM no centro do arranjo. A sondagem TDEM utilizada na inversão conjunta foi a TEM04-3 por conter os dados das três frequências. A Figura 52 mostra o resultado da inversão conjunta SEV2/TEM04-3 no centro do arranjo para a Área-2, bem como os dados do modelo geoelétrico gerado na Tabela 8. 

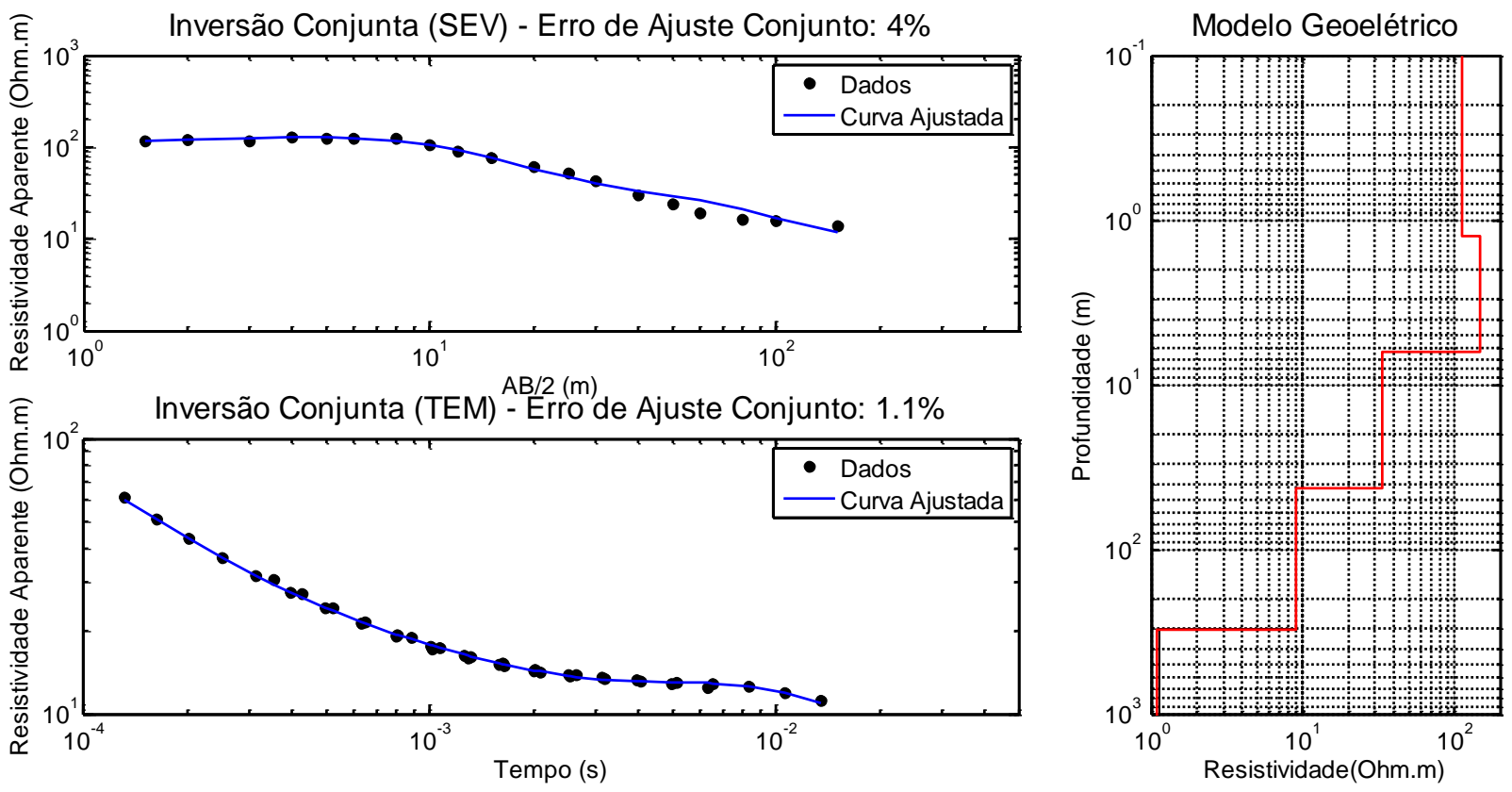

Figura 52: Inversão conjunta SEV2/TEM04-3 e o modelo geoelétrico associado da Área-2.

\begin{tabular}{lccc}
\hline & Resistividade (Ohm.m) & Profundidade (m) & Espessura (m) \\
\hline Camada 1 & 112 & 0 & 1,2 \\
Camada 2 & 148 & 1 & 5 \\
Camada 3 & 34 & 6 & 36 \\
Camada 4 & 9 & 42 & 266 \\
Camada 5 & 1 & 308 & - \\
\hline
\end{tabular}

Tabela 8: Modelo geoelétrico gerado pela inversão conjunta SEV2/TEM04-3 da Área-2.

A aquisição de dados realizada na Área-1 e Área-2 foram sistematicamente iguais, de forma que a interpretação baseada para os dados da Área-1 é exatamente a mesma para os dados da Área-2.

Como discutido anteriormente, de acordo com as informações de poços, as camadas mais rasas predominam pela composição de arenito, argila e argilito, as quais variam em espessura e profundidade, atingindo uma profundidade média de aproximadamente $30 \mathrm{~m}$. Uma vez que o contraste geoelétrico é visto em $\sim 50 \mathrm{~m}$ de profundidade nos perfis CTDEM e a profundidade da quarta camada geoelétrica da 
inversão conjunta SEV2/TEM04-3 atinge $42 \mathrm{~m}$, estima-se, analogamente a interpretação dos dados da Área-1, que o contato entre os sedimentos Quaternários e Terciários ocorra entre $\sim 30-50 \mathrm{~m}$ de profundidade.

De acordo com a inversão conjunta SEV2/TEM04-3, a quarta camada geoelétrica apresenta-se como a mais espessa e condutiva, iniciando-se em aproximadamente 42 $\mathrm{m}$ de profundidade (Tabela 8). Conforme as informações geológicas dos poços (SIAGAS-CPRM, 2018), a área de estudos indica uma composição intercalada entre folhelhos e argilitos em maiores níveis de profundidade, sendo interpretada como o Grupo Taubaté. Visto que todos os perfis CTDEM apresentam as mesmas características, as interpretações realizadas podem ser representadas por qualquer um dos perfis. A Figura 53 mostra os resultados interpretados sobrepostos ao perfil CTDEM 1 da Área-2.

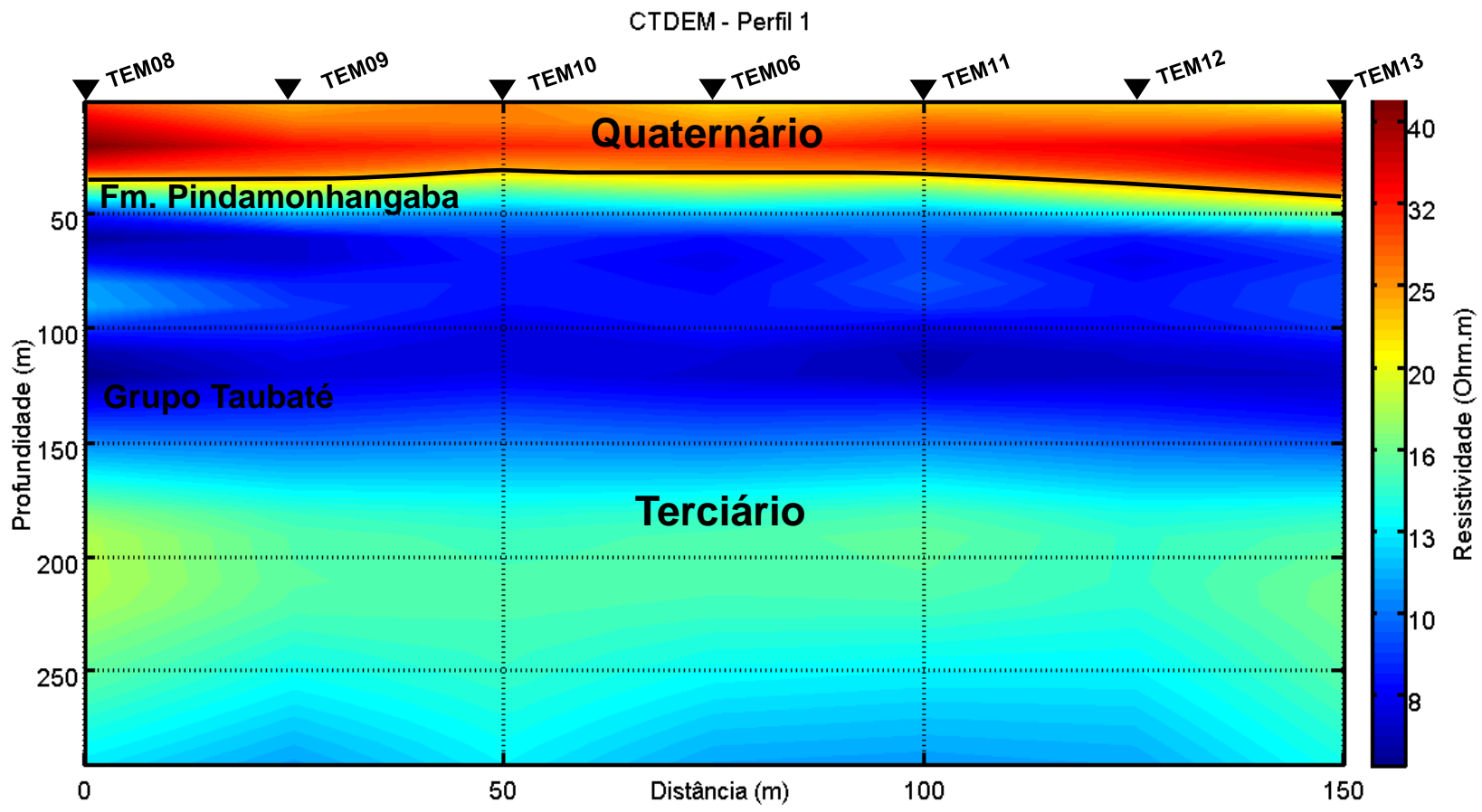

Figura 53: Perfil 1 CTDEM referente à Área-2 com os resultados interpretados.

De acordo com a informação vista no modelo geoelétrico gerado pela inversão conjunta SEV2/TEM04-3, verifica-se um valor resistividade baixo na última camada geoelétrica. Como discutido anteriormente, de acordo com as informação da geologia e informações de poços, infere-se o embasamento cristalino da Bacia de Taubaté em 
aproximadamente $300 \mathrm{~m}$ de profundidade. Contudo, como discutido anteriormente em analise conjunta com os perfis CTDEM da Área-1, nesta profundidade o TDEM pode também estar detectando uma variação faciológica dentro do Grupo Taubaté.

Em termos de CTDEM, a interpretação da Área-1 difere da Área-2. Nos perfis CTDEM da Área-2 pode-se observar a dissipação do sinal em aproximadamente $250 \mathrm{~m}$ de profundidade causado pela ausência da frequência de $3 \mathrm{~Hz}$, limitando a interpretação do Grupo Taubaté devido a sua alta condutividade e espessura, o que causou uma dissipação do sinal TDEM e não sendo possível detectar a variação de resistividade em $\sim 300 \mathrm{~m}$ de profundidade, como visto nos perfis da Área-1. Entretanto, a estimativa de contato entre os sedimentos Quaternários e Terciários pode ser estimada.

Portanto, conforme realizado com as informações obtidas dos dados da Área-1, conhecendo as características da geologia da área de estudos disponíveis por meio das informações de poços e trabalhos relacionados na Bacia de Taubaté, é possível obter um modelo geológico interpretado com base nessas informações e nas informações obtidas por meio das análises geofísicas, conforme mostra a Figura 54 abaixo. 


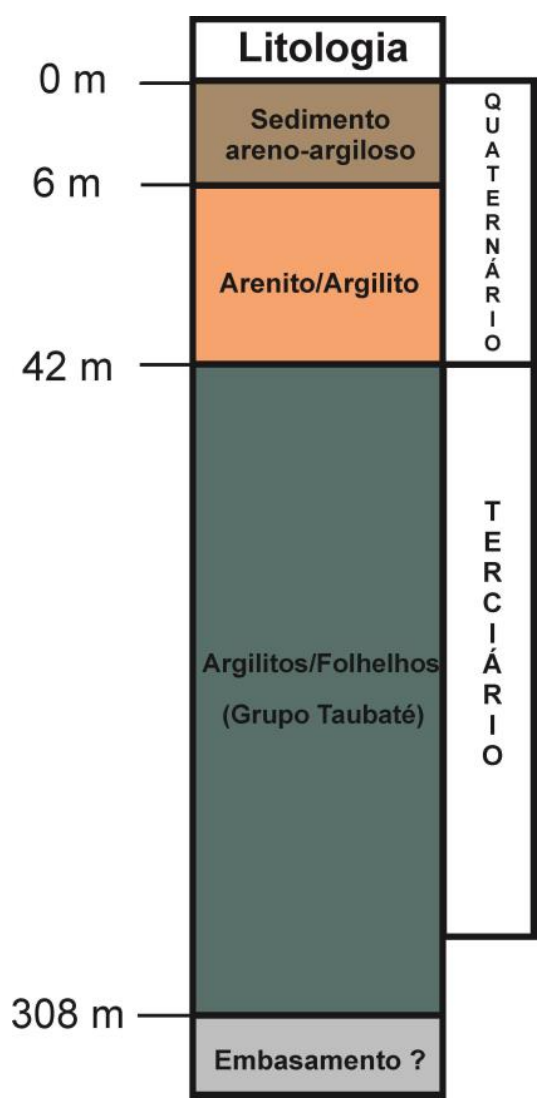

Figura 54: Modelo litoestratigráfico interpretado com base nas informações geofísicas e de poços para a Área-2. 


\section{CONCLUSÕES}

As análises dos dados Eletromagnético no Domínio do Tempo (TDEM) e Eletrorresistividade (ER) adquiridos na região central da Bacia sedimentar de TaubatéSP por meio de inversão individual e conjunta de dados SEV/TDEM permitiram mapear o contato entre os sedimentos Quaternários e Terciários entre $\sim 30-50 \mathrm{~m}$ de profundidade.

Com auxilio das inversões conjuntas SEV/TDEM e dos perfis CTDEM, foi possível determinar que pacote sedimentar mais condutivo varia entre $\sim 50-300 \mathrm{~m}$ de espessura, sendo estes os sedimentos pertencentes ao Grupo Taubaté e a Formação Pindamonhangaba. Essa informação pôde ser constatada através de informações geológicas fornecidas pelos poços, nos quais predominam uma composição de folhelhos e argilitos, caracterizando, portanto, a zona saturada em um aquiclude, de maneira que as interpretações apresentaram-se coerentes com as informações de poços.

No que se refere ao topo do embasamento, nada se pôde concluir. Contudo, com base em informações litológicas de poços e nos trabalhos realizados na porção central da bacia que indicam uma espessura sedimentar variando entre 300 e $800 \mathrm{~m}$ (Souza Filho, et al., 2012; Vidal, et al., 2004; Carvalho, et al., 2010) diminuindo nas margens da bacia (DAEE, IG, IPT, CPRM, 2005), infere-se que o topo do embasamento esteja em $\sim 300 \mathrm{~m}$ de profundidade. Entretanto, devido à ambiguidade na interpretação, o resultado TDEM pode também estar relacionado com uma variação faciológica dentro do Grupo Taubaté. Desta forma, mais estudos são necessários para verificar a veracidade destas informações.

A inversão conjunta SEV/TDEM mostrou-se eficiente, reduzindo as ambiguidades presentes na interpretação dos resultados TDEM e Eletrorresistivo, permitindo uma interpretação mais confiável e complementando as informações individuais apresentadas pela SEV e pelo TDEM.

Com base nas análises realizadas, conclui-se que os resultados desta pesquisa estão de acordo com as informações litológicas dos poços e contribuem com as pesquisas hidrogeofísicas no Estado de São Paulo. 
Recomenda-se para futuros trabalhos na Bacia de Taubaté, especificamente na área de estudos onde foi realizada esta pesquisa, que sejam realizadas analises geofísicas utilizando diferentes métodos: sísmica e gravimetria. Desta forma, utilizando diferentes métodos, a confiabilidade de determinar o topo do embasamento é maior, delimitando com maior precisão os limites do Grupo Taubaté. 


\section{REFERÊNCIAS BIBLIOGRAFICAS}

Almeida, E.R., 2011. Caracterização geoelétrica na região de Bebedouro-SP por meio de sondagens eletromagnéticas no domínio do tempo (TDEM). Dissertação de Mestrado (Geofísica), IAG-USP.

Abdullahi, M. G., Toriman, M. E., Gasim, M. B., 2015. The Application of Vertical Electrical Sounding (VES) for Groundwater Exploration in Tudun Wada Kano State, Nigeria. OMICS Publishing Group. Geology and Geoscience, v4.

Bortolozo, C.A., 2011. Inversão conjunta 1D de dados de SEV e TDEM: aplicações em hidrogeologia. Dissertação de Mestrado (Geofísica), IAG-USP.

Bortolozo, C. A., Porsani, J. L., 2012. "CurupiraV1.0". Software de inversão conjunta de sondagens SEV/TDEM. Registro de programa de computador ํo. 12988-1. Revista da propriedade industrial n‥2165, item 090, p. 145.

Bortolozo, C. A.; Couto Jr., M.A.; Porsani, J.L.; Almeida, E.R.; Monteiro Santos, F.A., 2014. Geoelectrical characterization using joint inversion of VES/TEM data: A case study in Paraná Sedimentary Basin, São Paulo State, Brazil. Journal of Applied Geophysics, v.111, p.33-46.

Bortolozo, C. A.; Porsani, J.L.; Santos, F.A. M.; Almeida, E.R., 2015. VES/TEM 1D joint inversion by using Controlled Random Search (CRS) algorithm. Journal of Applied Geophysics, v.112, p.157-174.

Bortolozo, C. A., 2016. Inversão conjunta 1D e 2D de dados de Eletrorresistividade e TDEM aplicados em estudos de hidrogeologia na bacia do Paraná. Tese de Doutorado (Geofísica), IAG-USP. 
Braga, A. C. O., 2006. Métodos da Eletrorresistividade e Polarização Induzida aplicados nos estudos da captação e contaminação de águas subterrâneas: Uma abordagem metodológica e prática. Tese apresentada ao concurso público para obtenção do título de Livre Docente. UNESP, Rio Claro.

Campaña, J.D.R., 2015. Análise do campo magnético secundário 3D usado no método TDEM: Aplicações em aquíferos fraturados. Dissertação de Mestrado (Geofísica), IAGUSP.

Campaña, J. D. R., Porsani, J. L., Bortolozo, C. A., Oliveira, G. S., Santos, F.A.M., 2017. Inversion of TEM Data and Analysis of the $2 D$ Induced Magnetic Field Applied to the Aquifers Characterization in the Paraná Basin, Brazil. Journal of Applied Geophysics, 138, 233-244.

Carvalho, A. M. A., Vidal, A. C., Kiang, C. H., 2010. Delimitação do embasamento da Bacia de Taubaté. Revista do Instituto de Geociências da USP. v. 11, no 01, p. 19-32.

Carrasquila, A. A. G., Ulugergerli, E., 2006. Evaluation of the transient electromagnetic geophysical method for stratigraphic mapping and hydrogeological delineation in campos basin, Brazil. Revista Brasileira de Geofísica 24, 333-341.

Christiansen, A. V., Auken, E., Sørensen, K., 2006. The transient electromagnetic method, in Kirsch, R., Groundwater geophysics. A tool for hydrogeology, $2^{\mathrm{a}}$ ed, Chapter 6, p 179-225.

Couto Jr., M.A., 2015. Caracterização hidrogeoelétrica na região de Termas de Ibirá, Bacia do Paraná, por meio de inversão conjunta $1 D$ de sondagens TDEM/SEVs. Dissertação de Mestrado (Geofísica), IAG-USP. 
Danielsen, J. E., Auken, E., Jorgensen, F., Sondergaard, V., Sørensen, K. I., 2003. The application of the transient electromagnetic method in geophysical surveys. Journal of Applied Geophysics, v. 53, p. 181-198.

Departamento de Águas e Energia Elétrica (DAEE), Instituto Geológico (IG), Instituto de Pesquisas Tecnológicas (IPT), Serviço Geológico do Brasil (CPRM), 2005. Mapa de águas subterrâneas do Estado de São Paulo: escala: 1:1.000.000. v. 03.

Departamento de Águas e Energia Elétrica, Instituto de Geociências e Ciências Exatas. Laboratório de Estudo de Bacias (DAEE/LEBAC), 2013. Água Subterrâneas no Estado de São Paulo. 44p.

Feitosa, F. A. C., Filho, J. M, 2000. Hidrogeologia - conceitos e aplicações. CPRM/REFO, LABHID-UFPE, 2ª edição.

Fernandes, F. L., 1993. Arcabouço estrutural e evolução da Bacia de Taubaté - SP. 1993. Dissertação de Mestrado - Universidade Federal de Ouro Preto, Ouro Preto, MG.

Fernandes, F. L.; Chang, H. K., 2001. Modelagem gravimétrica da Bacia de Taubaté Vale do Rio Paraíba do Sul, leste do Estado de São Paulo. Revista Brasileira de Geofísica, v. 19, p. 131-144.

Fernandes, F. L.; Chang, H. K., 2003. Arcabouço estrutural da Bacia de Taubaté - SP. In: Simpósio Nacional de Estudos Tectônicos. Boletim de Resumos.

Fitterman, D. V., Stewart, M. T., 1986. Transient electromagnetic sounding for groundwater. Geophysics, v. 51, no 4, pp. 955-1005.

Geonics, 1998. PROTEM-57MK2, operating manual. Geonics Limited, Mississauga, Ontario, Canada. 
Kaufman, A. A., Keller, G. V., 1983. Frequency and Transient Soundings. Elsevier, N. Y.

Kearey, P., Brooks, M., Hill, I., 2009. Geofísica de Exploração. Tradução em português de Maria Cristina Coelho, Oficina de Textos, São Paulo.

Keller, G. V. and Frischknecht, F.C., 1966. Electrical methods in geophysical prospecting. Pergamon Press, New York, p. 517.

Land, A. L., Lautier, J. C., Wilson, N. C., Chianese, G., Webb, S., 2003. Geophysical and monitoring evaluation of coastal plain aquifers. Ground Waters, v. 42, no 01, p. 5967.

Leite, D.N., 2013. Caracterização geoelétrica por meio de inversão conjunta $1 D$ de SEV/TDEM na região de Urupês-SP, Bacia do Paraná: aplicações em hidrogeologia. Dissertação de Mestrado, IAG-USP.

Leite, D. N., Bortolozo, C. A., Porsani, J. L., Couto Jr., M.A., Campaña, J.D.R., Monteiro Santos, F.A., Rangel, R.C., Hamada, L.R., Sifontes, R.V., Oliveira, G.S., Stangari, M.C., 2018. Geoelectrical Characterization with $1 D$ VES/TDEM Joint Inversion in Urupês-SP Region, Paraná Basin: Applications to Hydrogeology. Journal of Applied Geophysics (accept).

Mancini, F., 1995. Estratigrafia e Aspectos da Tectônica Deformadora da Formação Pindamonhangaba, Bacia de Taubaté, SP. Dissertação (Mestrado em Geociências) Instituto de Geociências, Universidade de São Paulo, p. 107.

Marques, A., 1990. Evolução tectono-sedimentar e perspectivas exploratórias da Bacia de Taubaté, São Paulo, Brasil. Boletim de Geociências da Petrobrás, v. 4, n. 3, p. 253262. 
McNeill, J.D., 1994. Principles and application of time domain electromagnetic techniques for resistivity sounding, Technical Note TN-27, Geonics Ltd, Mississauga, Ontario, Canada.

Meju, M.A., 2005. Simple relative space-time scaling of electrical and electromagnetic depth sounding arrays: implication for electrical static shift removal and joint DC-TEM data inversion with the most squares-criterion. Geophysical prospecting, v. 53, p 1-17.

Morais, E. R., Menezes, P. T. L., 2005. Estratigráfia geoelétrica da seção carbonática da Bacia de Sergipe-Alagoas, região de Campo de Riachuelo, Sergipe. Revista de geologia, vol. 18, no 2, pp. 175-185.

Moreira, C. A., 2005. Aplicação do método eletromagnético transiente em área contaminada sob atenuação natural, Rio Claro, São Paulo. Dissertação (Mestrado em geociências). Instituto de Geociencias e Ciências Exatas da Universidade Estadual Paulista.

Nabighian, M.N., Macnae, J.C., 1988. Time domain electromagnetic prospecting methods. In: NABIGHIAN MN (Ed.). Electromagnetic theory for geophysics application, Part A, Chapter 4.

Northwest Geophysical Associates (N.G.A.), 2002 - Time domain electromagnetic exploration. Nota Técnica.

Porsani, J.L., Bortolozo, C.A., Almeida, E.R., Santos Sobrinho, E. N., Santos, T.G., 2012a. TDEM survey in urban environmental for hydrogeological study at USP campus in São Paulo city, Brazil. Journal of Applied Geophysics 76, 102-108.

Porsani, J.L., Almeida, E.R., Bortolozo, C.A., Monteiro Santos, F.A., 2012b. TDEM survey in an area of seismicity induced by water wells in Paraná sedimentary basin, Northern São Paulo State, Brazil. Journal of Applied Geophysics 80, 1-9. 
Rangel, R. C., Porsani, J. L., Bortolozo, C. A., Hamada, L. R., 2018. Electrical Resistivity Tomography and TDEM Applied to Hydrogeological Study in Taubaté Basin, Brazil. International Journal of Geosciences, 9, p 119-130.

Riccomini, C. 1989. O rift continental do sudeste do Brasil. Tese de Doutorado, Instituto de Geociências, USP.

SIAGAS - CPRM. CPRM - Serviço Geológicos Brasileiro; SIAGAS - Sistema de Informações de Águas Subterrâneas. Disponível em: < http://siagasweb.cprm.gov.br/lay out/pesquisa_complexa.php>. Acessado em 30 de janeiro de 2018.

Singhal, B. B. S., Gupta, R. P. 2010. Applied hydrogeology of fractured rocks. Springer, $2^{2}$ edição.

Souza Filho, M. N., Pereira, S. Y., Barbuena, D., 2012. Potencial geotérmico da bacia sedimentar de Taubaté baseados em dados de perfilagem geofísica em poços. Águas Subterrâneas, 27(1): 37-52

Sørensen, K. I., Auken, E., Thomsen, P., 2000. TDEM in groundwater mapping - a continuous approach. Proceedings of the symposium on the application of geophysics to engineering and enrironmental problems. Virginia, p 485-491

Spies, B. R., 1989. Depth investigation in electromagnetic sounding methods. Geophysics, v.54, ำ 7, 872-888

Telford, W., Geldart, L., Sheriff, R., and Keys, D., 1976. Applied Geophysics, Cambridge University Press, New York.

Telford, W.M., Geldart, L.P., Sheriff, R.E., 1990. Applied Geophysics, Cambridge University Press, 2 a edição. 
Vidal, A.; Fernandes, F. L.; Chang, H. K., 2004 Distribuição dos arenitos na Bacia de Taubaté. São Paulo. Geociências UNESP, v.23, n1/2, p. 55-66.

Zohdy, A. A. R., 1969. The use of Schlumberger and Equatorial soundings in groundwater investigations near El Paso, Texas. Geophysics, no 5, p713-728. 


\section{Apêndice A: Inversões individuais dos dados TDEM dentro do Loop vermelho (Área-1)}
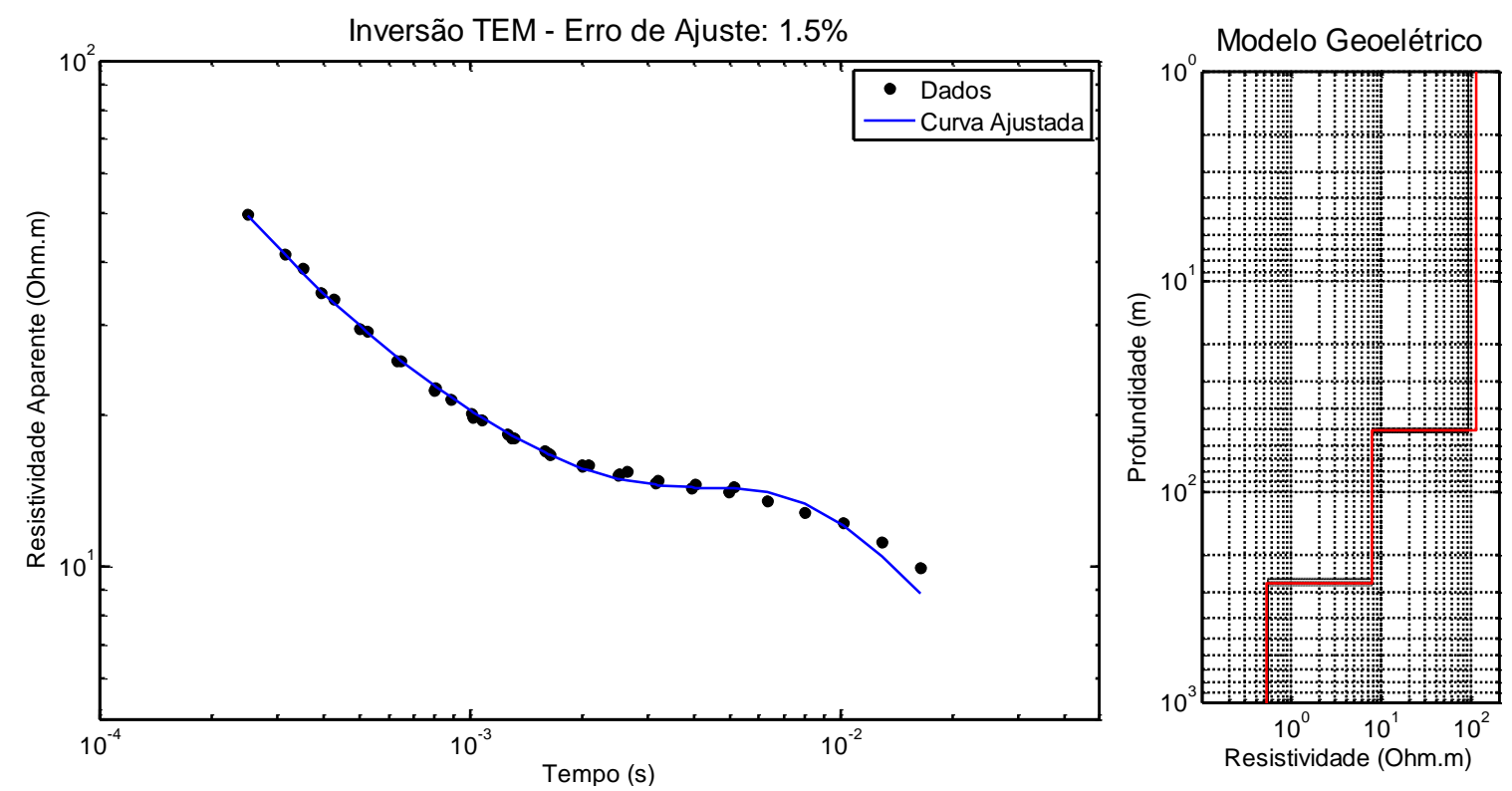

Figura A 1: Inversão individual TDEM da sondagem TEM22 e modelo geoelétrico associado.
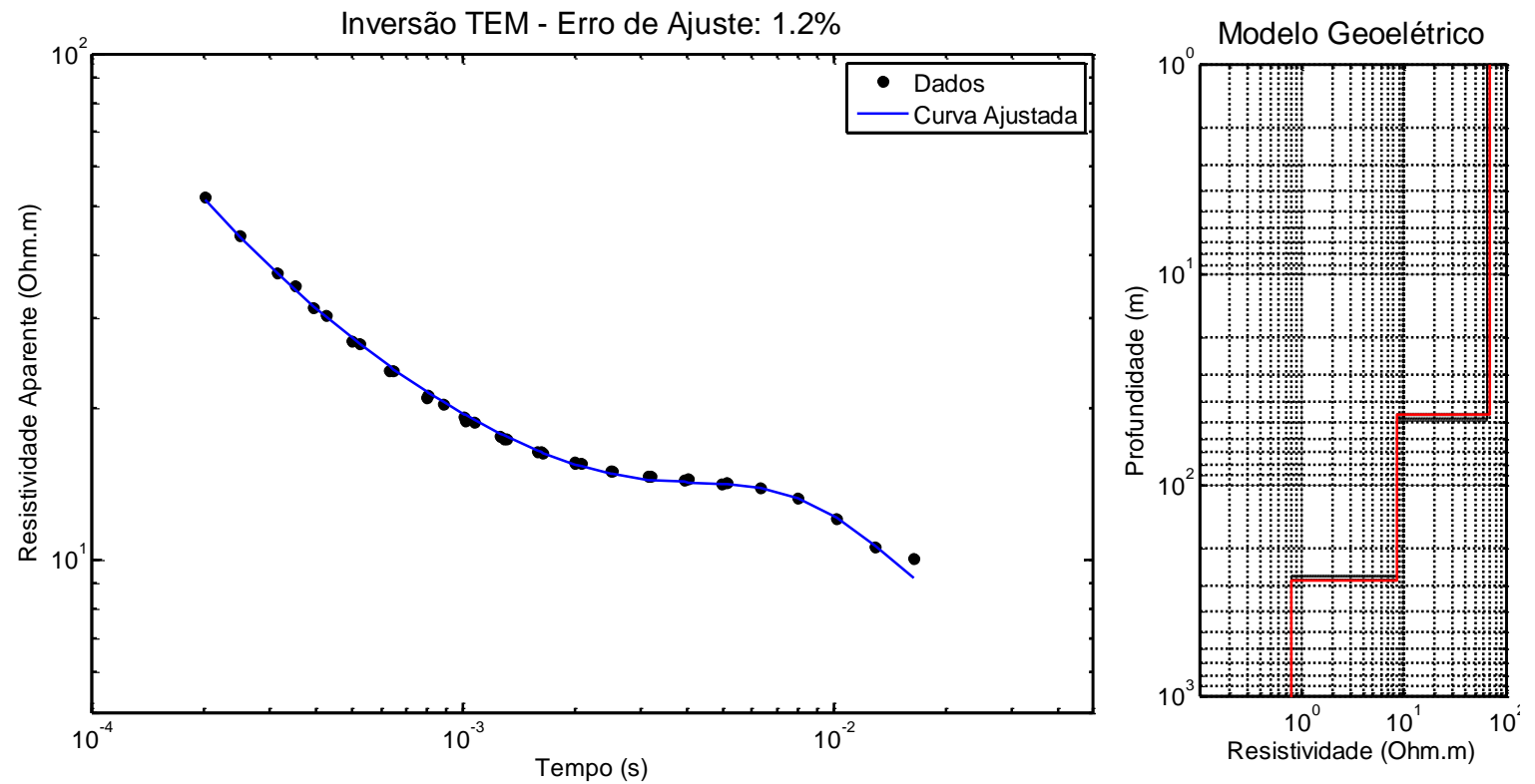

Figura A 2: Inversão individual TDEM da sondagem TEM11 e o modelo geoelétrico associado. 

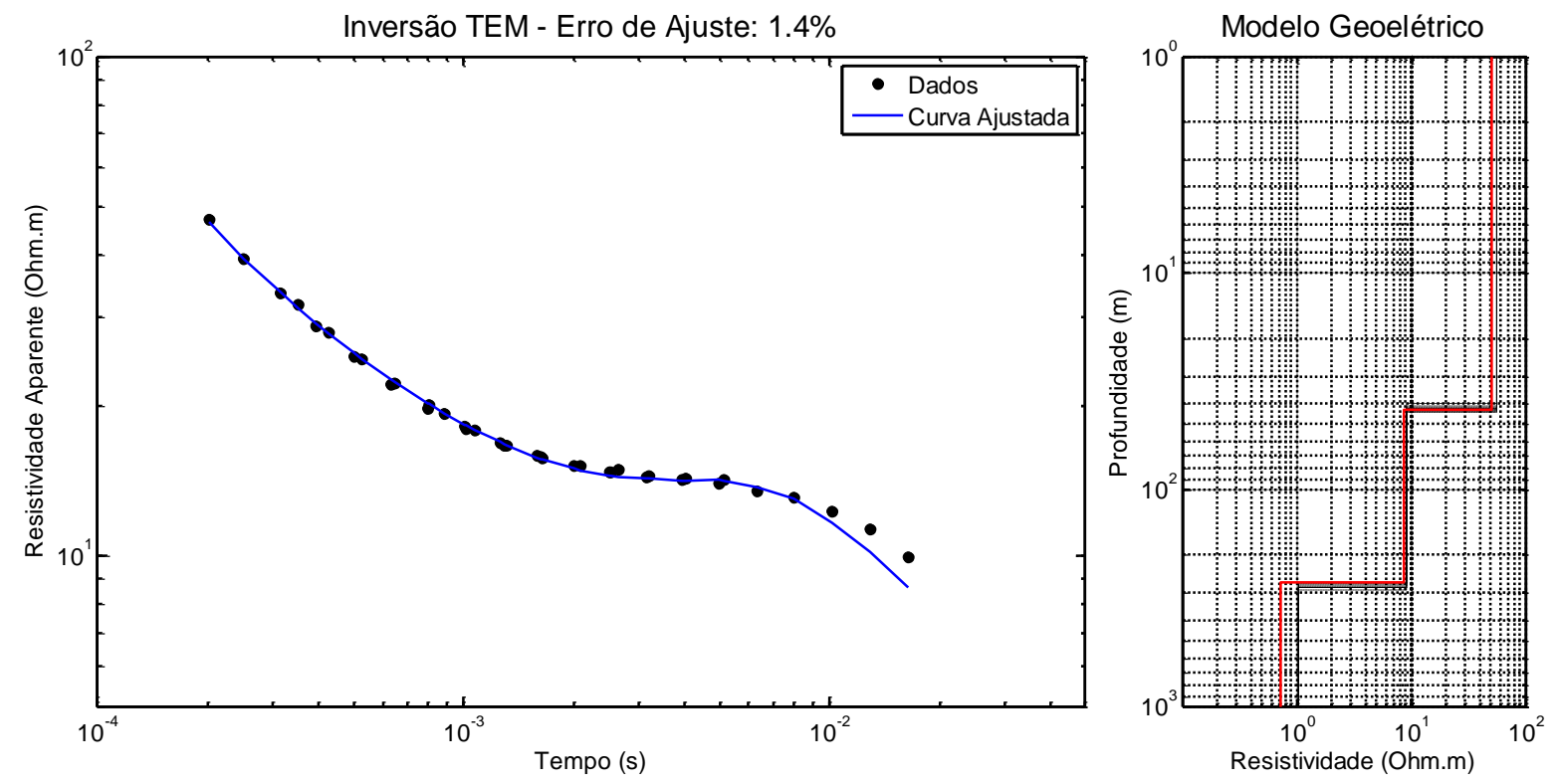

Figura A 3: Inversão individual TDEM da sondagem TEM23 o modelo geoelétrico associado.
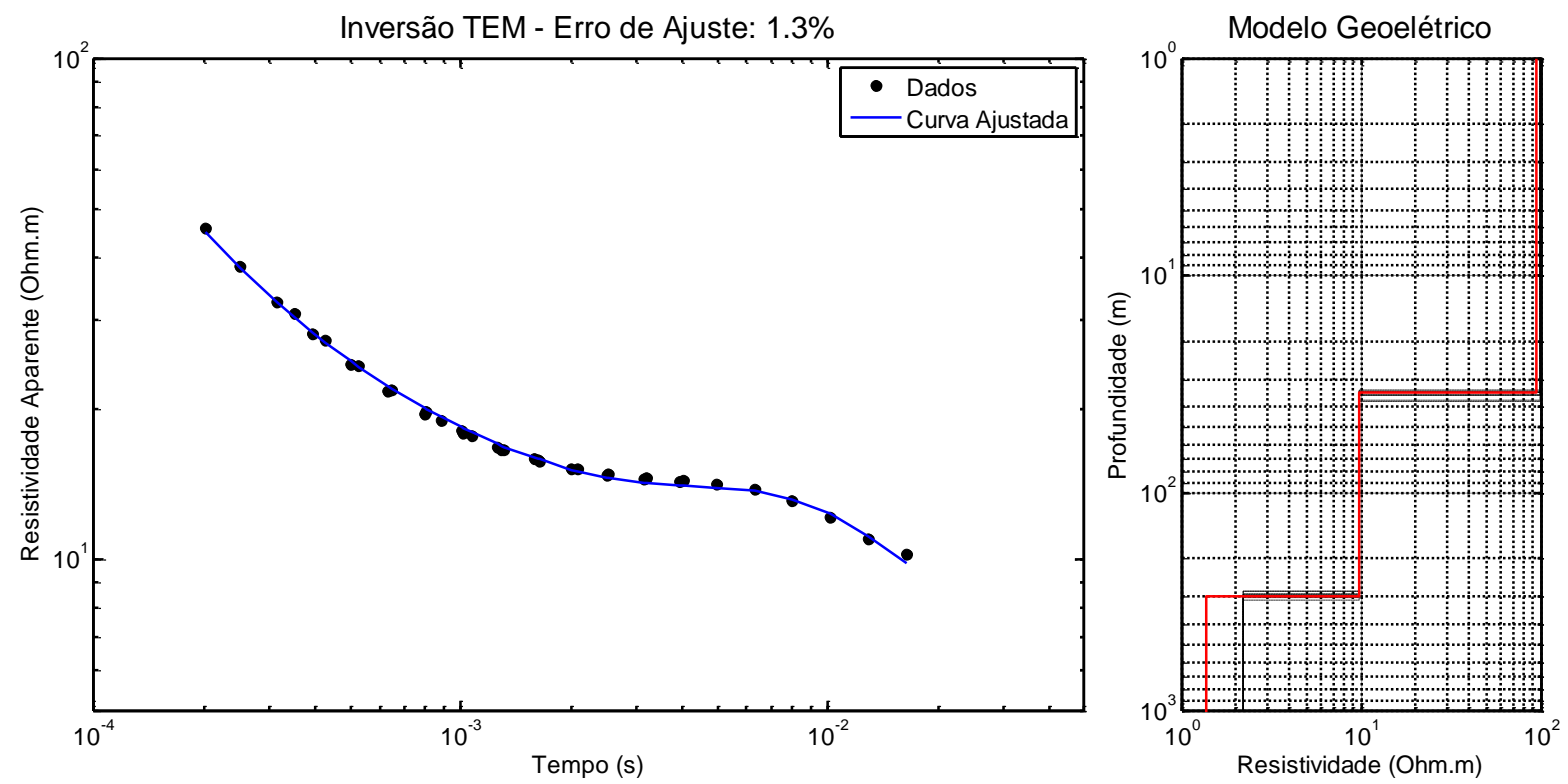

Figura A 4: Inversão individual TDEM da sondagem TEM24 e o modelo geoelétrico associado. 

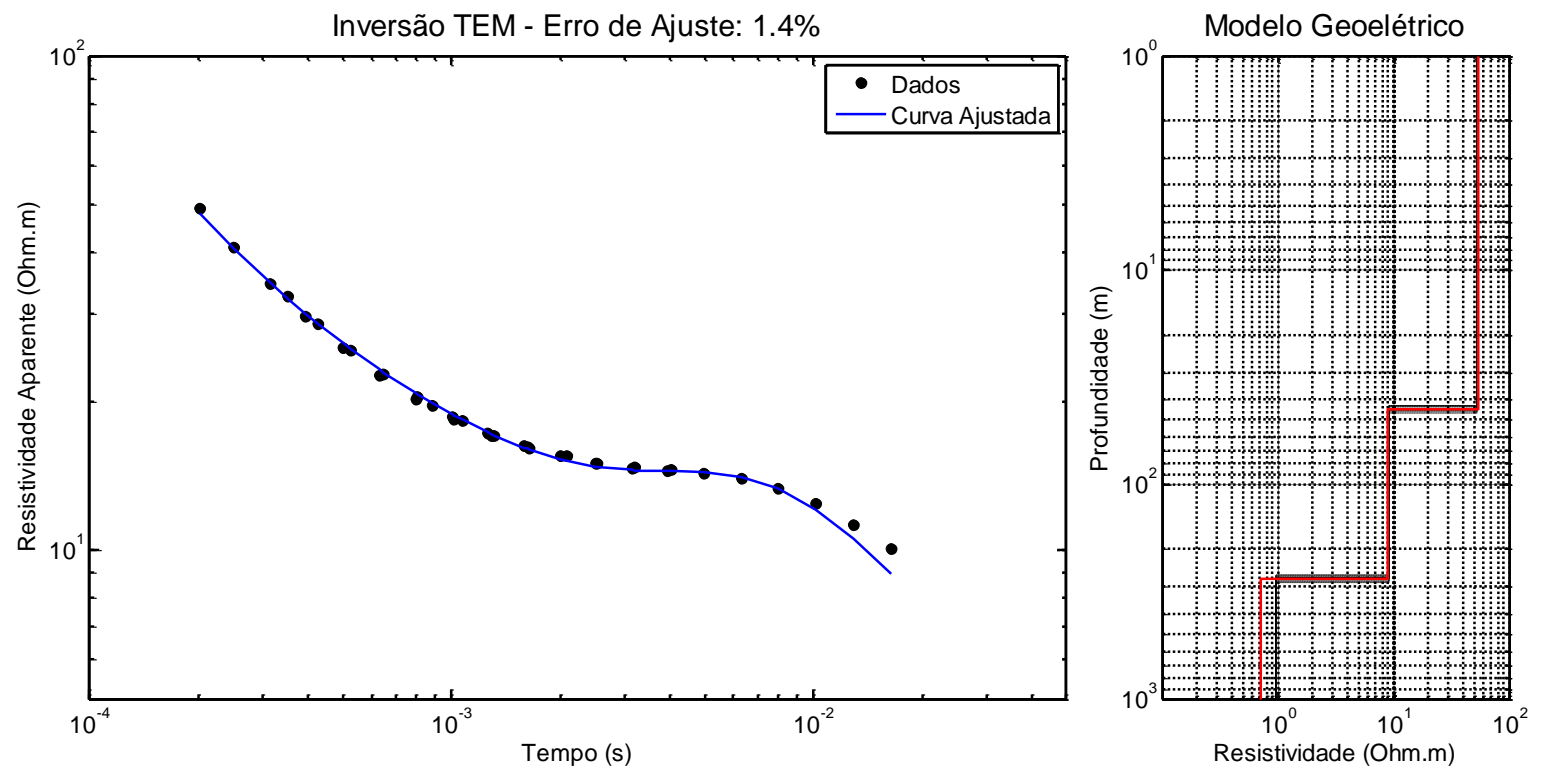

Figura A 5: Inversão individual TDEM da sondagem TEM18 e o modelo geoelétrico associado.
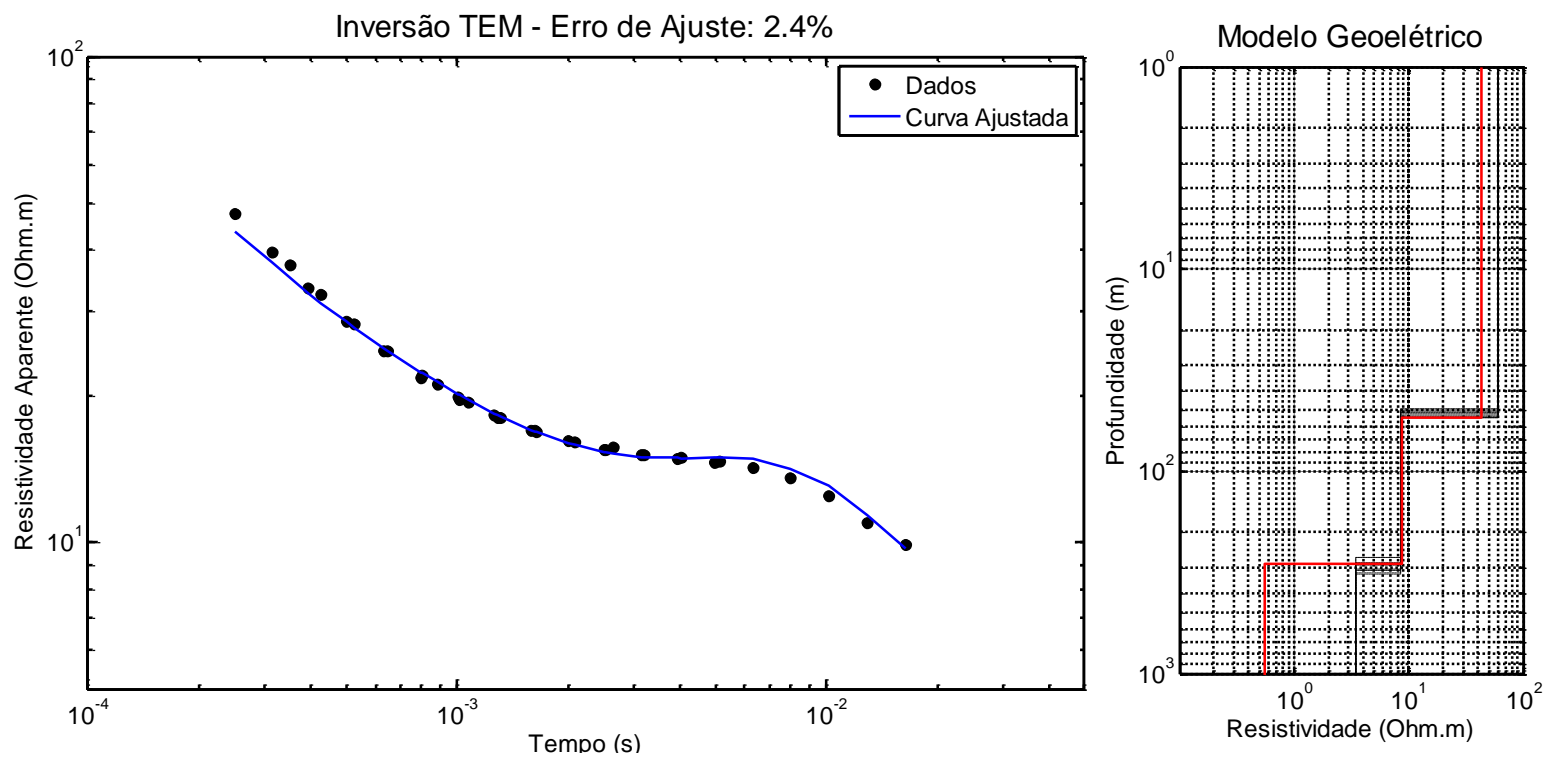

Figura A 6: Inversão individual TDEM da sondagem TEM25 e o modelo geoelétrico associado. 

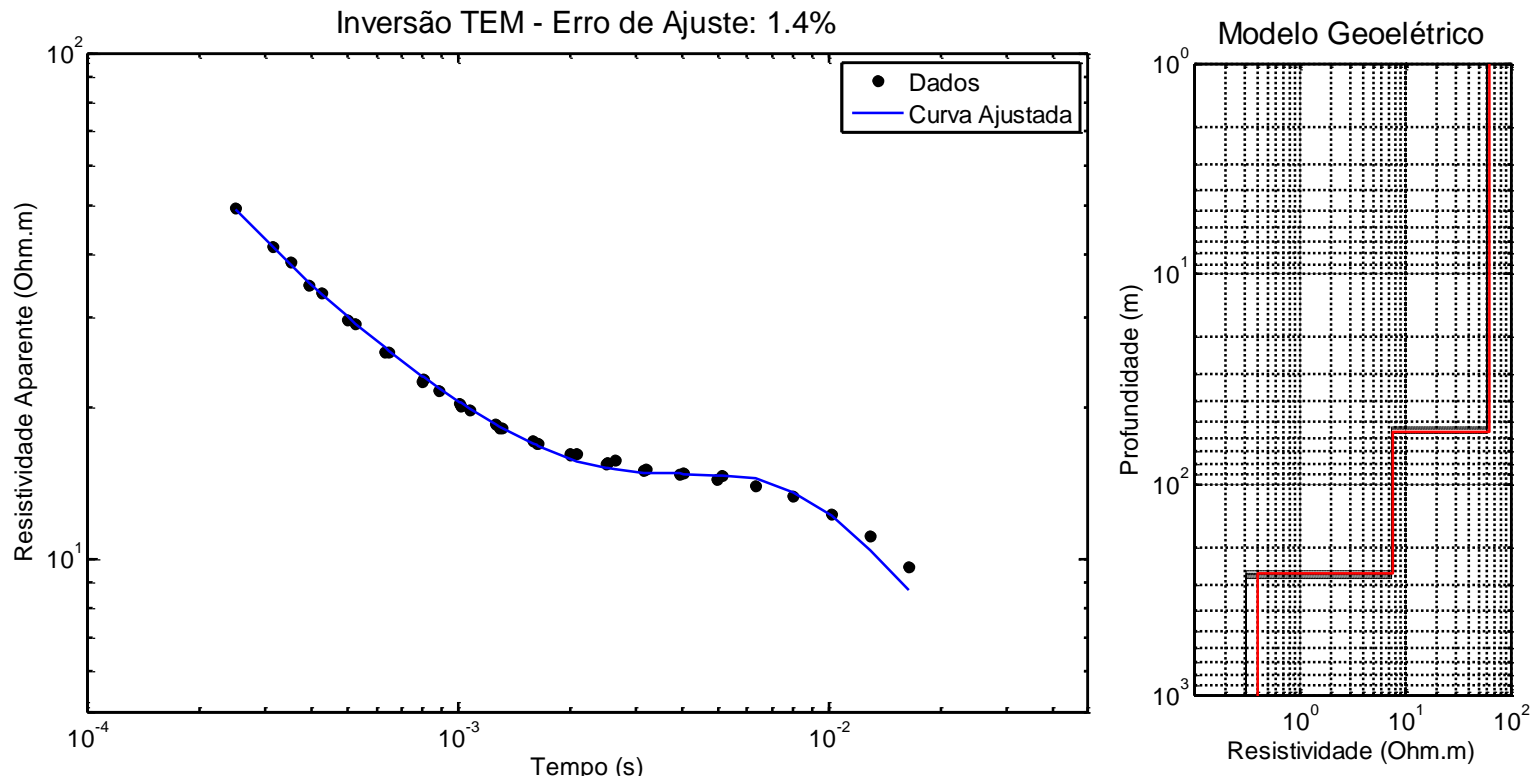

Figura A 7: Inversão individual TDEM da sondagem TEM01 e o modelo geoelétrico associado.
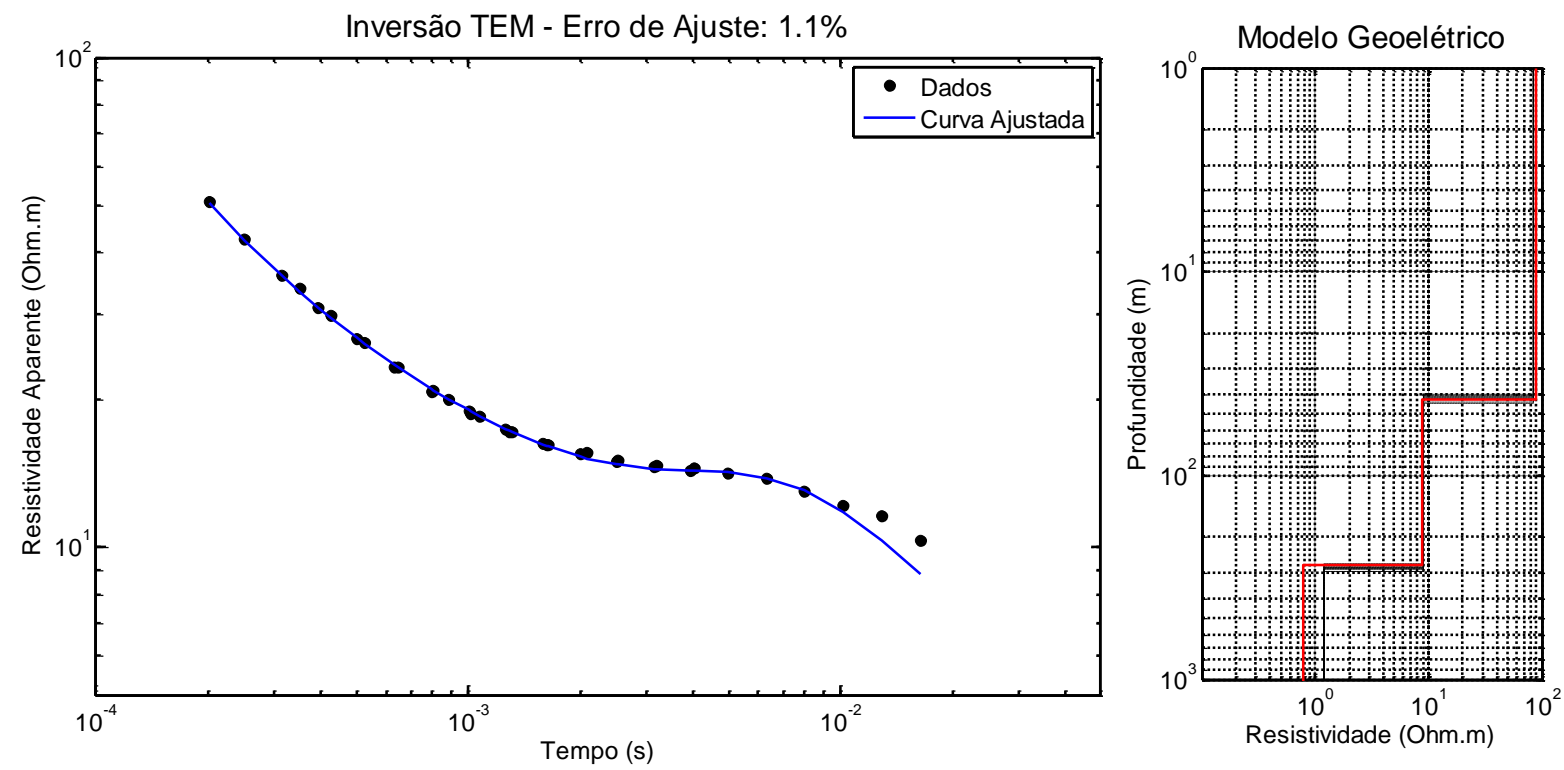

Figura A 8: Inversão individual TDEM da sondagem TEM02 e o modelo geoelétrico associado. 

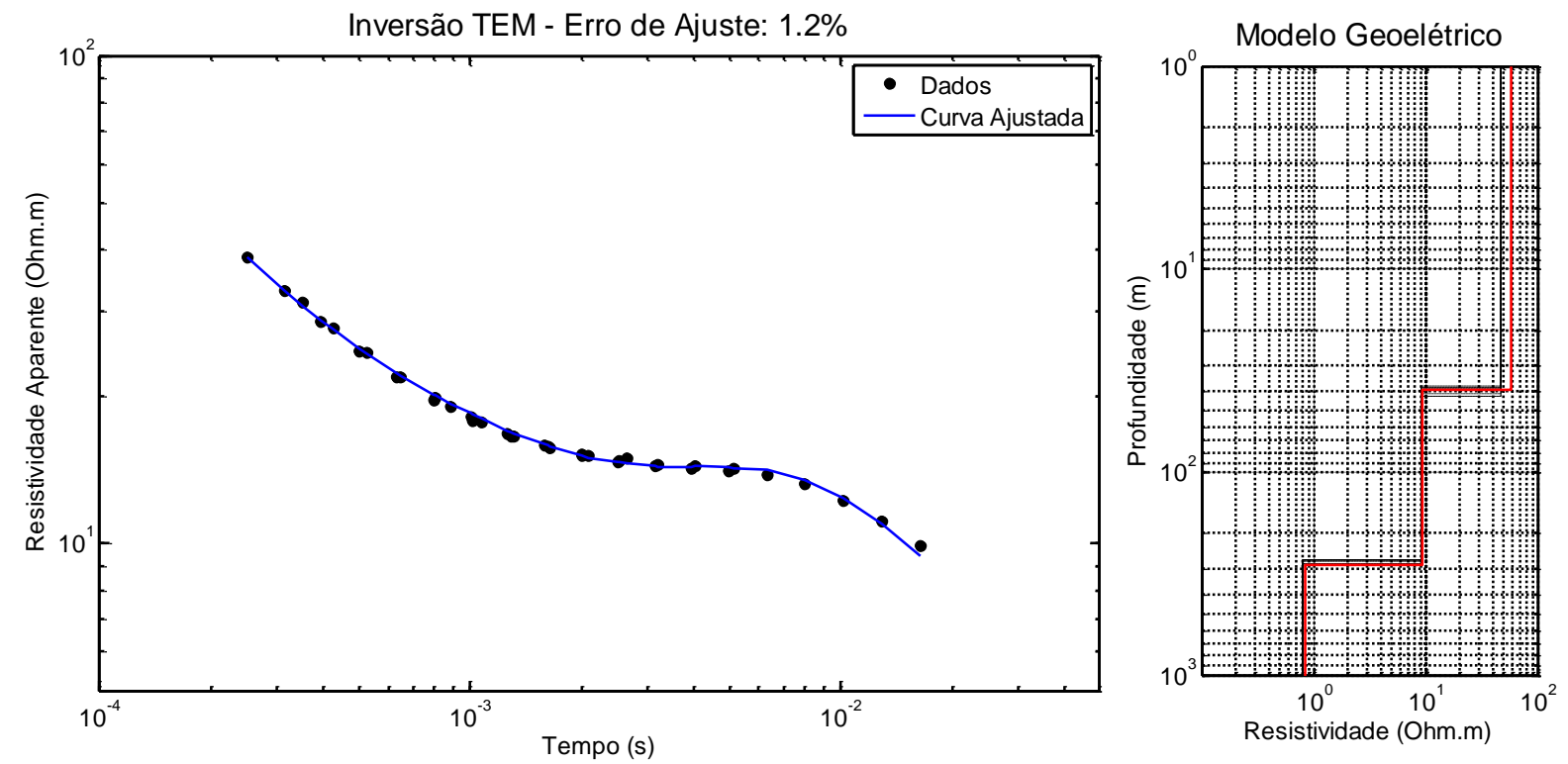

Figura A 9: Inversão individual TDEM da sondagem TEM03 e o modelo geoelétrico associado.
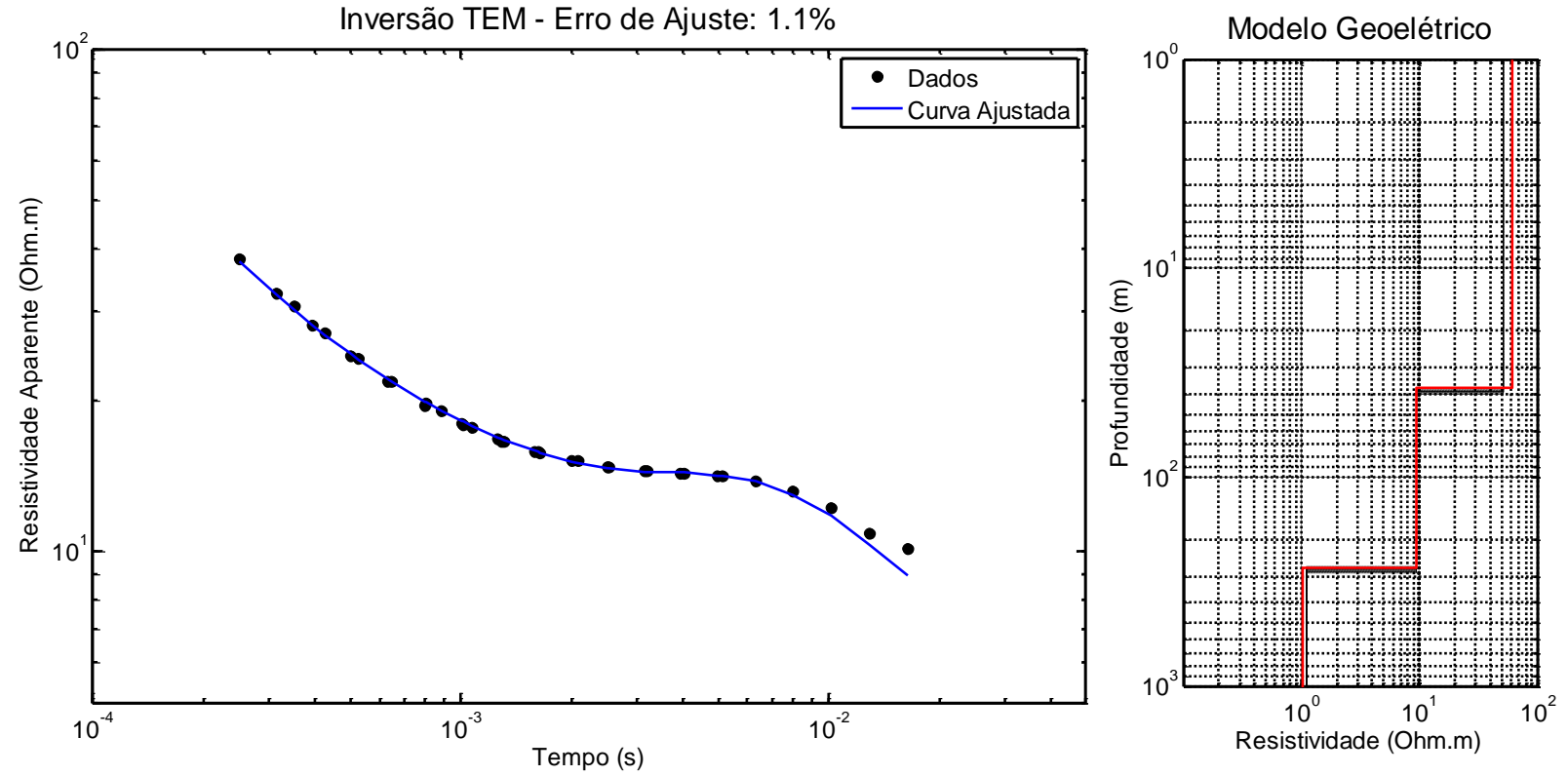

Figura A 10: Inversão individual TDEM da sondagem TEM05 e o modelo geoelétrico associado. 

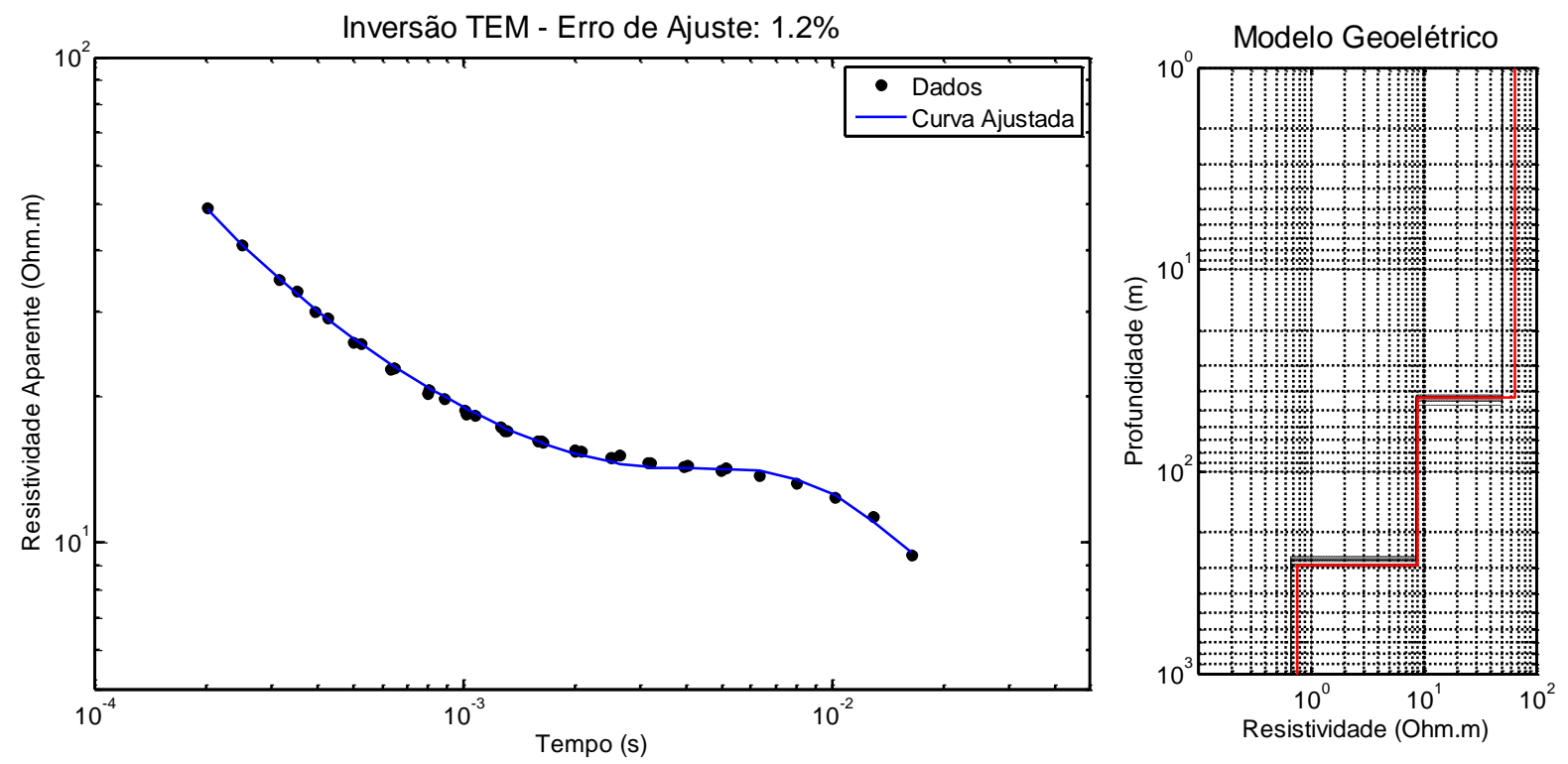

Figura A 11: Inversão individual TDEM da sondagem TEM06 e o modelo geoelétrico associado.
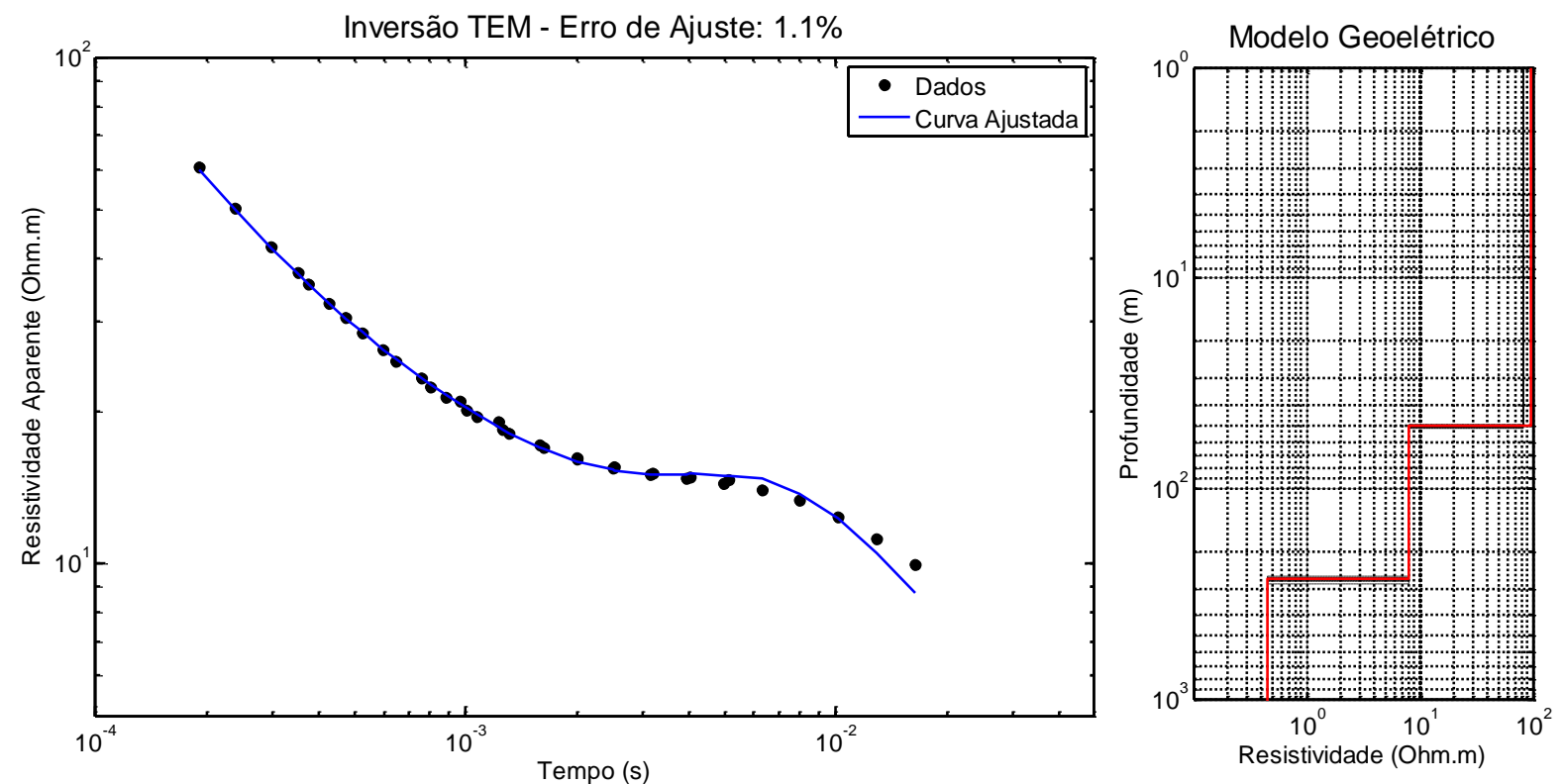

Figura A 12: Inversão individual TDEM da sondagem TEM07 e o modelo geoelétrico associado. 

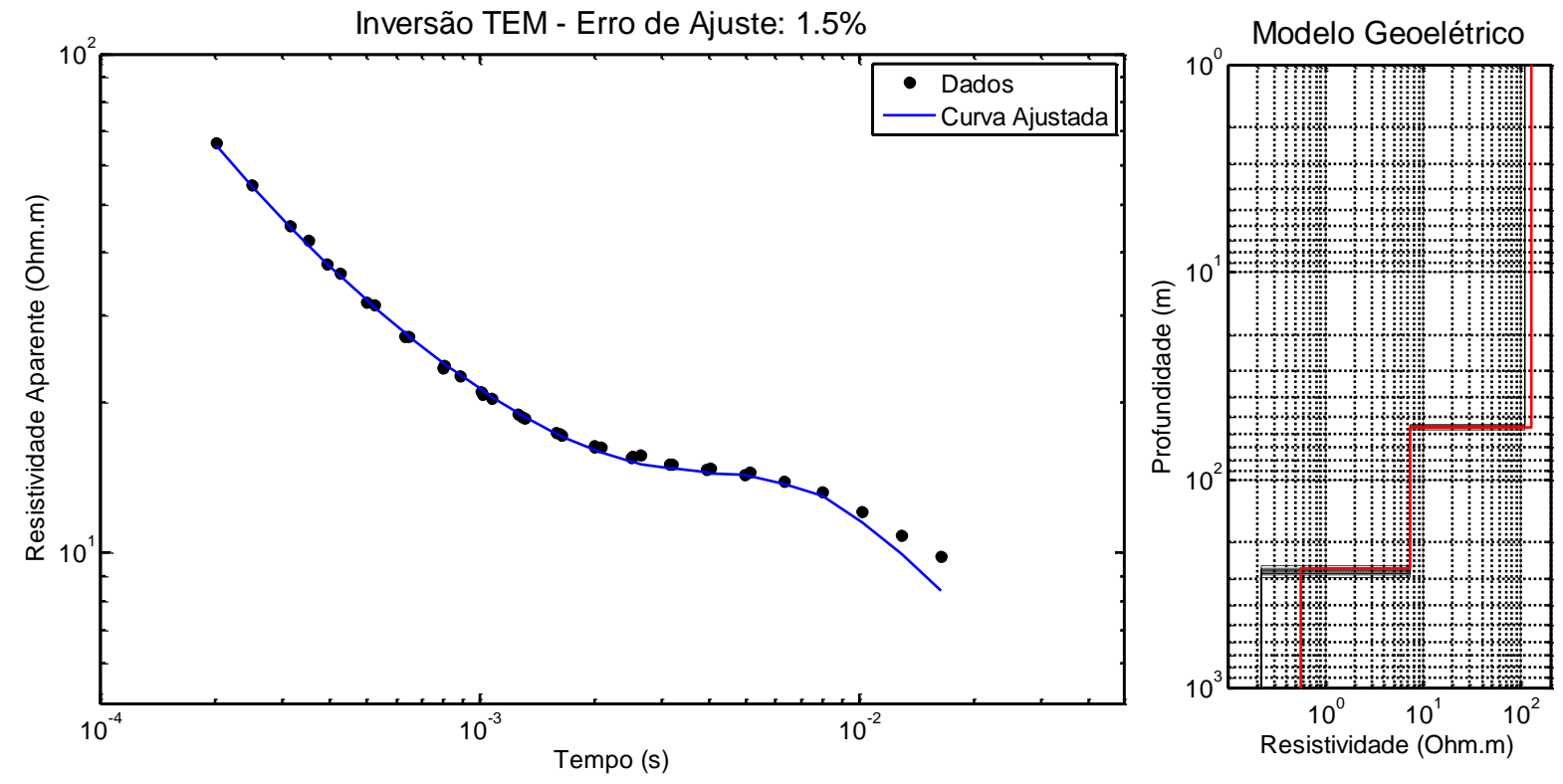

Figura A 13: Inversão individual TDEM da sondagem TEM08 e o modelo geoelétrico associado.
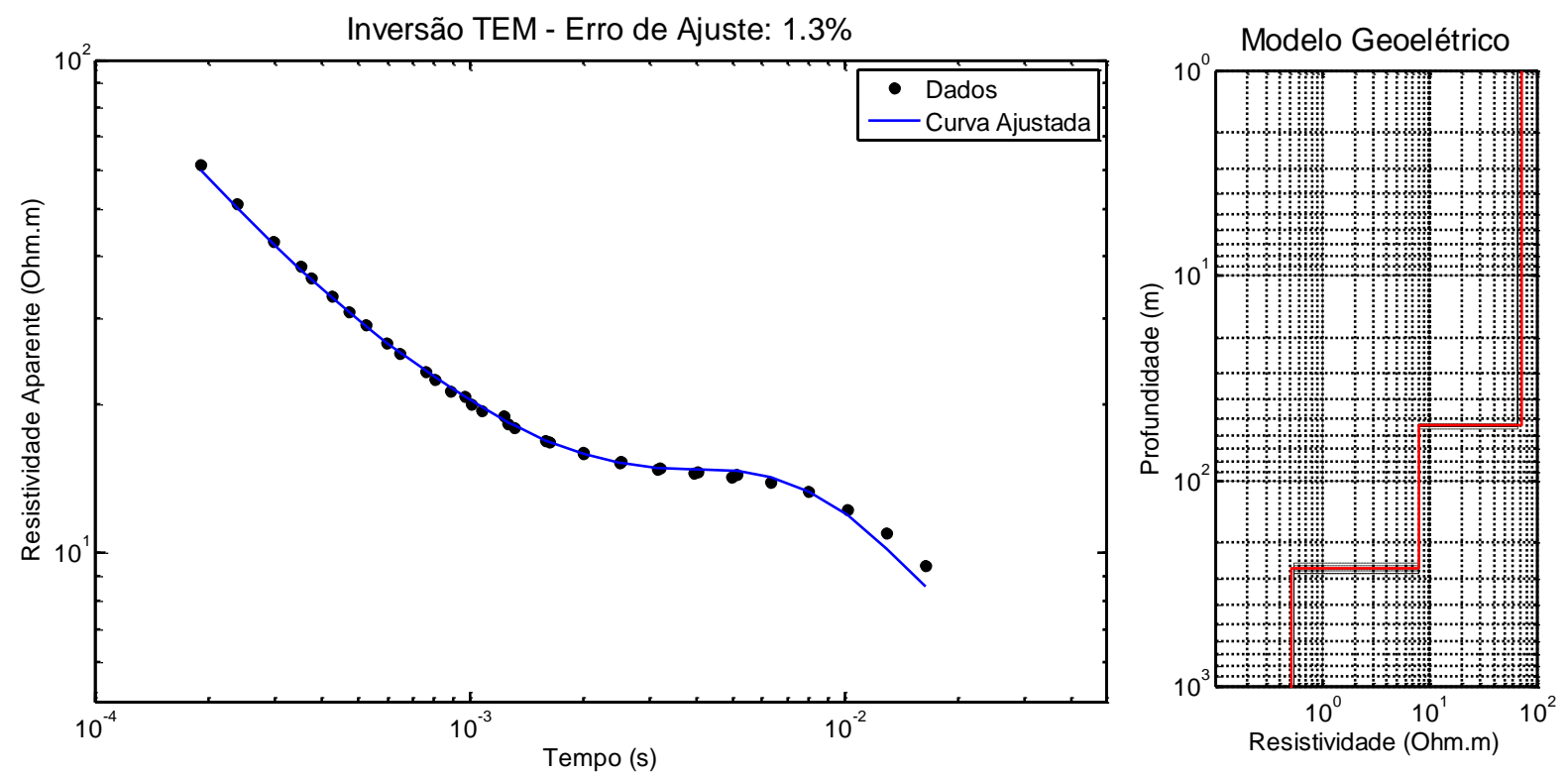

Figura A 14: Inversão individual TDEM da sondagem TEM09 e modelo geoelétrico associado. 

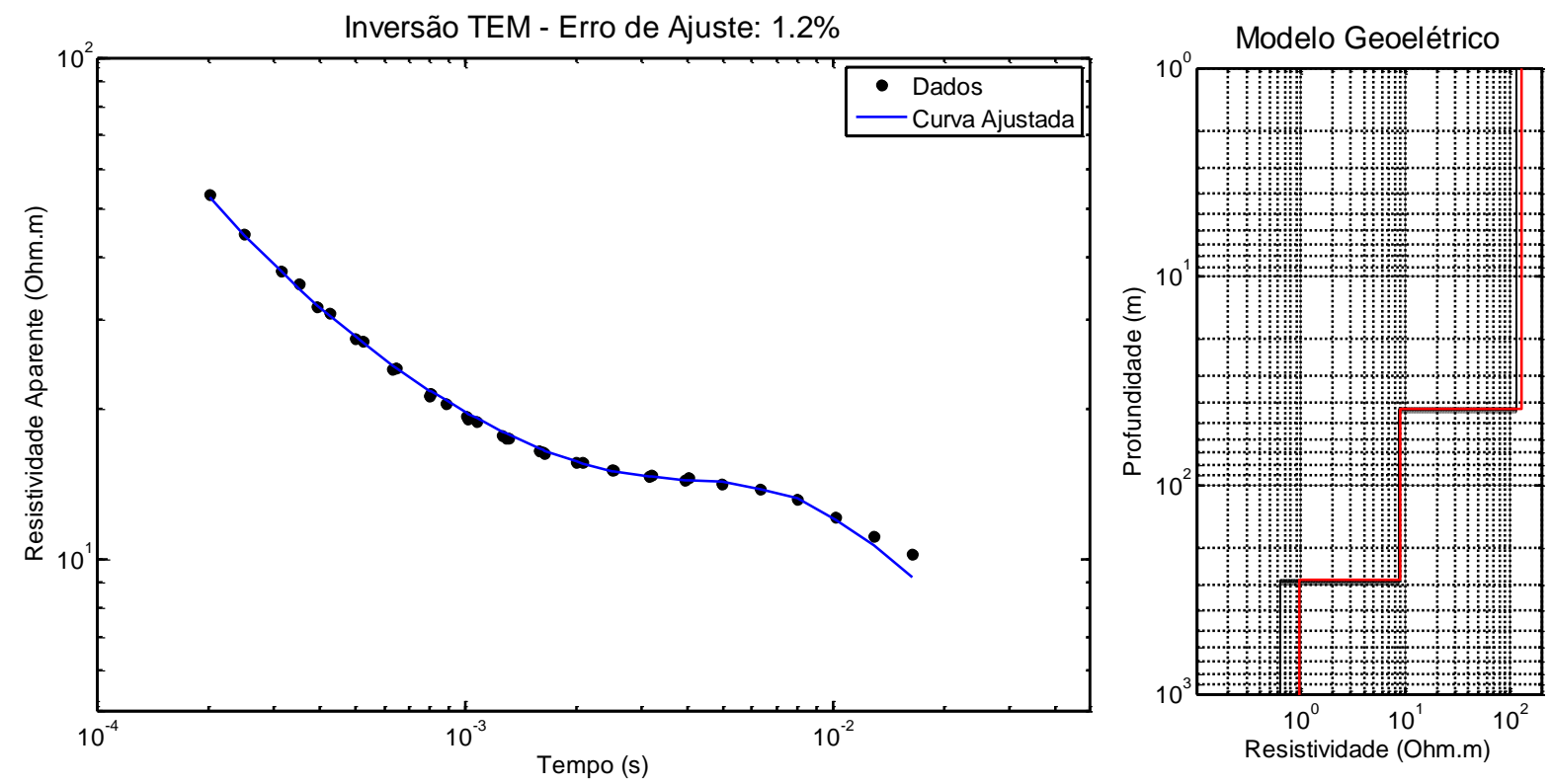

Figura A 15: Inversão individual TDEM da sondagem TEM10 e o modelo geoelétrico associado.
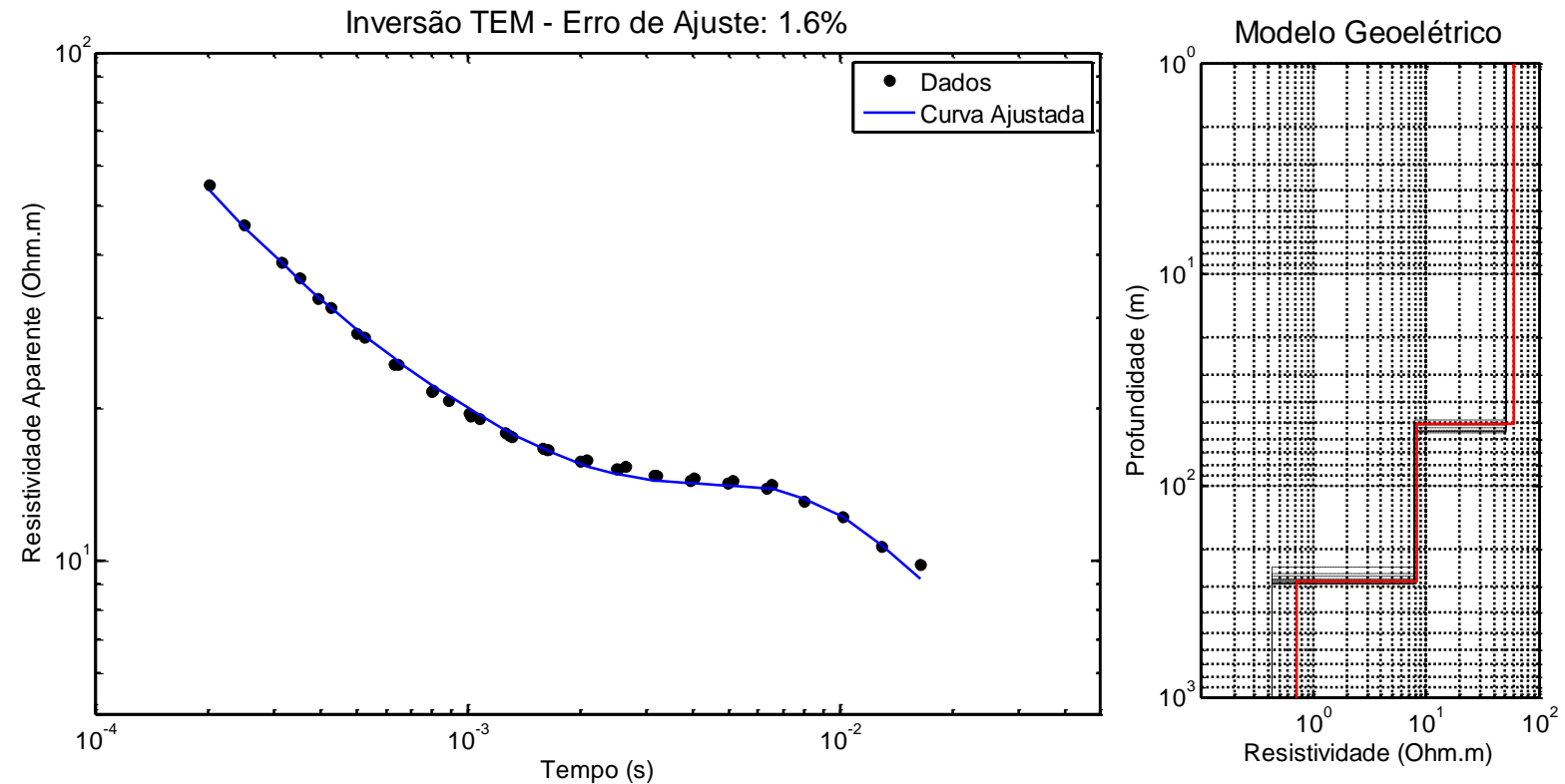

Figura A 16: Inversão individual TDEM da sondagem TEM12 e o modelo geoelétrico associado. 

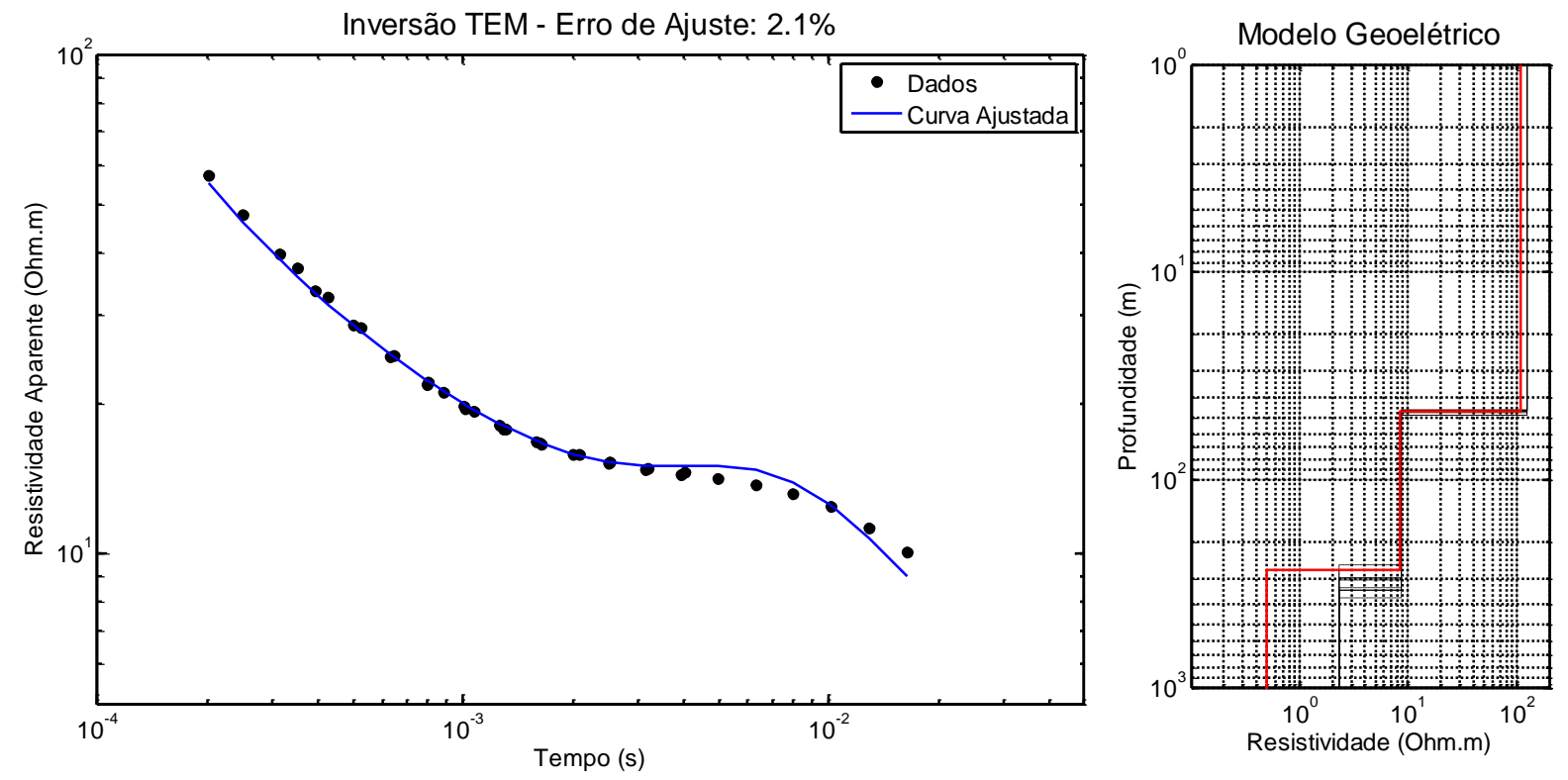

Figura A 17: Inversão individual TDEM da sondagem TEM13 e o modelo geoelétrico associado.
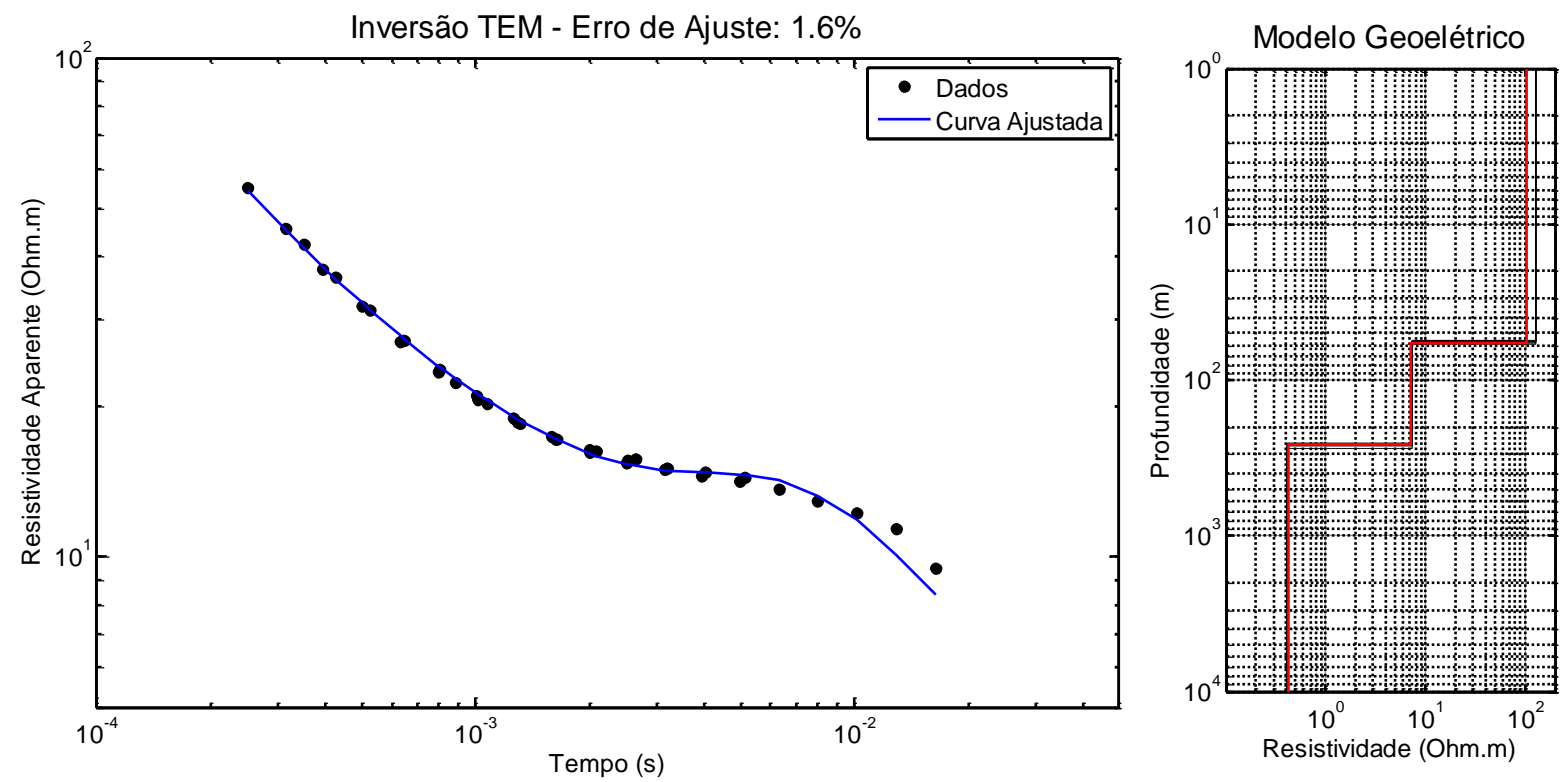

Figura A 18: Inversão individual TDEM da sondagem TEM14 e o modelo geoelétrico associado. 

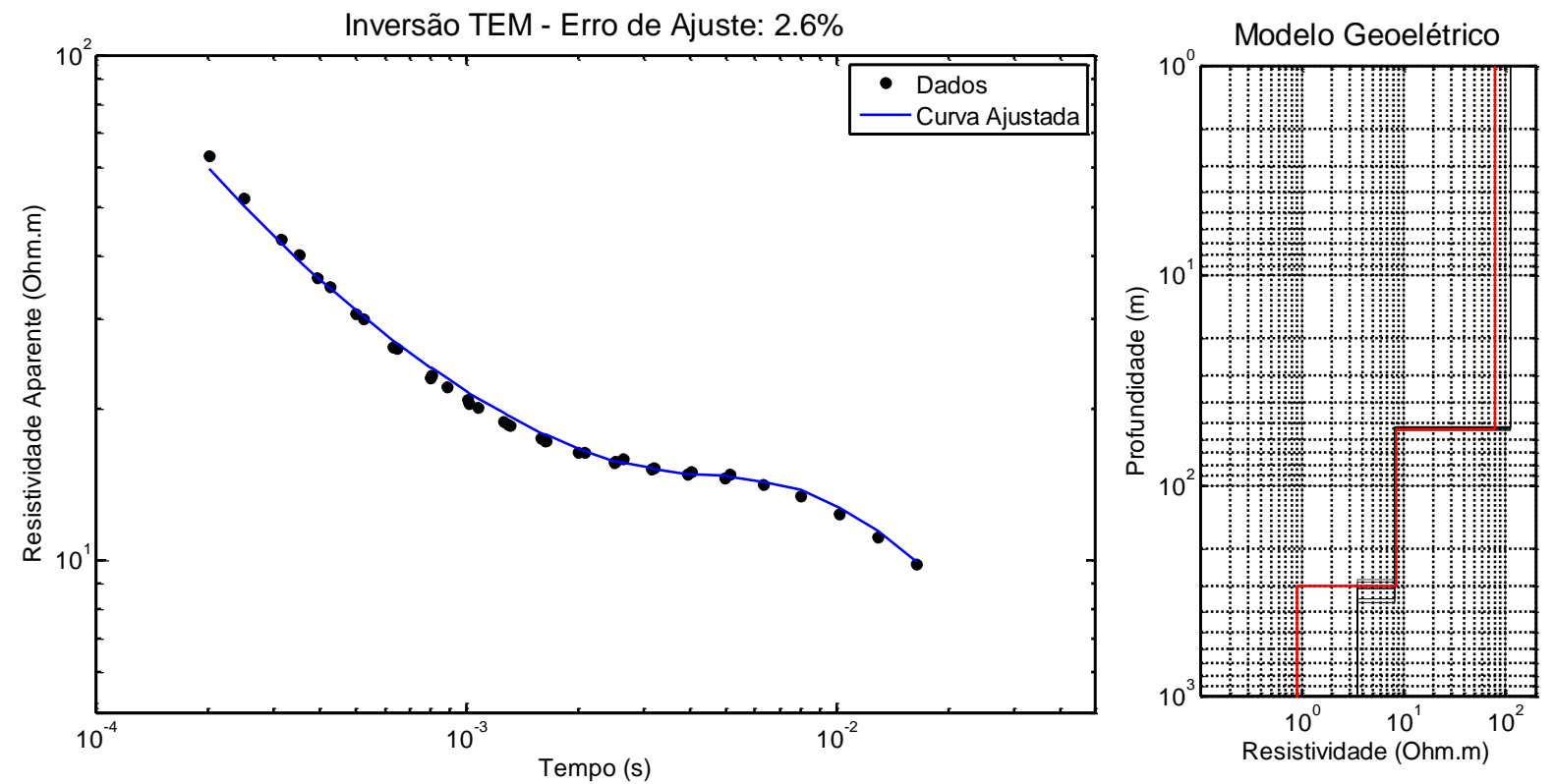

Figura A 19: Inversão individual TDEM da sondagem TEM15 e o modelo geoelétrico associado.
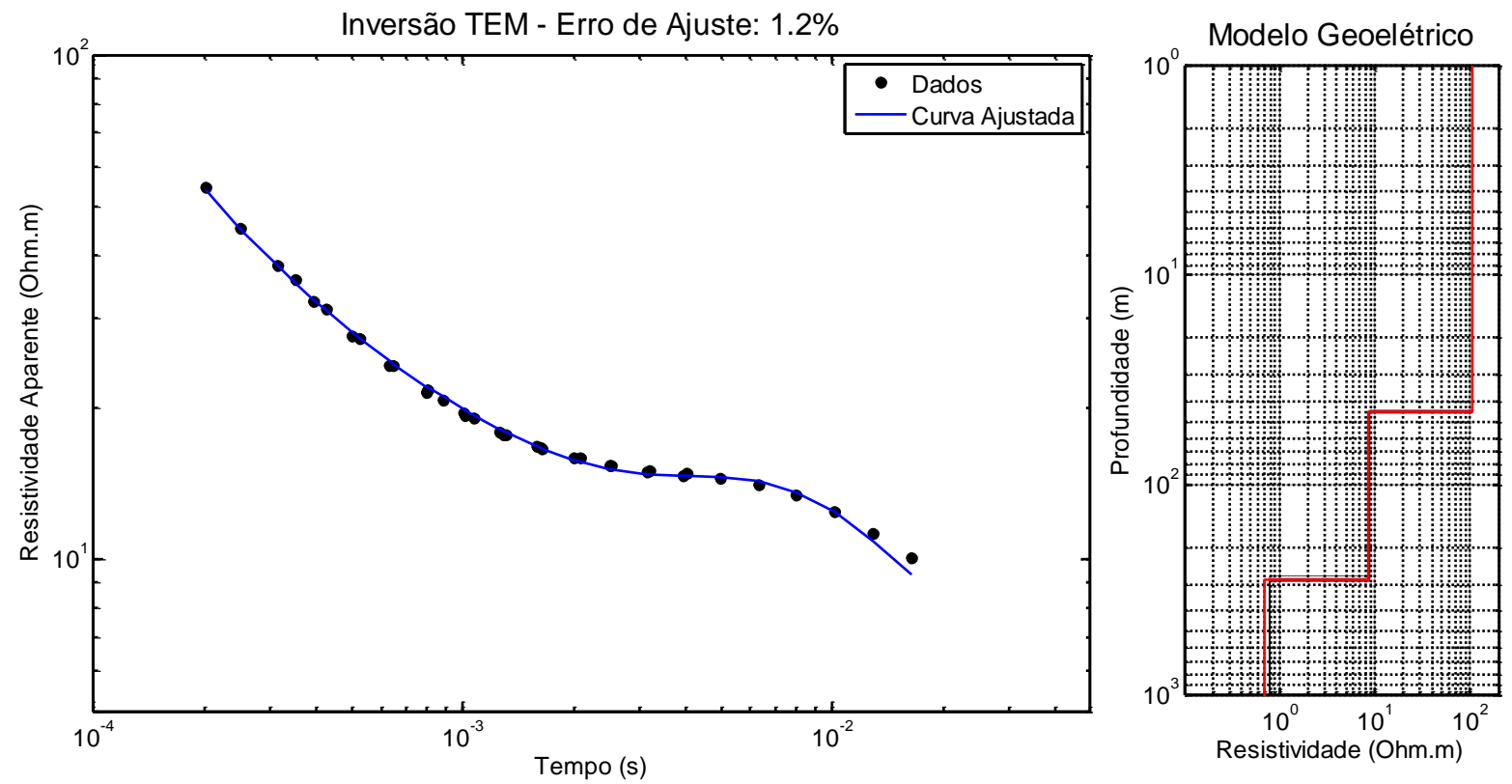

Figura A 20: Inversão individual TDEM da sondagem TEM16 e o modelo geoelétrico associado. 

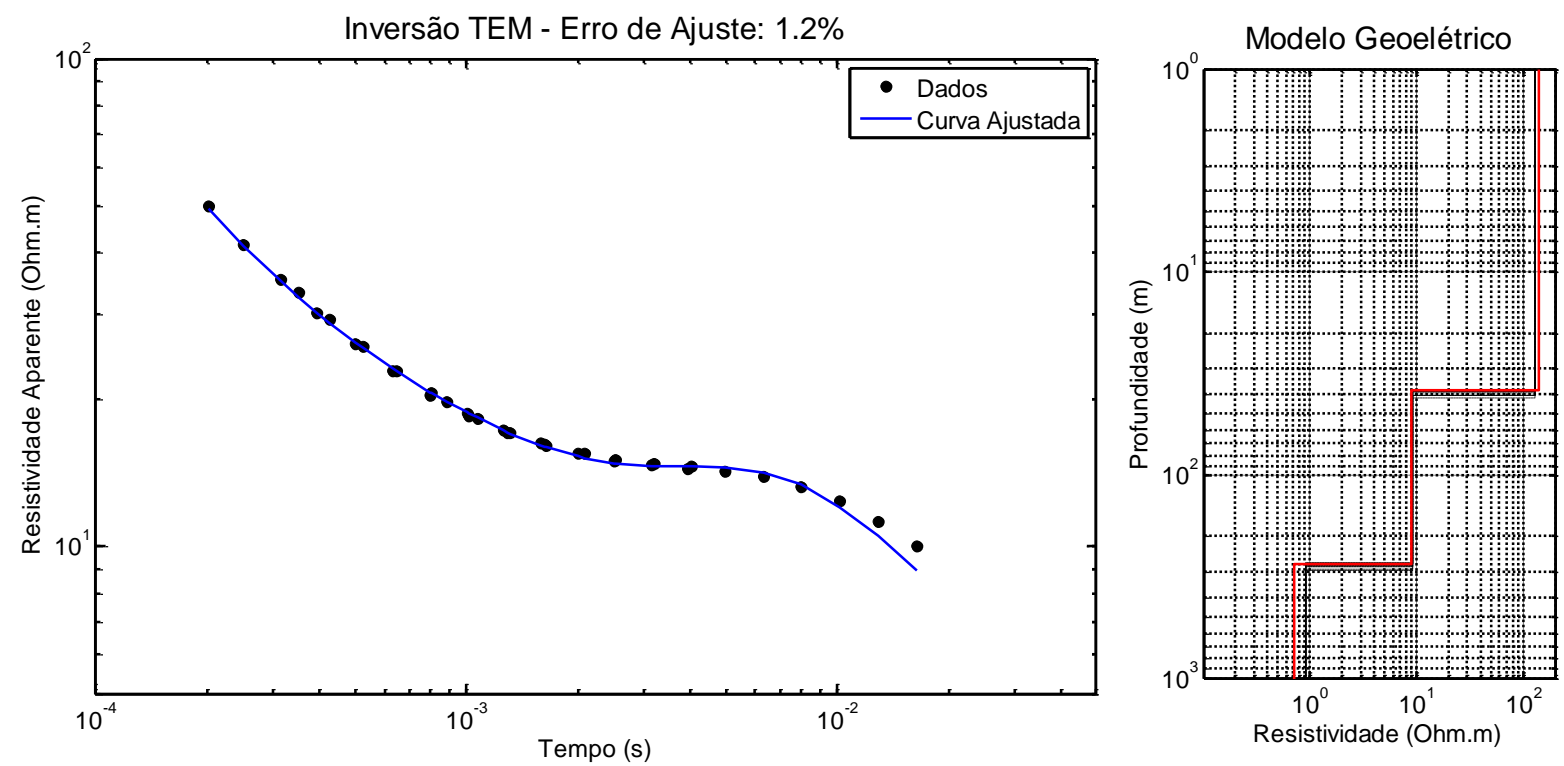

Figura A 21: Inversão individual TDEM da sondagem TEM17 e o modelo geoelétrico associado.
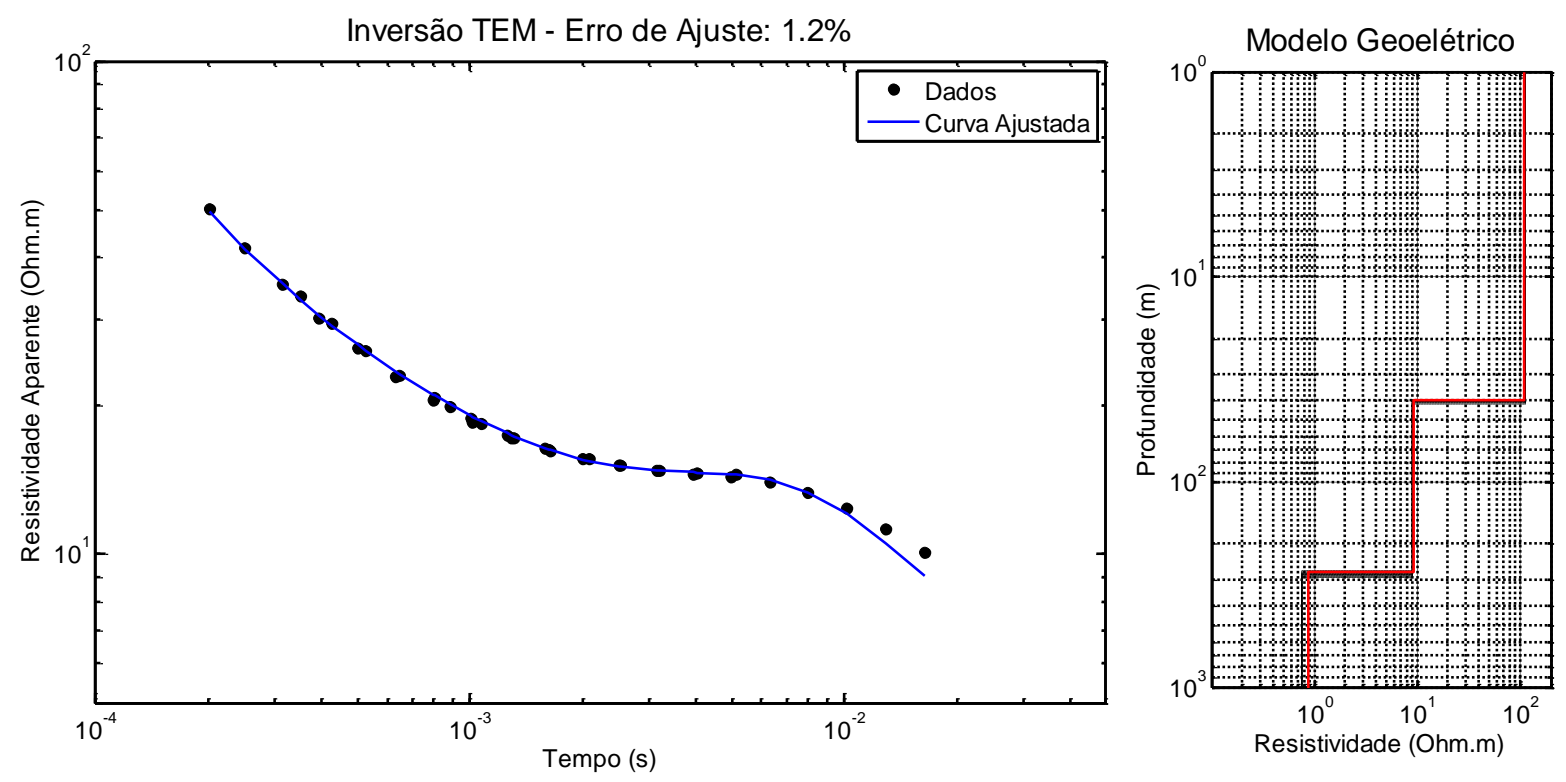

Figura A 22: Inversão individual TDEM da sondagem TEM19 e o modelo geoelétrico associado. 

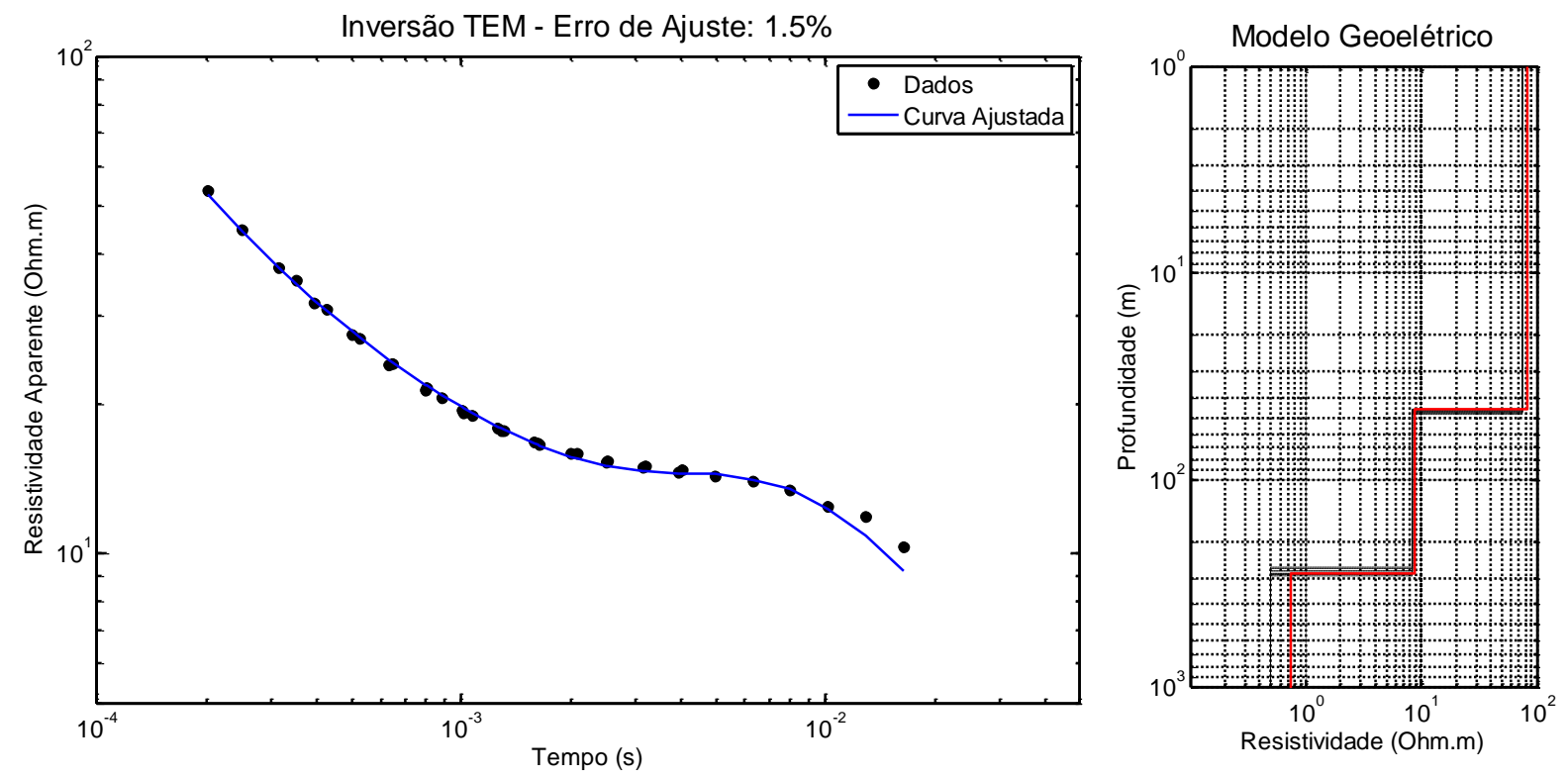

Figura A 23: Inversão individual TDEM da sondagem TEM20 e o modelo geoelétrico associado.
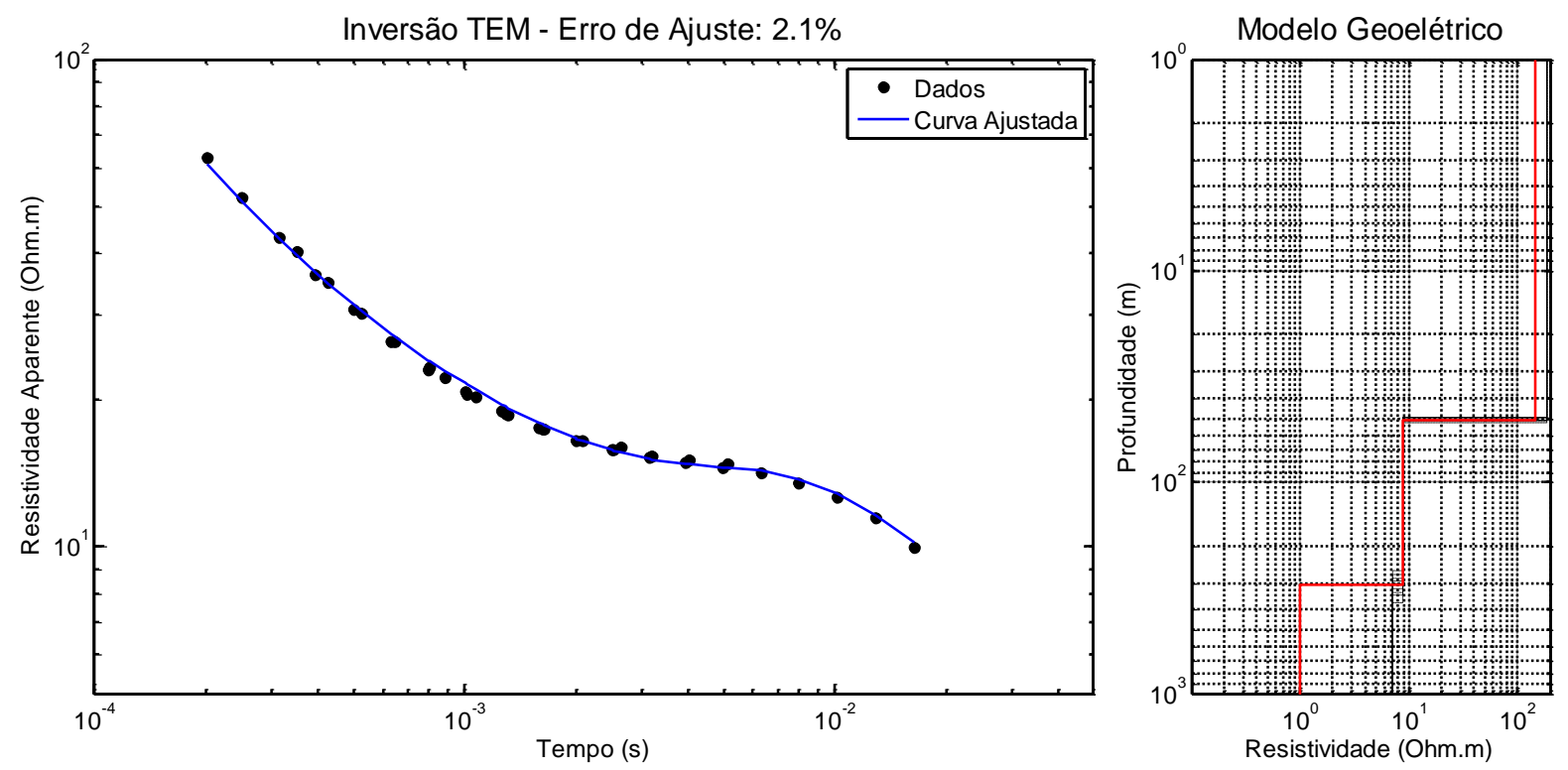

Figura A 24: Inversão individual TDEM da sondagem TEM21 e o modelo geoelétrico associado. 


\section{Apêndice B: Inversões individuais dos dados TDEM dentro do Loop preto (Área-2)}
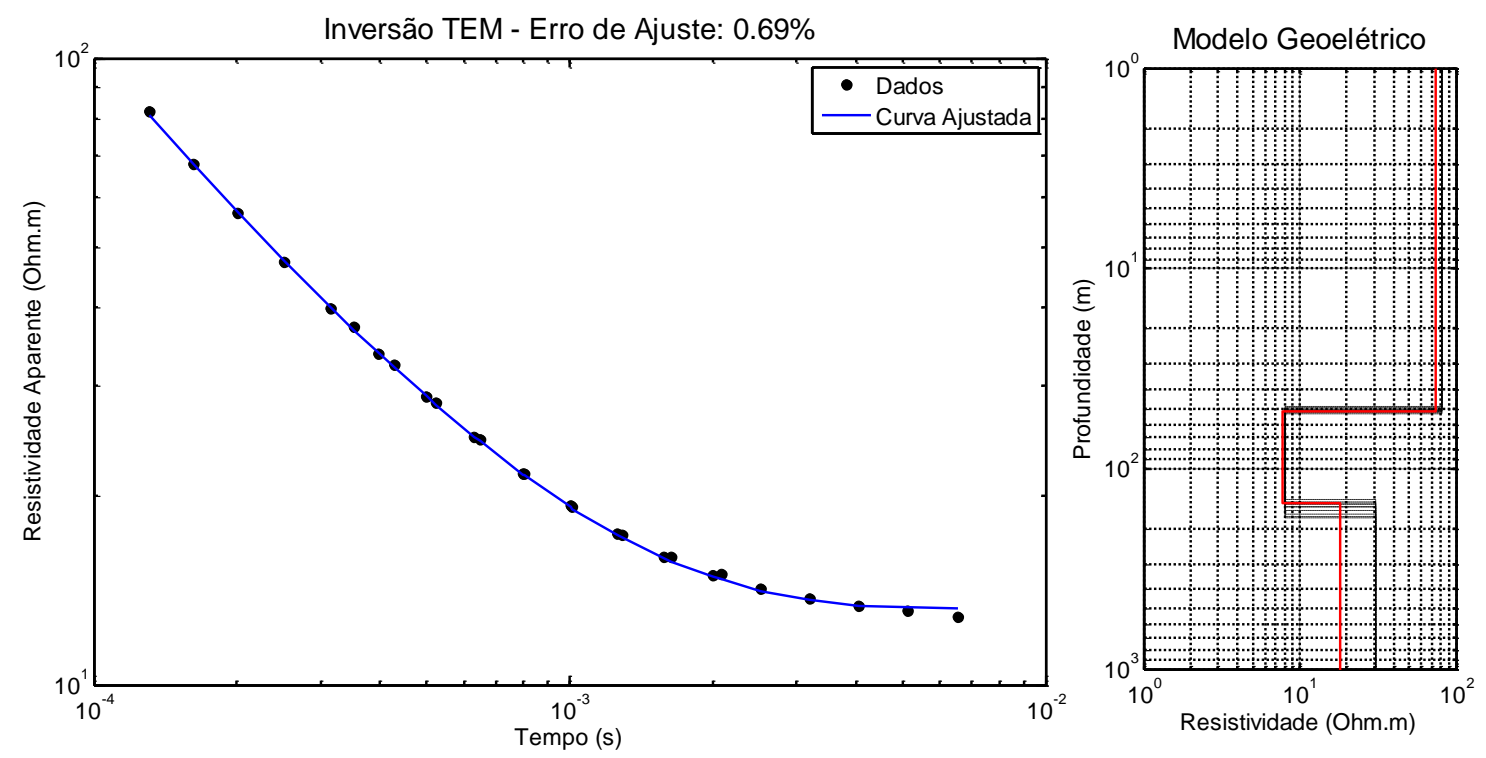

Figura B 1: Inversão individual TDEM da sondagem TEM01 e modelo geoelétrico associado.
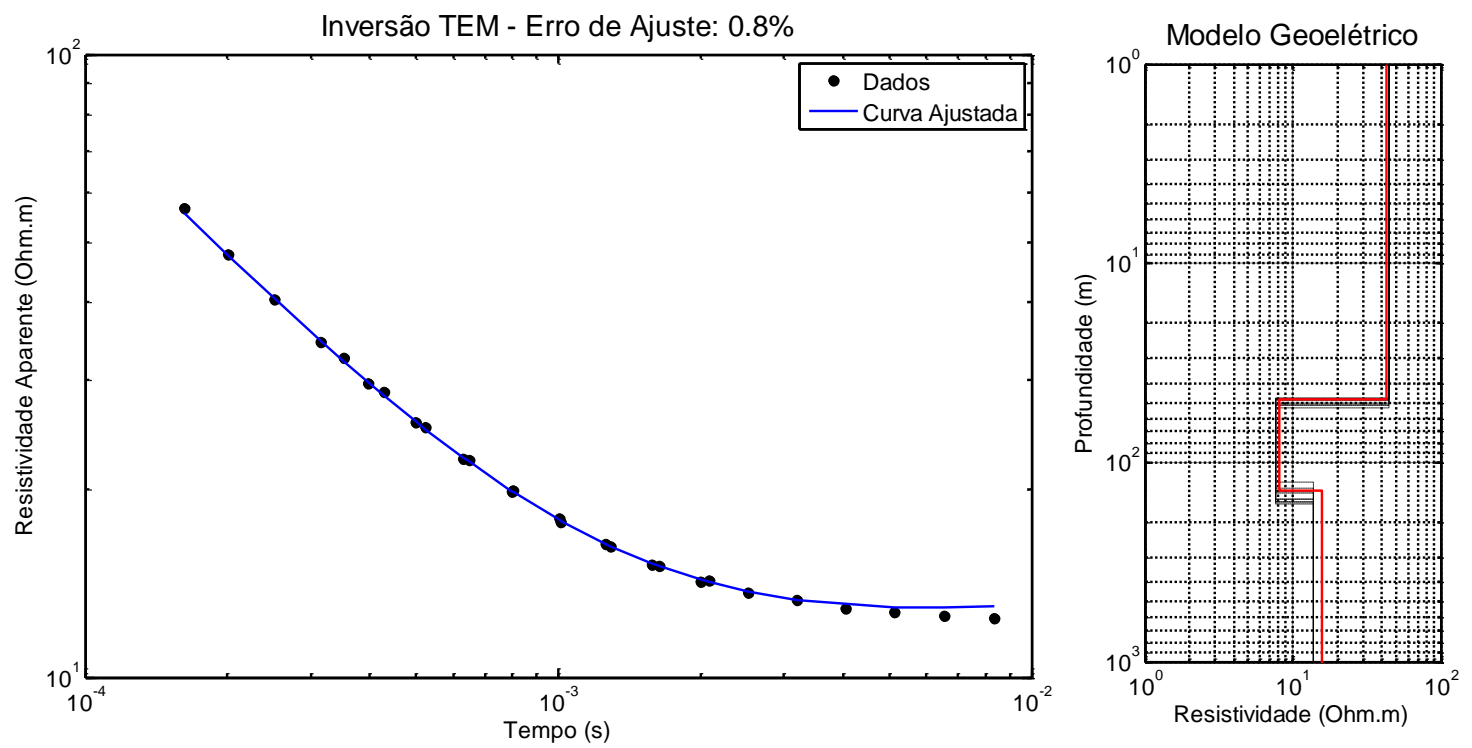

Figura B 2: Inversão individual TDEM da sondagem TEM02 e modelo geoelétrico associado. 

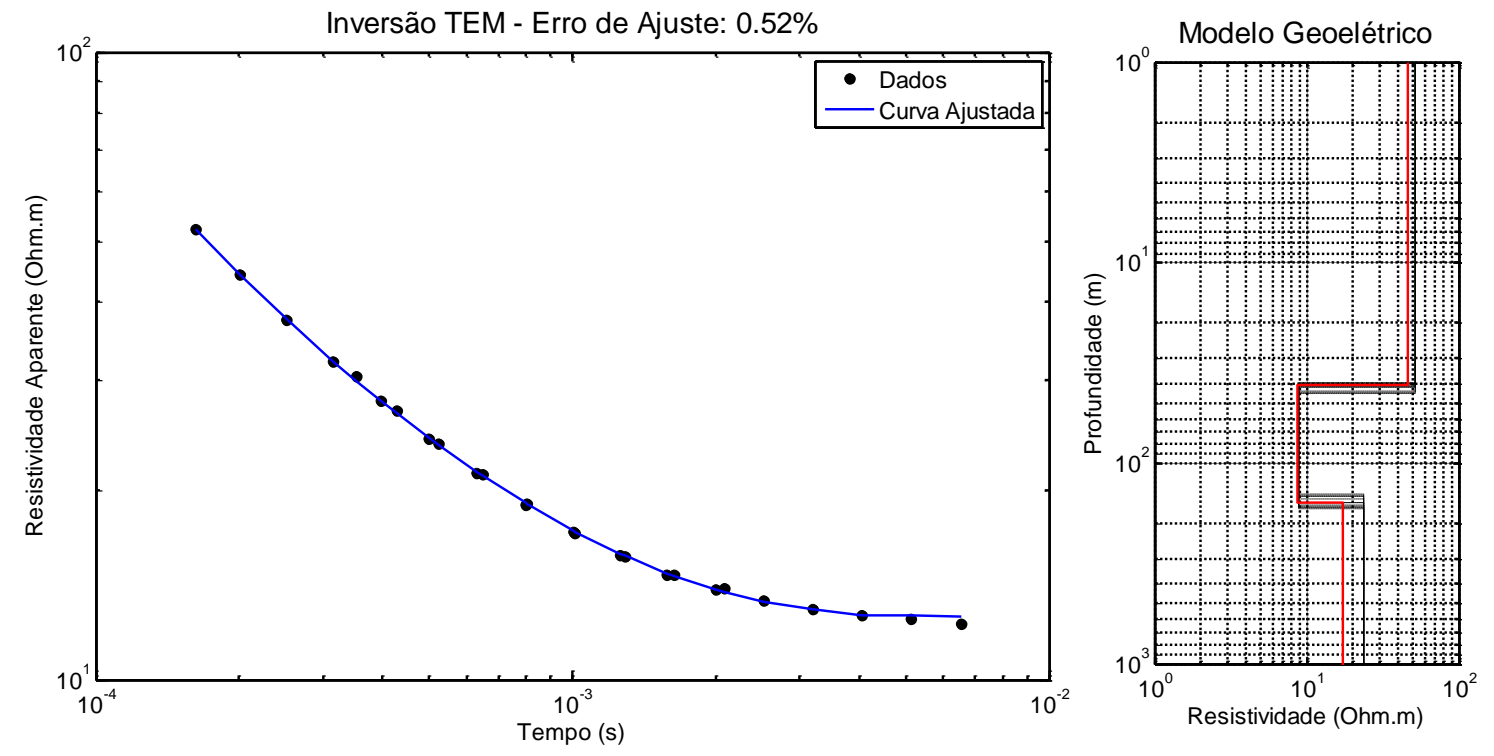

Figura B 3: Inversão individual TDEM da sondagem TEM03 e modelo geoelétrico associado.
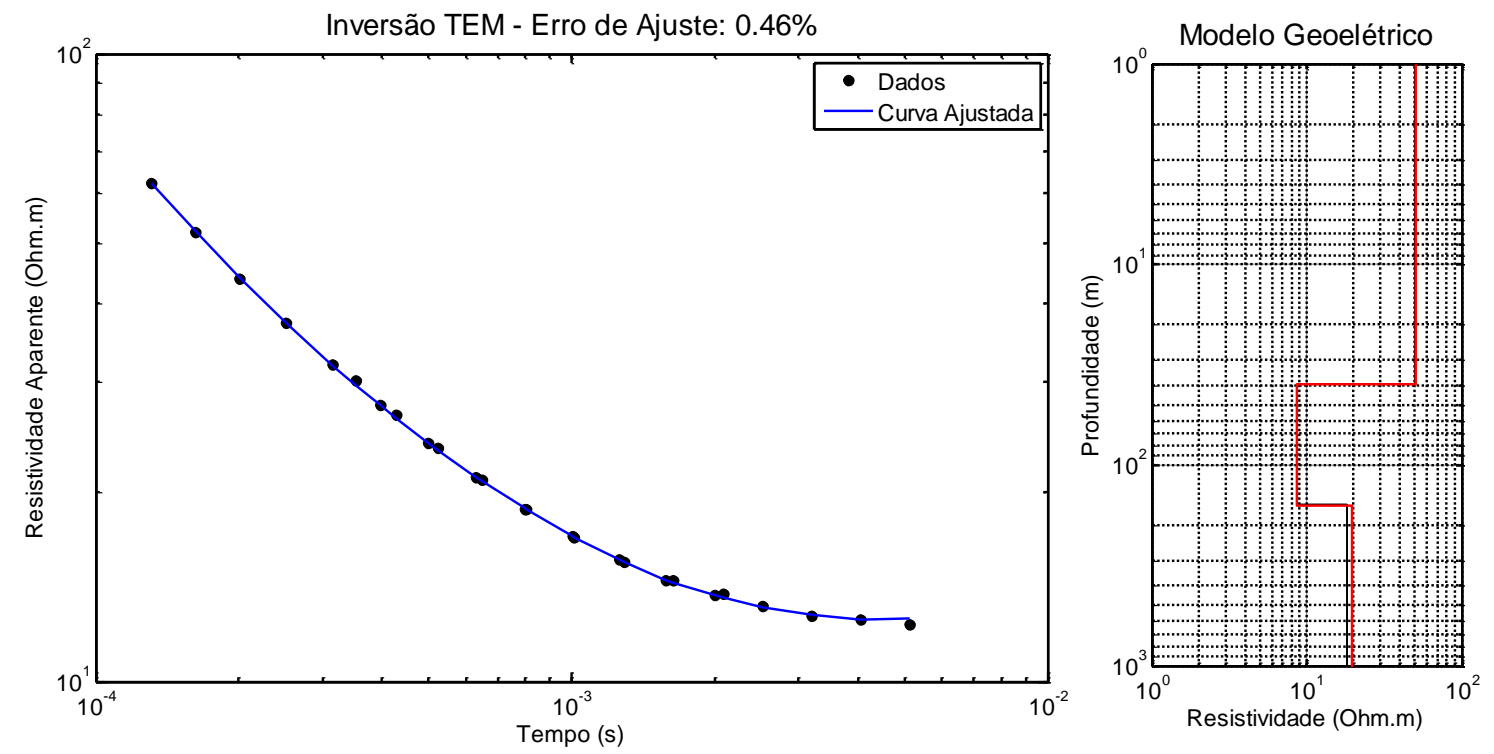

Figura B 4: Inversão individual TDEM da sondagem TEM05 e modelo geoelétrico associado. 

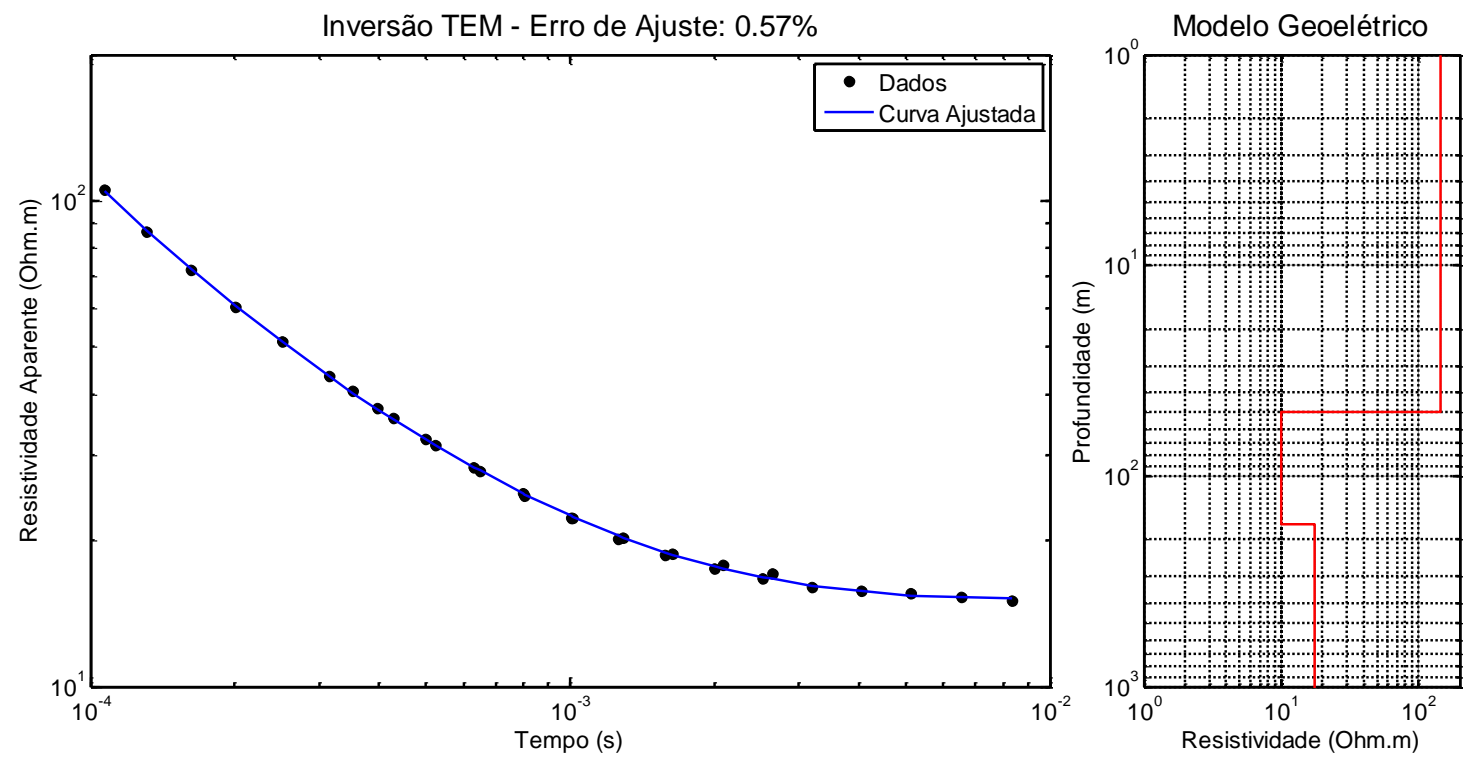

Figura B 5: Inversão individual TDEM da sondagem TEM06 e modelo geoelétrico associado.
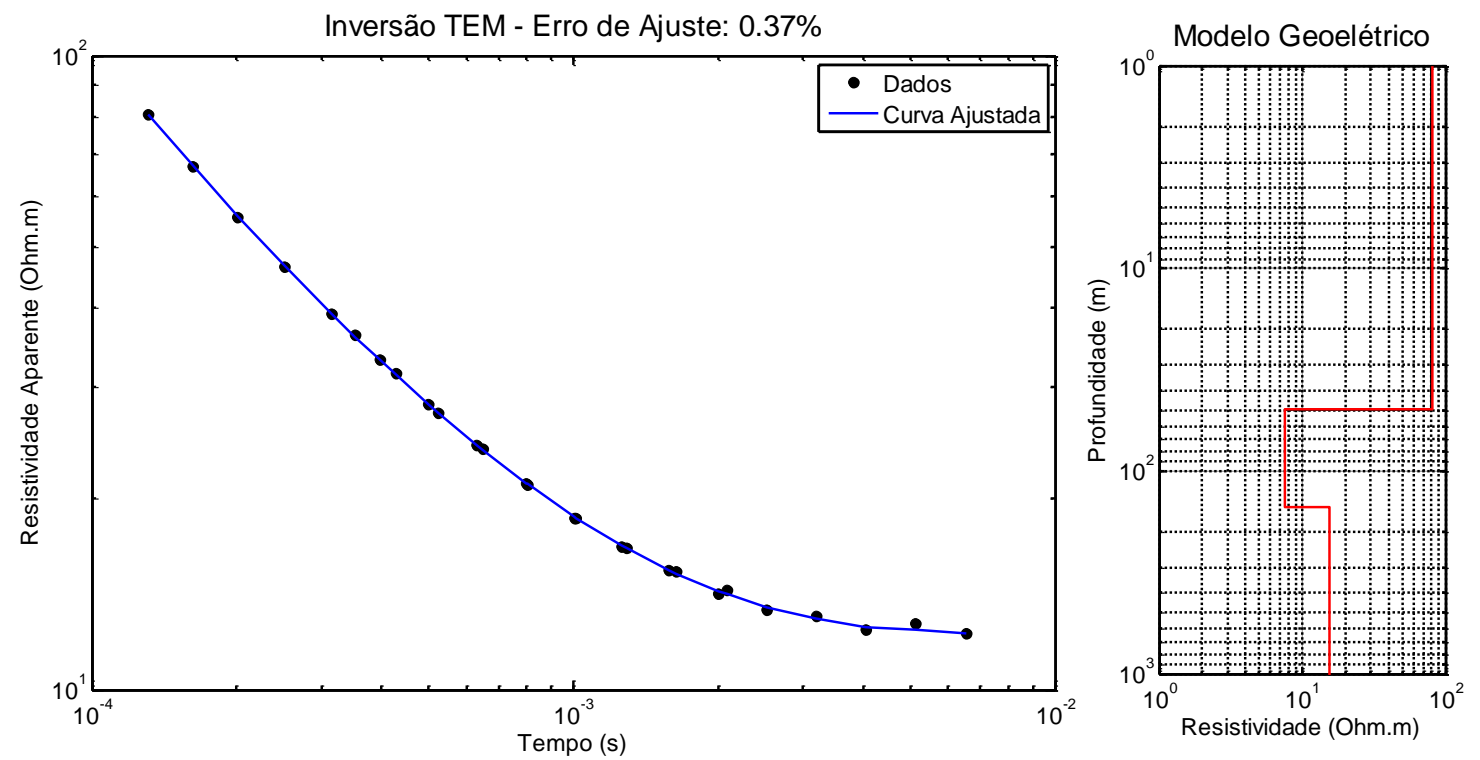

Figura B 6: Inversão individual TDEM da sondagem TEM07 e modelo geoelétrico associado. 

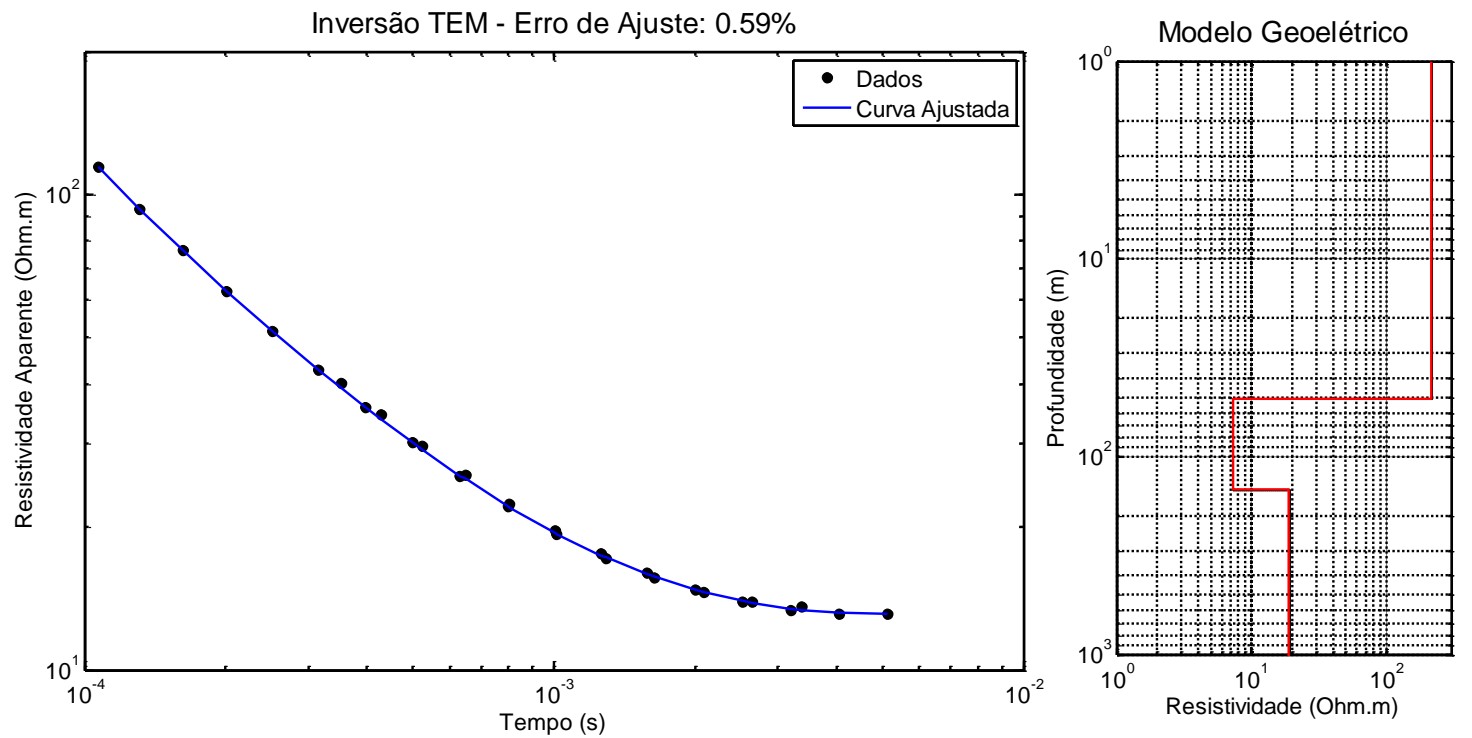

Figura B 7: Inversão individual TDEM da sondagem TEM08 e modelo geoelétrico associado.
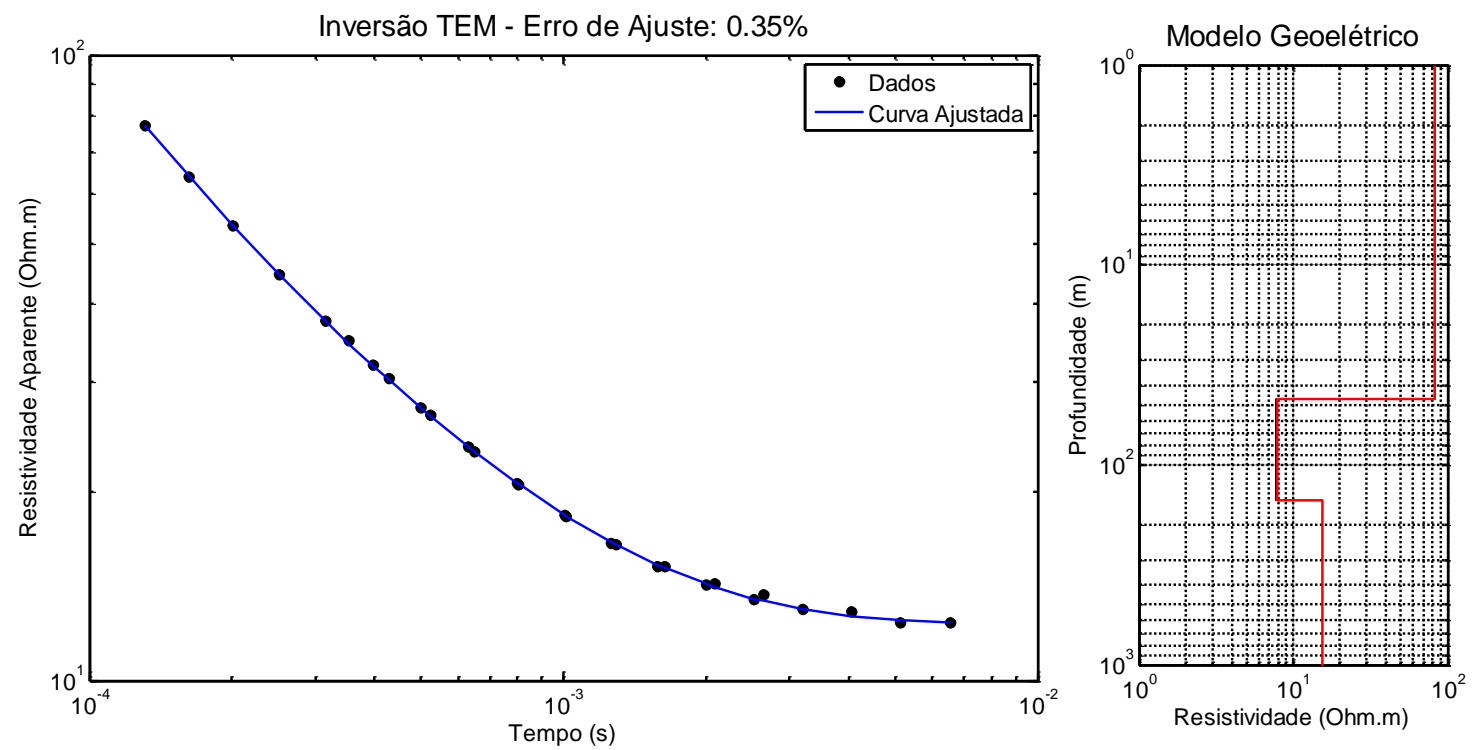

Figura B 8: Inversão individual TDEM da sondagem TEM09 e modelo geoelétrico associado. 

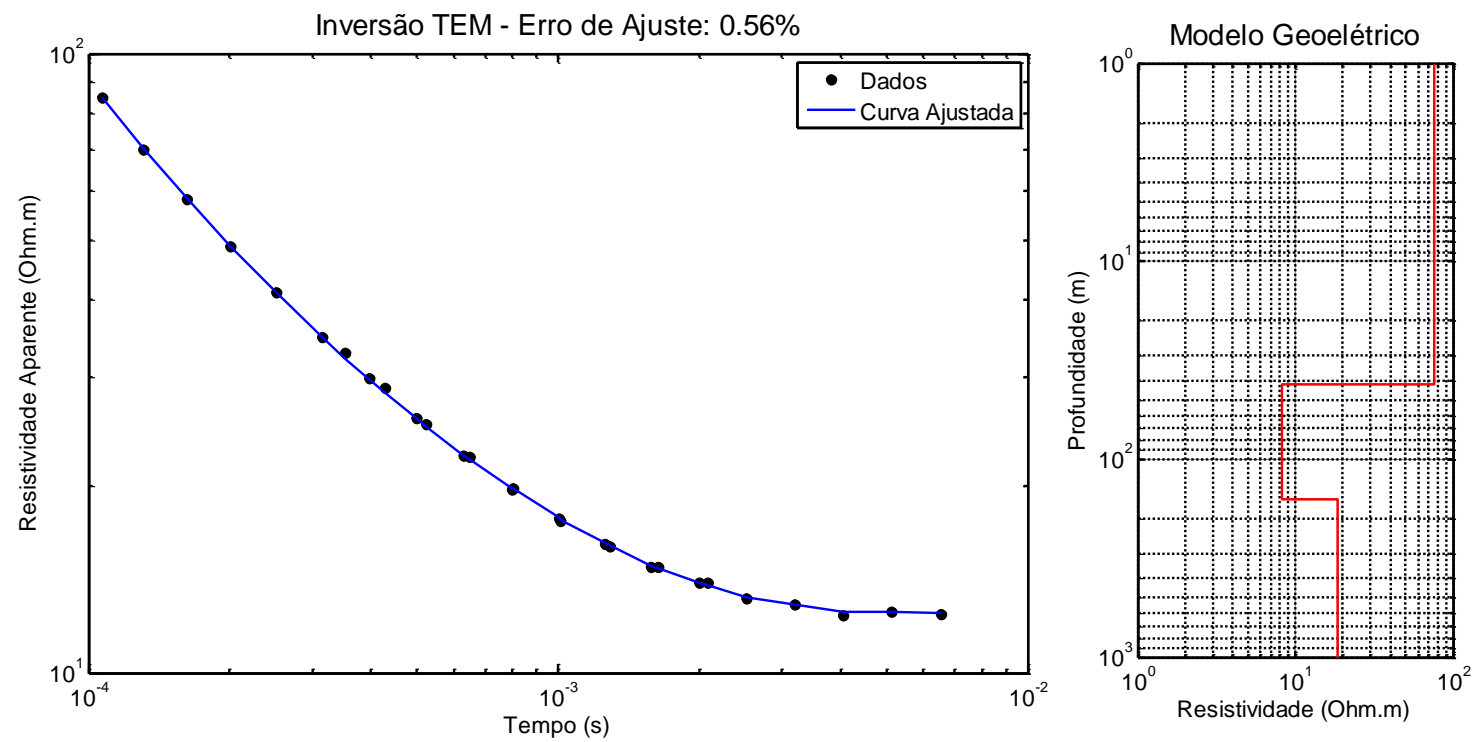

Figura B 9: Inversão individual TDEM da sondagem TEM10 e modelo geoelétrico associado.
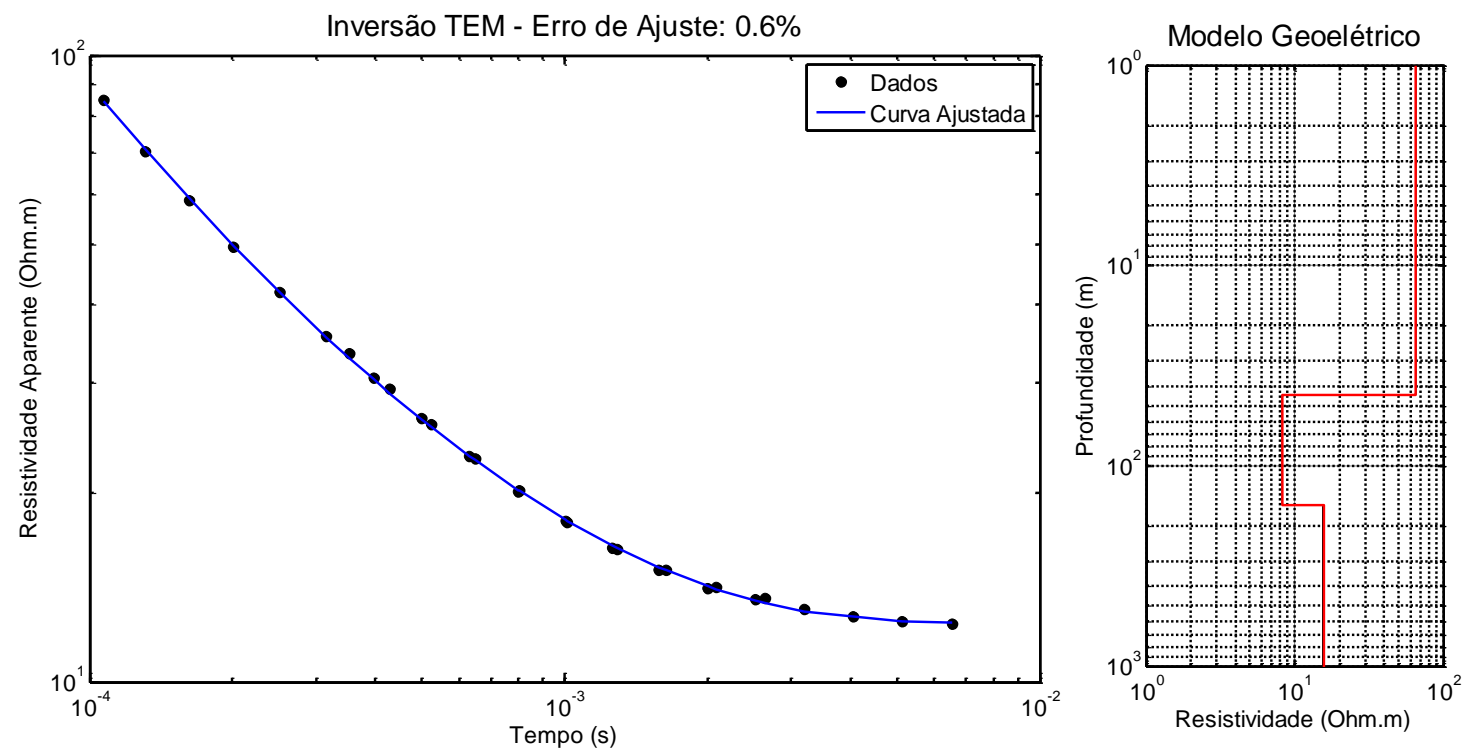

Figura B 10: Inversão individual TDEM da sondagem TEM11 e modelo geoelétrico associado. 

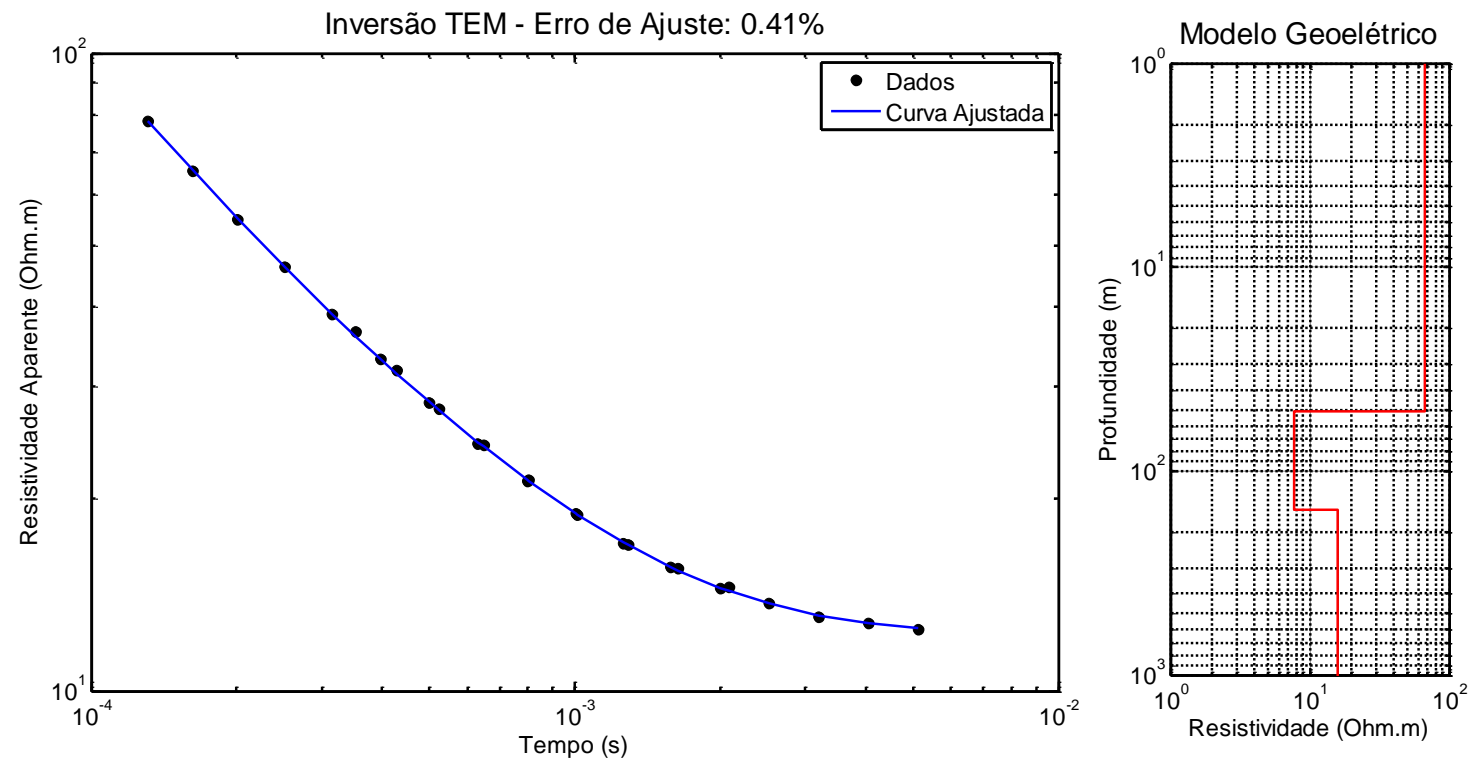

Figura B 11: Inversão individual TDEM da sondagem TEM12 e modelo geoelétrico associado.
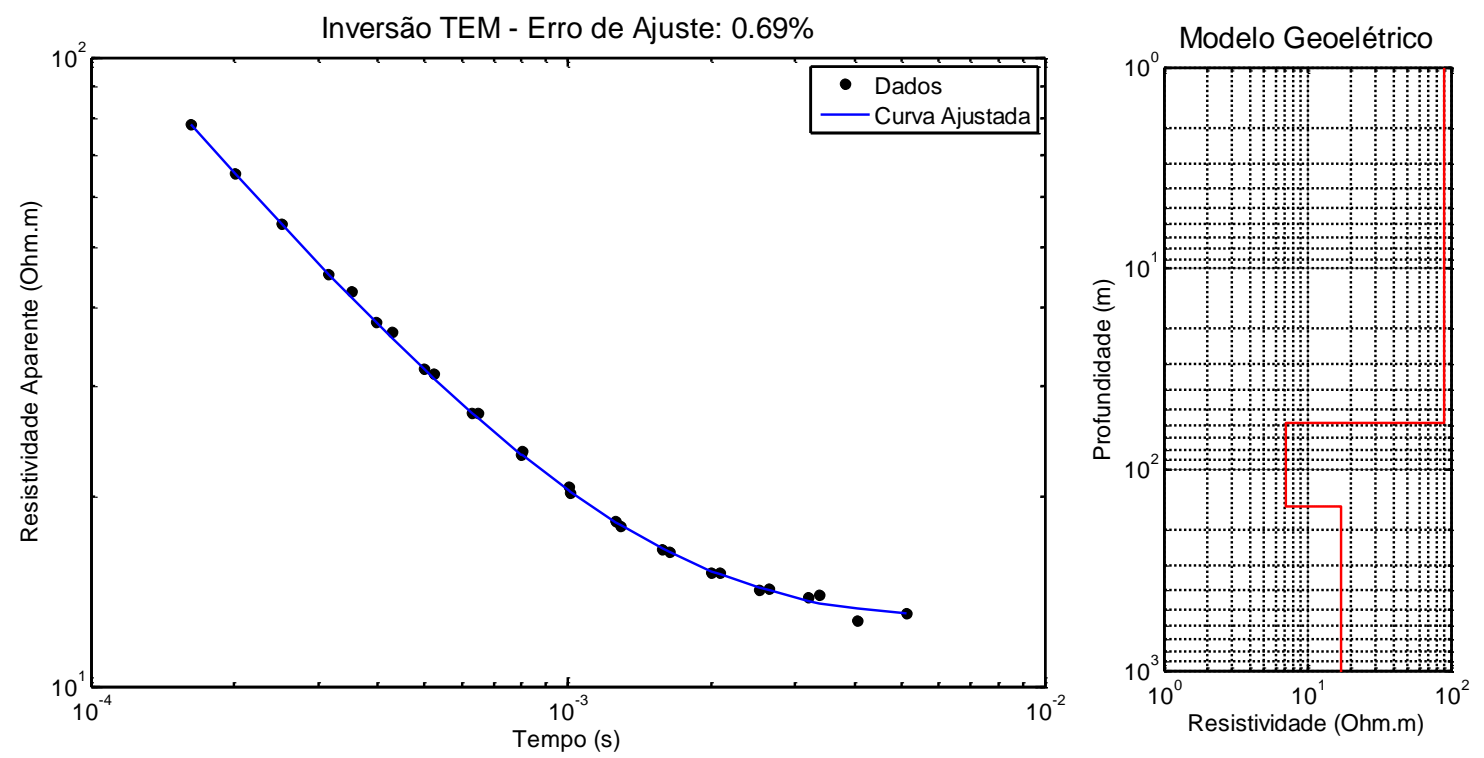

Figura B 12: Inversão individual TDEM da sondagem TEM13 e modelo geoelétrico associado. 

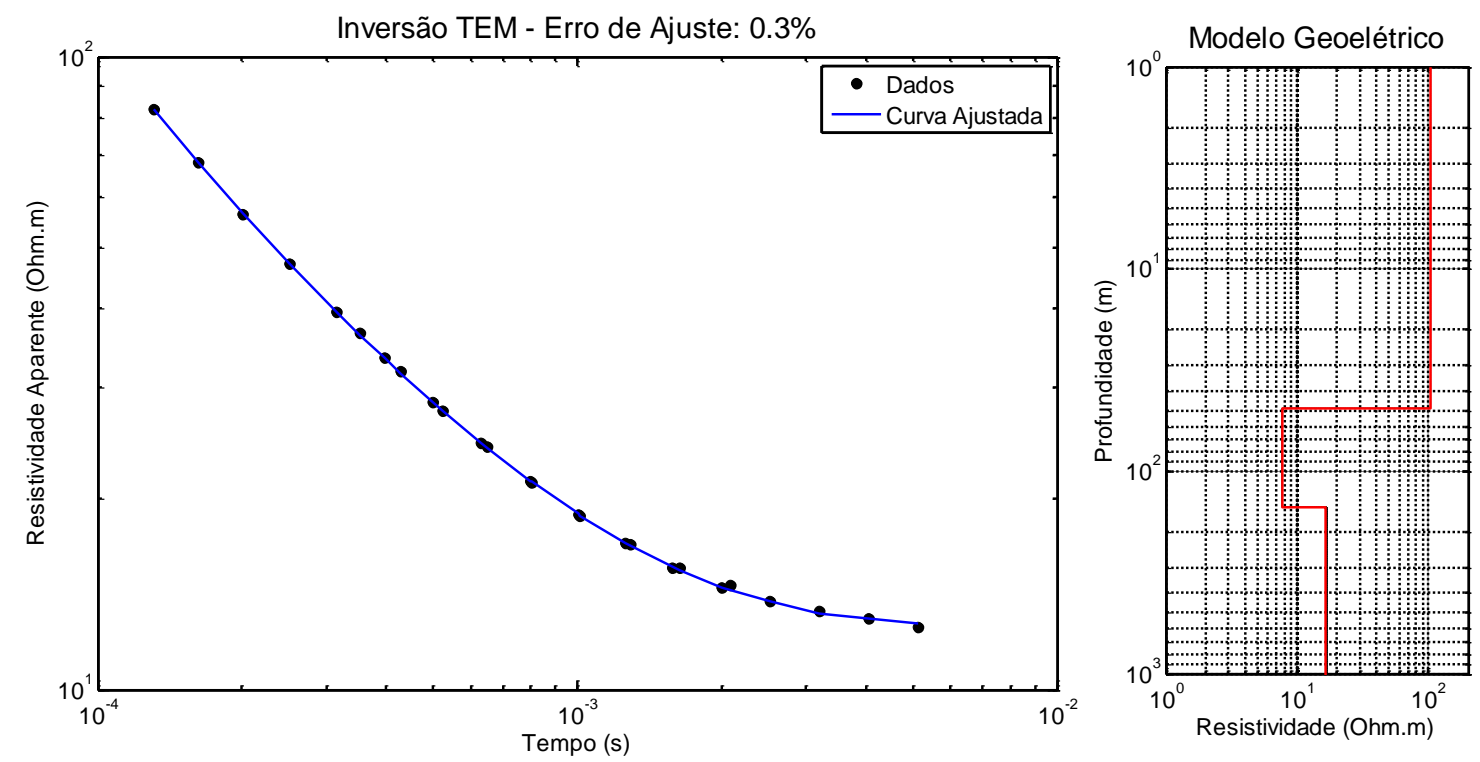

Figura B 13: Inversão individual TDEM da sondagem TEM14 e modelo geoelétrico associado.
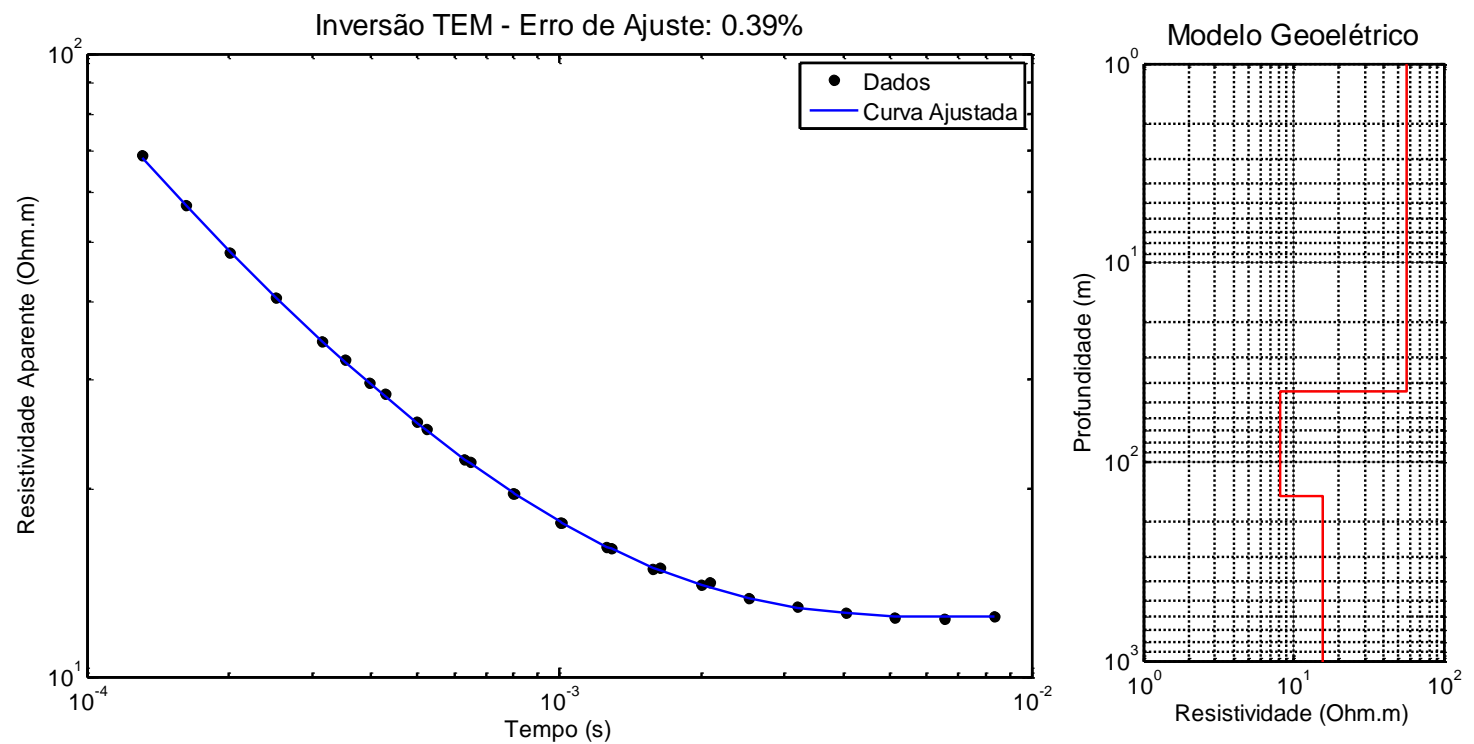

Figura B 14: Inversão individual TDEM da sondagem TEM15 e modelo geoelétrico associado. 

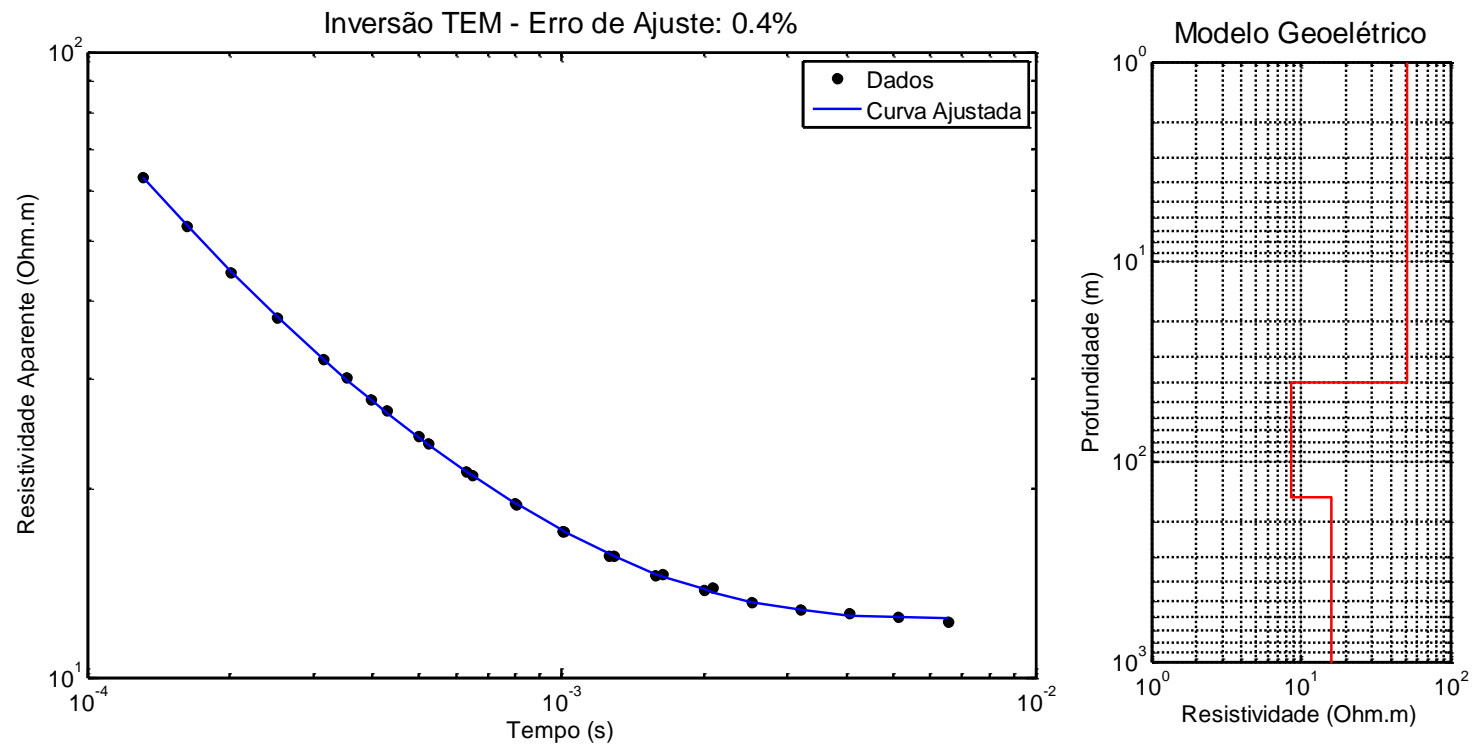

Figura B 15: Inversão individual TDEM da sondagem TEM16 e modelo geoelétrico associado.
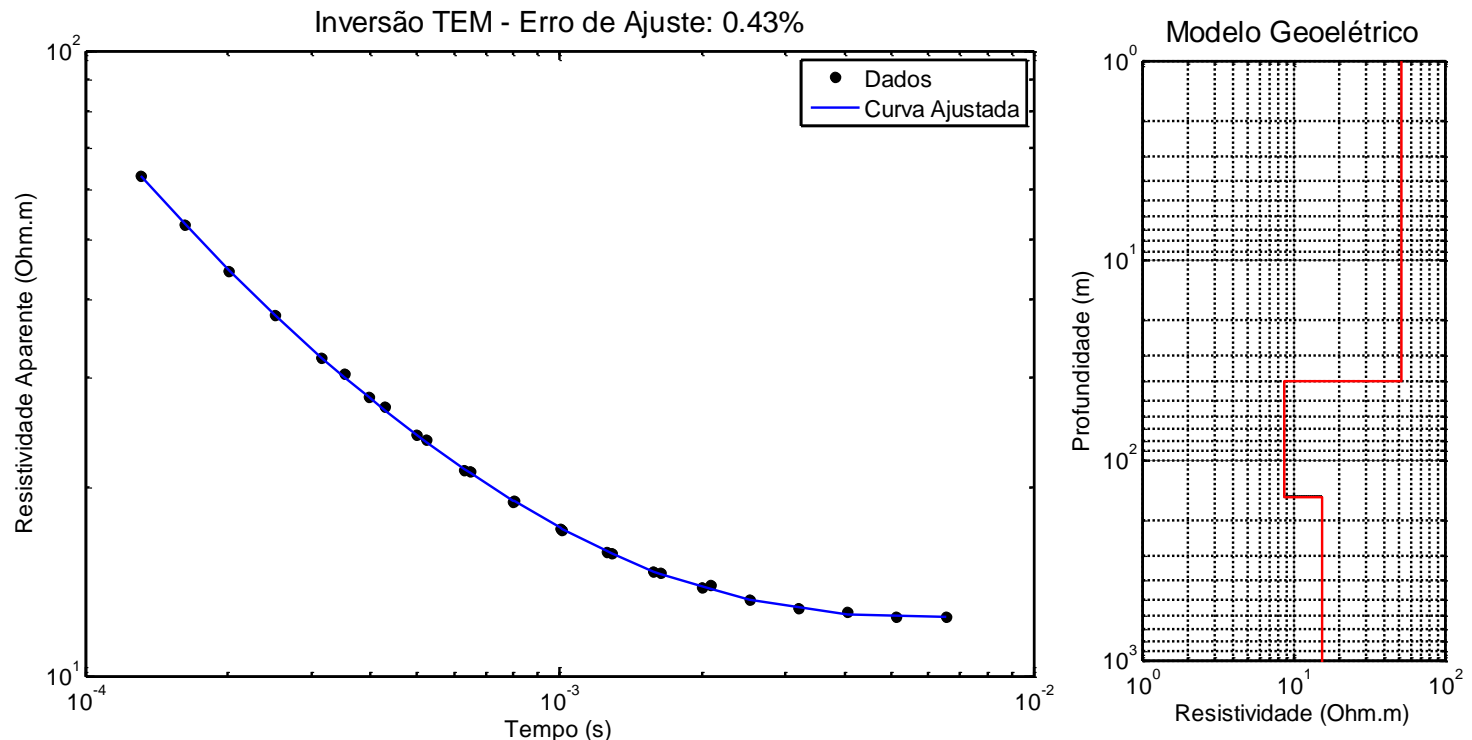

Figura B 16: Inversão individual TDEM da sondagem TEM17 e modelo geoelétrico associado. 

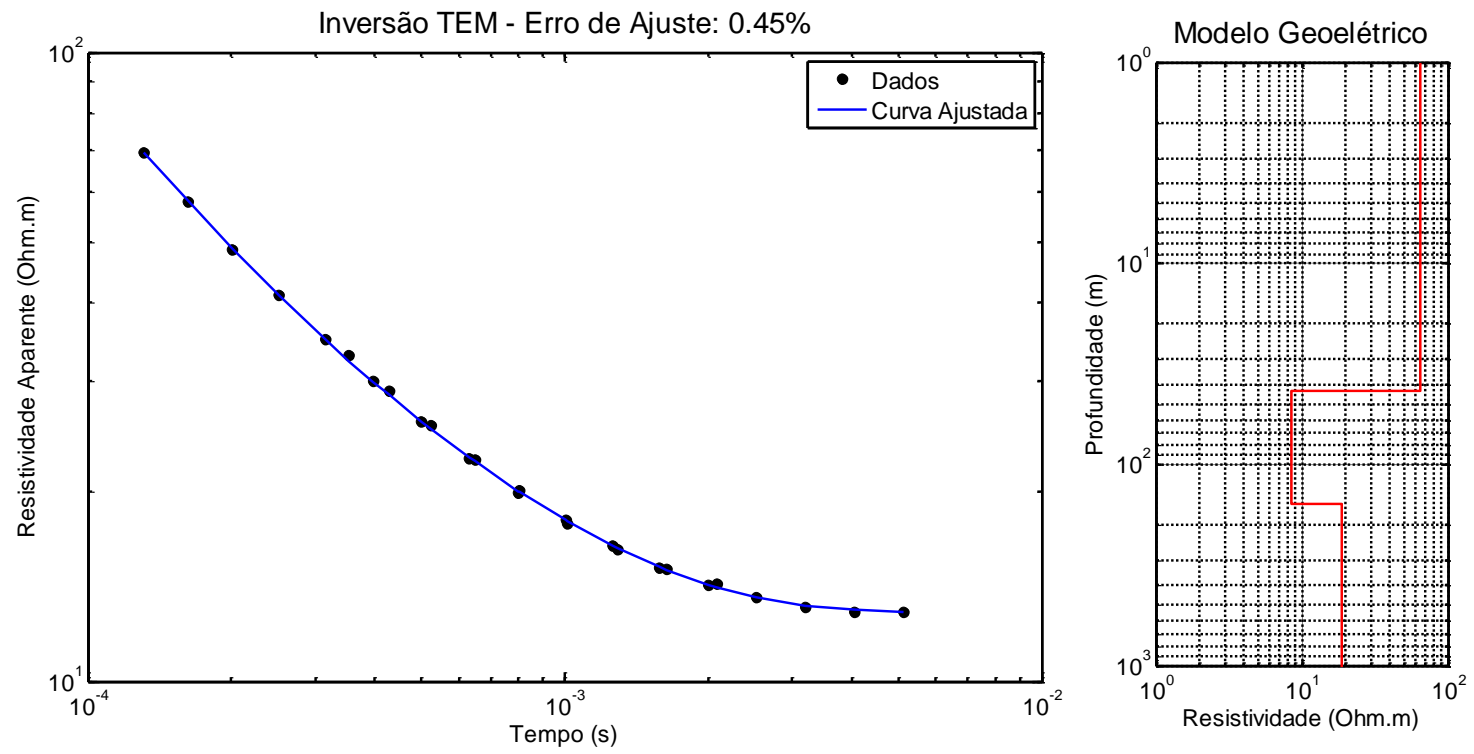

Figura B 17: Inversão individual TDEM da sondagem TEM18 e modelo geoelétrico associado.
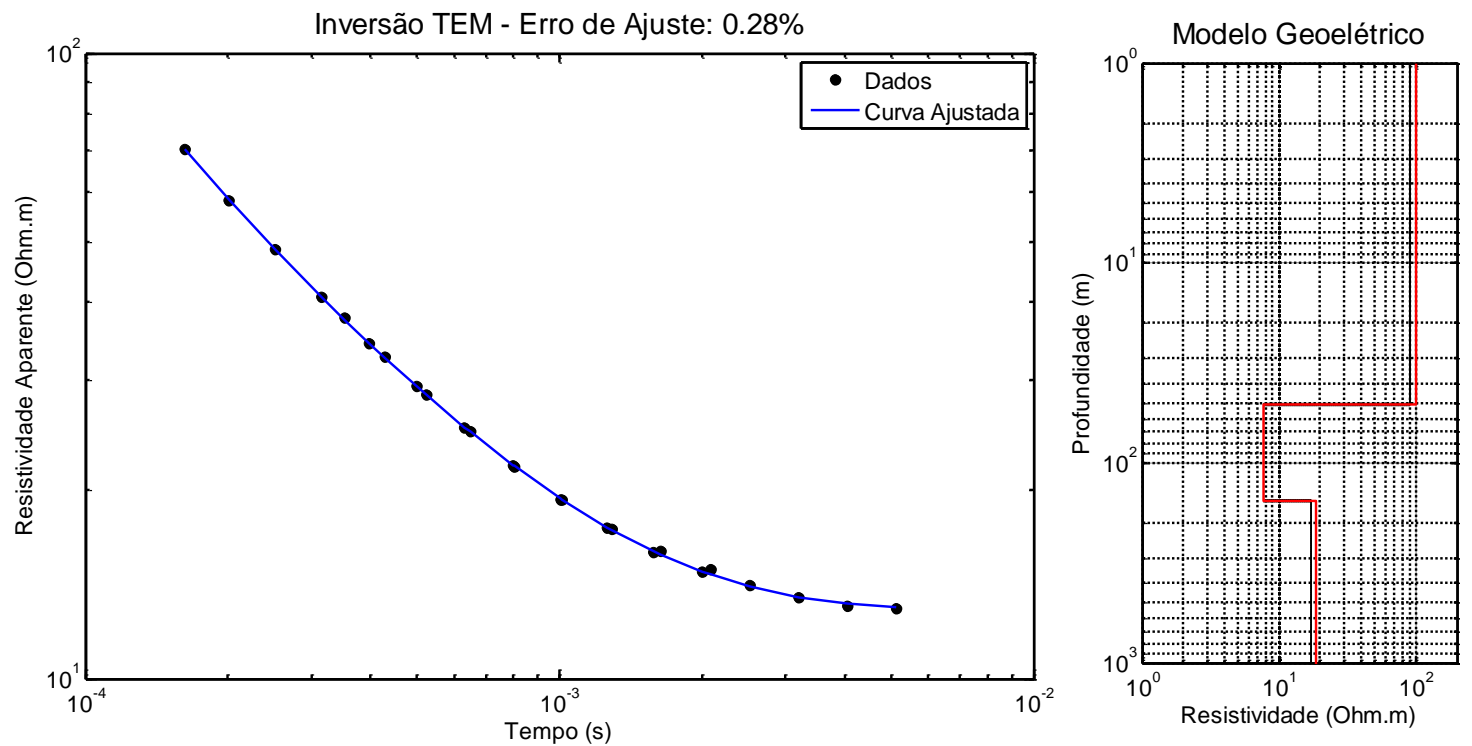

Figura B 18: Inversão individual TDEM da sondagem TEM19 e modelo geoelétrico associado. 

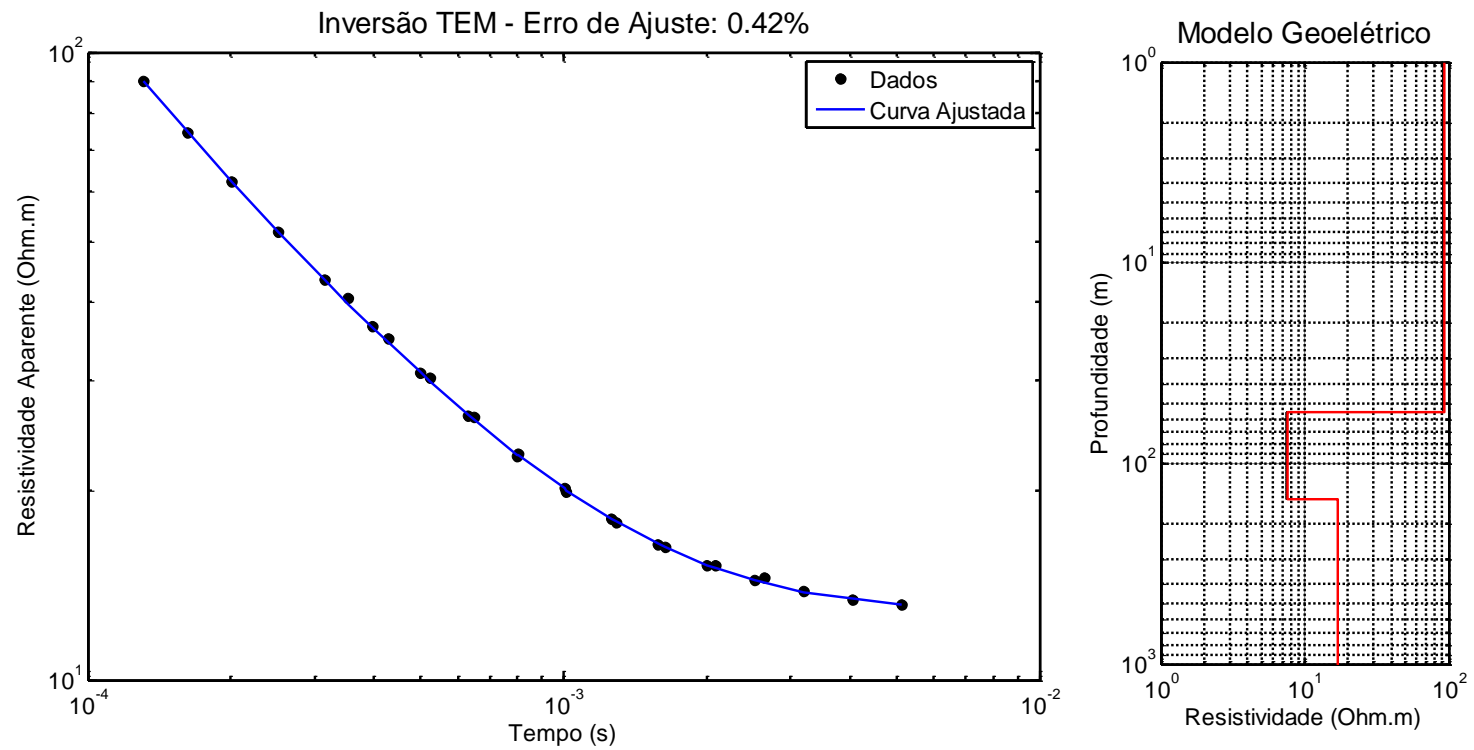

Figura B 19: Inversão individual TDEM da sondagem TEM20 e modelo geoelétrico associado.
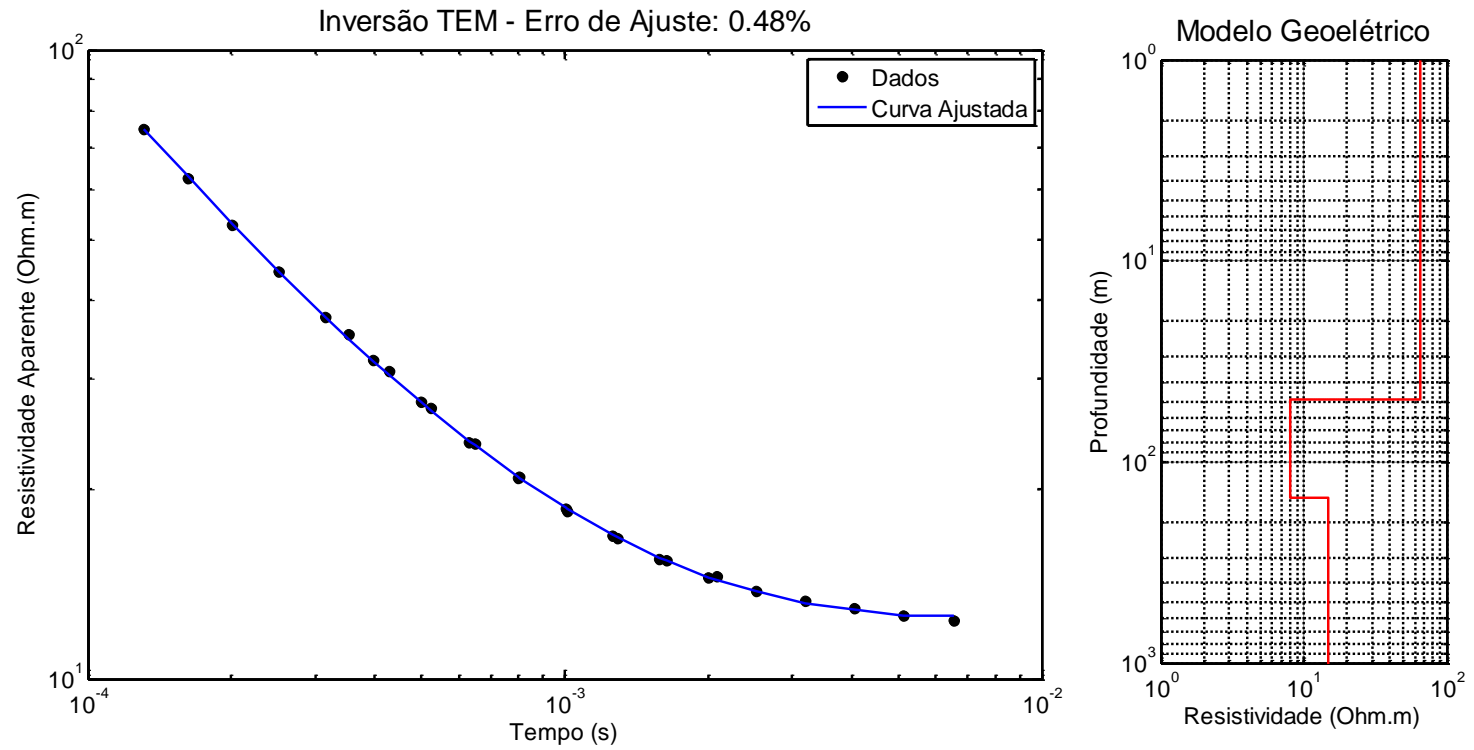

Figura B 20: Inversão individual TDEM da sondagem TEM21 e modelo geoelétrico associado. 

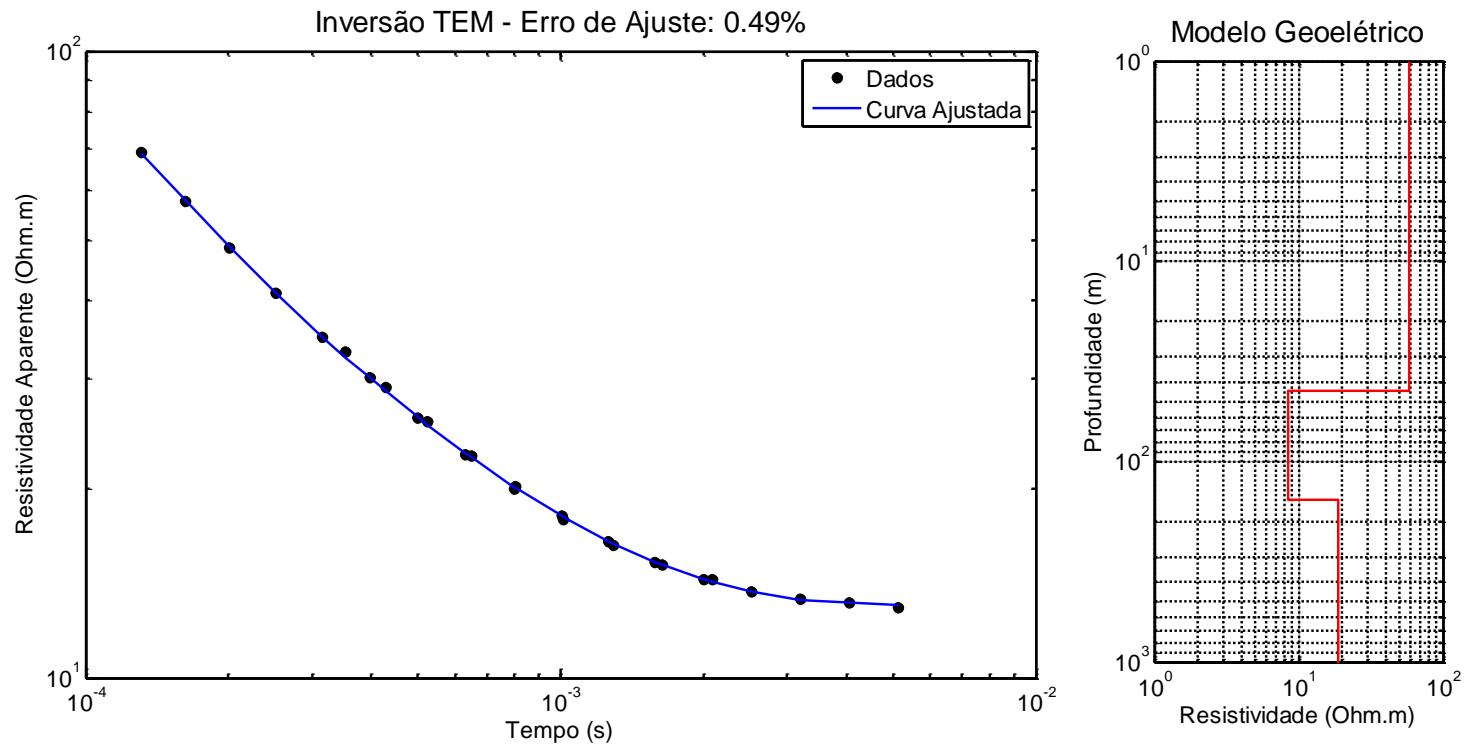

Figura B 21: Inversão individual TDEM da sondagem TEM22 e modelo geoelétrico associado.
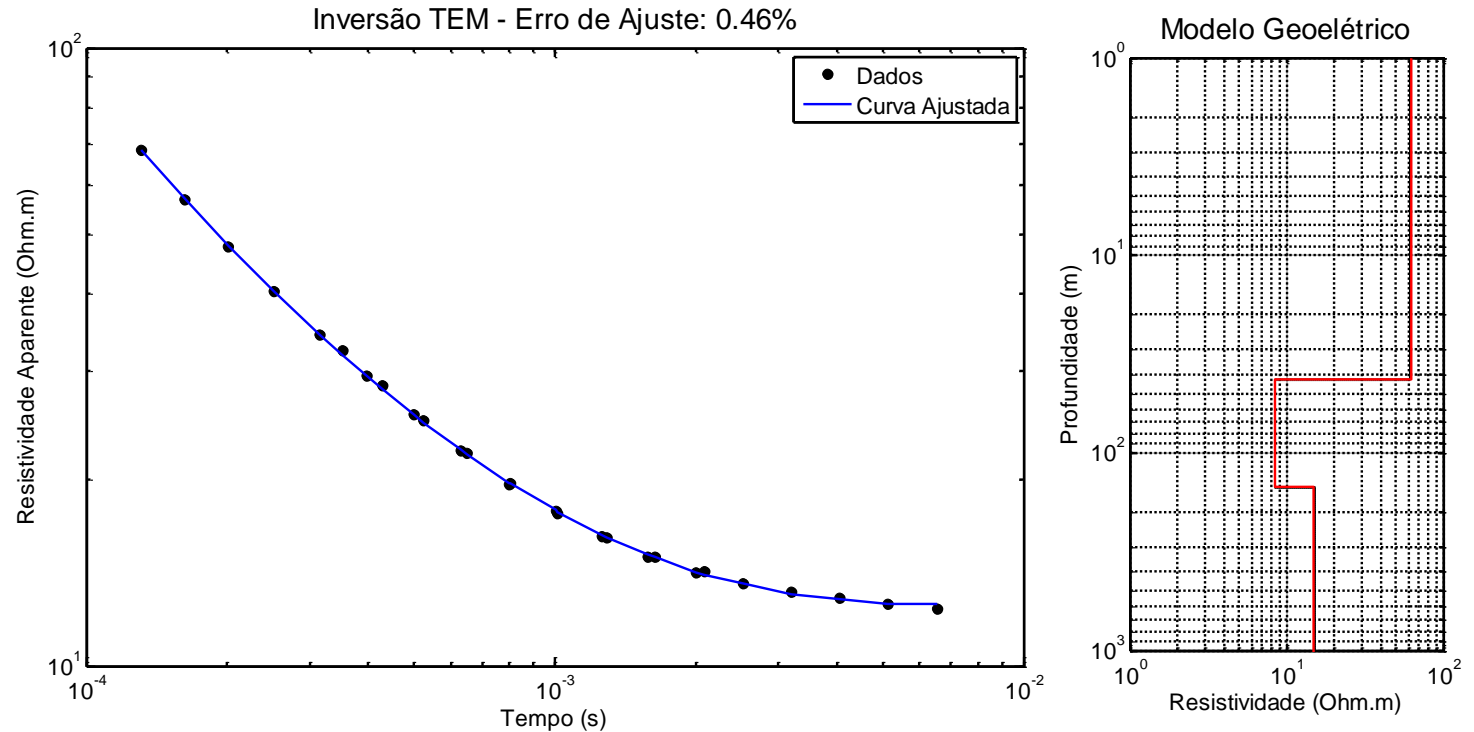

Figura B 22: Inversão individual TDEM da sondagem TEM23 e modelo geoelétrico associado. 

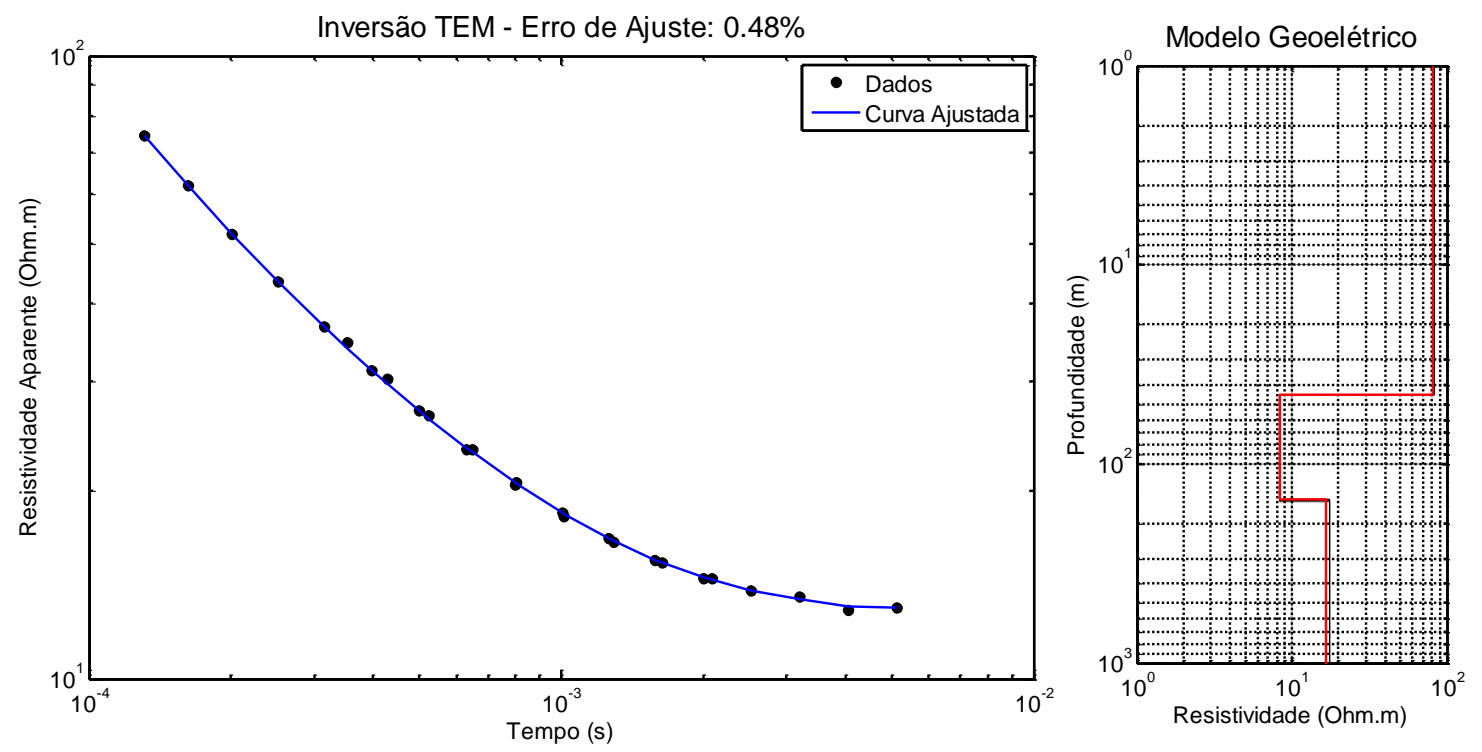

Figura B 23: Inversão individual TDEM da sondagem TEM24 e modelo geoelétrico associado.
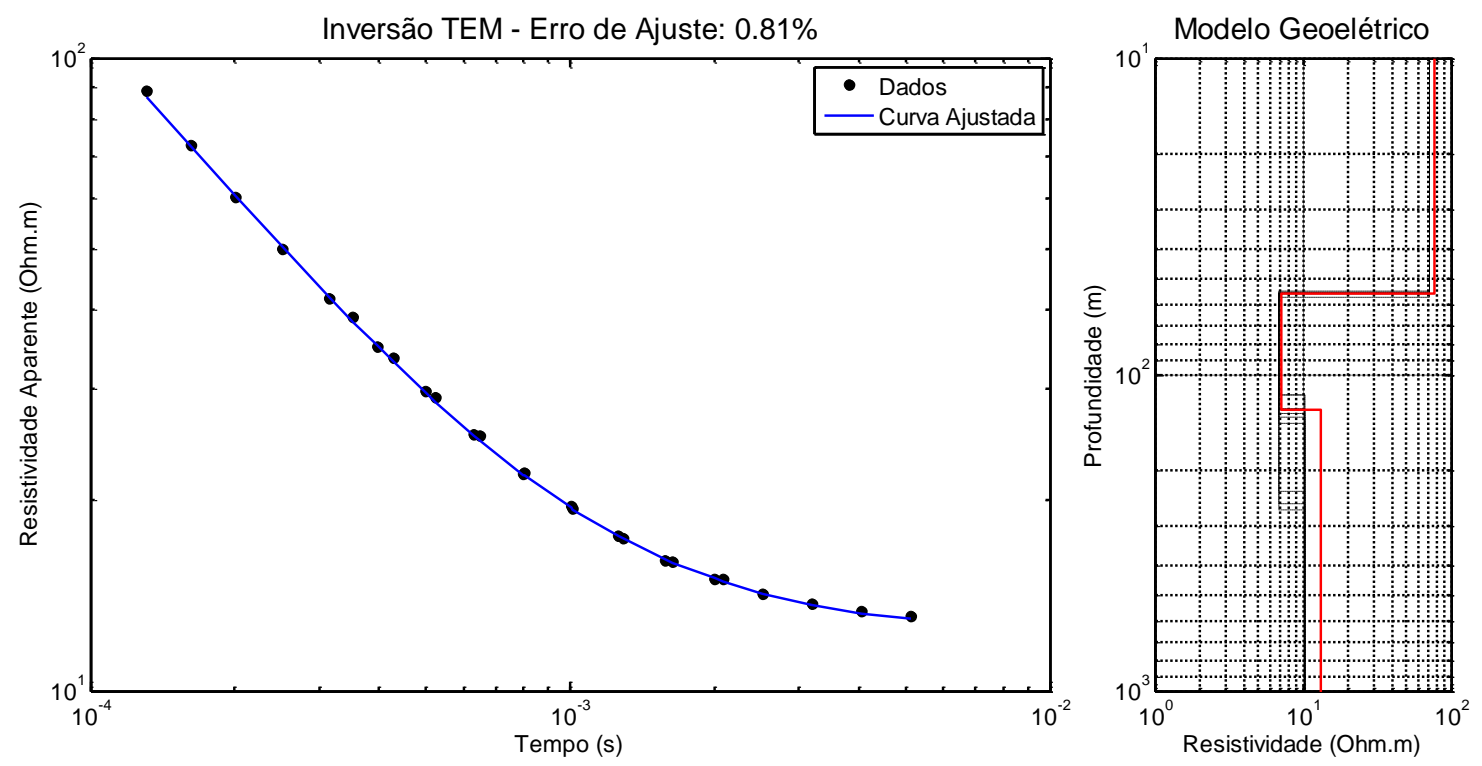

Figura B 24: Inversão individual TDEM da sondagem TEM25 e modelo geoelétrico associado. 


\section{Apêndice C: Tabela com informações dos poços da cidade de Taubaté (SP)}

\begin{tabular}{|c|c|c|c|c|c|c|}
\hline Poço & $\begin{array}{c}\text { Latitude } \\
\left({ }^{\circ}\right)\end{array}$ & $\begin{array}{c}\text { Longitude } \\
\left(^{\circ}\right)\end{array}$ & Uso da Água & $\begin{array}{l}\text { Profundidade } \\
\text { Inicial (m) }\end{array}$ & $\begin{array}{l}\text { Profundidade } \\
\text { final }(\mathrm{m})\end{array}$ & $\begin{array}{c}\text { Embasamento } \\
(\mathrm{m})\end{array}$ \\
\hline 3500006832 & $-23,047222$ & $-45,515277$ & $\begin{array}{l}\text { Abastecimento } \\
\text { doméstico }\end{array}$ & 0 & 124 & \\
\hline 3500007870 & $-23,070555$ & $-45,546111$ & & 0 & 186 & \\
\hline 3500049581 & $-22,998611$ & $-45,513333$ & $\begin{array}{l}\text { Abastecimento } \\
\text { industrial }\end{array}$ & 0 & 120 & \\
\hline 3500049582 & $-22,992222$ & $-45,514167$ & $\begin{array}{l}\text { Abastecimento } \\
\text { industrial }\end{array}$ & 0 & 340 & \\
\hline 3500049587 & $-22,982222$ & $-45,510556$ & $\begin{array}{l}\text { Abastecimento } \\
\text { industrial }\end{array}$ & 0 & 352 & \\
\hline 3500051119 & $-23,02$ & $-45,582222$ & $\begin{array}{c}\text { Outros } \\
\text { (lazer,etc.) }\end{array}$ & 0 & 7,5 & \\
\hline 3500051120 & $-23,02$ & $-45,582222$ & $\begin{array}{c}\text { Outros } \\
\text { (lazer,etc.) }\end{array}$ & 0 & 7,5 & \\
\hline 3500051121 & $-23,02$ & $-45,581944$ & $\begin{array}{c}\text { Outros } \\
\text { (lazer,etc.) }\end{array}$ & 0 & 7,5 & \\
\hline 3500051122 & $-23,02$ & $-45,581944$ & $\begin{array}{c}\text { Outros } \\
\text { (lazer,etc.) }\end{array}$ & 0 & 7,5 & \\
\hline 3500051123 & $-23,02$ & $-45,582222$ & $\begin{array}{c}\text { Outros } \\
\text { (lazer,etc.) }\end{array}$ & 0 & 7,5 & \\
\hline 3500051124 & $-23,02$ & $-45,582222$ & $\begin{array}{c}\text { Outros } \\
\text { (lazer,etc.) }\end{array}$ & 0 & 7,5 & \\
\hline 3500051125 & $-23,02$ & $-45,582222$ & $\begin{array}{c}\text { Outros } \\
\text { (lazer,etc.) }\end{array}$ & 0 & 7,5 & \\
\hline 3500051126 & $-23,02$ & $-45,581944$ & $\begin{array}{c}\text { Outros } \\
\text { (lazer,etc.) }\end{array}$ & 0 & 7,5 & \\
\hline 3500051127 & $-23,02$ & $-45,581944$ & $\begin{array}{c}\text { Outros } \\
\text { (lazer,etc.) }\end{array}$ & 0 & 7,5 & \\
\hline 3500051128 & $-23,02$ & $-45,581944$ & $\begin{array}{c}\text { Outros } \\
\text { (lazer,etc.) }\end{array}$ & 0 & 7,5 & \\
\hline 3500051130 & $-23,043333$ & $-45,574167$ & $\begin{array}{l}\text { Abastecimento } \\
\text { industrial }\end{array}$ & 0 & 40 & \\
\hline 3500051132 & $-23,020556$ & $-45,683056$ & $\begin{array}{l}\text { Abastecimento } \\
\text { doméstico }\end{array}$ & 0 & 200 & \\
\hline 3500051133 & $-23,062222$ & $-45,619444$ & $\begin{array}{l}\text { Abastecimento } \\
\text { doméstico }\end{array}$ & 0 & 314 & \\
\hline
\end{tabular}




\begin{tabular}{|c|c|c|c|c|c|}
\hline 3500051136 & $-23,116667$ & $-45,617778$ & $\begin{array}{l}\text { Abastecimento } \\
\text { doméstico }\end{array}$ & 0 & 100 \\
\hline 3500051137 & $-23,054444$ & $-45,6175$ & $\begin{array}{l}\text { Abastecimento } \\
\text { industrial }\end{array}$ & 0 & 6 \\
\hline 3500051139 & $-23,066667$ & $-45,56$ & $\begin{array}{l}\text { Abastecimento } \\
\text { doméstico }\end{array}$ & 0 & 134 \\
\hline 3500051140 & $-23,023611$ & $-45,583611$ & $\begin{array}{l}\text { Abastecimento } \\
\text { industrial }\end{array}$ & 0 & 20 \\
\hline 3500051142 & $-23,030556$ & $-45,509444$ & Irrigação & 0 & 115 \\
\hline 3500051147 & $-23,111111$ & $-45,558611$ & $\begin{array}{c}\text { Outros } \\
\text { (lazer,etc.) }\end{array}$ & 0 & 249 \\
\hline 3500051149 & $-23,039444$ & $-45,623056$ & $\begin{array}{c}\text { Abastecimento } \\
\text { industrial }\end{array}$ & 0 & 70 \\
\hline 3500051150 & $-23,0475$ & $-45,5975$ & $\begin{array}{l}\text { Abastecimento } \\
\text { industrial }\end{array}$ & 0 & 134 \\
\hline 3500051151 & $-23,050556$ & $-45,624444$ & $\begin{array}{l}\text { Abastecimento } \\
\text { industrial }\end{array}$ & 0 & 70 \\
\hline 3500051153 & $-23,038611$ & $-45,562778$ & $\begin{array}{l}\text { Abastecimento } \\
\text { industrial }\end{array}$ & 0 & 38 \\
\hline 3500051157 & $-23,073611$ & $-45,543611$ & $\begin{array}{c}\text { Abastecimento } \\
\text { urbano }\end{array}$ & 0 & 122 \\
\hline 3500051158 & $-23,084444$ & $-45,560278$ & $\begin{array}{l}\text { Abastecimento } \\
\text { industrial }\end{array}$ & 0 & 240 \\
\hline 3500051166 & $-23,0425$ & $-45,618333$ & $\begin{array}{l}\text { Abastecimento } \\
\text { industrial }\end{array}$ & 0 & 370 \\
\hline 3500051167 & $-23,0475$ & $-45,616944$ & $\begin{array}{l}\text { Abastecimento } \\
\text { industrial }\end{array}$ & 0 & 350 \\
\hline 3500051168 & $-23,045278$ & $-45,616389$ & $\begin{array}{c}\text { Outros } \\
\text { (lazer,etc.) }\end{array}$ & 0 & 200 \\
\hline 3500051169 & $-23,042778$ & $-45,620278$ & $\begin{array}{l}\text { Abastecimento } \\
\text { industrial }\end{array}$ & 0 & 80 \\
\hline 3500051170 & $-23,042222$ & $-45,571111$ & $\begin{array}{l}\text { Abastecimento } \\
\text { doméstico }\end{array}$ & 0 & 200 \\
\hline 3500051172 & -23 & $-45,614167$ & $\begin{array}{l}\text { Abastecimento } \\
\text { industrial }\end{array}$ & 0 & 393 \\
\hline 3500051174 & $-23,046944$ & $-45,525556$ & $\begin{array}{c}\text { Outros } \\
\text { (lazer,etc.) }\end{array}$ & 0 & 172 \\
\hline 3500051178 & $-23,051944$ & $-45,623333$ & $\begin{array}{l}\text { Abastecimento } \\
\text { industrial }\end{array}$ & 0 & 100 \\
\hline 3500051179 & $-23,029444$ & $-45,616389$ & $\begin{array}{c}\text { Abastecimento } \\
\text { industrial }\end{array}$ & 0 & 35 \\
\hline
\end{tabular}




\begin{tabular}{|c|c|c|c|c|c|c|}
\hline 3500051180 & $-23,010278$ & $-45,510556$ & $\begin{array}{c}\text { Abastecimento } \\
\text { industrial }\end{array}$ & 0 & 220 & \\
\hline 3500051181 & $-23,036389$ & $-45,561389$ & $\begin{array}{c}\text { Outros } \\
\text { (lazer,etc.) }\end{array}$ & 0 & 155 & \\
\hline 3500051182 & $-23,069722$ & $-45,553056$ & & 0 & 112,5 & \\
\hline 3500051186 & $-23,004444$ & $-45,519167$ & $\begin{array}{l}\text { Abastecimento } \\
\text { industrial }\end{array}$ & 0 & 132 & \\
\hline 3500051187 & $-23,006111$ & $-45,521944$ & $\begin{array}{l}\text { Abastecimento } \\
\text { industrial }\end{array}$ & 0 & 123 & \\
\hline 3500051188 & $-23,056389$ & $-45,622778$ & $\begin{array}{c}\text { Abastecimento } \\
\text { industrial }\end{array}$ & 0 & 100 & \\
\hline 3500051190 & $-23,018611$ & $-45,590278$ & $\begin{array}{c}\text { Abastecimento } \\
\text { industrial }\end{array}$ & 0 & 442,31 & $\begin{array}{l}442 \text { (Rocha } \\
\text { cristalina) }\end{array}$ \\
\hline 3500051191 & $-23,016944$ & $-45,594444$ & $\begin{array}{l}\text { Abastecimento } \\
\text { industrial }\end{array}$ & 0 & 647 & 510 (Gnaisse) \\
\hline 3500051197 & $-23,02$ & $-45,5825$ & $\begin{array}{c}\text { Outros } \\
\text { (lazer,etc.) }\end{array}$ & 0 & 7,5 & \\
\hline 3500051198 & $-23,02$ & $-45,582222$ & $\begin{array}{c}\text { Outros } \\
\text { (lazer,etc.) }\end{array}$ & 0 & 7,5 & \\
\hline 3500051199 & $-23,02$ & $-45,581944$ & $\begin{array}{c}\text { Outros } \\
\text { (lazer,etc.) }\end{array}$ & 0 & 7,5 & \\
\hline 3500051200 & $-23,019722$ & $-45,5825$ & $\begin{array}{c}\text { Outros } \\
\text { (lazer,etc.) }\end{array}$ & 0 & 7,5 & \\
\hline 3500051201 & $-23,019722$ & $-45,5825$ & $\begin{array}{c}\text { Outros } \\
\text { (lazer,etc.) }\end{array}$ & 0 & 7,5 & \\
\hline 3500051202 & $-23,019722$ & $-45,5825$ & $\begin{array}{c}\text { Outros } \\
\text { (lazer,etc.) }\end{array}$ & 0 & 7,5 & \\
\hline 3500051203 & $-23,019722$ & $-45,5825$ & $\begin{array}{c}\text { Outros } \\
\text { (lazer,etc.) }\end{array}$ & 0 & 7,5 & \\
\hline 3500051205 & $-23,02$ & $-45,5825$ & $\begin{array}{c}\text { Outros } \\
\text { (lazer,etc.) }\end{array}$ & 0 & 7,5 & \\
\hline 3500051206 & $-23,02$ & $-45,5825$ & $\begin{array}{c}\text { Outros } \\
\text { (lazer,etc.) }\end{array}$ & 0 & 7,5 & \\
\hline 3500051207 & $-23,02$ & $-45,5825$ & $\begin{array}{c}\text { Outros } \\
\text { (lazer,etc.) }\end{array}$ & 0 & 7,5 & \\
\hline 3500051208 & $-23,02$ & $-45,5825$ & $\begin{array}{c}\text { Outros } \\
\text { (lazer,etc.) }\end{array}$ & 0 & 7,5 & \\
\hline 3500051209 & $-23,02$ & $-45,5825$ & $\begin{array}{c}\text { Outros } \\
\text { (lazer,etc.) }\end{array}$ & 0 & 7,5 & \\
\hline 3500051210 & $-23,02$ & $-45,5825$ & $\begin{array}{c}\text { Outros } \\
\text { (lazer,etc.) }\end{array}$ & 0 & 7,5 & \\
\hline
\end{tabular}




\begin{tabular}{|c|c|c|c|c|c|}
\hline 3500051211 & $-23,02$ & $-45,5825$ & $\begin{array}{c}\text { Outros } \\
\text { (lazer,etc.) }\end{array}$ & 0 & 7,5 \\
\hline 3500051212 & $-23,02$ & $-45,582222$ & $\begin{array}{c}\text { Outros } \\
\text { (lazer,etc.) }\end{array}$ & 0 & 7,5 \\
\hline 3500051213 & $-23,019722$ & $-45,582222$ & $\begin{array}{c}\text { Outros } \\
\text { (lazer,etc.) }\end{array}$ & 0 & 7,5 \\
\hline 3500051214 & $-23,019722$ & $-45,582222$ & $\begin{array}{c}\text { Outros } \\
\text { (lazer,etc.) }\end{array}$ & 0 & 7,5 \\
\hline 3500051216 & $-23,019722$ & $-45,582222$ & $\begin{array}{c}\text { Outros } \\
\text { (lazer,etc.) }\end{array}$ & 0 & 7,5 \\
\hline 3500051217 & $-23,02$ & $-45,582222$ & $\begin{array}{c}\text { Outros } \\
\text { (lazer,etc.) }\end{array}$ & 0 & 7,5 \\
\hline 3500051218 & $-23,02$ & $-45,582222$ & $\begin{array}{c}\text { Outros } \\
\text { (lazer,etc.) }\end{array}$ & 0 & 7,5 \\
\hline 3500051219 & $-23,019722$ & $-45,582222$ & $\begin{array}{c}\text { Outros } \\
\text { (lazer,etc.) }\end{array}$ & 0 & 7,5 \\
\hline 3500051220 & $-23,019722$ & $-45,582222$ & $\begin{array}{c}\text { Outros } \\
\text { (lazer,etc.) }\end{array}$ & 0 & 7,5 \\
\hline 3500051221 & $-23,02$ & $-45,582222$ & $\begin{array}{c}\text { Outros } \\
\text { (lazer,etc.) }\end{array}$ & 0 & 7,5 \\
\hline 3500051222 & $-23,02$ & $-45,582222$ & $\begin{array}{c}\text { Outros } \\
\text { (lazer,etc.) }\end{array}$ & 0 & 7,5 \\
\hline 3500051223 & $-23,02$ & $-45,582222$ & $\begin{array}{c}\text { Outros } \\
\text { (lazer,etc.) }\end{array}$ & 0 & 7,5 \\
\hline 3500051224 & $-23,02$ & $-45,582222$ & $\begin{array}{c}\text { Outros } \\
\text { (lazer,etc.) }\end{array}$ & 0 & 7,5 \\
\hline 3500051225 & $-23,019722$ & $-45,581944$ & $\begin{array}{c}\text { Outros } \\
\text { (lazer,etc.) }\end{array}$ & 0 & 7,5 \\
\hline 3500051228 & $-23,1475$ & $-45,383611$ & $\begin{array}{l}\text { Abastecimento } \\
\text { industrial }\end{array}$ & 0 & 13 \\
\hline
\end{tabular}

